\title{
Análise do comportamento de blocos sobre quatro estacas com cálice embutido
}

\author{
Carlos Antônio Marek Filho
}

Dissertação apresentada à Escola de Engenharia de São Carlos da Universidade de São Paulo, como parte dos requisitos para a obtenção do Título de Mestre em Engenharia de Estruturas

Orientador: José Samuel Giongo

São Carlos

2010 
AUTORIZO A REPRODUÇÃO E DIVULGAÇÃO TOTAL OU PARCIAL DESTE TRABALHO, POR QUALQUER MEIO CONVENCIONAL OU ELETRÔNICO, PARA FINS DE ESTUDO E PESQUISA, DESDE QUE CITADA A FONTE.

Ficha catalográfica preparada pela Seção de Tratamento da Informação do Serviço de Biblioteca - EESC/USP

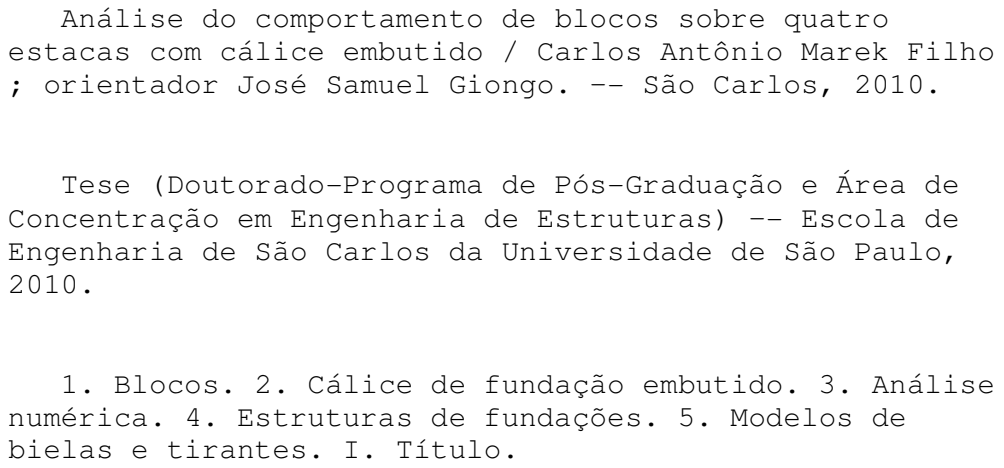


Candidato: Engenheiro CARLOS ANTÔNIO MAREK FILHO.

Dissertação defendida e julgada em 19/08/2010 perante a Comissão Julgadora:

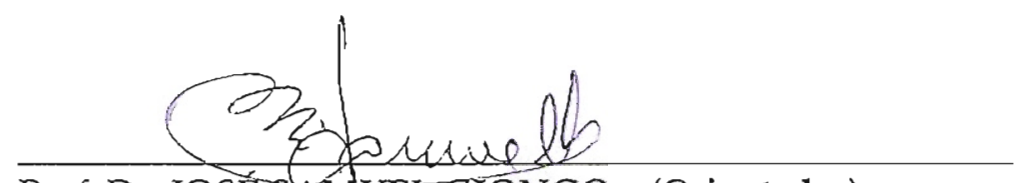

Prof. Dr. JOSÉ SAIMUEL GIONGO - (Orientador)

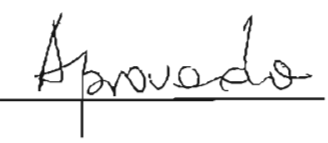

(Escola de Engenharia de São Carlos/USP)
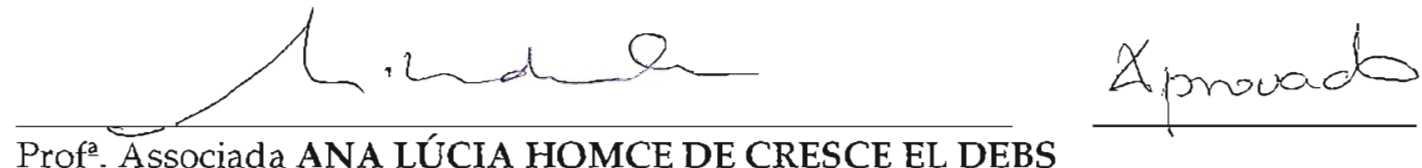

(Escola de Engenharia de São Carlos/USP)

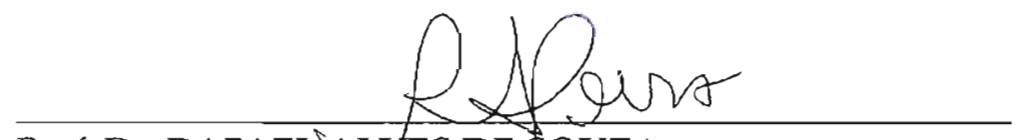

Prof. Dr. RAFAEL ALVES DE SOUZA

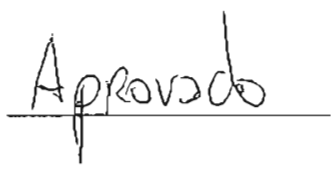

(Universidade Estadual de Maringá(JEM)
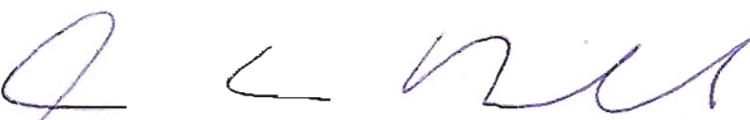

Prof. Associado MARCIO ANTONIO RAMALHO

Coordenador do Programa de Pós-Graduação em

Engenharia Civil (Engenharia de Estruturas)

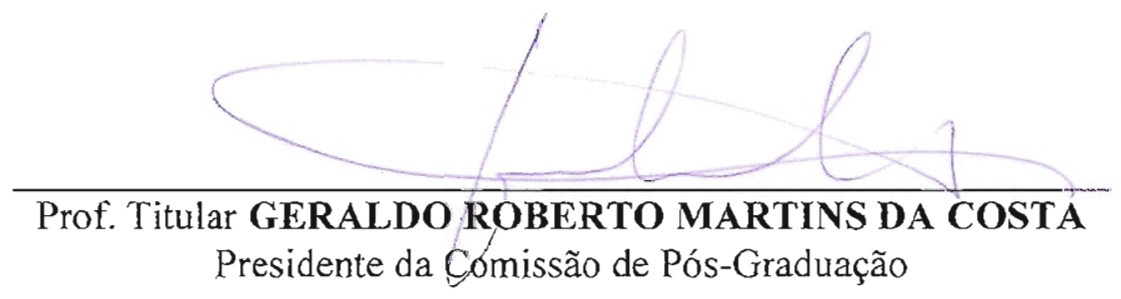



Aos meus pais, Ana e Carlos, e à minha irmã Carla. 



\section{Agradecimentos}

Ao final desta jornada, agradeço ao Pai Celestial por ter me iluminado e guardado no caminho pelo qual tenho trilhado.

Agradeço aos meus pais, Ana e Carlos, à minha irmã, Carla, e aos demais familiares pelo incentivo e apoio nos momentos de dificuldade e pela educação que me deram, responsável pelas oportunidades que tem surgido em minha vida.

Aos amigos que fiz durante minha graduação na Universidade Estadual de Maringá.

Ao Capítulo Maringá $n .^{\circ} 89$, onde fiz muitas amizades e pude cultivar as virtudes de seus ensinamentos.

À Universidade Estadual de Maringá, pela minha formação. Aos Professores da UEM, em especial Julio César Pigozzo, Rafael Alves de Souza, José Aparecido Canova e ao professor Romel Dias Vanderlei, pela amizade e por ter iniciado minha vida científica. Aos laboratórios de Estruturas e de Materiais de Construção e seus respectivos funcionários.

A todos os meus colegas e amigos da USP: André, Andreilton, Aref, Bruno, Calil, Charles, Cris, Daniele, Denis, Dorival, Eclache, Emerson, Ellen, Érica, Francisco, Gabriela, Giovanni, Hidelbrando, Higor, Hugo, Jesus Daniel, Jesus Garcia, Jonas, Luis Fernando, Mairal, Manoel Denis, Marcela, Marcelo Cuadrado, Marliane, Rodolfo, Rodrigo Barros, Rodrigo Delalibera, Rodrigo Pagnussat, Valmiro, Walter, Wanderson. Aos colegas e amigos que dividiram sala na Esquina da Produção: Antonio Carlos, Luiz Aquino, Cátia, Freddy, Nero, Marcelo Reis, Wagner e Wellison.

Às valiosas amigas de São Carlos e de Maringá, Engenheira Juliana e Arquiteta Marieli. Tive o privilégio desta amizade iniciada em Maringá se fortalecer em São Carlos.

Ao Professor e amigo José Samuel Giongo pela orientação, amizade e pelos conselhos e confiança neste trabalho. Uma das melhores pessoas que pude conhecer em São Carlos tendo a felicidade de ser seu orientado.

Ao CNPq pela bolsa de mestrado concedida.

Ao Departamento de Estruturas da Escola de Engenharia de São Carlos, aos seus funcionários e professores. 

"Procurando o bem para os nossos semelhantes encontramos o nosso." 



\section{RESUMO}

MAREK FILHO, C. A. Análise do Comportamento de Blocos sobre Quatro Estacas com Cálice Embutido. 2010. 190 f. Dissertação (Mestrado) - Escola de Engenharia de São Carlos, Universidade de São Paulo, São Carlos, 2010.

A racionalização e a industrialização da construção civil têm promovido o sistema construtivo baseado em elementos de concretos pré-moldados. O comportamento das ligações entre os elementos pré-moldados constitui uma das principais preocupações dos projetistas, sendo as ligações entre a superestrutura e as fundações determinantes na estabilidade e na distribuição de esforços solicitantes da estrutura. O comportamento de blocos sobre estacas com ligações para pilares pré-moldados possui particularidades em razão do diferente mecanismo de transferência de forças do pilar para o bloco mediante a ligação. Neste trabalho é estudado o comportamento de blocos de fundação apoiados sobre quatro estacas com cálice totalmente embutido para ligação com pilar pré-moldado. O estudo baseou-se em análise numérica nãolinear de modelos tridimensionais considerando a fissuração do concreto, a presença de armadura e a interface de ligação. O comportamento de blocos com pilares submetidos à força vertical centrada e excêntrica foi descrito em termos de força última, panorama de fissuração, fluxo de tensões principais e tensões nas armaduras do bloco. Os resultados indicam a ocorrência de transferência de esforços do pilar para a fundação a partir das paredes do cálice de interface lisa, entretanto com intensidade insuficiente para a formação de bielas de compressão, e o risco da ocorrência de punção em blocos onde os pilares são ligados por cálices de paredes lisas.

Palavras-chave: Blocos sobre estacas. Cálice de fundação embutido. Análise numérica. Estruturas de fundações. Modelo de Bielas e Tirantes. 



\section{AbSTraCT}

MAREK FILHO, C. A. Analysis of the Behavior of Four-Pile Caps with Embedded Socket. 2010. 190 f. Dissertação (Mestrado) - Escola de Engenharia de São Carlos, Universidade de São Paulo, São Carlos, 2010.

The rationalization and the industrialization of the civil constructions have stimulated the construction process based on precast elements. One of the main designer's worries is about the behavior of the joints between precast elements, and the joints between superstructure and the foundations which are determinant in the construction stability and behavior of elements. In reason of the mechanism of transference of the forces from column to pile-cap by socket connections, the behavior of pile-caps with joints for precast columns has some specificity. The behavior of four-pile caps with embedded socket for precast columns joints is studied in this research. The study is based in nonlinear numerical analysis of three dimensional models considering the cracking in concrete, the reinforcement and the joint interface. The behavior of pile caps under centered and eccentric vertical force is described by ultimate force, cracking patterns, principal stresses flow and reinforcements strains. The results suggests that occurs the transfer of forces from column to the pile cap in the socket walls with smooth interface, however the intensity is not enough to form the struts, and the risk of development of punching shear in pile caps which columns are connected by smooth interface socket walls.

Keywords: Pile-caps. Embedded socket foundation. Numerical analysis. Foundations structures. Strut-and-Tie model. 



\section{SUMÁRIO}

1 INTRODUÇÃO ............................................................................................................................17

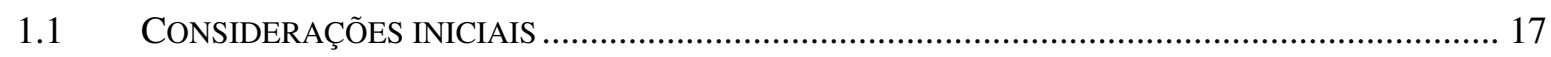

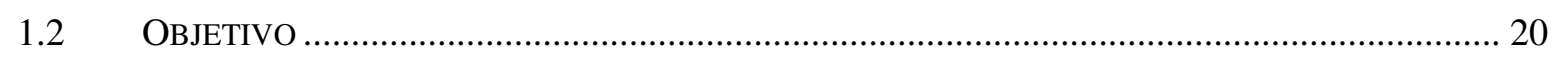

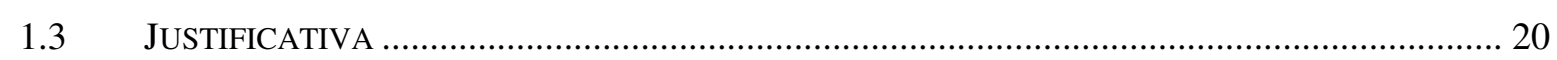

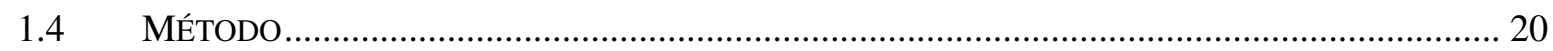

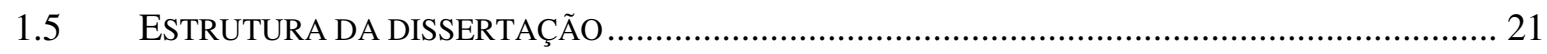

2 REVISÃO BIBLIOGRÁFICA .....................................................................................22

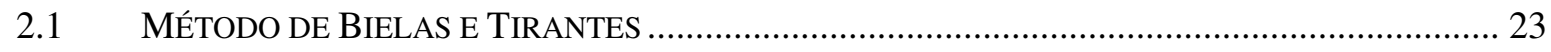

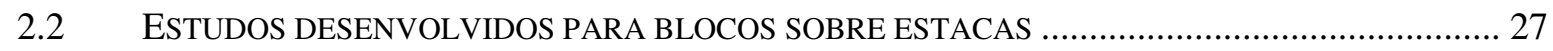

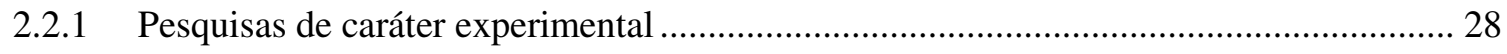

2.2.2 Pesquisas de caráter numérico ou analítico ..................................................................... 40

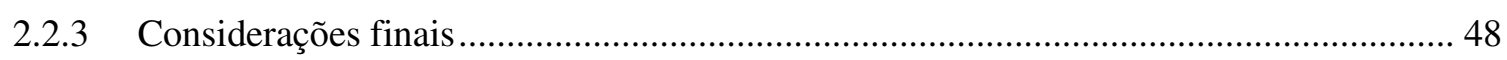

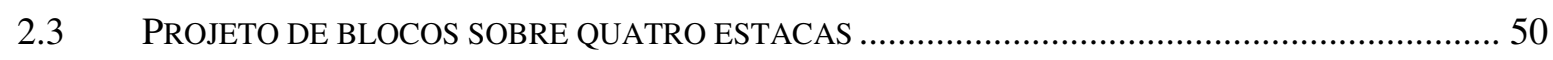

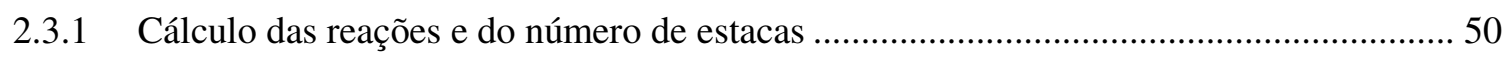

2.3.2 Classificação dos blocos e recomendações quanto à altura............................................... 51

2.3.3 Espaçamento entre estacas e distância das estacas ao perímetro do bloco.........................54

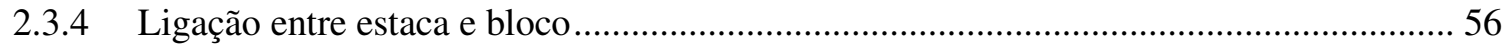

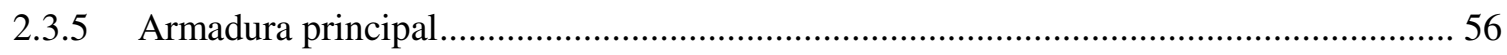

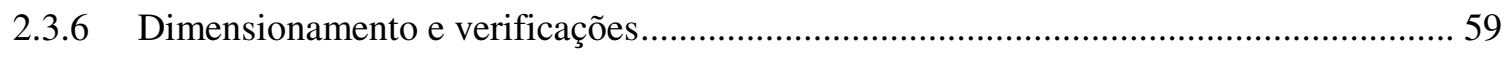

2.3.6.1 Método das Bielas de Blévot e Frémy (1967) ......................................................... 60

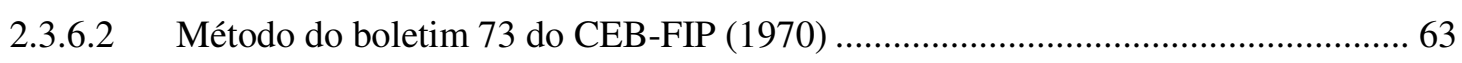

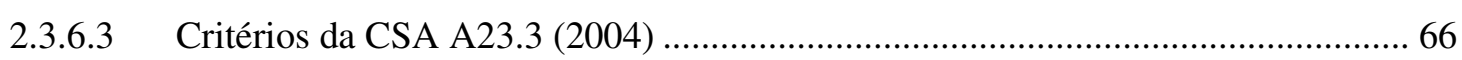

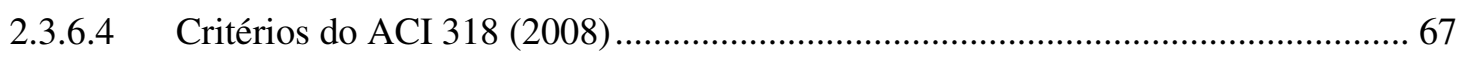

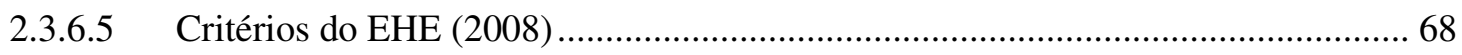

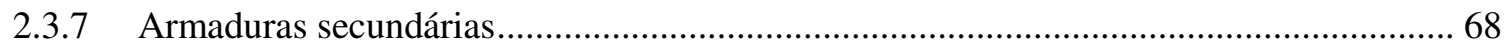

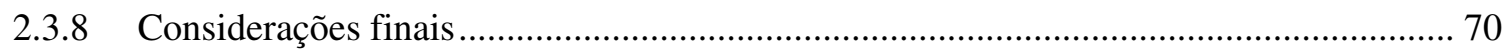

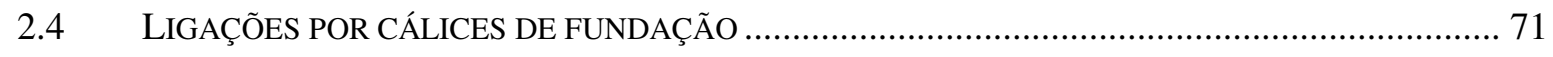

2.4.1 Modelo de Leonhardt e Mönnig (1977) e da ABNT NBR 9062:2006............................ 72

2.4.2 Outros modelos e estudos realizados........................................................................... 78

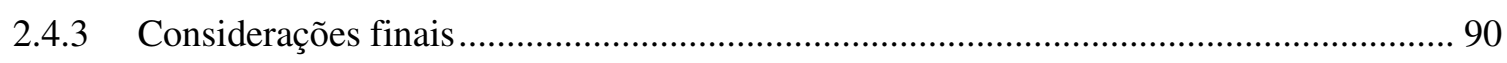

3 ESTUDO E ANÁLISE DOS MODELOS NUMÉRICOS..............................................91

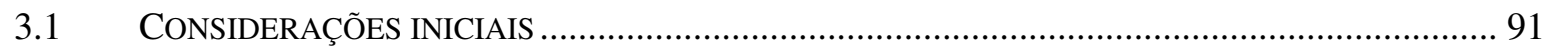




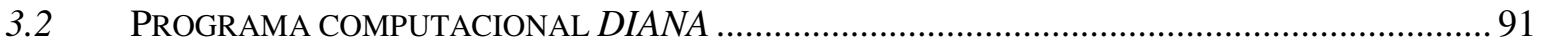

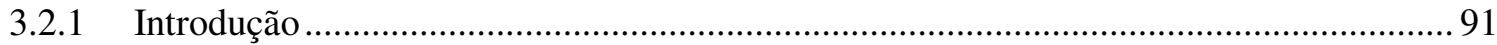

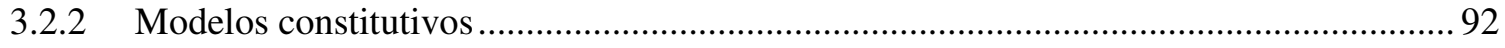

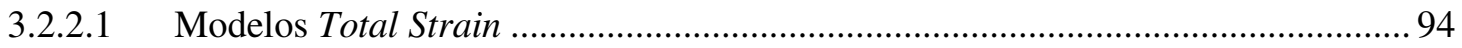

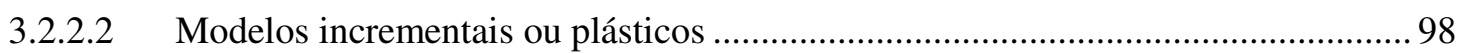

3.2.2.3 Modelo Maekawa Modificado ................................................................................ 98

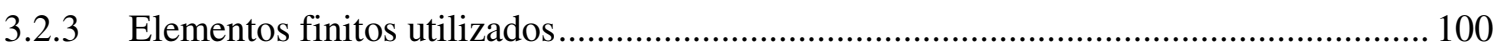

3.2.4 Métodos de solução do sistema de equações não-lineares............................................... 104

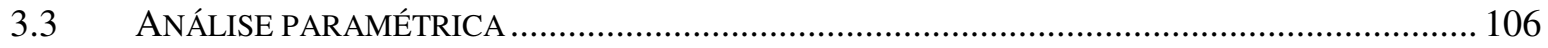

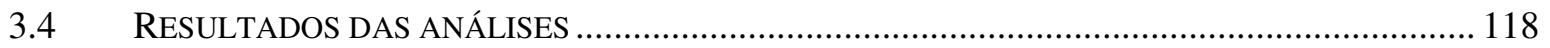

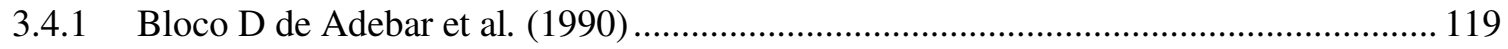

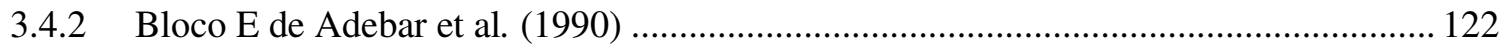

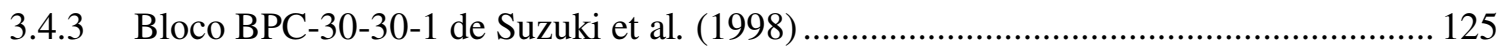

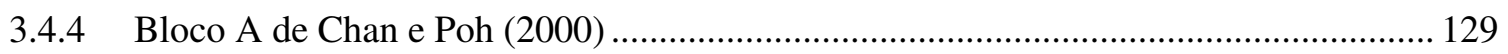

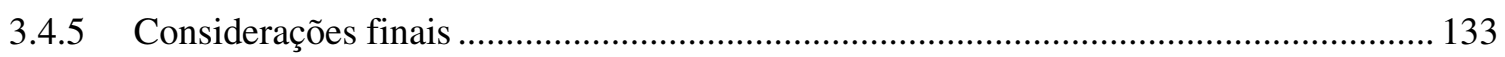

4 BLOCOS SOBRE QUATRO ESTACAS COM CÁLICE EMBUTIDO................. 135

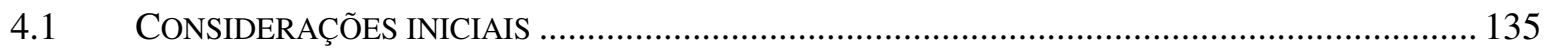

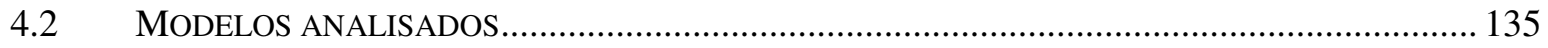

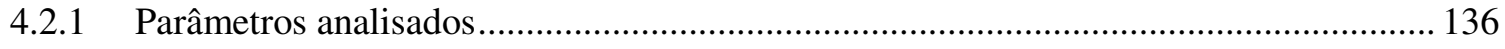

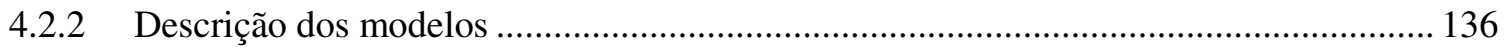

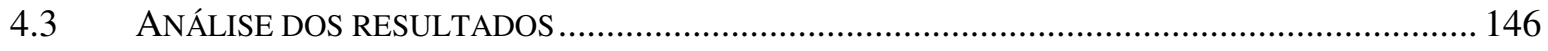

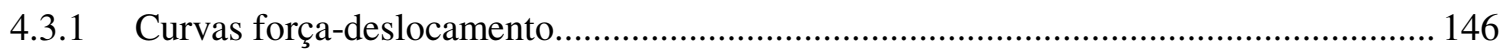

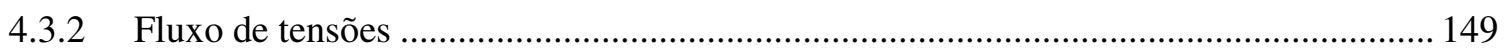

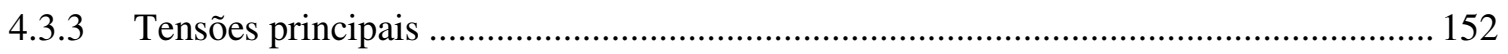

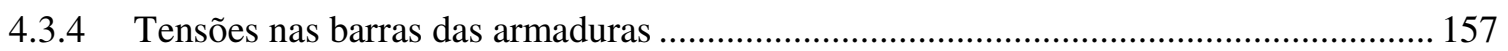

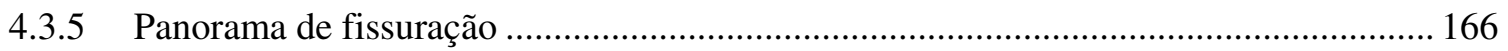

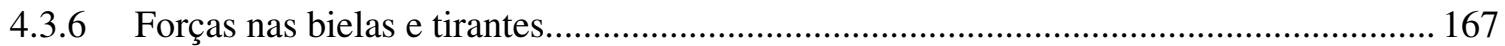

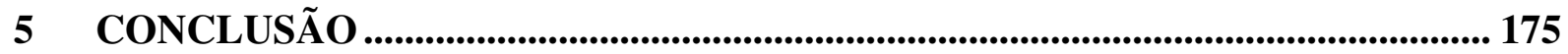

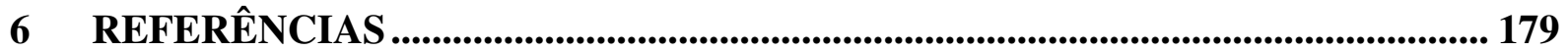




\section{Capítulo 1 \\ INTRODUÇÃO

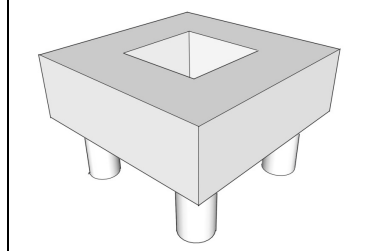

\subsection{CONSIDERAÇõES INICIAIS}

Os blocos sobre estacas, também chamados de blocos de coroamento, são elementos estruturais volumétricos, caracterizados por possuir as três dimensões da mesma ordem de grandeza, cujo papel é conduzir as ações provenientes da superestrutura para as estacas. As estacas e os tubulões são elementos de fundação adotados como alternativa para transmissão das ações ao solo quando este não possui resistência adequada nas suas camadas superiores.

Uma vez definida a necessidade dessas fundações baseado nas informações geotécnicas, intensidades das ações, vizinhança e fatores de ordem técnica e econômica da obra, faz-se necessário o dimensionamento dos blocos sobre estacas. Atualmente, dois são os métodos mais utilizados para o dimensionamento destes elementos: a Teoria da Flexão e o Método das Bielas.

Na maioria das situações, emprega-se a Teoria de Flexão para os blocos ditos flexíveis e o Método das Bielas para os blocos ditos rígidos. Como a rigidez do bloco é dada por suas dimensões torna-se necessário o prévio conhecimento das dimensões.

O dimensionamento segundo a Teoria de Flexão é fundamentado na verificação do equilíbrio em determinadas seções críticas. Desse equilíbrio obtém-se a área de aço necessária para absorver as tensões longitudinais de tração. O principal código normativo que adota este método atualmente é o ACI 318 (2008). O Método das Bielas mais clássico e que serve de base para os códigos normativos que o adotam, tal como a CSA A23.3 (2004) e a EHE (2008), é o proposto por Blévot e Frémy (1967) que, apesar de não terem sido os precursores da utilização da analogia de treliça em blocos, talvez tenham sido os primeiros a fazer a verificação das bielas. A relevância e a abrangência de seus estudos fizeram seu trabalho tornar se o principal divulgador do método. O Método das Bielas, de forma simples, consiste na idealização de bielas comprimidas em regiões de fluxo de tensões de compressão e de 
tirantes onde ocorre o fluxo de tensões de tração. O dimensionamento fundamenta-se na verificação da compressão das bielas e no dimensionamento dos tirantes.

Em razão da incessante busca pela industrialização da construção, há uma demanda crescente de edificações constituídas por estruturas formadas por elementos pré-moldados. De acordo com definição da ABNT NBR 9062:2006, o elemento pré-moldado é aquele “... moldado previamente e fora do local de utilização definitiva na estrutura". Desse modo busca-se também atingir situações de maior produtividade e racionalidade da construção civil.

Quando definida a opção pelo sistema estrutural formado por elementos de concreto pré-moldado, uma das maiores preocupações são as ligações entre os elementos. Em El Debs (2000), a importância da ligação é justificada pela sua influência tanto na produção como no comportamento da estrutura finalizada. Uma das ligações de maior influência no comportamento da estrutura montada é a que liga os pilares aos elementos de fundação. Estas ligações podem assumir comportamento rígido, semi-rígido ou de articulação, sendo mais comum a primeira. As principais maneiras de construções das ligações rígidas são: por meio de cálice, por meio de chapa de base, por emenda da armadura com graute e bainha e com emenda de armaduras salientes.

A ligação por meio de cálices é uma das alternativas mais utilizadas no Brasil e mais conhecidas no mundo e consiste no embutimento de uma parcela do comprimento do pilar no elemento estrutural de fundação. As vantagens são: facilidade de montagem e ajuste dos desvios de execução e a ótima capacidade de transferência de momentos. Em contrapartida a ligação por cálice externo resulta bastante pronunciada impedindo sua utilização em divisas. Elliott (2002) ainda cita que as ligações por cálices são as mais econômicas, mas possuem uso reservado a situações onde elementos de fundação de grandes dimensões não tenham restrições. Além disso, a opção por ligações em chapa de base, em vez de cálices de fundação, tende a ser embasada mais por argumentos de produção do que estruturais.

Os cálices podem se apresentar externo, parcialmente embutido ou embutido ao elemento de fundação, Figura 1.1. O cálice externo consiste na ligação onde a transferência das forças do pilar para a fundação ocorre totalmente a partir das paredes do colarinho, já a ligação por cálice embutido é aquela onde a transferência das forças ocorre pelas paredes de uma cavidade embutida no elemento de fundação. $\mathrm{O}$ cálice parcialmente embutido consiste de uma ligação onde parte do pilar está embutida no elemento de fundação e parte está envolvida pelo colarinho. O cálice embutido apresenta menor dificuldade para montagem da fôrma e 
possibilidade de ser utilizado em divisa, entretanto apresenta também um maior consumo de concreto e maiores incertezas quanto ao comportamento do conjunto cálice-bloco.

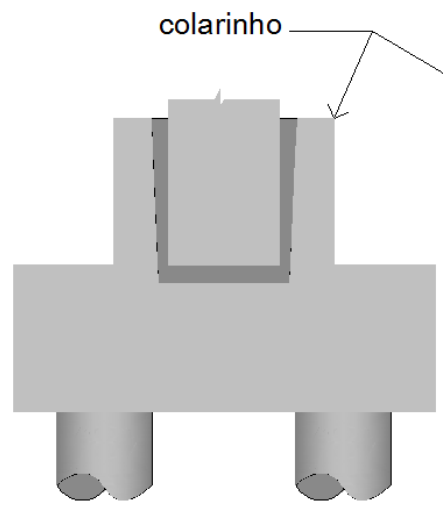

Cálice externo

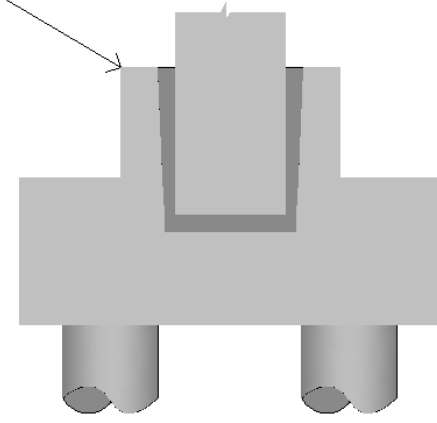

Cálice parcialmente embutido

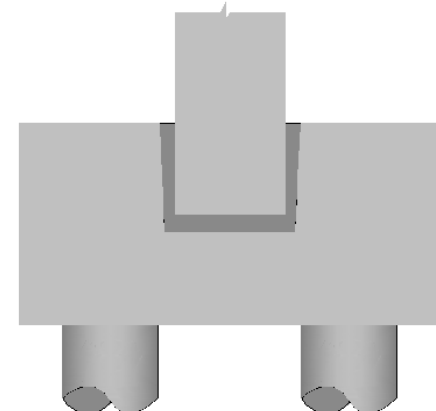

Cálice embutido

Figura 1.1 - Formas do cálice de fundação

A aplicação do Método de Bielas e Tirantes em blocos possuindo cálice embutido pode sugerir um procedimento para o dimensionamento de blocos de fundação que possuem a cavidade para o embutimento do pilar. Todavia, como o Método de Bielas e Tirantes idealiza uma treliça espacial formada por tirantes tracionados e bielas comprimidas representando o fluxo de tensões no elemento, e este depende das condições de contorno, ações atuantes, apoios e características geométricas do modelo, torna-se necessário conhecer o fluxo de tensões por meio de ensaios experimentais, ensaios fotoelásticos ou análises numéricas.

O advento de programas computacionais baseados no Método dos Elementos Finitos viabilizou a análise numérica e a obtenção do fluxo de tensões em elementos de concreto e em especial, as análises não-lineares para a obtenção dos deslocamentos, estados de tensões e deformações em elementos de maior complexidade. Dessa maneira, é possível estabelecer modelos de bielas e tirantes mais refinados e que levem em consideração a não-linearidade física do concreto. 


\subsection{OBJETIVO}

O objeto dessa pesquisa é:

- estudar o comportamento de blocos sobre quatro estacas com cálice totalmente embutido;

- estudar a influência de parâmetros como comprimento de embutimento, altura do bloco e conformação das paredes do cálice no comportamento de blocos sobre estacas, em especial sobre a geometria das bielas;

- construir um modelo numérico para a análise de blocos com ligações com pilar mediante cálice embutido, que possuem comportamento complexo.

\subsection{JUSTIFICATIVA}

A pesquisa justifica-se em razão da reduzida quantidade de estudos referentes aos blocos sobre estacas com cálice de fundação embutido e seu comportamento quando solicitados por força excêntrica. Além disso, ainda não foi elucidada a influência do comprimento de embutimento e da conformação das paredes do cálice e do pilar na transferência de esforços do pilar para o bloco, e, sua interferência na formação dos campos de tensões no bloco apesar de ser uma das ligações mais recorridas pelos projetistas de estruturas pré-moldadas.

\subsection{Método}

Para a investigação do problema propõe-se uma simulação numérica de modelos expressivos, mediante uso do programa computacional DIANA 9.2 que se baseia no método dos elementos finitos. Por meio desse programa, realizou-se uma análise não-linear dos 
modelos na qual se variou as ações, dimensões do bloco, comprimento de embutimento do pilar e a espessura da laje ${ }^{1}$ de fundo. As atividades realizadas foram as seguintes:

- levantamento de material bibliográfico bem como acompanhamento de trabalhos em desenvolvimento e artigos ligados ao tema;

- utilização do programa empregado para análise numérica dos modelos adotados;

- análise dos modelos e comparação.

\subsection{ESTRUTURA DA DiSSERTAÇÃo}

Este trabalho desenvolve-se em seis capítulos sendo:

Capítulo 1: Introdução - apresenta o tema, a justificativa, os objetivos e o método utilizado para o desenvolvimento desta pesquisa;

Capítulo 2: Revisão Bibliográfica - proporciona os fundamentos do método das bielas e tirantes seguindo de revisão e discussão de resultados das principais pesquisas a respeito de blocos sobre estacas, com ênfase aos blocos apoiados sobre quatro estacas. São também apresentados os principais modelos e recomendações para o cálculo e dimensionamento de blocos sobre quatro estacas oferecendo ao final uma breve explanação de alguns modelos utilizados para o cálculo e dimensionamento de alguns tipos de cálices;

Capítulo 3: Estudo e Análise dos Modelos Numéricos - este item do trabalho comenta os principais recursos do programa computacional DIANA, baseado no método dos elementos finitos, destacando os recursos utilizados nas análises propostas neste trabalho. É feita uma breve discussão a respeito dos modelos constitutivos disponíveis para o concreto, em especial os modelos de fissuração, e ao término são feitas análises paramétricas a fim de calibrar as respostas dos modelos numéricos com alguns resultados experimentais da literatura;

Capítulo 4: Blocos sobre Quatro Estacas com Cálice Embutido - são analisados 24 modelos de blocos sobre quatro estacas possuindo cálice de fundação e com pilares

\footnotetext{
${ }^{1}$ Nesse caso o termo laje de fundo talvez não seja o mais apropriado em razão de ser utilizado para elementos de flexão submetidos a ações predominantemente normais ao seu plano. Todavia, neste e em outros trabalhos denomina-se a camada inferior do bloco, localizada entre o topo das estacas e a base do pilar, de laje de fundo.
} 
submetidos à força vertical centrada e excêntrica. Os resultados obtidos são analisados criticamente considerando as respostas numéricas comparadas a alguns modelos analíticos;

Capítulo 5: Conclusão - a partir dos resultados apresentados no Capítulo 4, conclui-se a respeito do comportamento dos blocos analisados e apresentam-se as perspectivas de pesquisas futuras, a fim de complementar este trabalho e dirimir algumas dúvidas quanto ao comportamento destes elementos. 


\section{CAPÍtUlo 2 \\ REVISÃo BIBLIOGRÁFICA

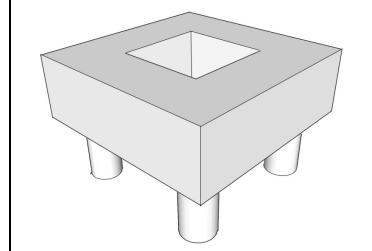

\subsection{Método de Bielas e TiRantes}

Na primeira década do século XX, E. Mörsch apresentou uma analogia de treliça para aplicação no dimensionamento à força cortante atuante em estruturas lineares de concreto. Essa proposta foi desenvolvida e generalizada, e hoje consiste no método utilizado para o dimensionamento de elementos reticulares de concreto submetidos a ação de força cortante e momento torsor, segundo as principais normas de concreto armado. Ao longo dos anos, o método foi expandido por pesquisadores como Leonhardt e Mönnig e Rüsch e no final do século XX, Schlaich e Schäfer apresentaram o método em sua forma mais generalizada e sistematizada, então denominado de Método de Bielas e Tirantes.

Segundo a ABNT NBR 6118:2003, o método é denominado por Método de Bielas e Tirantes, entretanto sabe-se que originalmente era conhecido apenas por Método das Bielas, uma vez que as bielas podem estar comprimidas (escoras) ou tracionadas (tirantes). O nome mais adequado é Método de Escoras e Tirantes, entretanto neste trabalho será utilizada a denominação que consta na norma brasileira.

Os elementos estruturais podem ser divididos em regiões $\mathrm{B}$ e regiões $\mathrm{D}$ sendo as regiões B aquelas onde a hipótese de Bernoulli é válida, ou seja, a distribuição de deformações em uma seção qualquer do elemento é linear e, sendo assim, está garantida a manutenção da forma plana da seção. As regiões D são as regiões descontínuas, onde a hipótese de Bernoulli não é válida. Conforme Schlaich e Schäfer (1991), regiões na proximidade de locais onde atuam forças concentradas, cantos, mudanças de direção do elemento, aberturas e mudança da seção transversal do elemento caracterizam regiões de descontinuidade. Considerando o princípio de Saint-Venant, a região de descontinuidade pode

ser delimitada por uma região de dimensões da mesma ordem de grandeza da seção transversal do elemento, conforme ilustra a Figura 2.1. Para as regiões D, os modelos de bielas e tirantes tornam-se interessantes por representarem, de modo aproximado, o fluxo interno das tensões. 

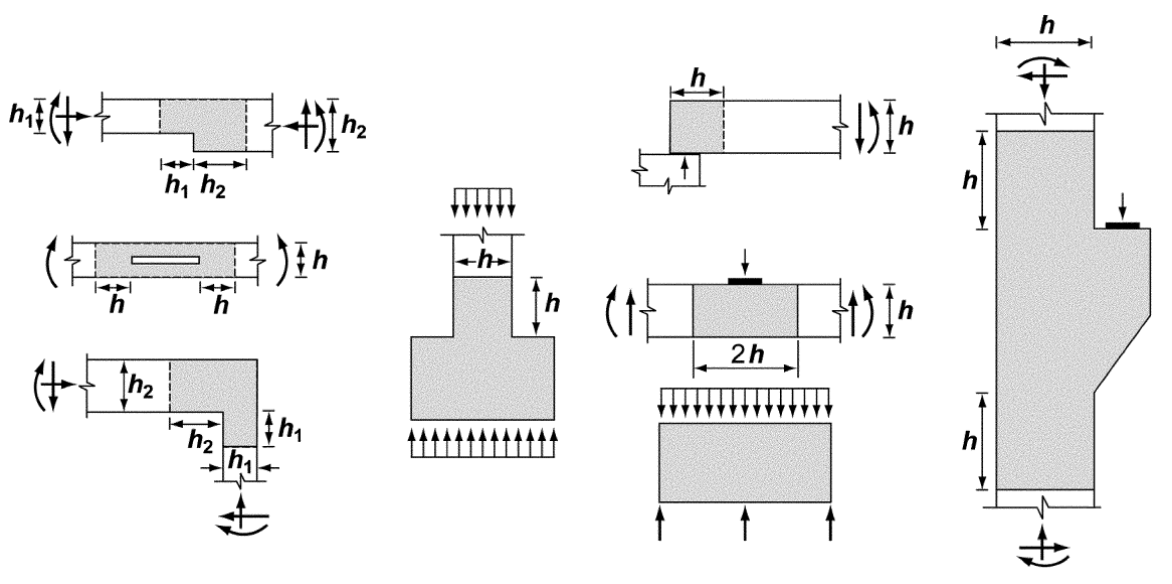

Figura 2.1 - Exemplos de regiões D Fonte: ACI 318(2008)

Considerando que a maior parte dos blocos sobre estacas são elementos cujas três dimensões são da mesma ordem de grandeza e sendo a ação e as reações aplicadas em áreas relativamente reduzidas do pilar e das estacas respectivamente, fica evidente que o bloco sobre estacas é um elemento descontínuo em toda sua extensão e sendo assim é conveniente o seu tratamento por modelos de bielas e tirantes.

Os modelos de bielas e tirantes consistem em representações discretas dos campos de tensões em elementos estruturais de concreto armado. O Método de Bielas e Tirantes é fundamentado na idealização de uma treliça formada por barras comprimidas e tracionadas, denominadas respectivamente de bielas e tirantes, que descrevem o fluxo de tensões em determinado elemento de concreto estrutural. Além dessa analogia de treliça, o método de bielas e tirantes prevê o dimensionamento do elemento de concreto a partir da determinação da área de aço dos tirantes e da verificação da segurança com relação à ruptura das bielas comprimidas e das regiões nodais.

Em Silva e Giongo (2000) encontra-se explicado o "Processo do Caminho de Carga", por meio do qual se pode sistematizar o desenvolvimento de modelos de bielas e tirantes pelo fluxo de tensões internas. Mas antes de aplicar o processo do caminho de carga é necessário satisfazer o equilíbrio de todas as forças atuantes no contorno. Após aplicação do processo do caminho de cargas, dimensionam-se os tirantes e verificam-se as bielas e as regiões nodais.

A modelagem pode oferecer ao projetista mais de uma opção de modelo de bielas e tirantes, de tal maneira que é possível otimizar a escolha do modelo por intermédio da consideração do princípio da mínima energia de deformação, pois, segundo Schlaich e 
Schäfer (1991), as ações tendem a utilizar o caminho de mínimas forças e deformações, descrito pela Expressão 2.1, sendo assim é conveniente a escolha do modelo que apresenta menores comprimentos de tirantes uma vez que estes são mais deformáveis que as bielas.

$$
\sum F_{i} \cdot l_{i} \cdot \varepsilon_{m i}=\text { mínimo }
$$

Sendo que, $F_{i}$ é a força, $l_{i}$ é o comprimento e $\varepsilon_{m i}$ é a deformação específica média das barras. As bielas são discretizações de campos de tensão de compressão no concreto e podem apresentar-se em três configurações típicas ilustradas na Figura 2.2. A distribuição de tensões paralela é típica de regiões B onde as tensões se distribuem uniformemente sem desenvolver tensões transversais de tração, já a distribuição de tensões em forma de garrafa ocorre quando forças concentradas são introduzidas e propagadas em curvaturas acentuadas ocasionando consideráveis tensões de tração transversais. Por fim, a distribuição de tensões radiais é uma idealização de um campo de tensão com curvatura desprezível, encontrada em regiões D onde forças concentradas são introduzidas e propagadas de maneira suave sem desenvolver tensões de tração transversais.

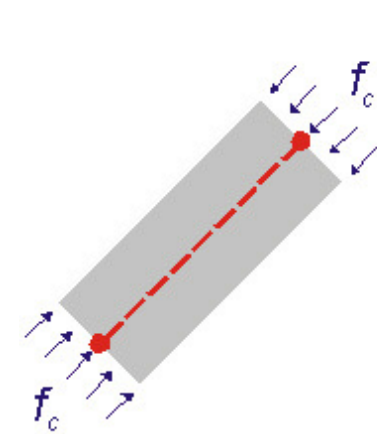

a)

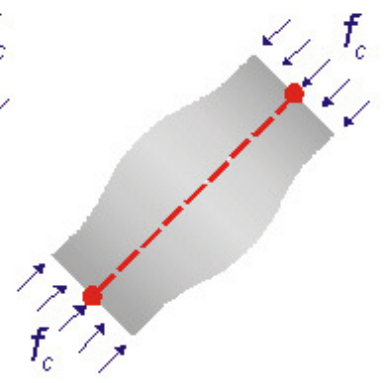

b)

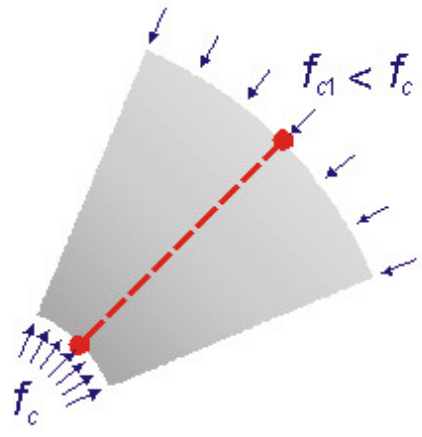

c)

Figura 2.2 - Configurações típicas de campos de compressão: a) Distribuição de tensões paralelas, b) distribuição curvilínea ou em forma de garrafa e c) distribuição radial ou em leque.

Fonte: Strut-and-Tie Resource Website

A verificação das tensões de compressão nas seções transversais das bielas e nos nós pode ser realizada por meio dos parâmetros de resistência fornecidos por pesquisadores, como Schlaich e Schäfer (1991) e Fusco (1994), ou ainda, pelos códigos normativos internacionais tais como: CEB-FIP 1990 (1993), Eurocode 2 (2002), CSA A23.3 (2004), ACI 318 (2008) e EHE (2008). Algumas dessas recomendações para as regiões nodais encontram-se descritas na Tabela 2.1, entretanto, estes valores devem ser utilizados com parcimônia e não devem ser comparados entre si, pois, a depender das normas, as resistências características à compressão 
dos concretos possuirão quantis diferentes e serão obtidas em corpos-de-prova de diferentes formas e dimensões.

O Eurocode 2 (2002) e a EHE (2008) adotam a resistência característica do concreto, $f_{\text {ck }}$, como sendo obtida em ensaios de corpos-de-prova cilíndricos considerando um quantil de $5 \%$ e o fator de minoração da resistência do concreto, $\gamma_{c}$, é de 1,5. O ACI 318 (2008) e a CSA A23.3 (2004) adotam resistência característica à compressão do concreto obtida em ensaios de corpos-de-prova cúbicos, considerando um quantil de $1 \%$.

Tabela 2.1 - Recomendações para a resistência das regiões nodais

\begin{tabular}{ccccc}
\hline Recomendação & $\begin{array}{c}\text { Nós que recebem } \\
\text { apenas bielas, ou } \\
\text { sob apoios ou } \\
\text { pontos de aplicação } \\
\text { de forças }\end{array}$ & $\begin{array}{c}\text { Nós que ancoram } \\
\text { apenas um tirante }\end{array}$ & $\begin{array}{c}\text { Nós que ancoram } \\
\text { tirantes em mais } \\
\text { de uma direção }\end{array}$ & $\begin{array}{c}\text { Nós sob } \\
\text { compressão } \\
\text { triaxial }\end{array}$ \\
\hline $\begin{array}{c}\text { Schäfer } \text { S Schlaich } \\
(1988)\end{array}$ & $0,935 \cdot f_{c d}$ & $0,68 \cdot f_{c d}$ & $0,68 \cdot f_{c d}$ & $0,935 \cdot f_{c d}$ \\
\hline $\begin{array}{c}\text { Schlaich } \text { S Schäfer } \\
(1991)\end{array}$ & $1,1 \cdot f_{c d}$ & $0,8 \cdot f_{c d}$ & $0,8 \cdot f_{c d}$ & $1,1 \cdot f_{c d}$ \\
\hline CEB-FIP 1990 & $0,85 \cdot\left(1-\frac{f_{c k}}{250}\right) \cdot f_{c d}$ & $0,60 \cdot\left(1-\frac{f_{c k}}{250}\right) \cdot f_{c d}$ & $0,60 \cdot\left(1-\frac{f_{c k}}{250}\right) \cdot f_{c d}$ & - \\
\hline Eurocode 2(2002) & $\left(1-\frac{f_{c k}}{250}\right) \cdot f_{c d}$ & $0,85 \cdot\left(1-\frac{f_{c k}}{250}\right) \cdot f_{c d}$ & $0,75 \cdot\left(1-\frac{f_{c k}}{250}\right) \cdot f_{c d}$ & $3 \cdot\left(1-\frac{f_{c k}}{250}\right) \cdot f_{c d}$ \\
\hline CSA A23.3 (2004) & $0,85 \cdot \emptyset_{c} \cdot f_{c}^{\prime}$ & $0,75 \cdot \emptyset_{c} \cdot f_{c}^{\prime}$ & $0,65 \cdot \emptyset_{c} \cdot f_{c}^{\prime}$ & - \\
\hline ACI $318(2008)$ & $0,85 \cdot f_{c}^{\prime}$ & $0,68 \cdot f_{c}^{\prime}$ & $0,51 \cdot f_{c}^{\prime}$ & - \\
\hline EHE (2008) & $f_{c d}$ & $0,70 \cdot f_{c d}$ & $0,70 \cdot f_{c d}$ & $3,30 \cdot f_{c d}$ \\
\hline
\end{tabular}

Sendo que:

$f_{c k} \quad$ é a resistência característica à compressão do concreto;

$f_{c d} \quad$ é a resistência de cálculo à compressão do concreto obtida em corpos-de-prova cilíndricos, considerando um quantil de $5 \%$ e um fator de minoração da resistência igual a 1,5 ;

$f_{c}$, é a resistência característica à compressão do concreto obtida em corpos-deprova cúbicos, considerando um quantil de $1 \%$;

$\emptyset_{c} \quad$ é o fator de segurança que minora a resistência do concreto cujo valor é 0,65.

Quanto à resistência das bielas, a CSA A23.3 (2004) sugere que seja calculada pela Expressão 2.2. 


$$
f_{c u}=\frac{f_{c}^{\prime}}{0,8+170 \cdot \varepsilon_{1}} \leq 0,85 \cdot f_{c}^{\prime}
$$

Sendo que:

$\varepsilon_{1} \quad$ é $\varepsilon_{s}+\left(\varepsilon_{s}+0,002\right) \cdot \operatorname{cotg}^{2} \theta_{s}$

$\theta_{s} \quad$ é o menor ângulo entre a biela e os tirantes;

$\varepsilon_{S} \quad$ é a deformação da armadura tracionada que atravessa a biela inclinada num ângulo $\theta_{s}$ em relação à biela.

A CSA A23.3 (2004) oferece subsídios para a determinação da área de concreto da biela, assim como o CEB-FIP 1990 (1993). A verificação da biela pelo CEB-FIP 1990 (1993) é feita pelas Expressões 2.3 e 2.4, sendo que a Expressão 2.3 é válida para zonas não fissuradas e a Expressão 2.4 é válida para zonas fissuradas.

$$
\begin{aligned}
& f_{c d 1}=0,85 \cdot\left(1-\frac{f_{c k}}{250}\right) \cdot f_{c d} \\
& f_{c d 1}=0,60 \cdot\left(1-\frac{f_{c k}}{250}\right) \cdot f_{c d}
\end{aligned}
$$

O ACI 318 (2008), a EHE (2008) e o Eurocode 2 (2002) também fornecem valores limites para a resistência das bielas. A norma brasileira ABNT NBR 6118:2003 recomenda a utilização do Método de Bielas e Tirantes em elementos como os blocos rígidos, todavia não fornece subsídios para a utilização do método sendo necessário recorrer a algumas dessas obras ou códigos citados.

\subsection{ESTUDOS DESENVOLVIDOS PARA BLOCOS SOBRE ESTACAS}

Nesta seção do trabalho são discutidos alguns dos principais estudos realizados durante um período de aproximadamente meio século que contribuíram para o entendimento do comportamento dos blocos sobre quatro estacas. As pesquisas envolvendo blocos sobre 
duas e três estacas que tiveram seus resultados discutidos contribuíram para a compreensão do comportamento dos blocos em geral e para o desenvolvimento deste trabalho.

A realização de ensaios experimentais de blocos de fundação, em larga escala, algumas vezes é limitada por dificuldades técnicas e financeiras. Por isso, em algumas pesquisas foram realizadas análises em programas computacionais empregando métodos numéricos, tal como o Método dos Elementos Finitos. Nessas análises é possível obter resultados em termos de esforços solicitantes, deslocamentos e fissuração, ao longo de todo o domínio, considerando a não-linearidade física do concreto e a presença de armadura.

Outras pesquisas se detiveram na avaliação de modelos de dimensionamento, analiticamente, abalizados em resultados experimentais provenientes de outras pesquisas.

\subsubsection{PESQUISAS DE CARÁTER EXPERIMENTAL}

Um dos primeiros estudos data do início da década de 1950 quando, por meio de formulações desenvolvidas considerando a teoria da elasticidade bidimensional, Hobbs e Stein (1957) obtiveram analiticamente a distribuição de tensão em blocos sobre duas estacas, sendo que esses resultados analíticos foram legitimados pelos obtidos experimentalmente em modelos de escala 1:2 e 1:3. Os pesquisadores concluíram que os modelos com armadura principal em forma de arco possuíam melhor eficiência permitindo a redução da área de aço da armadura.

Entre os anos de 1955 e 1961, Blévot e Frémy (1967) realizaram aproximadamente cem ensaios experimentais em modelos de blocos sobre duas, três e quatro estacas, em escala reduzida e em escala natural, com a finalidade de avaliar o comportamento estrutural para diferentes arranjos de armadura e altura. As condições de apoio das estacas permitiam a translação, no plano horizontal de todas as seções, e a rotação na seção inferior. Também foi avaliado o coeficiente de segurança resultante da aplicação do método das bielas. Diferentes disposições de armadura, e sua influência no estado de formação de fissuras e estado limite último, foram também examinadas.

Para blocos sobre duas estacas os pesquisadores ensaiaram modelos que possuíam 0,40 $m$ de largura, pilar de seção transversal quadrada, estacas quadradas e biela formando um 
ângulo maior que $40^{\circ}$ com a face inferior do bloco. A armadura do tirante possuía dois arranjos: barras lisas com ganchos e barras com nervuras desprovidas de ganchos, Figura 2.3.
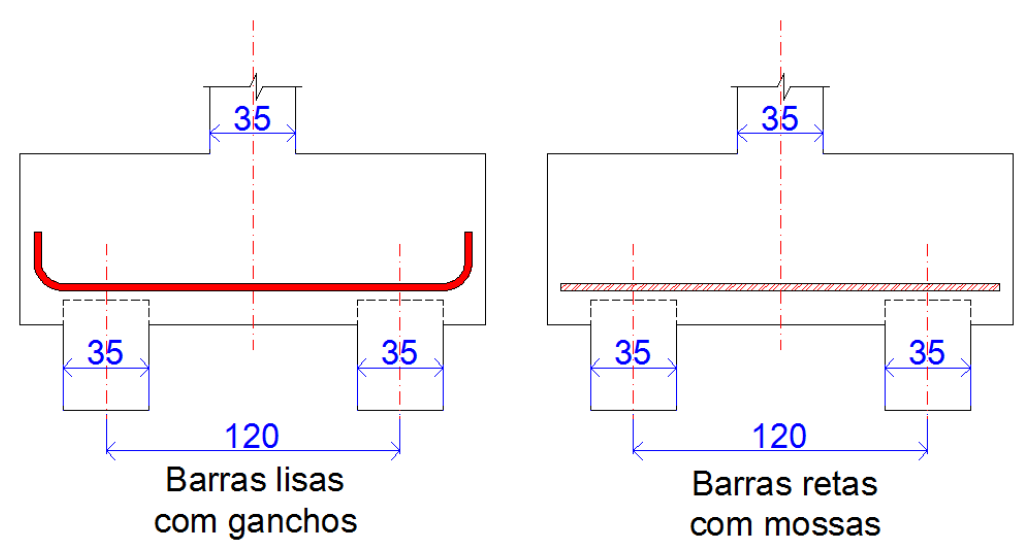

Figura 2.3 - Tipos de armadura avaliados nos modelos sobre duas estacas de Blévot e Frémy (1967)

Durante os ensaios, Blévot e Frémy (1967) observaram que a ruína, cuja causa foi atribuída à ruptura por compressão do concreto próximo ao pilar, à estaca ou ambos, foi precedida por várias fissuras. Após a ruptura da biela, houve o escorregamento das barras com nervuras e sem ganchos. A fissuração foi induzida por tensões de tração transversais ao fluxo de tensões de compressão. Após a ruptura do concreto, as forças passaram a ser resistidas apenas pelas barras da armadura.

Quanto aos blocos sobre três estacas, os pesquisadores utilizaram cinco disposições diferentes para a armadura, ilustradas na Figura 2.4.

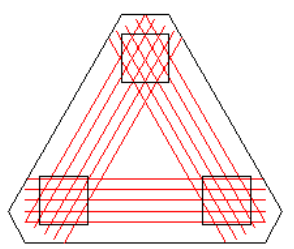

Armadura segundo os lados

a

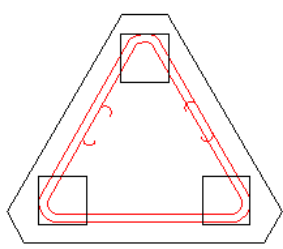

Armadura em forma de laço contornando as estacas

$\mathrm{b}$

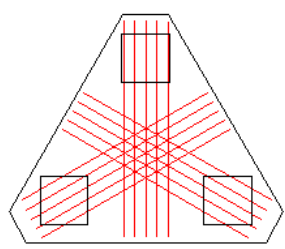

Armadura sobre as medianas

C

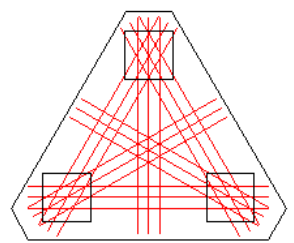

Armadura sobre as medianas e segundo os lados

d

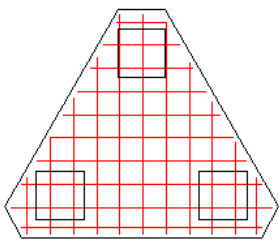

Armadura em forma de malha ortogonal

e

Figura 2.4 - Disposições de armaduras para blocos sobre três estacas avaliadas por Blévot e Frémy (1967)

Os arranjos " $a$ ", " $b$ " e " $d$ " apresentaram resultados satisfatórios nos ensaios sendo que a disposição do tipo " $d$ " deve possuir armadura preponderante segundo os lados. O bloco com disposição do tipo "c" apresentou força última significativamente menor que os anteriores, justificado pela necessidade de um carregamento perfeitamente centrado para que 
o modelo experimental seja coerente com o analítico. Já o bloco com arranjo do tipo " $e$ " apresentou aproximadamente metade da força última dos demais além de ruptura brusca por meio de fissura formada ao redor de uma das estacas, caracterizando que a armadura foi insuficiente para resistir às tensões de tração.

Quanto à fissuração, as armaduras dispostas nos lados e com laços apresentaram melhor desempenho para as faces laterais e deficiência na face inferior do bloco, quanto à fissuração. Na maioria dos modelos a ruína se deu pela ruptura à tração do concreto, observada a partir do surgimento de fissuras que iniciaram na região das estacas, ou seja, caracterizando o fendilhamento da biela.

Foi observado que para ângulos de inclinação da biela no intervalo de $40^{\circ}$ a $55^{\circ}$, as forças de ruína nos ensaios foram maiores que as calculadas, garantindo assim a segurança quando respeitado esses valores. Já para ângulos que não pertencem a este intervalo, as forças de ruína calculadas foram superiores às obtidas nos ensaios indicando assim uma situação desfavorável à segurança. Segundo Blévot e Frémy (1967), a segurança à punção do bloco é garantida desde que seja respeitado o limite inferior, de $40^{\circ}$, da inclinação da biela.

Blévot e Frémy (1967) também ensaiaram blocos sobre quatro estacas com os cinco arranjos de armaduras, ilustrados na Figura 2.5. A quantidade de aço, em massa, para os arranjos é equivalente.

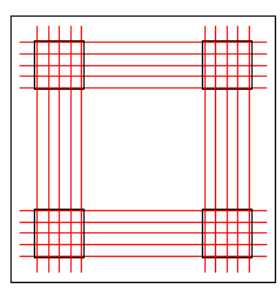

Armadura segundo os lados

a

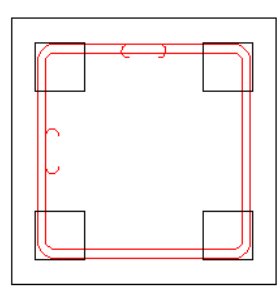

Armadura em forma de laço contornando as estacas

$b$

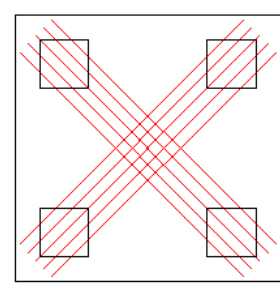

Armadura sobre as diagonais

C

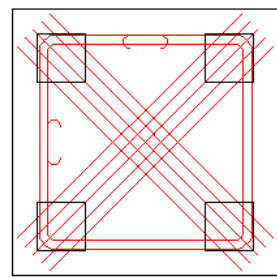

Armadura sobre as diagonais e em forma de laço

d

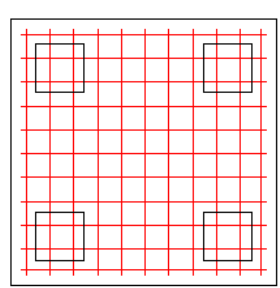

Armadura em forma de malha ortogonal

e

Figura 2.5 - Disposições de armaduras para blocos sobre quatro estacas avaliadas por Blévot e Frémy

Quanto à segurança contra a ruína, os blocos com disposições de armadura " $a$ " e " $d$ " apresentaram-se igualmente eficientes, já o modelo com arranjo " $e$ " apresentou força de ruína $20 \%$ menor. Em relação à fissuração, os blocos com armadura nas diagonais apresentaram grande número de fissuras para forças de pequena intensidade, em especial nas faces laterais provavelmente ocasionadas pela falta de armadura nessa região, assim como os blocos com 
armadura em forma de laço e segundo as laterais apresentaram maior fissuração na face inferior. De acordo com Blévot e Frémy (1967), esse aspecto pode ser melhorado pela adição de uma armadura em forma de malha, sendo que a maior parcela da força seja resistida pela armadura posicionada segundo os lados.

Nestes blocos, assim como nos blocos apoiados sobre três estacas, foi observado que as ruínas aconteceram a partir de fissuras iniciadas junto às estacas. Em nenhum dos casos houve ruína por punção de tal maneira que os resultados experimentais não divergiram das previsões teóricas obtidas pelo método de bielas e tirantes.

Para todos os blocos cujas bielas possuíam ângulo de inclinação entre $40^{\circ}$ e $55^{\circ}$ a ruína foi precedida pelo escoamento da armadura principal e aconteceu para ações superiores àquelas calculadas pelo método de bielas e tirantes. Blévot e Frémy (1967) ainda recomendam que, apesar do limite inferior de $40^{\circ}$ ser favorável à segurança, é preferível adotar ângulos maiores que $45^{\circ}$ em benefício à economia de aço. Percebeu-se também que para ângulos das bielas superiores a $55^{\circ}$ o bloco teve comportamento de consolo curto.

No Brasil, Mautoni (1972) ensaiou vinte blocos sobre duas estacas com dois arranjos de armadura: armadura em laçada contínua na horizontal e armadura em forma de bigode. A ruína dos modelos aconteceu por fendilhamento da biela comprimida com plano de fratura em seção localizada entre a estaca e o pilar, como ilustra a Figura 2.6. Percebe-se que as fissuras possuem direção paralela à da biela idealizada mostrando que a ruptura se deu em razão do campo de tensões de tração, transversal à biela.

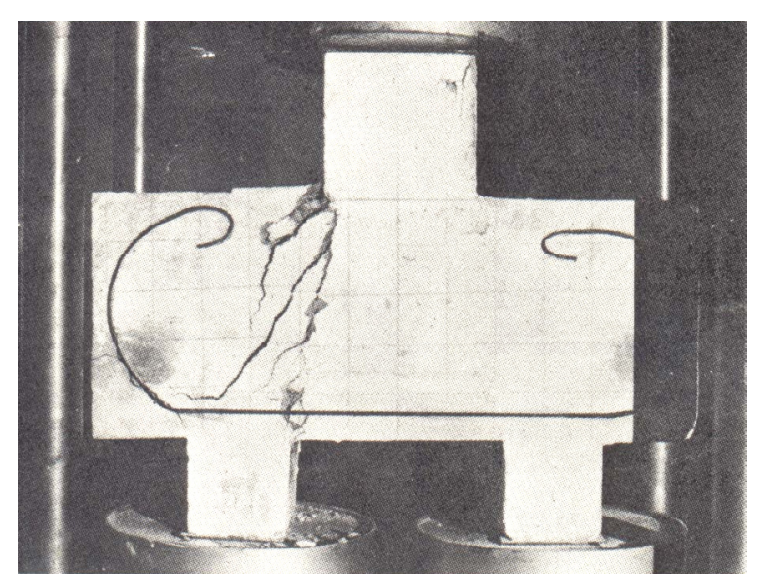

Figura 2.6 - Ruína do modelo ensaiado por Mautoni (1972) e detalhe da armadura em bigode Fonte: Mautoni (1972)

Mautoni (1972) relata que a armadura em bigode, além de ter apresentado inconveniência na ancoragem, conduziu a um elevado consumo de aço. Já a armadura em 
laçada contínua é inconveniente quanto à produtividade e ainda reduz a altura útil do bloco em razão do seu uso em múltiplas camadas. Por meio deste estudo, Mautoni (1972) conseguiu estabelecer um procedimento para a determinação da força última do bloco e seu mecanismo de ruína.

Clarke (1973) ensaiou quinze blocos apoiados sobre quatro estacas e avaliou três diferentes disposições de armadura: em malha, segundo os lados e segundo as diagonais. Esses três arranjos de armadura estão ilustrados na Figura 2.7.

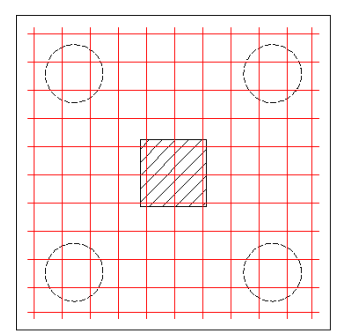

Armadura em forma de malha ortogonal

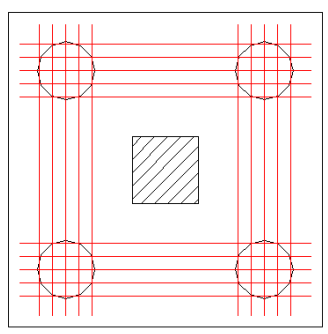

Armadura segundo os lados

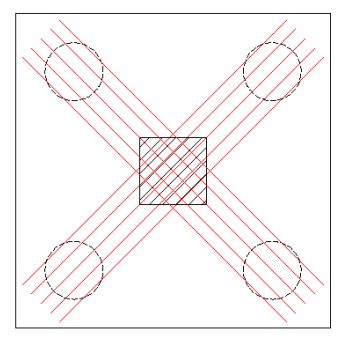

Armadura sobre as diagonais

Figura 2.7 - Arranjos de armadura dos blocos ensaiados por Taylor e Clarke (1976)

Além da disposição, o pesquisador estudou a influência do tipo de ancoragem das barras variando-a nos quatro tipos que estão representados na Figura 2.8. Os blocos ensaiados possuíam espaçamento entre estacas de duas e de três vezes o diâmetro da estaca, resultando em blocos quadrados de $0,75 \mathrm{~m}$ e de $0,95 \mathrm{~m}$ de lado respectivamente. As estacas possuíam $0,20 \mathrm{~m}$ de diâmetro e altura total de $0,45 \mathrm{~m}$.
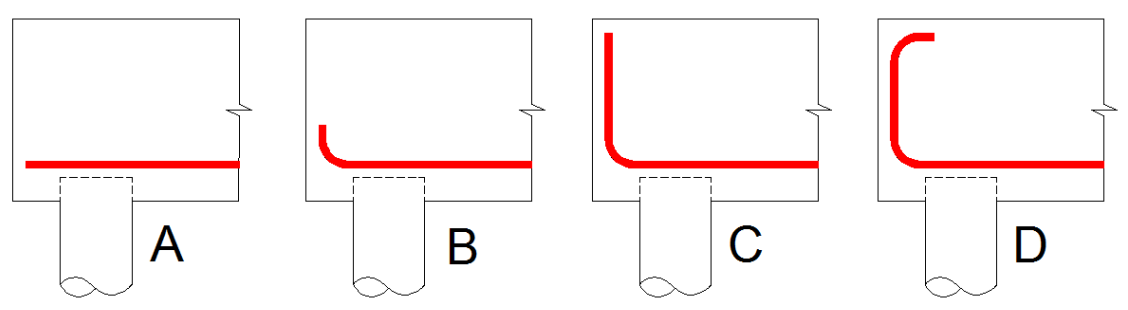

Figura 2.8 - Tipos de ancoragens da armadura ensaiados por Taylor e Clarke (1976)

Os resultados destes mesmos ensaios também foram apresentados em um trabalho de Taylor e Clarke (1976) no qual foi investigada a influência dos detalhamentos de ligações em estruturas de concreto e elementos cujo comportamento ainda não estava esclarecido, tais como os blocos de fundação. Nos blocos com armaduras ancoradas conforme os tipos $A$ e $B$, a disposição da armadura influenciou na força última do bloco, mas não em seu modo de ruína, 
de tal maneira que a força última dos blocos com armadura segundo os lados foi $15 \%$ maior que a dos blocos com armadura em forma de malha ou disposta segundo as diagonais.

O tipo de ancoragem teve maior influência nos blocos com armadura em forma de malha. Nos blocos com armadura em malha o tipo de ancoragem $B$ resultou em $5 \%$ de acréscimo da força última em relação à ancoragem do tipo $A$. Já a ancoragem do tipo $C$ resultou em força última $30 \%$ superior em relação ao tipo $A$ e ainda alterou a forma de ruína, que ocorreu por flexão e não por cisalhamento. A ancoragem do tipo $D$ não alterou a força última nem o comportamento em relação ao modo de ruína.

As primeiras fissuras formaram-se na porção central das quatro faces laterais. Com o desenvolvimento da força, as fissuras se estenderam até o topo do bloco fazendo com que o bloco fosse seccionado em quatro. Dois tipos de ruptura por cisalhamento foram observados: a primeira semelhante ao cisalhamento que ocorre em vigas e a outra destacando uma cunha de concreto na porção central do bloco, Figura 2.9.
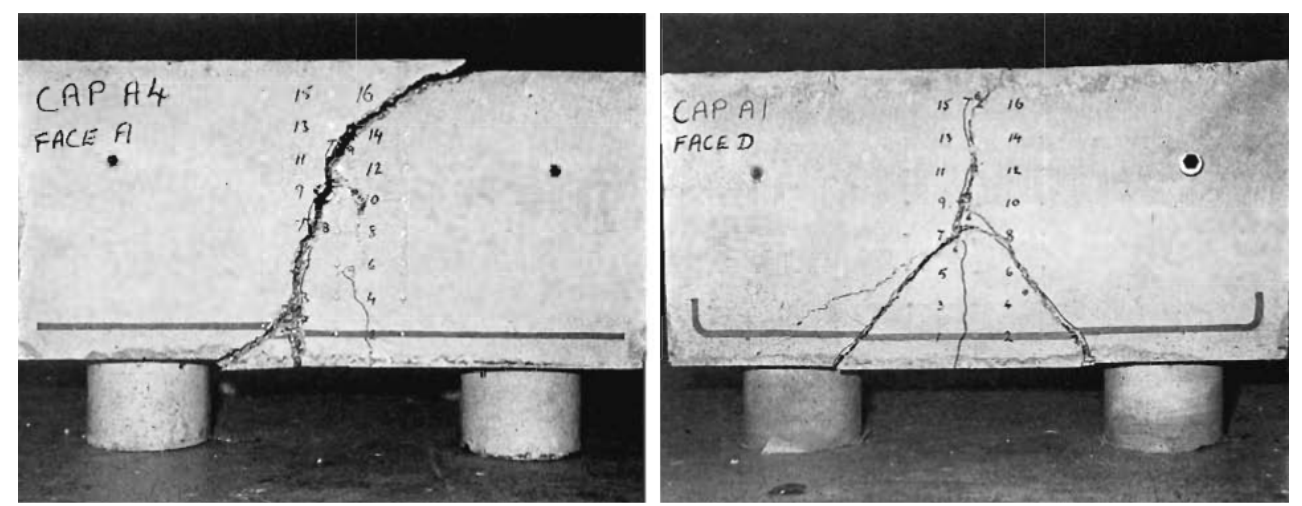

Figura 2.9 - Tipos de ruptura por cisalhamento observado por Taylor e Clarke (1976) Fonte: Taylor e Clarke (1976)

Sabnis e Gogate (1984, apud Delalibera, 2006, p. 16), mediante resultados obtidos em ensaios de blocos sobre quatro estacas nos quais foram variados a taxa de armadura distribuída, sugeriram um procedimento de dimensionamento de blocos apoiados sobre quatro estacas. Os pesquisadores ${ }^{2}$ concluíram que valores de taxa de armadura principal superiores a 0,2\% têm influência desprezível na força de ruína. Essa constatação permite inferir que, nestas condições, a ruína do bloco de fundação está atrelada à ruptura da biela por compressão ou fendilhamento.

\footnotetext{
${ }^{2}$ SABNIS, G. M.; GOGATE, A. B. Investigation of Thick Slab (pile cap) Behavior. ACI Journal. Title n. 81-5, p. 35-39, Jan/Fev, 1984.
} 
Adebar et al. (1990) ensaiaram seis blocos sobre estacas de altura de 0,60 m, dimensão do pilar de $0,30 m$ x $0,30 m$ e estacas pré-moldadas de $0,20 m$ de diâmetro. A Figura 2.10 ilustra os modelos de blocos ensaiados.

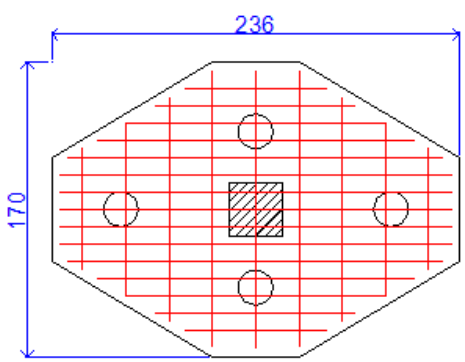

BLOCO A

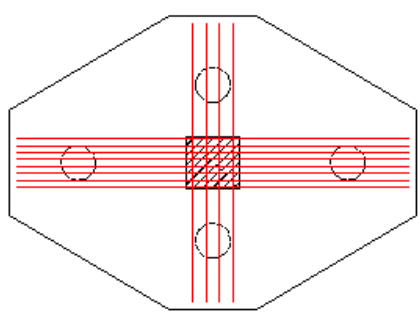

BLOCO D

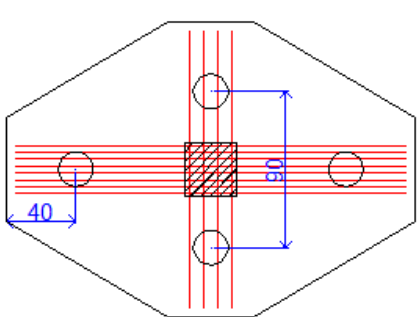

BLOCO B

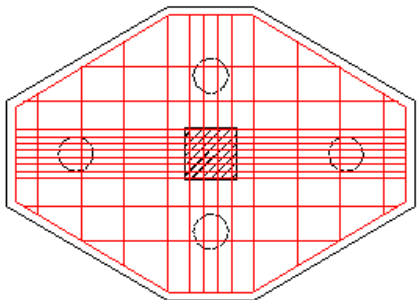

BLOCO E

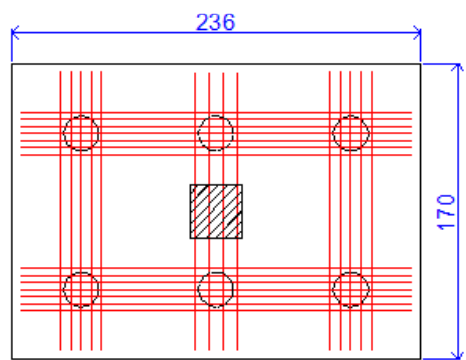

BLOCO C

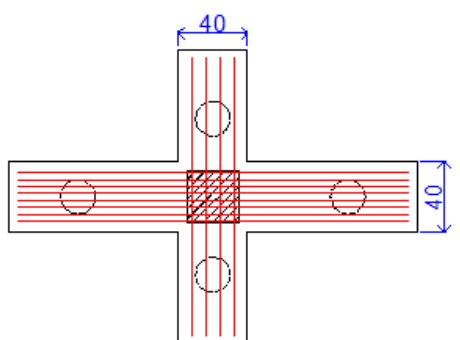

BLOCO F

Figura 2.10 - Modelos de blocos ensaiados por Adebar et al. (1990)

O bloco $A$ foi dimensionado conforme o ACI $318(1983)^{3}$, os blocos $B$, $C$ e $D$ foram dimensionados pelo Método das Bielas sendo o bloco $D$ semelhante ao bloco $B$, todavia com o dobro da armadura a fim de investigar a ruína do bloco antes do escoamento da armadura. $\mathrm{O}$ bloco $E$ era similar ao bloco $D$, entretanto a distribuição da armadura seguiu o código ACI 318 (1983). Já o bloco $F$ foi construído semelhante ao bloco $D$, mas sem os cantos chanfrados de concreto onde seriam os vértices do bloco a fim de avaliar uma hipótese do código ACI. O bloco $C$, sobre seis estacas dispostas em planta retangular, foi ensaiado a fim de investigar a distribuição das reações nas estacas.

Nos blocos $A$ e $B$, que possuíam uma menor taxa de armadura, as deformações das barras de aço aumentaram repentinamente assim que se formou a primeira fissura. Os blocos apresentaram poucas fissuras antes da ruína. Geralmente surgiu uma grande fissura de flexão em cada espaço entre estacas. Em todos os blocos a ruptura do concreto foi definida pelo desenvolvimento de novas fissuras.

\footnotetext{
${ }^{3}$ AMERICAN CONCRETE INSTITUTE. Committee 318 (ACI 318-83): Building Code Requirements for Structural Concrete and Commentary. Detroit, Michigan, 1983.
} 
O bloco A rompeu com $83 \%$ do carregamento calculado conforme código o ACI 318 (1983). No ensaio do bloco $B$ percebeu-se que inicialmente o maior quinhão da força aplicada era resistido pelas estacas mais próximas do pilar, este comportamento também foi observado por Munhoz (2004) nos modelos numéricos de blocos sobre cinco estacas, sendo uma delas centralizada. A ruptura ocorreu após uma significante redistribuição das forças nas estacas. A força última resistida pelo bloco foi $9 \%$ maior que a força estimada pelo Método das Bielas. Não foi verificado o escoamento do tirante presente ao longo do maior comprimento entre as estacas, apenas escoou o tirante presente na menor direção.

No bloco $C$ a maior parte da força aplicada foi resistida pelas duas estacas intermediárias enquanto as outras estacas, mais afastadas do pilar, resistiram a uma pequena parcela da força aplicada. Os blocos $D$ e $E$ apresentaram ruína antes do escoamento das armaduras de qualquer um dos tirantes. O bloco $F$ permitiu avaliar o método de dimensionamento utilizado pelo código ACI 318 (1983), baseado na verificação da flexão e do cisalhamento em uma seção transversal crítica. Os ensaios indicaram que a força de tração na parte inferior do bloco não diminui significativamente conforme se aproxima do apoio como seria esperado no comportamento de flexão. Mediante análise das deformações ao longo de uma seção transversal, perceberam que não há uniformidade na sua distribuição e que não é adequada a consideração do comportamento de flexão conforme indica o ACI 318 (1983).

O bloco $D$ de acordo com o código ACI 318 (1983) deveria ser 63\% mais resistente que o bloco $F$, semelhante ao bloco $D$ exceto pelo fato do bloco $F$ não possuir os "cantos" chanfrados, todavia a diferença entre as forças última foram menores que $7 \%$, comprovando a previsão feita pelo Método de Bielas e Tirantes e a hipótese de que apenas a porção mais central do bloco mobiliza resistência e não a seção completa, conforme considera o ACI 318 (1983).

Ainda, Adebar et al. (1990) observaram que as deformações principais de compressão não atingiram valores críticos em nenhum dos blocos de tal maneira que a ruptura da biela não se deu por compressão mas por tensões de tração transversais. Por meio destes resultados experimentais e dos obtidos mediante análise numérica linear baseada no Método dos Elementos Finitos, os pesquisadores sugeriram um modelo de biela e tirante mais refinado, possuindo um tirante transversal de concreto para representar o estado de tensões resultantes do alargamento do fluxo de tensões de compressão na região entre o pilar e as estacas, Figura 2.11 . 


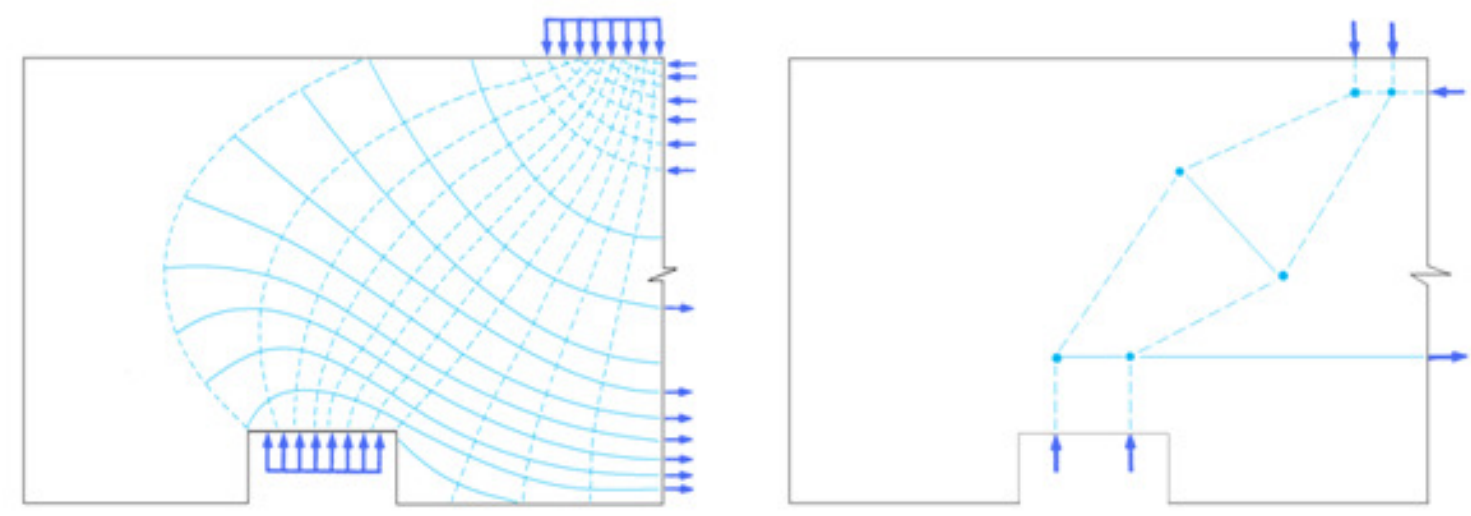

Figura 2.11 - Modelo de Bielas e Tirantes proposto por Adebar et al. (1990)

As forças últimas dos ensaios foram comparadas com os valores previstos por meio do ACI 318 e da CSA A23.3 A norma canadense, CSA A23.3, forneceu valores mais próximos dos observados nos ensaios.

Com o objetivo de estudar o comportamento estrutural de blocos, em especial as características de força-deslocamento, as deformações da armadura, os padrões de fissuras e a força última, Iyer e Sam (1995) conduziram ensaios experimentais e análise numérica nãolinear baseada no Método dos Elementos Finitos em blocos sobre quatro estacas.

Utilizando um elemento cúbico isoparamétrico de oito nós para representar o concreto e um elemento de treliça espacial de dois nós para representar a armadura, foram modelados três blocos, Figura 2.12, assumindo pilar e estacas de seção quadrada sendo a distância entre eixos das estacas igual a três vezes a sua dimensão e a altura efetiva do bloco de 0,225 $\mathrm{m}$.

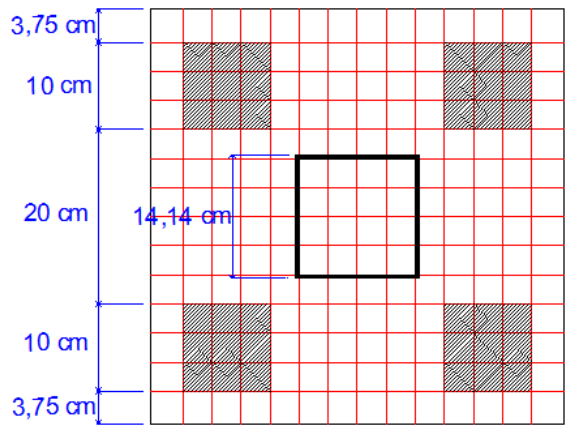

$15 ø 6 \mathrm{~mm}$ em cada direção

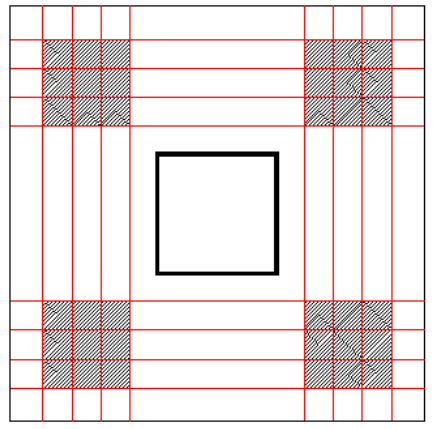

$4 \varnothing 8 \mathrm{~mm}$ em cada faixa

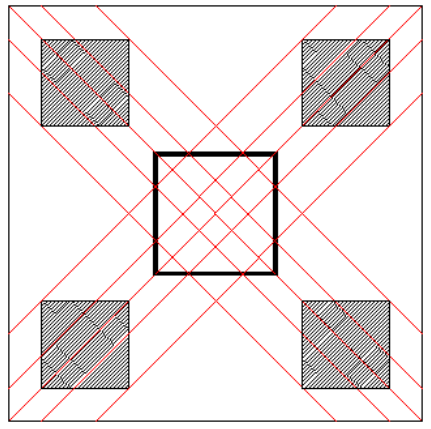

$5 \varnothing 10 \mathrm{~mm}$ em cada faixa

Figura 2.12 - Modelos numéricos de blocos sobre quatro estacas ensaiados por Iyer e Sam (1995)

Como parâmetros físicos do concreto foram considerados: resistência à compressão do concreto de $19 M P a, 1,9 M P a$ de resistência a tração, módulo de elasticidade de 22.077 $M P a$ 
e diâmetro máximo do agregado de $10 \mathrm{~mm}$. Para o aço os parâmetros considerados foram: resistência ao escoamento de $300 \mathrm{MPa}$ e módulo de elasticidade de $200.000 \mathrm{MPa}$.

As conclusões de Iyer e Sam (1995) contrastam com as conclusões de Blévot e Frémy (1967) e de Taylor e Clarke (1976) no que diz respeito ao melhor arranjo de armadura. Nos resultados experimentais, a força média de ruína para os blocos com armadura em forma de malha e com armadura sobre as diagonais foram respectivamente $10 \%$ e $8 \%$ superior à obtida no bloco armado segundo os lados. Já para os modelos numéricos, a superioridade da força última dos blocos com armadura distribuída em malha ou sobre as diagonais foi de $7 \%$ em relação ao bloco com armadura segundo os lados.

Assim, os pesquisadores concluíram que os blocos com armadura em forma de malha são mais rígidos e, além disso, observaram que o comportamento dos blocos nos estágios iniciais de carregamento assemelha-se ao comportamento de viga, com a deformação da armadura sendo máxima no meio do bloco e diminuindo quando se aproxima das estacas. À medida que aparecem tantas fissuras que façam com que as tensões do concreto fissurado sejam transmitidas pela armadura, a deformação da armadura torna-se mais uniforme ao longo do seu comprimento caracterizando um tirante e, por conseqüência, a resistência do bloco torna-se dependente da resistência da biela comprimida.

Carvalho (1995) realizou prova de carga em diferentes blocos apoiados sobre grupos de estacas de pequeno diâmetro com a finalidade de estudar o comportamento quanto à fissuração, deformações e distribuição de força nas estacas. Também foi avaliada a parcela de força transferida pelo bloco diretamente ao solo além de terem sido confrontados os resultados obtidos com as previsões dos modelos teóricos proposto por Blévot e Frémy (1967) e pelo boletim 73 do CEB-FIP (1970).

Os blocos foram construídos sobre estacas moldadas no local em um campo experimental sendo que foram avaliados blocos sobre uma, duas, três e quatro estacas. Duas configurações de blocos sobre três estacas foram estudadas: três estacas segundo os vértices de um triângulo eqüilátero e três estacas alinhadas. Durante os ensaios foram aferidos os deslocamentos no bloco, as deformações em alguns pontos da armadura, as reações nas estacas e a pressão aplicada pela superfície inferior do bloco no solo.

Carvalho (1995) observou que para as cargas de serviço, as armaduras de finalidade construtivas foram pouco solicitadas, entretanto não conseguiu avaliar os métodos de dimensionamento, pois o bloco não foi carregado até seu limite, sendo interrompida a prova 
de carga quando as estacas atingiram recalques da ordem de $50 \mathrm{~mm}$. A contribuição da reação exercida pelo solo na base do bloco foi de $12 \%$, em média, da força aplicada ao conjunto. As estacas resistiram, aproximadamente, à mesma parcela da força aplicada sendo que as diferenças apresentadas podem ser remetidas à imprecisão das células de carga.

Interessados em avaliar o comportamento de blocos pré-moldados sobre quatro estacas, Chan e Poh (2000) realizaram ensaios em três blocos, um moldado convencionalmente, bloco $A$, e outros dois pré-moldados, blocos $B$ e $C$. Os blocos prémoldados consistiam de uma casca de concreto de 7,5 $\mathrm{cm}$ que servia de fôrma para a concretagem do bloco sendo que as armaduras do bloco estavam ancoradas nesta casca de tal modo a formar um conjunto. Os blocos $A, B$ e $C$ possuíam dimensões em planta de $100 \mathrm{~cm} \mathrm{x}$ $100 \mathrm{~cm}$ e estacas de seção transversal quadrada de $15 \mathrm{~cm}$. Todos possuíam pilar de seção quadrada de $20 \mathrm{~cm}$. Os blocos $A$ e $B$ mediam $40 \mathrm{~cm}$ de altura e utilizavam mesma armadura, já o bloco C possuía altura de $30 \mathrm{~cm}$ e quantidade maior de armadura, designada para avaliar a ruptura por cisalhamento.

Chan e Poh (2000) observaram que o comportamento quanto à fissuração e à capacidade resistente não alterou entre o bloco moldado convencionalmente e o pré-moldado, além disso, os procedimentos adotados para o dimensionamento levaram a resultados conservadores sendo que o procedimento adotado para blocos usuais poderia ser aplicado com segurança neste tipo de bloco pré-moldado.

Mediante ensaios experimentais em nove modelos de escala natural e por meio de análise numérica considerando a não-linearidade do concreto, mas desconsiderando a presença de armaduras, Miguel (2000) estudou a formação de fissuras e o modo de ruína de blocos sobre três estacas. A análise numérica baseada no Método dos Elementos Finitos foi realizada por intermédio do programa computacional LUSAS.

A pesquisadora constatou que: o Método das Bielas e Tirantes é seguro, com margem de segurança mínima de 12\%; os modelos com armadura segundo os lados combinados com armaduras segundo as medianas ou combinados com armadura em gaiola apresentaram maior eficiência quanto à resistência; todos os blocos tiveram ruína por fendilhamento das bielas seguido do escoamento das barras da armadura principal.

Delalibera (2006) analisou experimentalmente quatorze blocos sobre duas estacas e simulou numericamente oitenta e um blocos sobre duas estacas a fim de analisar a formação das bielas de compressão, avaliar a eficiência dos ganchos na ancoragem das barras da 
armadura do tirante e propor um modelo de bielas e tirantes mais refinado para blocos sobre duas estacas. Mediante a utilização do programa computacional ANSYS, Delalibera (2006) simulou modelos numéricos baseados no Método dos Elementos Finitos, considerando a fissuração do concreto e a presença de armaduras. Esses modelos foram divididos em três grupos, sendo que foram variadas a excentricidade da ação vertical do pilar, a seção transversal das estacas, a seção transversal do pilar e a altura do bloco. Mediante utilização do critério ANOVA, de analise de variância, o pesquisador conseguiu avaliar qual a sensibilidade que o bloco tem com relação aos parâmetros estudados, concluindo que a excentricidade da força vertical aplicada ao bloco, a altura do bloco, a área da seção transversal do pilar e da estaca e o acoplamento destes fatores foram os parâmetros que tiveram maior influência na força última. Delalibera (2006) observou que apenas uma parte da seção transversal do topo da estaca é solicitada de maneira mais intensa sendo que, aproximadamente, a um terço da profundidade do fuste as tensões na seção da estaca se uniformizam. Acredita-se que este comportamento possa sofrer variações quando alteradas as condições de vinculação das estacas.

O pesquisador, nos ensaios experimentais, constatou que a deformação dos ganchos é desprezível, assim como já havia antecipado Adebar et al. (1990) e Miguel (2000). Este comportamento pode ser atribuído ao aumento da eficiência da ancoragem promovido pelo confinamento das barras pelas tensões de compressão oriundas das bielas. Do mesmo modo pode-se inferir que a redução das tensões nas barras da armadura principal, quando localizadas próximas às estacas, tenha a mesma razão. Ao término de seu trabalho, Delalibera (2006) sugere um Modelo de Bielas e Tirantes para blocos sobre duas estacas submetidos à força vertical e momento. Propõe também o dimensionamento de uma armadura de fendilhamento a fim de limitar a abertura de fissuras paralelas à biela.

Com o propósito de analisar o comportamento de blocos sobre estacas com cálice externo para ligação com pilar pré-moldado, Campos (2007) realizou estudo experimental em três modelos de escala 1:2 de blocos com cálice externo apoiados sobre estacas metálicas onde se variou o comprimento de embutimento em cada modelo. As paredes do cálice e do pilar foram moldadas com a rugosidade descrita na ABNT NBR 9062:1985 de um centímetro de amplitude a cada dez centímetros de comprimento e as dimensões do modelo foram tais que os ângulos de inclinação das bielas de compressão atendessem ao intervalo recomendado por Blévot e Frémy (1967). Durante os ensaios foram medidos: deslocamentos verticais, da 
face inferior do bloco, e horizontal, a partir de sua face lateral; força aplicada; reações nas estacas; deformações nas armaduras principais do bloco e do pilar.

Campos (2007) observou que: nos três modelos a primeira fissura surgiu para uma força de aproximadamente $60 \%$ da força última; as forças no tirante reduziram, em média, $31 \%$ em seções localizadas no centro das estacas quando comparadas com as forças dos tirantes no meio do vão; a ruína dos três modelos adveio do fendilhamento das bielas nas proximidades das estacas, sendo que no terceiro modelo a ruína também foi acompanha pelo escoamento da armadura principal do bloco; houve a redução da força nas barras da armadura principal do pilar à medida que aumentou-se a parcela de comprimento de embutimento do pilar. Este fenômeno pode ser atribuído à transmissão das forças verticais, que antes atuavam somente na seção transversal do pilar, ao colarinho.

A partir dessas observações, o pesquisador concluiu que: a utilização de blocos com cálices possuindo maior comprimento de embutimento acarreta menores quantidades de aço, maior força última e menos fissuração; a recomendação de se considerar 2/3 do comprimento de embutimento para a transmissão das forças por atrito, feita por Melo (2004), é conservadora.

\subsubsection{PESQUiSAS DE CARÁTER NUMÉRICO OU ANALÍTICO}

Confrontando a força última dos blocos ensaiados experimentalmente por Deutsch e Walker (1963) ${ }^{4}$, Blévot e Frémy (1967), Clarke (1973), Sabnis e Gogate (1984) e Adebar et al. (1990) com as forças últimas obtidas segundo as recomendações do ACI 318 (1977), ACI 318 (1983), ACI 318 (1983) seção 11.3 e pelo método de bielas proposto pelos próprios pesquisadores, Adebar e Zhou (1996) avaliaram os procedimentos para o dimensionamento de blocos rígidos segundo a norma americana.

Os pesquisadores comprovaram que os procedimentos sugeridos por estes códigos não são convenientes para blocos rígidos, pois as previsões obtidas pelo dimensionamento ao cisalhamento foram muito conservadoras e pela flexão foram contra a segurança. Já o método de bielas e tirantes proposto por Adebar e Zhou (1996) levou a resultados favoráveis à

\footnotetext{
${ }^{4}$ DeUTSCH, G. P.; WALKeR, D. N. O. Pile Caps. Civil Engineering Research Project. University of Melbourne, 1963. 75p.
} 
segurança e com menor variação em relação aos valores experimentais. Para generalizar o procedimento de dimensionamento de blocos rígidos e flexíveis, Adebar e Zhou (1996) recomendam a obtenção da altura do bloco por meio do dimensionamento sugerido pelo ACI 318 nas versões anteriores a 1983, ou seja, verificando o cisalhamento em uma direção na seção que dista $d$ da face do pilar e em duas direções, em seguida recomendam a verificação da tensão nas bielas por meio da formulação sugerida pelos autores, que leva em consideração o acréscimo de resistência promovido pelo efeito de confinamento, e se necessário, aumentase a altura ou as dimensões do bloco para incrementar o efeito de confinamento. Este procedimento também é adotado pela CSA A23.3 (2004).

A fim de avaliar as rotinas de projeto de blocos de fundação mais utilizadas, Munhoz (2004) analisou trinta e três modelos de blocos sobre uma, duas, três, quatro e cinco estacas que foram avaliados analiticamente pelos métodos propostos por: Blévot e Frémy (1967), CEB-FIP (1970) e EHE (2001) ${ }^{5}$. Estes modelos também foram analisados numericamente pelo método dos elementos finitos, considerando o comportamento elástico-linear, por meio do programa computacional ANSYS.

As séries elaboradas pela pesquisadora contemplavam sete modelos para blocos sobre quatro estacas sob ação de força centrada. Estes sete modelos apresentavam as dimensões do bloco constantes com variação apenas das dimensões dos pilares. Para facilitar a modelagem e a criação da malha de elementos finitos, a pesquisadora aproveitou a simetria em uma direção e definiu estacas retangulares de área equivalente à das estacas circulares, Figura 2.13.

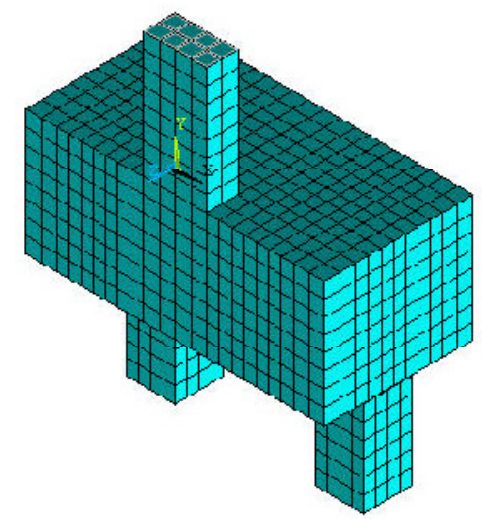

Figura 2.13 - Modelos de bloco sobre quatro estacas analisados por Munhoz (2004) Fonte: Munhoz (2004)

${ }^{5}$ COMISIÓN PERMANENTE DEL HORMIGÓN. EHE: Instrucción Española de Hormigón Armado. Ministerio de Fomento, Centro de Publicaciones, Madrid, 2001. 
$\mathrm{Na}$ análise numérica dos blocos sobre quatro estacas, Munhoz (2004) constatou que ao aumentar o diâmetro das estacas, as tensões de compressão nas bielas decresceram em razão do alargamento do campo de tensões de compressão além da seção do pilar e estacas, ainda, houve a diminuição da força de tração no tirante situado na região inferior do bloco, entretanto não tão expressivo quanto para blocos sobre duas estacas para os quais a pesquisadora observou diferenças de tensões chegando a $20 \%$.

Os blocos com pilares de seção retangular de $0,20 m$ x 0,80 $m$ e os blocos com pilares de seção quadrada equivalente de 0,40 $m$ x 0,40 $m$ apresentaram pequena diferença entre valores máximos de tensões de tração, ao contrário do que foi observado para os blocos sobre duas estacas.

A intensidade das tensões de compressão nas bielas dos blocos com pilares de seção quadrada foi maior que nos blocos com pilares de seção retangular, demonstrando que a estratégia dos métodos analíticos que propõem a simplificação de um pilar de seção retangular para um de seção quadrada de área equivalente é conservadora. Esse aspecto pode estar relacionado à diminuição do ângulo de inclinação da biela idealizada quando se adota essa simplificação, entretanto o autor acredita que esse procedimento possa resultar contra a segurança em situações quando o pilar possuir uma seção retangular muito alongada.

Ao término de seu trabalho, Munhoz (2004) sugere um modelo de Bielas e Tirantes mais refinado, baseado nos resultados obtidos em termos de tensões principais e que se assemelha com aquele proposto por Adebar et al. (1990)

Ramos (2007) estudou o comportamento de blocos apoiados sobre dez estacas quanto à distribuição das forças reativas entre as estacas e quanto ao fluxo de tensões nas direções principais. $\mathrm{O}$ estudo foi baseado em resultados de análise numérica não-linear por meio do programa computacional ANSYS. A fim de considerar a deformabilidade do solo, o pesquisador empregou elementos de mola, de comportamento elasto-plástico multi-linear, nos nós de apoio das estacas. Nos modelos analisados o pesquisador variou a altura dos blocos, a resistência à compressão do concreto, o tipo de ação atuante e o tipo de vinculação, se deformável ou não.

Ramos (2007) constatou que a resistência à compressão do concreto não exerce influência significativa no comportamento do bloco. Os resultados obtidos pelo pesquisador indicam que o comportamento estrutural do bloco depende do tipo de vinculação das estacas, ou seja, do comportamento do solo e da altura do bloco. Para os blocos em que foram 
simulados apoios deformáveis, houve uma melhor distribuição das reações entre as estacas. Para a situação de apoios indeformáveis, houve concentração das reações de maior intensidade nas estacas mais próximas ao pilar. Com o aumento da altura do bloco, consequientemente de sua rigidez, houve a maior uniformização na distribuição das reações entre as estacas. Os blocos solicitados por momento, além da força vertical, apresentaram valores de reações nas estacas diferentes daqueles obtidos analiticamente por meio da utilização da formulação que deriva do cálculo de flexão composta. Essas variações chegaram a ser superiores a $100 \%$ e em alguns casos houve inversão do sinal da reação.

Por meio de análise numérica não-linear baseada no Método dos Elementos Finitos, Delalibera (2007) estudou o comportamento e as formas geométricas das bielas dos blocos sobre duas estacas com o cálice embutido sob ação de força axial, horizontal e momento no pilar. Nessa pesquisa foram analisados 54 modelos, por intermédio do programa computacional ANSYS, considerando a fissuração do concreto, a presença de armaduras e o atrito na interface entre as paredes do cálice e do pilar.

Nessa investigação, Delalibera (2007) variou o comprimento de embutimento do pilar no bloco, $\ell_{e m b}$, a espessura da "laje" de fundo do bloco, $h_{s}$, a excentricidade da ação vertical e o tipo de conformação das paredes da interface de ligação. As seções do pilar e das estacas foram fixadas em valores usuais de seção quadrada, com $40 \mathrm{~cm}$ e $30 \mathrm{~cm}$ de lado respectivamente. A taxa de armadura dos blocos também foi fixada em favorecimento à praticidade da montagem dos modelos sendo justificada em razão da ruína do bloco ficar definida pela ruptura da biela e não pelo escoamento das armaduras. O bloco não teve variação das suas dimensões em planta e, em razão da influência na distribuição de tensões no bloco exercida pela rigidez das estacas e pelo tipo de solo de apoio, foram avaliados alguns modelos com estacas de comprimento real considerando o solo como meio contínuo. $\mathrm{Na}$ Figura 2.14 são ilustrados os elementos e malhas que foram utilizados em um dos modelos. 

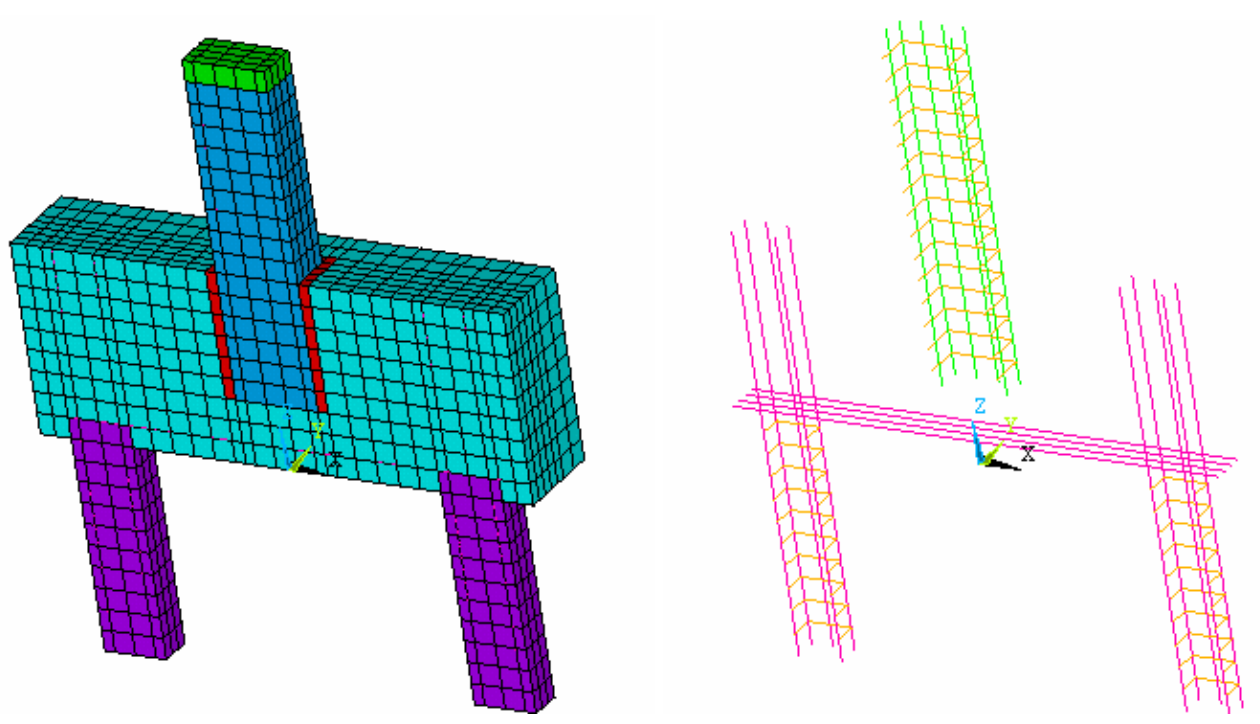

Figura 2.14 - Discretização dos elementos de volume (SOLID 65) e de barra (LINK 8) Fonte: Delalibera (2007)

As principais observações de Delalibera (2007) foram: as tensões nas estacas não são distribuídas uniformemente sendo a intensidade maior nas regiões da estaca mais afastadas da borda do bloco; as tensões nas estacas foram uniformizadas a partir de 1/3 do comprimento do fuste; ocorrem diferenças significativas entre a área da seção da biela junto á estaca quando calculada conforme os critérios de Blévot e Frémy (1967) e quando obtida da análise numérica; blocos de interface lisa cujo comprimento de embutimento do pilar e a espessura da "laje" de fundo são reduzidos possuem capacidade resistente determinada pela punção do bloco; modelos de bielas e tirantes devem ser modificados de acordo com as ações atuantes no bloco.

Por meio de uma análise de variância, Delalibera (2007) pôde determinar quais das variáveis estudadas exerceram maior influência no comportamento estrutural dos blocos analisados. Nos blocos de paredes lisas solicitado por força axial ou por força axial e momento, os resultados foram influenciados principalmente por $\ell_{e m b}$ seguido de $h_{s}$, sendo que foi verificado que a presença do momento tem influência no valor de $\ell_{e m b}$. Naqueles solicitados apenas por momento, o atrito e a resistência dos materiais da interface blocopreenchimento-pilar exerceram maior influência na capacidade portante. Nos blocos de interface rugosa, as variáveis analisadas não exerceram influência significativa na resistência do bloco, ou seja, a ruína do bloco estará condicionada à ruptura das bielas por compressão ou fendilhamento, ou ainda, ao escoamento das armaduras do tirante. 
Souza et al. (2007) propuseram um modelo de bielas e tirantes adaptável à geometria do bloco e ao tipo de carregamento que atua na base do pilar em blocos sobre quatro estacas, Figura 2.15. Este modelo considera a formação das bielas a partir do ponto onde atua a força vertical excêntrica de tal modo que a inclinação das bielas, o valor da tensão nos tirantes e as reações nas estacas são obtidos em função do valor da excentricidade da ação vertical do pilar. O modelo proposto possui restrições quanto à excentricidade, que não deve superar a região limitada pelo perímetro do pilar, e quanto à existência de estacas tracionadas. A fim de evitar a ruína por cisalhamento, caracterizada pelo fendilhamento das bielas, os pesquisadores sugerem limitar os valores das tensões de compressão na base do pilar.

O modelo analítico proposto foi comparado com os resultados obtidos em modelos numéricos analisados pelo Método dos Elementos Finitos tendo sido considerada a nãolinearidade física. Os resultados indicaram que o modelo de bielas proposto para blocos submetidos à ação de força excêntrica conduz à situação de segurança, uma vez que a força última obtida não ultrapassou a dos modelos numéricos.

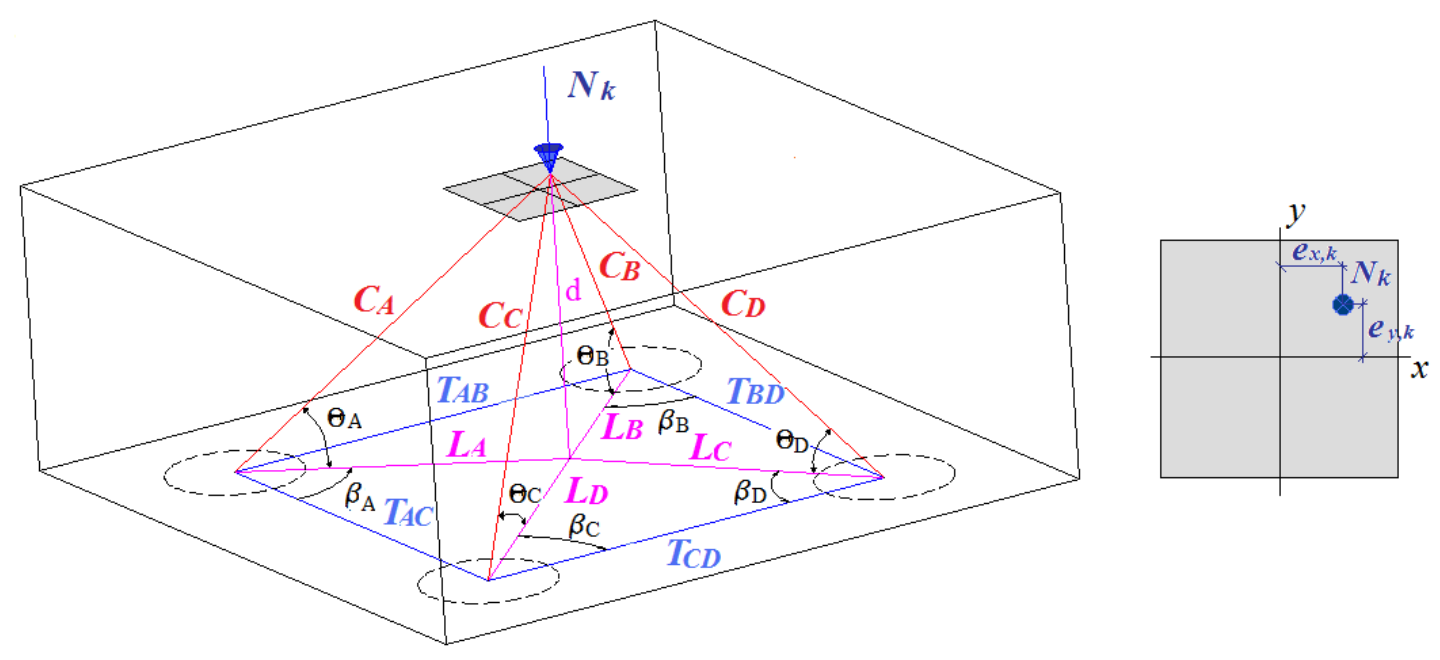

Figura 2.15 - Treliça espacial idealizada para blocos onde atuam força vertical excêntrica

Souza et al. (2007) concluem que o valor limite de compressão na base do pilar deve ser igual ao proposto por Adebar et al. (1990), 1,0·f $f_{\text {ck }}$. Os pesquisadores também avaliaram numericamente os mesmos blocos retirando-se as suas armaduras e concluíram que, para os modelos analisados, a resistência à tração do concreto, geralmente não considerada nos projetos, contribuiu significativamente na resistência dos blocos. Apesar de o modelo abranger boa parte das situações em construções de concreto moldado in loco, ainda existe 
uma demanda por modelos de bielas para o dimensionamento de blocos apoiados em estacas tracionadas.

Souza et al. (2009) confrontaram os resultados experimentais obtidos em blocos apoiados sobre quatro estacas ensaiados nas pesquisas de Blévot e Frémy (1967), Clarke (1973), Suzuki et al. (1998) ${ }^{6}$, Suzuki et al. (1999) ${ }^{7}$, Suzuki et al. (2000) ${ }^{8}$ e Suzuki e Otsuki $(2002)^{9}$ com os resultados obtidos por meio do modelo proposto. Para a previsão do comportamento dos blocos, os pesquisadores propuseram equações que estimam a força correspondente ao início de fissuração, à força última e a força que provoca o escoamento das armaduras, sejam elas em forma de malha ortogonal e/ou concentrada sobre as estacas. Também fizeram previsões do modo de ruína, se por momento fletor ou força cortante. Cada uma das formulações foi calibrada por meio de um coeficiente cujo valor foi obtido por intermédio dos resultados experimentais supracitados.

Depois de comparar os valores obtidos experimentalmente com os valores obtidos pelas equações propostas, Souza et al. (2009) chegaram a coeficientes de variação das previsões de fissuração e de escoamento da armadura de 0,14 e 0,15 respectivamente, e do coeficiente de variação da força última de 0,23. Também constataram que em $87 \%$ dos modelos analisados as previsões do modo de ruína foram corretas. Estes dois estudos evidenciam que a utilização do modelo de bielas e tirantes conduz a um dimensionamento racional que pode ser aprimorado para a previsão de outros eventos importantes que ocorrem no bloco em serviço.

Barros (2009) estudou o comportamento de blocos sobre duas estacas possuindo ligação pilar-fundação do tipo cálice embutido, para pilar pré-moldado. O estudo baseou-se na análise numérica não-linear de modelos em elementos finitos considerando a presença de armaduras, a fissuração do concreto e a interface da ligação entre pilar pré-moldado e bloco. Para analisar o modelo numérico e calibrar os parâmetros de entrada do modelo constitutivo, o pesquisador utilizou os resultados experimentais e numéricos da pesquisa de Delalibera (2006), envolvendo blocos sobre duas estacas. Toda a análise foi realizada por intermédio do

\footnotetext{
${ }^{6}$ SUZUKI, K.; OTSUKI, K.; TSUBATA, T. Influence of Bar Arrangement on Ultimate Strength of Four-Pile Caps. Transactions of the Japan Concrete Institute, v. 20, pp. 195-202, 1999.

${ }^{7}$ SUZUKI, K.; OTSUKI, K.; TSUBATA, T. Experimental Study on Four-Pile Caps with Taper. Transactions of the Japan Concrete Institute, v. 21, pp. 327-334, 1999.

${ }^{8}$ SUZUKI, K.; OTSUKI, K.; TSUCHIYA, T. Influence on Edge Distance on Failure Mechanism of Piles Caps. Transactions of the Japan Concrete Institute, v. 22, pp. 361-367, 2000.

${ }^{9}$ SUZUKI, K.; OTSUKI, K. Experimental Study on Corner Shear Failure of Pile Caps. Transactions of the Japan Concrete Institute, v. 23, 2002.
} 
programa computacional DIANA sendo que foram comparados os resultados obtidos por este programa com os resultados obtidos pelo programa ANSYS. Para representar a progressão das fissuras no modelo, em razão da elevação da intensidade do carregamento, o pesquisador optou por utilizar o modelo Total Strain que descreve esse comportamento levando em consideração parâmetros da Mecânica da Fratura. Assim como Souza (2006), que utilizou o mesmo programa computacional e o mesmo modelo constitutivo na análise de blocos de fundação, Barros (2009) obteve sucesso na obtenção da força de ruína, entretanto as respostas em termos de deslocamentos não foram compatíveis com os resultados experimentais, sendo mais próximas de outros resultados numéricos. Esse comportamento pode ser atribuído às limitações do modelo em representar os fenômenos considerados e também à presença de outros fenômenos, tais como fissuras pré-existentes, deformabilidade do pórtico de reação e desvios que possam ter ocorrido durante os ensaios experimentais, como pequenas excentricidades.

Um total de vinte e quatro blocos possuindo cálice embutido foram numericamente analisados sendo que dezesseis deles possuíam também viga lateral de travamento, Figura 2.16. A ligação foi simulada mediante a utilização de elementos de interface na ligação pilargraute. O pesquisador justificou o uso dos elementos de interface por considerar que elementos de contato devam ser utilizados para simular a não-linearidade de contato e que os elementos de interface podem representar satisfatoriamente as ligações entre concretos. Para o comportamento da interface foi escolhido o modelo de fricção de Coulomb.

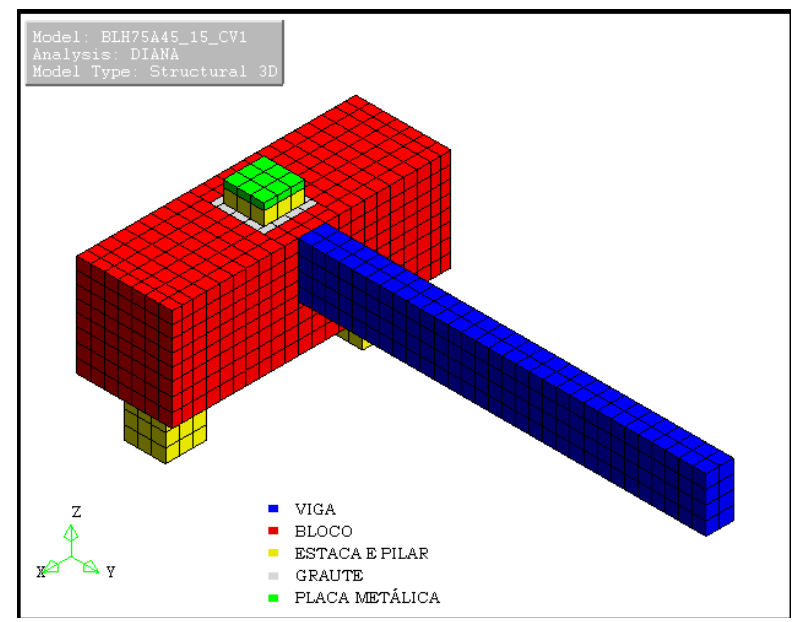

Figura 2.16 - Exemplo de um dos modelos analisados por Barros (2009).

Barros (2009) constatou que os blocos cuja espessura da parede do cálice era de $15 \mathrm{~cm}$ obtiveram maior resistência que àqueles cuja espessura era de $20 \mathrm{~cm}$. Esse comportamento 
não é preditivo, de tal modo que pode ser que, em razão da maior espessura da parede do cálice, uma parcela maior da força tenha sido transferida para a parte inferior central do bloco resultando em uma menor resistência. A força última atingiu maiores valores nos blocos de maior altura, tanto para a ligação de conformação lisa quanto rugosa. A presença da viga lateral de travamento fez com que a intensidade da força última reduzisse para os blocos cujo ângulo de inclinação da biela era de $55^{\circ}$, esse fenômeno não foi observado quando a inclinação das bielas era de $45^{\circ}$. Quanto ao fluxo de tensões principais de compressão, o pesquisador concluiu que, em ambos os tipos de conformação da interface da ligação, houve a formação de bielas de compressão a partir do início do embutimento do pilar no bloco, sendo maior a distribuição de tensões de compressão quando a interface era rugosa. Ainda quanto ao fluxo de tensões, Barros (2009) verificou que há uma grande intensidade de tensões de compressão na parte inferior do bloco. Isto é um indicativo de que deve ser verificada a possibilidade de punção do bloco pelo pilar como uma das configurações de ruína do elemento.

Quanto às tensões nas armaduras, o pesquisador observou que o gancho poderia ser desprezado, em razão das tensões nas barras serem muito reduzidas em seções ao longo da face da estaca até a face do bloco. As armaduras secundárias foram mais solicitadas nas seções em que atravessam as bielas, indicando que uma parcela das tensões transversais à biela é resistida por esse tipo de armadura.

\subsubsection{CONSIDERAÇÕES FINAIS}

Os ensaios realizados por Adebar et al. (1990) indicaram que a aplicação do Método das Bielas conduz a resultados favoráveis a segurança e ainda demonstraram, por meio de um dos ensaios, que o Método das Bielas representa com maior veracidade o comportamento do bloco. Além disso, confirmaram a observação feita por Taylor e Clarke (1976) quanto à reduzida variação da tensão ao longo da armadura do bloco armado sobre os lados, indicando que a armadura está se comportando mais como o tirante da treliça idealizada do que uma armadura longitudinal do bloco.

Quanto à disposição das armaduras em blocos sobre quatro estacas, as dispostas segundo as laterais apresentam maior eficiência em relação às demais disposições tais como 
segundo as diagonais e em malha. Esse fato foi primeiramente observado por Blévot e Frémy (1967) e posteriormente por Taylor e Clarke (1976) por meio de ensaios experimentais, entretanto, Iyer e Sam (1995) chegaram a resultados díspares em seu estudo envolvendo ensaios experimentais e numéricos. Mas, percebe-se que o ângulo de inclinação das bielas dos modelos ensaiados por Iyer e Sam (1995) é de $54,2^{\circ}$, próximo ao valor máximo indicado por Blévot e Frémy (1967) de 55 para o uso do Método das Bielas com segurança. Considerando que o tirante idealizado situa-se sobre as estacas, pela lógica do Método das Bielas, é conveniente que haverá maior eficiência quando houver maior concentração de armaduras nessa região, todavia, ao se aumentar o ângulo de inclinação das bielas ocorre uma redução da força de tração no tirante que pode explicar os resultados obtidos por Iyer e Sam (1995). Acredita-se que a disposição mais interessante quanto à segurança e quanto à economia seja a de armadura principal segundo os lados acrescida de armadura mínima em forma de malha para combater a fissuração na face inferior do bloco.

A respeito da ruína, verificou-se que essa ocorre a partir de ruptura da biela comprimida, seja pela compressão ou pelo fendilhamento. A ruína nos ensaios de Blévot e Frémy (1967) foi caracterizada pela ruptura à compressão do concreto próximo à estaca e/ou à base do pilar. Já Adebar et al. (1990) admite que a ruptura das bielas resultam das tensões transversais de tração que surgem em razão do alargamento do campo de tensões compressivas ao longo da biela, fendilhamento.

Em relação aos blocos com cálice embutido, por intermédio das análises numéricas de Delalibera (2007) e de Barros (2009), acredita-se que quando a ligação possuir interface lisa, o comportamento do bloco dependerá do comprimento de embutimento e da espessura da "laje" de fundo do bloco. Para um comprimento de embutimento e uma espessura da laje de fundo reduzida, os resultados indicam que a capacidade resistente do bloco será regida pela resistência à punção da camada inferior situada sob a base do pilar. Em relação ao comportamento do bloco cujo cálice de fundação possui interfaces rugosas, os pesquisadores admitiram o mesmo desempenho de uma ligação monolítica. 


\subsection{PROJETO DE Blocos SOBRE QUATRO ESTACAS}

A seguir são descritos os principais métodos e critérios para o dimensionamento e detalhamento de blocos apoiados sobre quatro estacas. As recomendações foram obtidas de códigos normativos e de autores e pesquisadores consagrados na área.

\subsubsection{CÁlCULO DAS REAÇÕES E DO NÚMERO DE ESTACAS}

O número de estacas é determinado a partir da capacidade de carga da estaca adotada no projeto. A capacidade de carga das estacas corresponde ao menor valor entre a máxima força que a estaca é capaz de transmitir ao maciço, de forma a respeitar os limites de resistência e de deformação, e a máxima força que a seção da estaca resiste como elemento estrutural.

Tomando como base um bloco sobre estacas cuja base do pilar possua reação em forma de força vertical e de momento em duas direções, Figura 2.17, Schiel (1957) sugere o cálculo das reações das estacas por intermédio da Expressão 2.2.

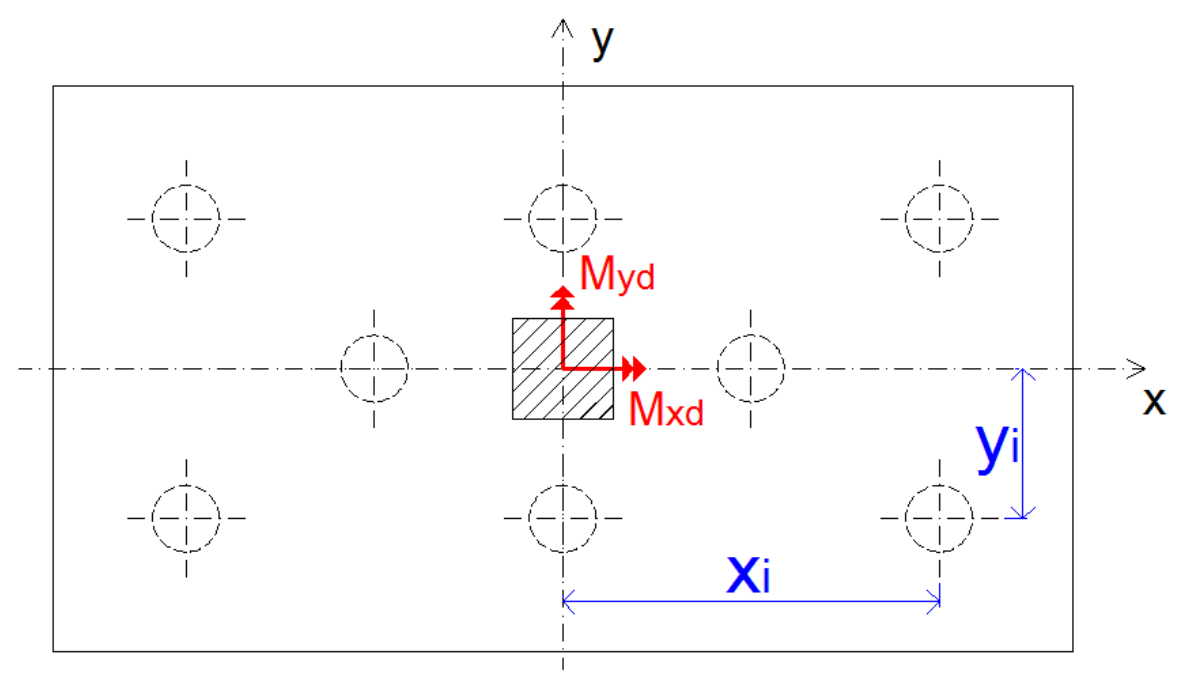

Figura 2.17 - Bloco sobre um número qualquer de estacas submetido à ação vertical excêntrica

A aplicação dessa expressão para o cálculo das reações das estacas deriva do cálculo de flexão composta de um corpo infinitamente rígido, desse modo, aplicada aos blocos rígidos 
apoiados sobre estacas verticais que possuam mesma seção transversal e mesmo comprimento.

$$
R_{i}=\frac{N_{d}}{n} \pm \frac{M_{y d} \cdot x_{i}}{\sum_{i=1}^{n} x_{i}^{2}} \pm \frac{M_{x d} \cdot y_{i}}{\sum_{i=1}^{n} y_{i}^{2}}
$$

Sendo que:

$R_{i} \quad$ é a reação da estaca cujo centróide situa-se em $x_{j}, y_{i}$,

$N_{d} \quad$ é a força vertical da reação do pilar somada ao peso próprio do bloco;

$M_{x d} \quad$ é o momento em torno do eixo $x$,

$M_{y d} \quad$ é o momento em torno do eixo $y$,

$n \quad$ é o número de estacas.

O estaqueamento é determinado de forma iterativa até que sejam atendidos os critérios de segurança e economia. A Expressão 2.2 vem sendo usada satisfatoriamente em projetos de fundações, no entanto é oportuno observar os resultados obtidos em algumas pesquisas que sugerem que a maior parte da força aplicada ao bloco é transmitida às estacas que se encontram mais próximas ao pilar. Munhoz (2004) verificou este comportamento nos blocos apoiados sobre cinco estacas, sendo uma delas centralizada. Este fenômeno pode ser atribuído ao fato dos blocos não possuírem rigidez infinita, apesar de serem classificados rígidos, e a tendência das forças internas serem conduzidas a uma situação de equilíbrio que atenda ao princípio de mínima energia, portanto pelo menor caminho, conforme descrito no item 2.1.

\subsubsection{CLASSIFICAÇÃO DOS BLOCOS E RECOMENDAÇÕES QUANTO À ALTURA}

Geralmente os blocos são classificados quanto ao seu comportamento em rígidos e flexíveis. Essa classificação é feita a partir das dimensões do bloco e, desse modo, pode apresentar variações de acordo com a bibliografia consultada. A ABNT NBR 6118:2003 admite que os blocos sejam rígidos quando a altura $h$ do bloco atende à Expressão 2.3: 


$$
h \geq \frac{a-a_{p}}{3}
$$

Sendo que:

$h \quad$ é a altura do bloco;

$a \quad$ é a dimensão do bloco em uma direção;

$a_{p} \quad$ é a dimensão do pilar na mesma direção considerada em $a$.

Nos blocos flexíveis admite-se o comportamento de viga ou de laje maciça com dimensionamento baseado na determinação da armadura principal, que resistirá às tensões de tração longitudinais em uma seção crítica, e na determinação da altura necessária para que o bloco resista à força cortante em uma seção crítica. Nos blocos rígidos não é comprovado o comportamento de viga, ou seja, a distribuição de deformações ao longo de uma seção do bloco não apresenta linearidade. Sendo um elemento estrutural caracterizado pela descontinuidade, a ABNT NBR 6118:2003 recomenda a adoção de modelos teóricos adequados para o cálculo e dimensionamento de blocos rígidos.

Em relação à altura do bloco, Guerrin (1955) recomenda que a altura útil $d$ atenda à Expressão 2.4.

$$
d \geq 0,70 \cdot\left(l_{e}-\frac{a_{p}}{2}\right)
$$

Sendo que:

$d \quad$ é a altura útil do bloco;

$l_{e} \quad$ é a distância entre eixos das estacas.

Os ensaios conduzidos por Blévot e Frémy (1967) permitiram estabelecer recomendações para a aplicação com segurança do método das bielas em blocos cujo ângulo de inclinação da biela, $\theta$, atenda o intervalo entre $40^{\circ}$ e $55^{\circ}$, contudo bielas com ângulo de inclinação inferior a $45^{\circ}$ resultam em grande área de seção transversal de armadura de tal modo que são recomendados valores superiores a $45^{\circ}$. Dessa maneira, para atender a recomendação de ângulos entre $45^{\circ}$ e $55^{\circ}$, a altura útil do bloco sobre quatro estacas pode ser determinada pela Expressão 2.5: 
$0,71 \cdot\left(l_{e}-\frac{a_{p}}{2}\right) \leq d<\left(l_{e}-\frac{a_{p}}{2}\right)$

O Boletim 73 do CEB-FIP (1970) apresenta recomendações para o dimensionamento de blocos cuja altura $h$ esteja compreendida no intervalo dado pela Expressão 2.5.

$$
\frac{2}{3} \cdot l_{c} \leq h \leq 2 \cdot l_{c}
$$

Sendo que as dimensões $l_{c}$ e $h$ estão indicadas na Figura 2.18 .

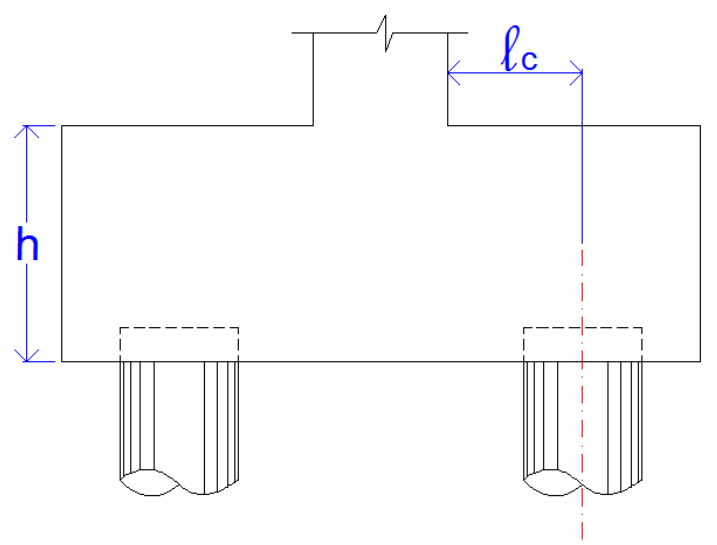

Figura 2.18 - Dimensões utilizadas pelo Boletim 73 do CEB-FIP (1970)

As recomendações do boletim 73 do CEB-FIP (1970) não são aplicáveis aos blocos nas quais a altura $h$ é maior que o dobro de $l_{c}$, pois neste caso o bloco teria uma rigidez muito elevada. Em blocos cuja altura $h$ é inferior ao limite dado pela Expressão 2.6, o boletim recomenda o dimensionamento segundo a mais adequada das teorias, de vigas ou de placas.

Tratando dos blocos apoiados sobre quatro estacas, Calavera (2000) faz a distinção entre blocos rígidos e flexíveis baseando-se na distância entre eixos de estacas, $l_{e}$, e na altura do bloco, $h$. Calavera (2000) sugere que o bloco seja considerado rígido quando atender à Expressão 2.7, caso contrário será considerado flexível.

$$
h \geq \frac{l_{e}}{3}
$$

Montoya (2000) faz a distinção entre blocos rígidos e flexíveis baseando-se na medida $l_{c}$, contabilizada desde a face do pilar até o eixo da estaca, e na altura total do bloco, $h$, 
conforme ilustrado na Figura 2.18. O bloco será considerado rígido se a Expressão 2.8 for verificada em todas as direções:

$$
h \geq \frac{l_{c}}{2}
$$

$\mathrm{Na}$ situação das dimensões do bloco não atenderem à Expressão 2.8, este será classificado como flexível. Essa distinção é a mesma adotada pela norma espanhola de concreto armado, EHE (2008).

A altura útil do bloco recomendada por Montoya (2000) é calculada pela Expressão 2.9 .

$$
d=\frac{F_{d}}{500 \cdot b}-0,14 \leq 0,34
$$

Sendo que:

$F_{d} \quad$ é a força axial transmitida pelo pilar em $k N$;

$b \quad$ é a largura do bloco em $m$ na seção em que será verificada à força cortante.

Essa expressão permite obter uma altura útil suficiente para evitar, na maioria dos casos, a verificação da resistência à força cortante e dispensar a utilização de armadura para resistir às tensões tangenciais.

\subsubsection{ESPAÇAMENTO ENTRE ESTACAS E DistÂNCIA DAS ESTACAS AO PERÍMETRO DO BLOCO}

O espaçamento mínimo entre as estacas é determinado com a finalidade de evitar a sobreposição de tensões no maciço e para atender às restrições impostas pelo processo construtivo, seja de escavação ou de cravação da estaca. Este efeito de grupo das estacas deve ser considerado também entre as estacas pertencentes aos blocos vizinhos. De acordo com a ABNT NBR 6122:1996, “A carga admissível de um grupo de estacas ou tubulões não pode ser superior à de uma sapata de mesmo contorno que o do grupo, e assente a uma profundidade acima da ponta das estacas ou tubulões igual a $1 / 3$ do comprimento de penetração na camada suporte [...]", sendo que a distribuição de pressões deve ser calculada por um dos métodos consagrados na Mecânica dos Solos. 
A ABNT NBR 6118:2003 estabelece que, no caso de conjunto de blocos e estacas rígidos e sendo a distância entre eixos de estacas de duas vezes e meia a três vezes o diâmetro da estaca, pode-se admitir que a distribuição de cargas nas estacas seja plana. Para os blocos flexíveis, a norma brasileira de concreto recomenda que esta hipótese seja revista.

Alonso (1983) e Moraes (1978) recomendam um espaçamento mínimo igual a duas vezes e meia o diâmetro da estaca, caso seja pré-moldada, e de três vezes se a estaca for moldada in loco. Para ambos os casos o espaçamento deverá ser maior que $60 \mathrm{~cm}$. Em Montoya (2000) é recomendado um espaçamento mínimo entre eixos de estacas de duas vezes o diâmetro desta, caso seja circular, e 1,75 vez a diagonal da estaca se a seção da mesma for quadrada e em ambos os casos os valores devem ser superiores a $75 \mathrm{~cm}$. Calavera (2000) sugere que o espaçamento entre eixos de estacas deve ser de duas vezes o seu diâmetro, sendo melhor se for três vezes, a menos que as estacas funcionem predominantemente pela resistência de ponta.

Quanto à distância do eixo da estaca à face do bloco, Figura 2.19, Alonso (1983) indica a distância mínima por meio da Expressão 2.10.

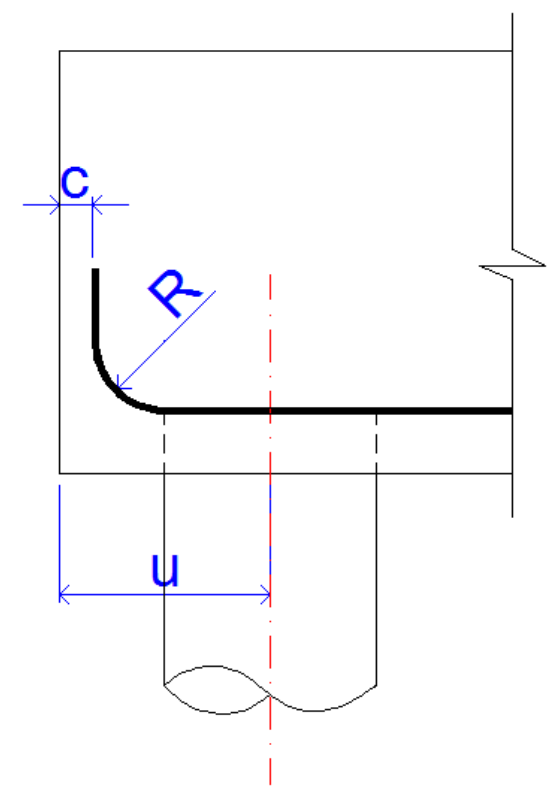

Figura 2.19 - Distância do eixo da estaca à face do bloco, Alonso (1983)

$$
u \geq\left\{\begin{array}{l}
R+c+\emptyset_{t i r} \\
\frac{\emptyset_{e s t}}{2}+15 c m
\end{array}\right.
$$


sendo que:

$\emptyset_{\text {tir }} \quad$ é o diâmetro da armadura do tirante;

$\emptyset_{\text {est }} \quad$ é o diâmetro da estaca.

Montoya (2000) e Calavera (2000) indicam que a distância da face da estaca à face do bloco deve ser maior ou igual à metade do diâmetro da estaca e não menor que $25 \mathrm{~cm}$.

\subsubsection{LIGAÇ̃̃O ENTRE ESTACA E BLOCO}

Tanto Calavera (2000) como Montoya (2000), recomendam a construção de um lastro de concreto de $10 \mathrm{~cm}$ sobre o qual será moldado o bloco, que tem sido considerado adequado pela prática da construção nacional. Segundo estes autores, as estacas precisam ter um comprimento de $10 \mathrm{~cm}$ a $15 \mathrm{~cm}$ dentro do bloco. Já Alonso (1983) indica que a estaca precisa ultrapassar o topo da camada de concreto não estrutural $\mathrm{em} 5 \mathrm{~cm}$ a $10 \mathrm{~cm}$.

A ABNT NBR 6122:1996 estabelece que caso a estaca não atinja o nível da cota de arrasamento especificado em projeto, deve-se completar ou demolir o excesso, se for o caso. Quanto à demolição, devem ser tomadas precauções para que a cabeça da estaca não fissure.

\subsubsection{ARMADURA PRINCIPAL}

De acordo com a ABNT NBR 6118:2003, o dimensionamento de blocos pode ser feito por modelos tridimensionais, lineares ou não, e modelos de bielas e tirantes tridimensionais, sendo este preferível por definir melhor a distribuição de esforços. Nos blocos rígidos, mais de $85 \%$ da armadura principal deve ser disposta nas faixas definidas pelas estacas, estendendo-se de face a face do bloco e terminando em gancho nas duas extremidades, sendo que para barras com diâmetro igual ou superior a $20 \mathrm{~mm}$ devem ser usados ganchos com dobras de $135^{\circ}$ ou $180^{\circ}$. 
Montoya (2000) também indica que a armadura principal precisa ser alojada em faixas sobre as estacas, sendo essa faixa da largura da estaca mais duas vezes a distância da face superior da estaca até o centro de gravidade da armadura.

Segundo Blévot e Frémy (1967), a armadura poderá ser disposta conforme os arranjos ilustrados na Figura 2.20, com preponderância das armaduras segundo os lados ou em laço.

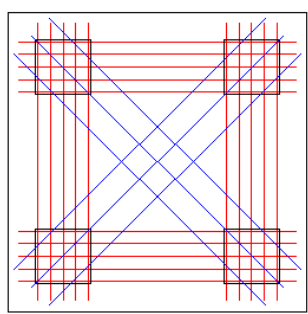

( I) Armadura segundo os lados e sobre as diagonais

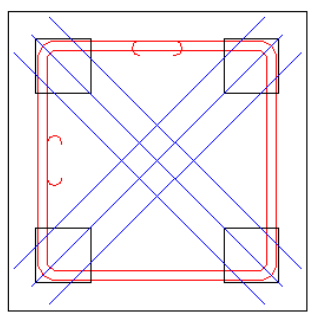

(II) Armadura em forma de laço e sobre as diagonais

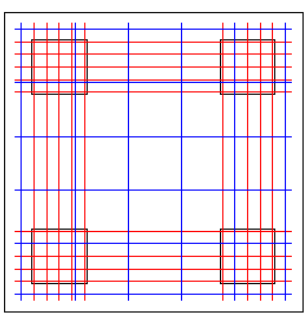

( III ) Armadura segundo os lados e em malha

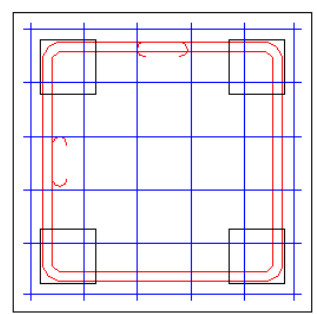

( IV ) Armadura em forma de laço e em malha

Figura 2.20 - Possíveis disposições de armaduras, Blévot e Frémy (1967)

O boletim 73 do CEB-FIP (1970) indica que as armaduras precisam ser dispostas de tal modo que sejam corretamente ancoradas além das estacas periféricas, podendo se considerar que, quando a armadura inferior atravessar a superfície cilíndrica centrada no eixo da estaca e cujo diâmetro é igual a três vezes o diâmetro da estaca, a armadura pode equilibrar uma força igual a $80 \%$ da reação da estaca. Somente as barras ancoradas além do plano axial da estaca, perpendicular às barras, podem ser consideradas. Esta recomendação ainda é favorecida pelos resultados de Delalibera (2007) e Barros (2009), que observaram que a partir da face da estaca as barras da armadura já apresentam uma brusca redução dos valores das tensões.

Leonhardt e Mönnig (1978) recomendam que quando a força se distribuir espacialmente entre três ou mais estacas, os tirantes precisam ser dispostos concentrados sobre as estacas nas direções em que a distância entre elas são menores. No caso de blocos quadrados sobre quatro estacas, essa disposição é obtida distribuindo a armadura em faixas laterais sobre as estacas.

Fusco (1994) comenta que a disposição de armadura segundo os planos que contêm as bielas ocasiona a superposição de várias camadas de armadura na região central, em blocos sobre muitas estacas. Entretanto, no caso de blocos sobre quatro estacas, são ilustradas as disposições de armadura em faixas laterais e diagonais, sobre as estacas, e armadura em 
malha uniformemente distribuída não sendo feita qualquer observação quanto à eficiência dos tipos de arranjos.

Segundo Calavera (2000), a armadura principal calculada pela analogia de treliça é disposta em faixas sobre as estacas de largura igual ao diâmetro destas. Montoya (2000) indica, para blocos rígidos e flexíveis, a distribuição da armadura principal em faixas laterais, sobre as estacas, de largura igual ao diâmetro da estaca mais duas vezes a distância entre o topo da estaca e o centro de gravidade da armadura dos tirantes.

A descrição da ABNT NBR 6118:2003 quanto ao plano a partir do qual se pode considerar a ancoragem é dúbia, pois é indicado que a ancoragem seja medida a partir da face das estacas, podendo ser considerado o efeito favorável da compressão transversal promovida pela reação da estaca e pelas bielas, entretanto não é especificada qual face da estaca deve ser considerada. Para os blocos flexíveis, devem ser atendidos os requisitos relativos às lajes. $\mathrm{O}$ comprimento de ancoragem é obtido a partir da Expressão 2.11.

$$
\ell_{b, n e c}=\alpha \cdot \ell_{b} \cdot \frac{A_{s, \text { calc }}}{A_{s, e f}}=\alpha \cdot \frac{\emptyset_{\text {tir }}}{4} \cdot \frac{f_{y d}}{f_{b d}} \cdot \frac{A_{s, \text { calc }}}{A_{s, \text { ef }}} \geq \ell_{b, \text { min }}
$$

Sendo que:

$\ell_{b, n e c} \quad$ é o comprimento de ancoragem necessário;

$\alpha \quad$ é 1,0 para barras sem ganchos e 0,7 para barras com gancho, cujo cobrimento no plano normal ao do gancho for no mínimo de $3 \cdot \emptyset_{\text {tir }}$, ou quando houver barras transversais soldadas;

$\ell_{b} \quad$ é o comprimento de ancoragem básico;

$A_{s, c a l c}$ é a área de aço calculada;

$A_{s, e f} \quad$ é a área de aço efetiva;

$\emptyset_{\text {tir }} \quad$ é o diâmetro da armadura do tirante;

$\ell_{b, \min }$ é o comprimento de ancoragem mínimo, que é o menor valor entre: $\left\{\begin{array}{c}0,3 \cdot \ell_{b} \\ 10 \cdot \emptyset_{\text {tir }} \\ 10 \mathrm{~cm}\end{array}\right.$;

$f_{y d} \quad$ é a resistência ao escoamento, de cálculo, do aço da armadura;

$f_{b d} \quad$ é a resistência de aderência, calculada pela Expressão 2.12. 
$f_{b d}=\eta_{1} \cdot \eta_{2} \cdot \eta_{3} \cdot f_{c t d}$

sendo que:

$\eta_{1} \quad$ é 1,0 para barras lisas, 1,4 para barras entalhadas e 2,25 para barras nervuradas;

$\eta_{2} \quad$ é 1,0 para situações de boa aderência e 0,7 para situações de má aderência;

$\eta_{3} \quad$ é 1,0 para $\emptyset_{\text {tir }}<32 \mathrm{~mm}$ e $\left(132-\emptyset_{\text {tir }}\right) / 100$ para $\emptyset_{\text {tir }} \geq 32 \mathrm{~mm}$;

$f_{c t d} \quad$ é $0,15 \cdot f_{c k}^{2 / 3}$.

Quanto à ancoragem, Fusco (1994) indica que todas as barras devem possuir ganchos ou dobras de extremidade, situados além da posição da estaca, sem necessidade de comprimentos retos de ancoragem.

Montoya (2000) recomenda que a ancoragem das barras seja feita a partir de um plano vertical que passe pelo eixo de cada estaca. A ancoragem pode ser por prolongamento reto ou mediante barras transversais soldadas. Montoya (2000) indica que o efeito benéfico da compressão vertical da estaca nas barras permite reduzir em $20 \%$ o comprimento de ancoragem destas.

Leonhardt e Mönnig (1978) recomendam a ancoragem reta das barras dos tirantes, em razão das elevadas tensões compressivas que as armaduras estão submetidas na direção perpendicular ao plano horizontal das estacas.

A norma canadense CSA A23.3 (2004) também admite a ancoragem dispensando o uso de ganchos nas extremidades das barras.

\subsubsection{DimEnSIONAMENTO E VERIFICAÇÕES}

Os métodos mais utilizados para o dimensionamento de blocos de fundação são baseados na Teoria de Flexão ou no Método de Bielas e Tirantes. Como os blocos flexíveis apresentam o comportamento análogo ao de placas, é plausível a consideração da hipótese de Bernoulli, já para blocos rígidos é mais recomendado o Método de Bielas e Tirantes. A seguir 
são descritos os procedimentos de dimensionamento de blocos sobre quatro estacas pelo Método de Bielas e Tirantes e pelo boletim 73 do CEB-FIP (1970). Os critérios adotados pelo CSA A23.3 (2004), ACI 318 (2008) e EHE (2008) são discutidos com brevidade.

\subsubsection{MÉtodo das Bielas de BlÉvot E FRÉmy (1967)}

Conforme apresentado no item anterior, é recomendado o dimensionamento do bloco pelo Método das Bielas quando este for considerado rígido. Os tirantes são idealizados no plano médio da armadura principal, logo acima do plano de arrasamento das estacas. As bielas são idealizadas com seus eixos inclinados, tendo início em um ponto contido na seção do pilar na altura em que intercepta a face superior do bloco e indo até o ponto em que o eixo das estacas intercepta o plano médio da armadura que constitui os tirantes.

O método consiste no cálculo da força de tração nos tirantes, e dimensionamento das respectivas armaduras, e na verificação das tensões de compressão nas bielas em seções localizadas na proximidade do pilar e das estacas.

O método que segue foi idealizado considerando ações centradas, pilares de seção quadrada e estacas eqüidistantes ao centro do pilar. Em blocos apoiados sobre quatro estacas, Blévot e Frémy (1967) sugerem o dimensionamento mediante equilíbrio da treliça idealizada na Figura 2.21.
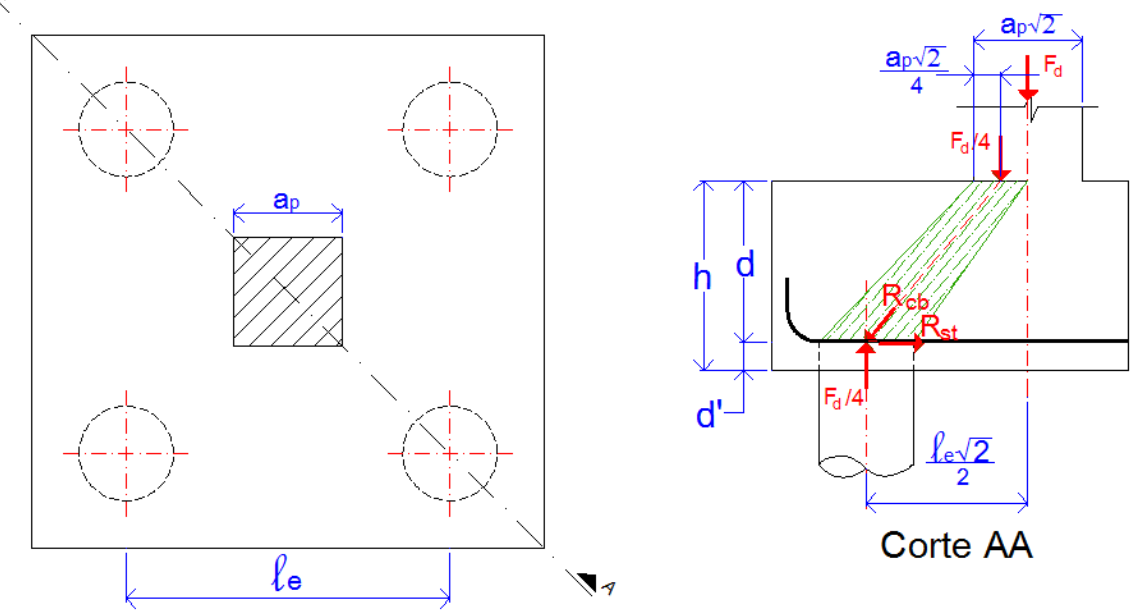

Figura 2.21 - Modelo de Bielas e Tirantes para blocos apoiados sobre quatro estacas 
O cálculo da armadura é feito a partir da força que atua no tirante. Caso os tirantes fossem dispostos nas diagonais do bloco, esta força seria calculada pela Expressão 2.13.

$$
R_{s t}=\frac{F_{d} \cdot \sqrt{2} \cdot\left(2 \cdot l_{e}-a_{p}\right)}{16 \cdot d}
$$

Sendo que:

$R_{s t} \quad$ é a força no tirante;

$F_{d} \quad$ é a força axial na base do pilar, que atua sobre o bloco;

$l_{e} \quad$ é a distância entre eixos das estacas;

$a_{p} \quad$ é o dimensão do pilar de seção quadrada;

$d \quad$ é a altura útil do bloco.

De acordo com os arranjos ilustrados na Figura 2.20, a força $R_{s t}$ nas armaduras que formam os tirantes segundo os lados e em forma de laço, para as disposições $i$, ii, iii e $i v$, é calculada pela Expressão 2.14, que difere da Expressão 2.13.

$$
R_{s t}=\frac{F_{d, l a d o} \cdot\left(2 \cdot l_{e}-a_{p}\right)}{16 \cdot d}
$$

Sendo $F_{d \text {,lado }}$ a parcela da força resistida pela armadura segundo os lados ou em forma de laço. A parcela $F_{d, l a d o}$ da força deve estar compreendida entre $50 \%$ e $65 \%$ de $F_{d}$, se a armadura complementar for constituída por faixas dispostas sobre as diagonais, e entre $75 \%$ e $85 \%$ de $F_{d}$ se a armadura complementar for constituída por barras uniformemente distribuídas em malha.

A área de aço da seção transversal da armadura de cada um dos tirantes é obtida por meio da Expressão 2.15:

$$
A_{s}=\frac{R_{s t}}{f_{y d}}
$$

Já as armaduras em malha ou segundo as diagonais são dimensionadas de acordo com as expressões indicadas na Tabela 2.2:

\begin{tabular}{|c|c|c|}
\hline Disposição & Força resistida & Área de aço \\
\hline Segundo as diagonais & $R_{s t, \text { sec }}=\frac{\left(F_{d}-F_{d, l a d o}\right) \cdot \sqrt{2} \cdot\left(2 \cdot l_{e}-a_{p}\right)}{16 \cdot d}$ & $A_{s}^{\prime}=\frac{R_{s t}^{\prime}}{f_{y d}}$ \\
\hline Em malha & $R_{s t, s e c}=1,2 \cdot \frac{\left(F_{d}-F_{d, l a d o}\right) \cdot\left(2 \cdot l_{e}-a_{p}\right)}{8 \cdot d}$ & $A_{s}^{\prime}=\frac{R_{s t}^{\prime}}{f_{y d}}$ \\
\hline
\end{tabular}

Tabela 2.2 - Expressões para a determinação da força resultante nas barras e área de aço da armadura secundária 
$\mathrm{Na}$ expressão que representa a força resistida pela armadura em malha, o coeficiente 1,2 foi indicado por Blévot e Frémy (1967) com a finalidade de considerar a eficiência reduzida que as barras em malha apresentaram nos ensaios experimentais.

Calavera (2000) e Montoya (2000) adotam o mesmo procedimento para blocos rígidos, entretanto não consideram a formação da biela no topo do bloco e sim a partir de 0,15 de $d$ do topo do bloco. Para eles, toda a força é resistida pela armadura que está disposta em faixas sobre as estacas.

A verificação da biela faz parte do dimensionamento de blocos pelo Método de Bielas e Tirantes. Para os blocos sobre quatro estacas, as tensões de compressão nas bielas nas proximidades do pilar devem ser verificadas pela Expressão 2.16.

$$
\sigma_{c b, p}=\frac{F_{d}}{A_{p} \cdot \operatorname{sen}^{2} \theta}<0,9 \cdot f_{c k}
$$

sendo que:

$\sigma_{c b, p}$ é a tensão de compressão na biela, em uma seção próxima ao pilar;

$F_{d} \quad$ é a força axial na base do pilar, que atua sobre o bloco;

$A_{p} \quad$ é a área da seção transversal do pilar;

$\theta \quad$ é o ângulo de inclinação da biela, calculado pela Expressão 2.17;

$$
\theta=\operatorname{arctg}\left(\frac{d \cdot \sqrt{2}}{l_{e}-\frac{a_{p}}{2}}\right)
$$

As tensões de compressão nas bielas nas proximidades das estacas devem ser verificadas pela Expressão 2.18.

$$
\sigma_{c b, e}=\frac{F_{d}}{4 \cdot A_{e} \cdot \operatorname{sen}^{2} \theta}<0,9 \cdot f_{c k}
$$

Sendo que $A_{e}$ é a área da seção transversal da estaca. A rigor a tensão limite de compressão em seções próximas ao pilar é superior às tensões limites em seções próximas às estacas, em razão do estado multiaxial de compressão logo abaixo do pilar.

Baseado nos mesmos resultados encontrados por Blévot e Frémy (1967), Moraes (1976) propõe limites mais brandos para a resistência da biela nas seções próximas à estaca e 
ao pilar. Atualizando os valores propostos por Moraes (1976) com os coeficientes de segurança recomendados na ABNT NBR 6118:2003 tem-se que, tanto para seções próximas às estacas quanto ao pilar, o limite é de $1,5 \cdot f_{c k}$.

\subsubsection{MÉtodo do BOLETIM 73 do CEB-FIP (1970)}

As hipóteses consideradas para o cálculo são de que a distribuição de forças das reações das estacas, sobre a superfície de apoio do bloco é plana. Na ocorrência de forças de tração sobre a superfície de apoio, o equilíbrio será assegurado pela resistência da estaca à tração, considerando-se também o peso próprio da estaca, a resistência ao arrancamento, a área de armadura longitudinal e a eficiência da ancoragem dessa armadura no bloco. $\mathrm{Na}$ situação do bloco estar submetido a ações horizontais, estas serão equilibradas pelas forças de atrito desenvolvidas entre a face inferior do bloco e o solo não sendo admitida redução da força de tração na armadura principal em razão dessa força de atrito.

O dimensionamento da armadura inferior é feito na seção $S_{1}$, situada a $0,15 \cdot a_{p}$ internamente a face do pilar, sendo que $a_{p}$ é a dimensão do pilar medida na direção normal ao plano da seção $S_{1}$, conforme ilustra a Figura 2.22. A altura útil da seção $S_{1}$ é igual à altura útil da seção paralela à $S_{1}$ e situada na face do pilar, devendo ser no máximo igual a uma vez e meia o valor de $\ell_{c}$, que é a distância medida do eixo da estaca à face do pilar. Caso o bloco possua várias estacas, a dimensão $\ell_{c}$ será tomada a partir do eixo da estaca mais afastada da face do pilar. 


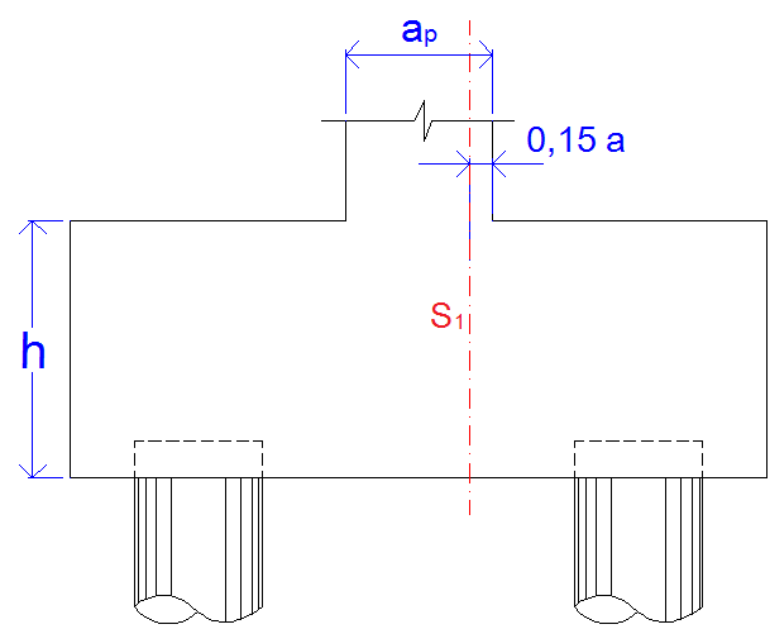

Figura 2.22 - Posição da seção de referência $S_{1}$

A área da seção transversal da armadura inferior do bloco é calculada para resistir ao momento fletor originado pela totalidade das reações das estacas situadas entre a seção $S_{1}$ e a face lateral do bloco, paralela a essa seção e que não atravessa o centro do pilar. Nos blocos apoiados sobre quatro estacas, essas armaduras podem ser dispostas conforme indicado na Figura 2.23.

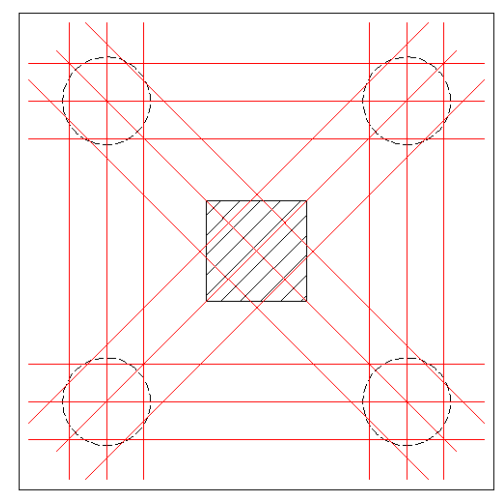

Figura 2.23 - Disposição de armaduras segundo os lados e diagonais

A verificação do cisalhamento é feita para a força cortante que atua na seção de referência $S_{2}$, que dista da face do pilar um comprimento igual à metade da altura útil do bloco, Figura 2.24. 


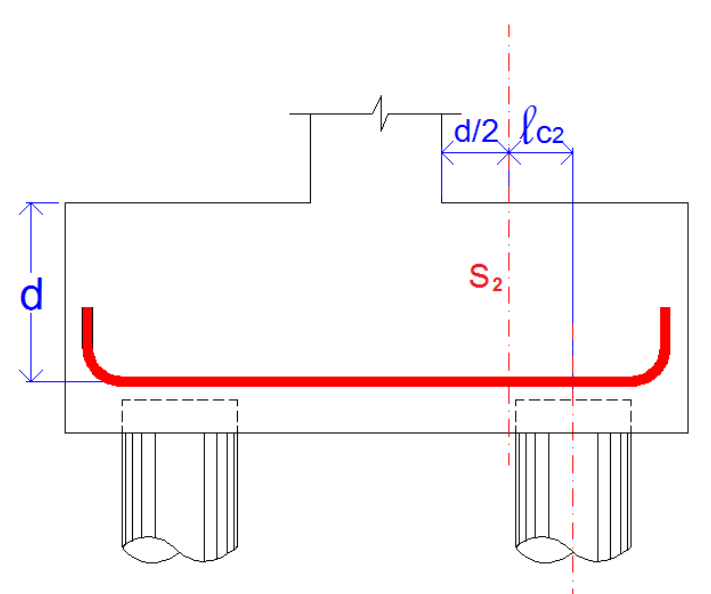

Figura 2.24 - Posição da seção de referência $S_{2}$

Se existirem estacas próximas ao pilar, situadas a uma distância da face do pilar inferior à metade da altura útil do bloco, $d$, a seção $S_{2}$ será considerada na própria face do pilar. A altura útil $d_{2}$, da seção $S_{2}$, é igual à altura útil do bloco na respectiva seção sendo limitada ao valor fornecido pela Expressão 2.19:

$$
d_{2} \leq 1,5 \cdot l_{c 2}
$$

sendo $\ell_{c 2}$ medido a partir da seção $S_{2}$ até o eixo da estaca mais afastada, a largura da seção de referência $b_{2}$ é calculada pela Expressão 2.20:

$$
b_{2}=b_{p}+d
$$

sendo $b_{p}$ a dimensão da face do pilar paralela à seção $\mathrm{S}_{2}$, força cortante de referência $V_{s d}$ deve satisfazer a Expresão 2.21:

$$
V_{s d} \leq V_{s d, l i m}=\frac{0,25}{\gamma_{c}} \cdot\left(1-\frac{l_{c}}{5 \cdot d}\right) \cdot b_{2} \cdot d_{2} \cdot \sqrt{f_{c k}} \rightarrow f_{c k} \mathrm{em} \mathrm{kN/ \textrm {cm } ^ { 2 }}
$$

Sendo que $\gamma_{c}$ é o coeficiente ponderador que considera a variabilidade da resistência do concreto, cujo valor é 1,4. A resistência à força cortante deve ser verificada em todas as seções do bloco em que as condições geométricas e a intensidade das reações das estacas possam provocar situação mais desfavorável que aquela relativa à seção de referência, como ocorre nas proximidades das estacas de canto dos blocos.

Nestas situações a força cortante solicitante na seção é igual à reação da estaca de canto. A posição da seção $S_{2}^{\prime}$, que deverá ser verificada, está ilustrada na Figura 2.25. 

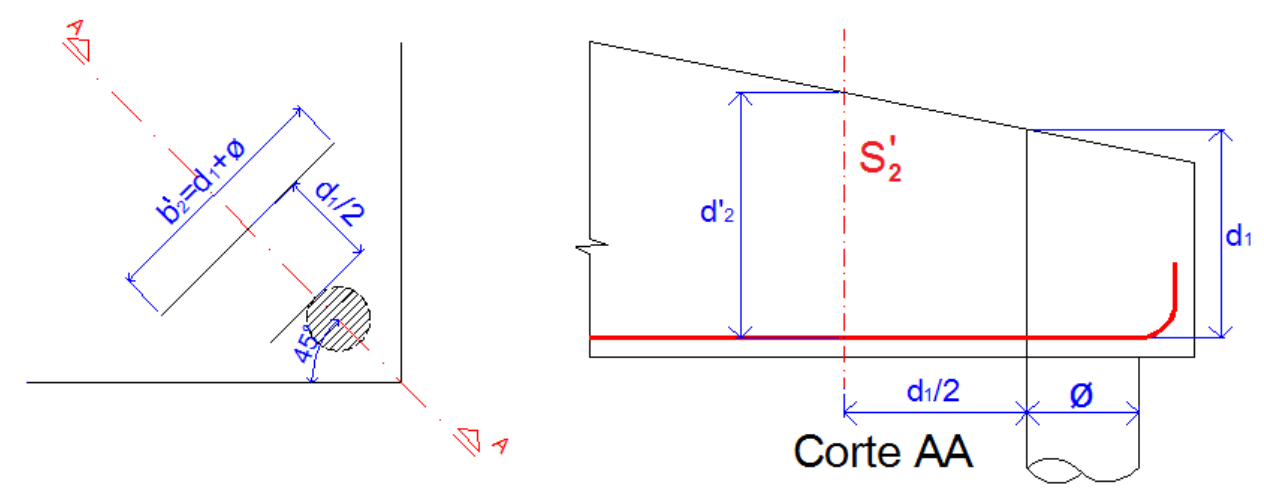

Figura 2.25 - Posição da seção de referência $S_{2}^{\prime}$

A reação da estaca $R_{d}$ deverá atender à Expressão 2.22:

$$
R_{d} \leq R_{d, l i m}=\frac{0,12}{\gamma_{c}} \cdot b_{2}^{\prime} \cdot d_{2}^{\prime} \cdot \sqrt{f_{c k}} \rightarrow f_{c k} \text { em } \mathrm{kN} / \mathrm{cm}^{2}
$$

\subsubsection{CRITÉRIOS DA CSA A23.3 (2004)}

A norma canadense propõe uma análise para blocos de fundação baseada no Método de Bielas e Tirantes modificado, fundamentado nas recomendações de Adebar e Zhou (1996).

Neste modelo de bielas e tirantes os efeitos favoráveis do confinamento do concreto são considerados. A altura do bloco é definida de tal modo que satisfaça os limites de tensão nos nós e nos apoios e os limites de cisalhamento da seção transversal, verificando a segurança com relação à punção do bloco pelo pilar e pela estaca. Para blocos rígidos, a verificação é feita com base nas tensões limites nos nós. Já para blocos flexíveis, o projeto é baseado na teoria de vigas e consiste na verificação do cisalhamento em seções à $d_{v}$, que é o maior valor entre $0,9 \cdot d$ e $0,72 \cdot h$, e $d / 2$ da face do pilar. A verificação do cisalhamento é feita em uma e em duas direções.

Quanto à ancoragem das barras da armadura principal, a CSA A23.3 (2004) sugere que seja feita por comprimento reto, ao contrário do que indica a ABNT NBR 6118:2003. 


\subsubsection{CRITÉRIOS DO ACI 318 (2008)}

O código ACI 318 (2008) não classifica o bloco em rígido e flexível, entretanto é distinto o tratamento dado aos blocos onde a dimensão $l_{e}$ é maior que duas vezes $d$ e onde é menor ou igual a duas vezes $d$, Figura 2.26.

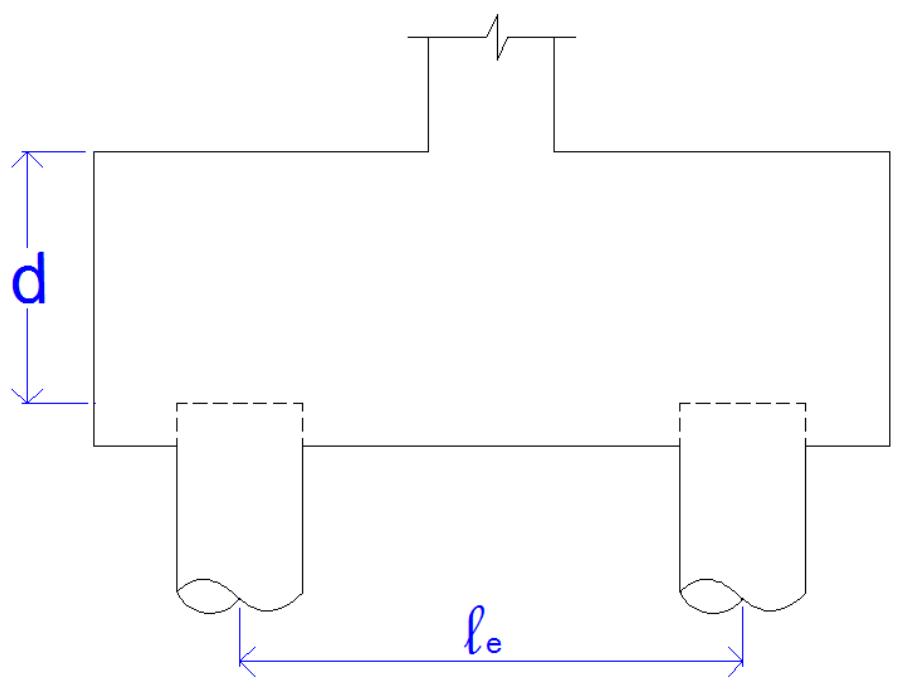

Figura 2.26 - Dimensões consideradas pelo ACI 318 (2008) para indicar o comportamento do bloco

O código americano de estruturas de concreto ACI 318 (2008) admite em ambos os casos a aplicabilidade da teoria de flexão. O dimensionamento à flexão é feito a partir de uma seção crítica perpendicular ao bloco e que atravessa a face do pilar. O momento fletor nesta seção crítica é calculado considerando todas as forças que atuam em um dos lados da seção. A verificação quanto ao cisalhamento é feita em uma seção crítica perpendicular ao bloco e que dista $d$ da face do pilar, no caso de blocos cujas forças cortantes são predominantes em uma direção. Em blocos cujas forças cortantes solicitem as duas direções, o cisalhamento também é verificado em um perímetro crítico que dista $d / 2$ do perímetro do pilar.

Nos blocos onde $l_{e}$ é menor ou igual à duas vezes $d$, também é admitido o dimensionamento à partir do Modelo de Bielas e Tirantes, seguindo as recomendações do apêndice A, no qual são especificadas as resistência dos nós e bielas para cada uma das situações mais freqüentes. 


\subsubsection{CRITÉRIOS DO EHE (2008)}

Para os blocos rígidos, a EHE (2008) admite o dimensionamento segundo o Método de Bielas e Tirantes com a armadura disposta em faixas laterais, sobre as estacas, de largura igual à largura da estaca mais duas vezes a distância do topo da estaca ao eixo da armadura do tirante. O cálculo da armadura principal, bem como o cálculo e a disposição da armadura secundária, é feito conforme Montoya (2000).

No caso de blocos flexíveis, o dimensionamento da armadura considerando a flexão é feita em uma seção de referência situada na posição indicada na Figura 2.22, a mesma considerada pelo boletim 73 do CEB-FIP (1970). Quanto à disposição da armadura, ela será distribuída uniformemente se o bloco trabalhar em uma direção ou se o bloco for quadrado e trabalhar em duas direções, como na maioria dos blocos apoiados sobre quatro estacas.

A verificação das tensões tangenciais é feita em uma seção crítica que se situa a uma distância de valor igual ao da altura útil do bloco, $d$, em relação à face do pilar. O estado limite de punção também precisa ser avaliado mediante a verificação dessas tensões em seções críticas situadas na face e a $2 \cdot d$ da face do pilar - para bloco sem armadura de punção e na face, a $2 \cdot d$ da face do pilar e a $2 \cdot d$ da última linha de armadura de punção no caso do bloco ser armado à punção.

\subsubsection{ARMADURAS SECUNDÁRIAS}

Em princípio, o boletim 73 do CEB-FIP (1970) recomenda que as armaduras secundárias distribuídas horizontalmente e verticalmente não são necessárias, exceto nos blocos sobre duas estacas. As orientações dadas por Calavera (2000) baseiam-se nos requisitos mínimos que estão dispostos na EHE $(1998)^{10}$ que estabelece que deve ser disposta armadura secundária horizontal em forma de malha sendo que a capacidade mecânica em cada direção não deve ser menor que $25 \%$ da armadura principal colocada em faixas. Calavera (2000) recomenda que, apesar de caber julgamento pessoal, em blocos de grandes dimensões ou que estejam submetidos a ações de grande intensidade seja adotada armadura

${ }^{10}$ COMISIÓN PERMANENTE DEL HORMIGÓN. EHE: Instrucción Española de Hormigón Armado. Ministerio de Fomento, Centro de Publicaciones, Madrid, 1998. 
em malha. Essa observação corrobora com as recomendações feitas por Blévot e Frémy (1967) em relação aos blocos sobre quatro estacas armados segundo os lados.

Para os blocos sobre quatro estacas, Montoya (2000) recomenda uma armadura vertical formada por estribos, laçando a armadura principal das faixas, além de recomendar a armadura em forma de malha conforme Calavera (2000), Figura 2.27.

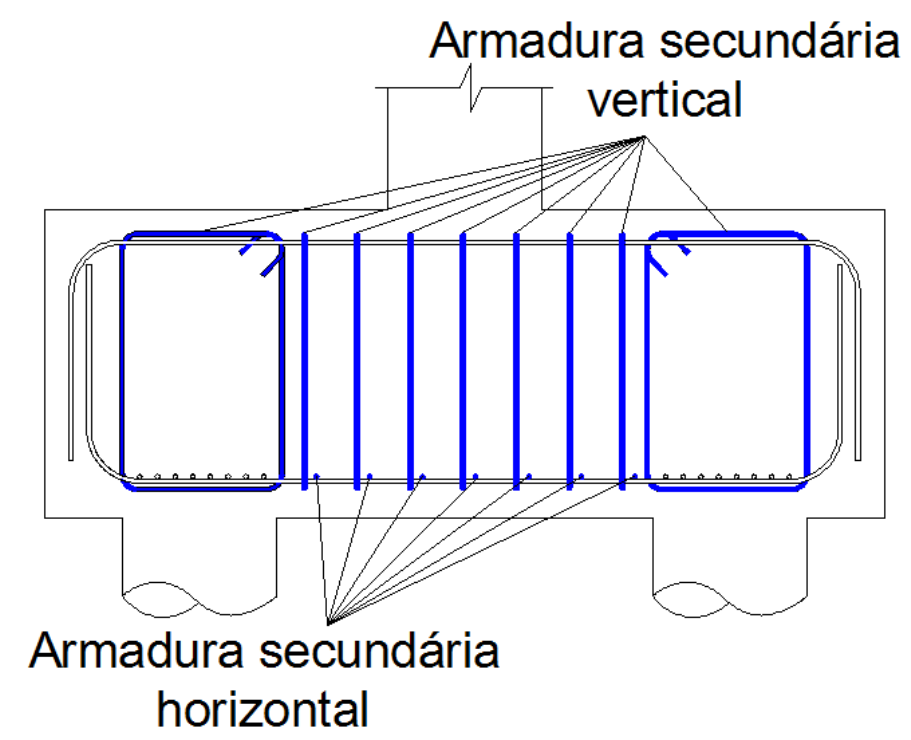

Figura 2.27 - Disposição de armaduras em blocos rígidos sobre várias estacas, Montoya (2000)

Baseados em ensaios, Leonhardt e Mönnig (1978) sugerem que, quando houver a disposição de armadura entre as estacas ou quando a distância entre as faces internas das estacas for maior que três vezes a altura do bloco, é necessária armadura de suspensão dimensionada para resistir a uma força total igual à força advinda do pilar dividida por uma vez e meia o número de estacas. Essa armadura tem a finalidade de evitar o surgimento de fissuras que acarretam a ruína prematura do bloco.

Para controlar a fissuração, a ABNT NBR 6118:2003 indica armadura adicional de distribuição em forma de malha, distribuída uniformemente nas duas direções, para no máximo $20 \%$ dos esforços totais, completando a armadura principal. Essa armadura deverá ser calculada considerando que a resistência de cálculo é de $80 \%$ da resistência à tração de cálculo do aço.

A ABNT NBR 6118:2003 recomenda a utilização de armadura de suspensão na situação em que é prevista armadura de distribuição para mais de $25 \%$ dos esforços totais ou 
em blocos nos quais o espaçamento entre as estacas for superior a três vezes o diâmetro da mesma. A armadura de suspensão deve ser calculada para a parcela de carga a ser equilibrada.

\subsubsection{CONSIDERAÇÕES FINAIS}

Existem dois processos para o dimensionamento de blocos sobre estacas, um consiste na teoria da flexão e outro na analogia de treliça. A teoria da flexão é fundamentada no dimensionamento de blocos a partir da verificação da flexão e do cisalhamento em seções críticas enquanto que a analogia de treliça avalia o equilíbrio de não apenas uma seção de referência, mas do elemento em toda sua extensão. O Método das Bielas é um modelo mais completo da aplicação da analogia de treliça no qual além da analogia de treliça e determinação da área de aço dos tirantes são também verificadas as tensões de compressão nas bielas e nos nós.

Atualmente os principais códigos normativos internacionais sugerem os dois modelos havendo um direcionamento para o uso do Método das Bielas para blocos considerados rígidos e a teoria da flexão para blocos ditos flexíveis. O Eurocode 2 (2002) recomenda a escolha do modelo de dimensionamento que for julgado mais adequado pelo projetista, o ACI 318 (2008) recomenda o dimensionamento pela teoria de flexão para blocos flexíveis e para blocos rígidos é permitido a escolha entre um dos dois métodos. A EHE (2008) admite o uso da teoria da flexão apenas para os blocos flexíveis, para os blocos rígidos ela recomenda o Método das Bielas.

A norma brasileira ABNT NBR 6118:2003 considera que os blocos rígidos são caracterizados pelo trabalho à flexão nas duas direções, com tração concentrada em linhas sobre as estacas, e cargas transmitidas às estacas por bielas de compressão e trabalho ao cisalhamento em duas direções apresentando ruptura por compressão das bielas. Os blocos flexíveis, segundo a ABNT NBR 6118:2003, devem ser analisados desde as forças nas estacas e tirantes de tração até a verificação da punção, conforme as lajes.

Os métodos discutidos para blocos rígidos por Guerrin (1955), Montoya (2000) e Calavera (2000) não contemplam a verificação da região nodal tampouco da biela de tal maneira que não podem ser considerados como Método das Bielas, apenas uma analogia de 
treliça. Guerrin (1955) apresenta três possibilidades de disposição da armadura em blocos sobre quatro estacas: em malha, segundo as diagonais e em laçada lateral. Para os três arranjos, Guerrin (1955) considera que a eficiência quanto à força última é equivalente, entretanto isso é refutado pelos resultados obtidos pelos pesquisadores que estudaram a influência do arranjo, tais como Blévot e Frémy (1967) e Clarke (1973).

Para os blocos rígidos, pode-se aprimorar o dimensionamento sugerido por Blévot e Frémy (1967) utilizando diferentes valores limites de resistência à compressão da biela para a seção próxima ao pilar e próxima à estaca. Em razão do confinamento existente próximo ao pilar, a resistência da biela poderá ser superior nessa região.

A disposição da armadura depende do modelo de cálculo utilizado isto é, caso seja considerado o comportamento de flexão a armadura será distribuída ao longo da seção do bloco e, para o caso de utilização da analogia de treliça a disposição mais adequada é em faixas concentradas sobre as estacas.

\subsection{LIGAÇõeS POR CÁLICES DE FUNDAÇÃo}

Nesta seção discorrem-se as principais recomendações para o dimensionamento de cálices encontrados nos códigos normativos e em bibliografias a respeito do assunto além das observações de algumas pesquisas realizadas na Escola de Engenharia de São Carlos.

Os modelos apresentados em Leonhardt e Mönnig (1977) e na ABNT NBR 9062:2006 são os mais utilizados no Brasil para o dimensionamento de cálices externos, além das recomendações feitas em El Debs (2000). Por possuírem muitas semelhanças, estes modelos são discutidos em um único item. 


\subsubsection{Modelo de Leonhardt E Mönnig (1977) E da ABNT NBR 9062:2006}

A seguir são descritos os procedimentos de dimensionamento do cálice de fundação baseados em Leonhardt e Mönnig (1977), El Debs (2000) e na Norma Brasileira de concreto pré-moldado. Também são discutidos o comportamento do cálice e os modelos de transferência das ações entre o pilar, cálice e elemento de fundação.

A ABNT NBR 9062:2006 estabelece que na composição de ações atuantes no cálice precisam ser consideradas todas as forças verticais e horizontais e os momentos transmitidos pelos pilares, assim como aqueles provenientes dos efeitos de segunda ordem global.

O modelo proposto por Leonhardt e Mönnig (1977) considera que a transmissão das ações à fundação depende do comportamento conjunto do pilar com as paredes do cálice de fundação. Desse modo, o tratamento dispensado aos cálices de paredes lisas é distinto daquele de paredes rugosas. Na Figura 2.28 está esquematizado, de forma genérica, o sistema de forças que atuam nas paredes do cálice segundo este modelo.
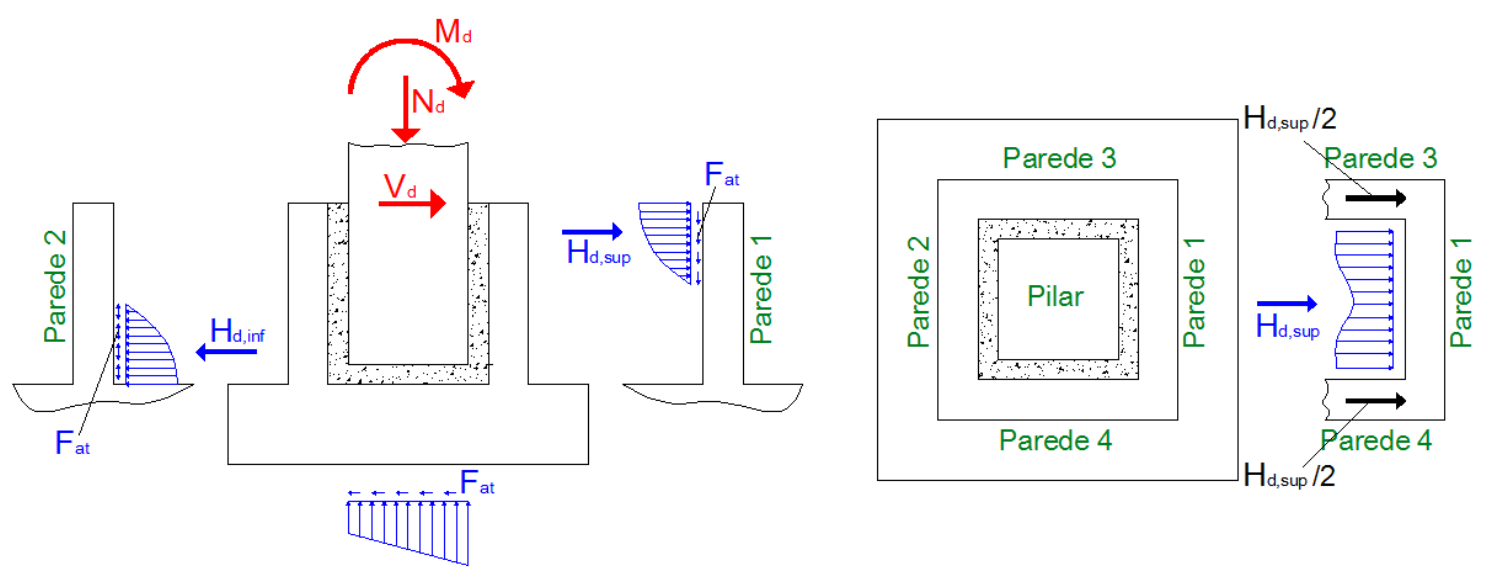

Figura 2.28 - Transferência de esforços em cálices Fonte: Adaptação de El Debs (2000)

A ABNT NBR 9062:2006 recomenda que as superfícies internas do cálice possuam pelo menos a mesma característica superficial que a dos pilares. O cálice é considerado de parede rugosa quando possuir uma rugosidade formada por chave de cisalhamento cuja profundidade dos sulcos corresponda no mínimo a $10 \mathrm{~mm}$ a cada $100 \mathrm{~mm}$ de comprimento. Leonhardt e Mönnig (1977) aconselham que a espessura da parede do cálice $t$, seja maior ou igual à $1 / 3$ da menor distância entre as paredes do colarinho e no mínimo $10 \mathrm{~cm}$. Este último valor também é recomendado pela ABNT NBR 9062:2006 que ainda prescreve uma 
espessura da laje no fundo do cálice não inferior a $20 \mathrm{~cm}$. O comprimento de embutimento, $\ell_{e m b}$, nos cálices de paredes lisas e rugosas para pequena e grande excentricidade é fornecido pela Tabela 2.3 .

Tabela 2.3 - Comprimento de embutimento do pilar no cálice

\begin{tabular}{|c|c|c|c|c|}
\hline \multirow[b]{2}{*}{ Conformação } & \multicolumn{2}{|c|}{ Leonhardt e Mönnig (1977) } & \multicolumn{2}{|c|}{ ABNT NBR 9062:2006 / El Debs (2000) } \\
\hline & $\frac{M_{d}}{N_{d} \cdot b_{p i l}} \leq 0,15$ & $\frac{M_{d}}{N_{d} \cdot b_{p i l}} \geq 2,00$ & $\frac{M_{d}}{N_{d} \cdot b_{p i l}} \leq 0,15$ & $\frac{M_{d}}{N_{d} \cdot b_{p i l}} \geq 2,00$ \\
\hline Rugosa & $1,20 \cdot b_{p i l}$ & $2,00 \cdot b_{p i l}$ & $1,20 \cdot b_{p i l}$ & $1,60 \cdot b_{\text {pil }}$ \\
\hline Lisa & $1,68 \cdot b_{\text {pil }}$ & $2,80 \cdot b_{\text {pil }}$ & $1,50 \cdot b_{\text {pil }}$ & $2,00 \cdot b_{p i l}$ \\
\hline \multicolumn{5}{|c|}{ Observação: Valores intermediários obtidos por interpolação } \\
\hline
\end{tabular}

As ações atuantes nas paredes do cálice estão representadas na Figura 2.29. No cálice de paredes rugosas, Leonhardt e Mönnig (1977) apresentam dois modelos que representam situações extremas: cálice de parede perfeitamente lisa, não ponderando as forças de atrito desenvolvidas na interface da ligação pela pressão que o pilar exerce na parede do cálice, e cálice com parede muito rugosa. Não é considerada a contribuição da força de atrito que surge em resposta à pressão exercida pela força axial do pilar contra o fundo do cálice. A consideração dessa força faria com que a resultante de forças $H_{d, i n f}$, aplicada na parte inferior da parede transversal, também sofresse uma redução. El Debs (2000) limita a tensão de contato na interface a $60 \%$ de $f_{c d}$ e no caso de flexão oblíqua essa tensão é limitada a $50 \%$ de $f_{c d}$.
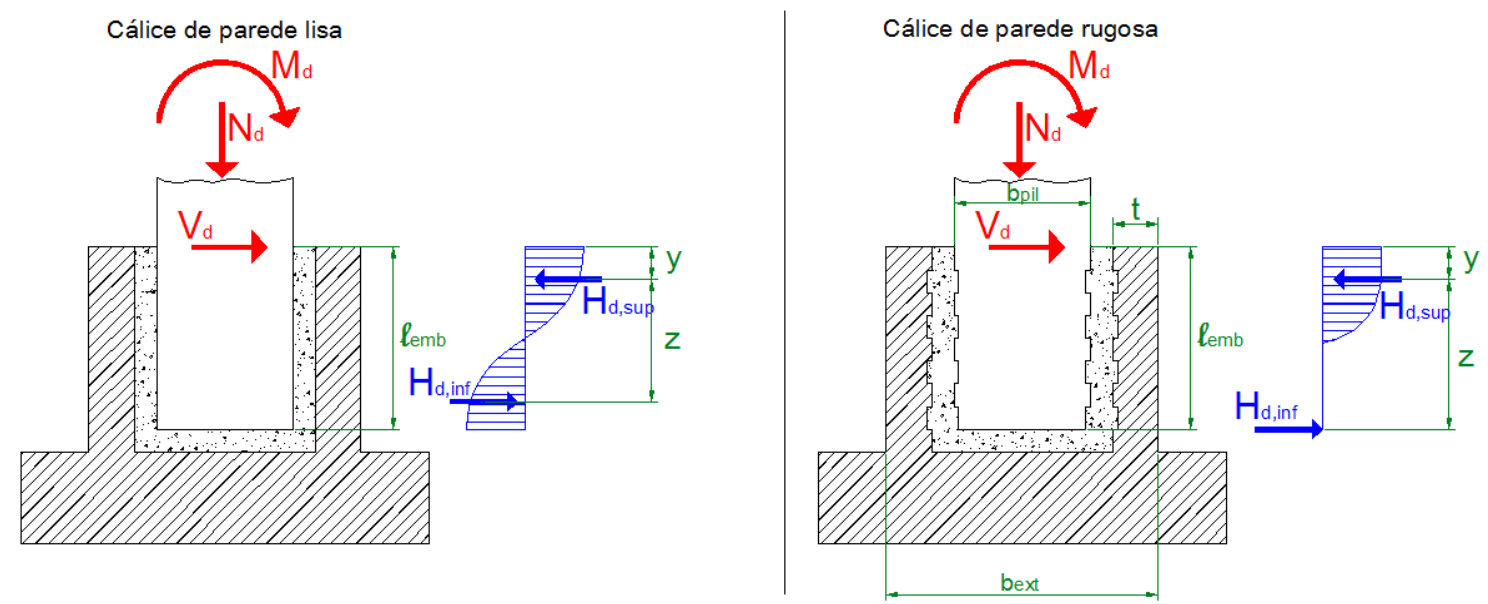

Figura 2.29 - Diagrama de tensões atuantes no colarinho

As forças resultantes $H_{d, \text { inf }}$ e $H_{d, \text { sup }}$, e seus respectivos pontos de atuação, podem ser obtidas pelas formulações que se encontram na Tabela 2.4. 
Tabela 2.4 - Forças resultantes e respectivos pontos de atuação.

\begin{tabular}{|c|c|c|c|c|}
\hline & \multicolumn{2}{|c|}{ Leonhardt e Mönnig (1977) } & \multicolumn{2}{|c|}{ ABNT NBR 9062:2006 / El Debs (2000) } \\
\hline & Parede Lisa & Parede Rugosa & Parede Lisa & Parede Rugosa \\
\hline$H_{d, \text { sup }}$ & $\frac{M_{d}}{0,67 \cdot l_{e m b}}+1,25 \cdot V_{d}$ & $\frac{M_{d}}{0,83 \cdot l_{e m b}}+1,20 \cdot V_{d}$ & $1,5 \cdot \frac{M_{d}}{l_{e m b}}+1,25 \cdot V_{d}$ & $1,2 \cdot \frac{M_{d}}{l_{e m b}}+1,20 \cdot V_{d}$ \\
\hline$H_{d, i n f}$ & $\frac{M_{d}}{0,67 \cdot l_{e m b}}+0,25 \cdot V_{d}$ & $\frac{M_{d}}{0,83 \cdot l_{e m b}}+0,20 \cdot V_{d}$ & $1,5 \cdot \frac{M_{d}}{l_{e m b}}+0,25 \cdot V_{d}$ & $1,2 \cdot \frac{M_{d}}{l_{e m b}}+0,20 \cdot V_{d}$ \\
\hline$y$ & $0,167 \cdot l_{e m b}$ & $0,167 \cdot l_{e m b}$ & $0,167 \cdot l_{e m b}$ & $0,150 \cdot l_{e m b}$ \\
\hline$z$ & $0,667 \cdot l_{e m b}$ & $0,833 \cdot l_{e m b}$ & $0,67 \cdot l_{e m b}$ & $0,85 \cdot l_{e m b}$ \\
\hline
\end{tabular}

Seguindo a nomenclatura fornecida pela Figura 2.28, é necessário armar as paredes do cálice para o modelo idealizado, onde a parede 1 recebe a pressão de resultante $H_{d, \text { sup }} \mathrm{e}$ transfere para as paredes 3 e 4 que encaminham estas forças ao elemento de fundação por meio de comportamento de consolo curto. Em conseqüência do comportamento de consolo curto das paredes 3 e 4, é necessária a verificação da segurança com relação à ruptura da biela comprimida nessas paredes. El Debs (2000) apresenta um procedimento para o cálculo das armaduras do cálice seguindo a disposição ilustrada na Figura 2.30.

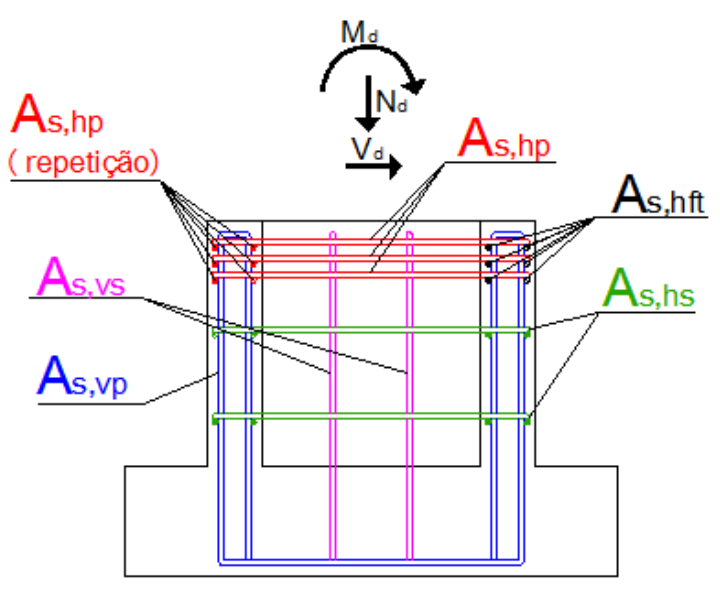

Vista Frontal

As,hp - Armadura horizontal principal

As,vp - Armadura vertical principal

As,hs - Armadura horizontal secundária

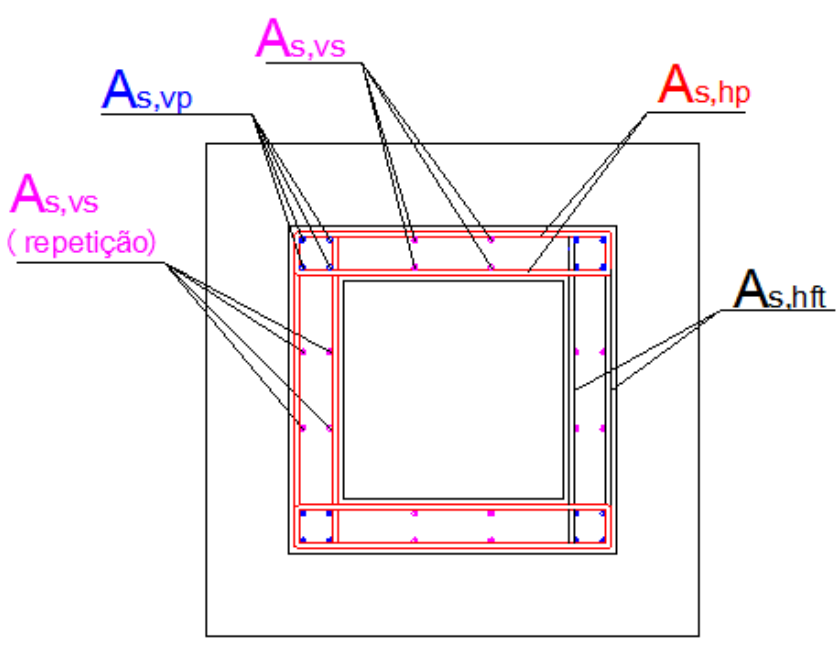

\section{Planta}

As,vs - Armadura vertical secundária

As, hft - Armadura de flexão da parede 1

Figura 2.30 - Armaduras do cálice

A armadura $A_{s, h p}$ é responsável por transmitir a força horizontal $H_{d, \text { sup }}$ para as paredes 3 e 4 . O consolo, transfere as forças para o elemento de fundação por meio da treliça formada pelo tirante de armadura $A_{s, v p}$ e pela biela comprimida. Além dessas armaduras, são dispostas 
armaduras secundárias vertical, $A_{s, v s}$, e horizontal, $A_{s, h s}$, nas paredes do cálice. As armaduras secundárias cumprem o papel de armadura de costura e de distribuição. As expressões para o cálculo das áreas destas armaduras estão compiladas na Tabela 2.5.

Tabela 2.5 - Áreas de armadura do cálice

\begin{tabular}{cc}
\hline Armadura & Área \\
\hline $\boldsymbol{A}_{s, \boldsymbol{h p}}$ & $\frac{H_{d, s u p}}{2 \cdot f_{y d}}$ \\
\hline $\boldsymbol{A}_{s, v p}$ & $\frac{F_{t i r, d}}{f_{y d}}$ \\
\hline $\boldsymbol{A}_{s, \boldsymbol{h s}}$ & $0,20 \cdot A_{s, v p}$ \\
\hline $\boldsymbol{A}_{s, v s}$ & $0,40 \cdot A_{s, v p}$ \\
\hline
\end{tabular}

Segundo El Debs (2000), é necessária a armadura $A_{s, h f t}$ em razão da flexão que ocorre nas paredes de superfície lisa, originada pela pressão exercida pelo pilar, o esquema ilustrativo desse fenômeno encontra-se na Figura 2.31.

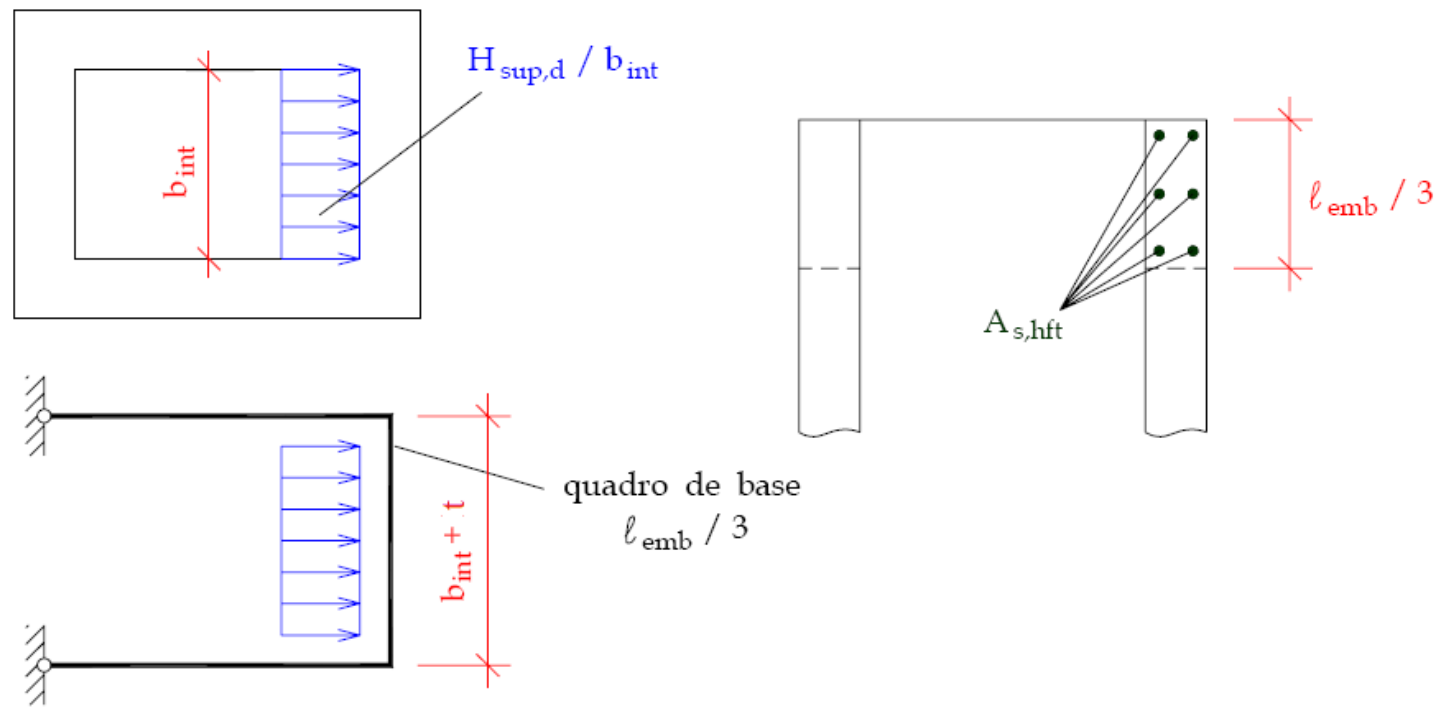

Figura 2.31 - Flexão e armadura na parte superior do colarinho adaptado de El Debs (2000)

Quanto a disposição das armaduras, El Debs (2000) recomenda que a armadura $A_{s, h p}$ precisa ser disposta em uma altura igual a $2 \cdot y$, sendo $y$ a distância do ponto de atuação da força horizontal resultante $H_{d, \text { sup }}$ ao topo do colarinho, Figura 2.32. A armadura $A_{s, h f t}$ precisa ser disposta na região superior da parede do colarinho, que dista até $\ell_{e m b} / 3$ da face superior da parede do cálice, e as armaduras $A_{s, h s}$ e $A_{s, v s}$ tem espaçamento variando entre 15 a $30 \mathrm{~cm}$. 


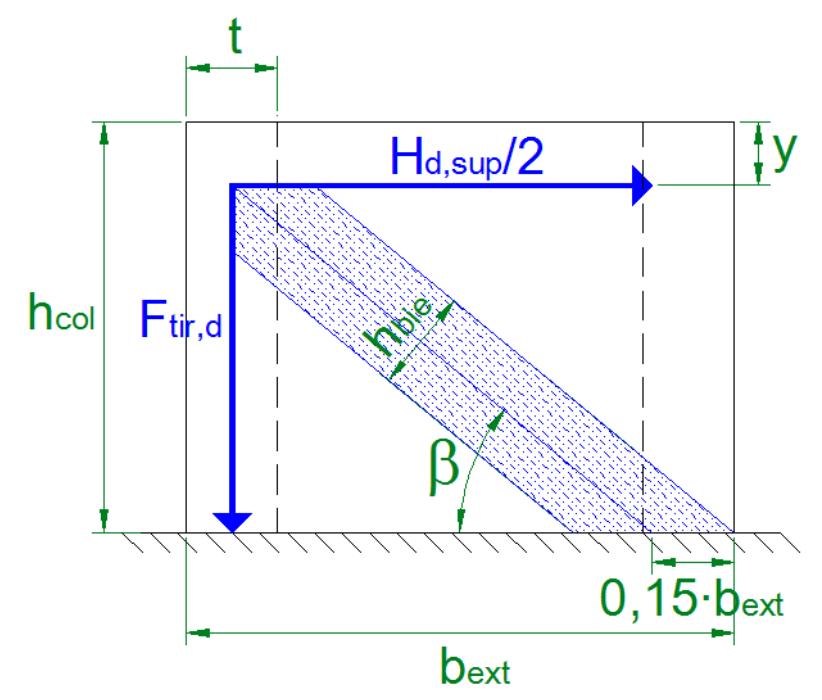

Figura 2.32 - Transferência de tensões pela parede longitudinal do cálice

Considerando o exposto na Figura 2.32, o ângulo $\beta$ pode ser obtido por meio da Expressão 2.23. O dimensionamento das paredes longitudinais depende da geometria das mesmas, sendo assim tem-se que o consolo pode ser: muito curto $(\operatorname{tg} \beta \leq 0,5)$, curto $(0,5 \leq \operatorname{tg} \beta$ $\leq 1,0)$, longo $(\operatorname{tg} \beta \geq 1,0)$. Para consolos muito curtos, o dimensionamento é baseado no Modelo Atrito-Cisalhamento, em consolos curtos é baseado no Modelo de Bielas e Tirantes e no caso de consolos longos, que tem o comportamento de viga, o mais adequado é a Teoria de Flexão.

$$
\beta=\operatorname{arctg}\left(\frac{h_{c o l}-y}{0,85 \cdot b_{\text {ext }}-\frac{t}{2}}\right)
$$

Para a situação de consolo curto, maior parte dos cálices usuais, faz-se necessário determinar a força $F_{t i r, d}$ por meio da Expressão 2.24 e a área de aço necessária para resistir à esta força mediante a expressão dada pela Tabela 2.5 além disso é preciso calcular a força $R_{c b}$, dada pela Expressão 2.25, e verificar a segurança da biela por meio da Expressão 2.26.

$$
\begin{aligned}
& F_{t i r, d}=\frac{H_{d, \text { sup }}}{2} \cdot \operatorname{tg} \beta \\
& R_{c b}=\frac{H_{d, \text { sup }}}{2 \cdot \cos \beta} \\
& \sigma_{c b, c a ́ l}=\frac{R_{c b}}{h_{b i e \cdot t}} \leq 0,85 \cdot f_{c d}
\end{aligned}
$$

sendo que a largura da biela, $h_{b i e}$, pode ser calculada pela Expressão 2.27:

$$
h_{b i e}=0,3 \cdot b_{\text {ext }} \cdot \operatorname{sen} \beta
$$


$\mathrm{O}$ arranjo das armaduras do cálice encontram-se ilustrados na Figura 2.33. Leonhardt e Mönnig (1977) e El Debs (2000) ainda permitem um detalhamento mais simplificado para situações de pequena excentricidade das ações.
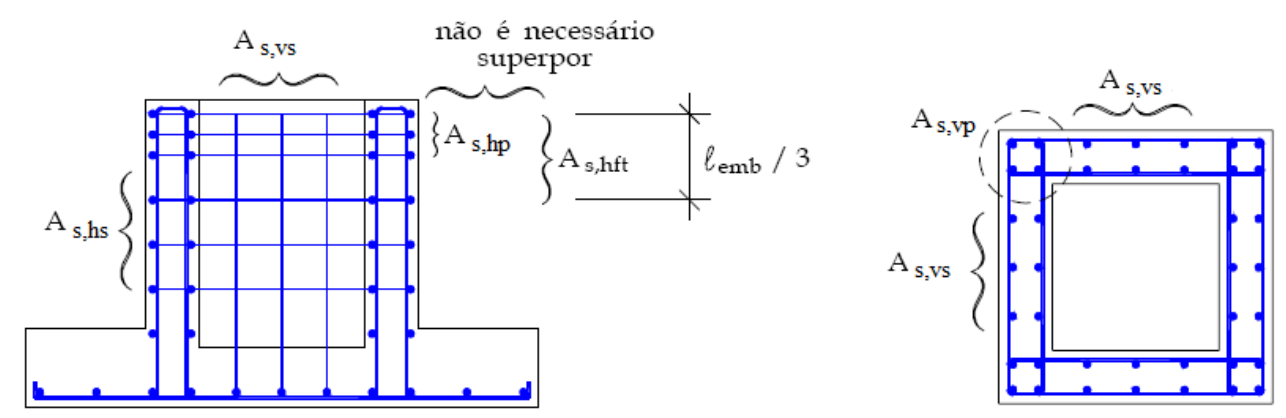

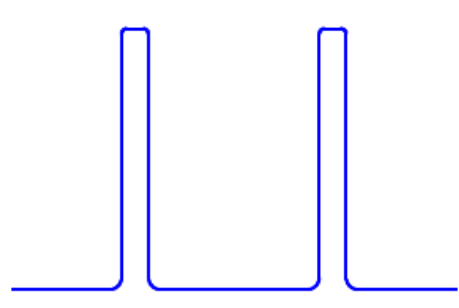

Alternativa 1

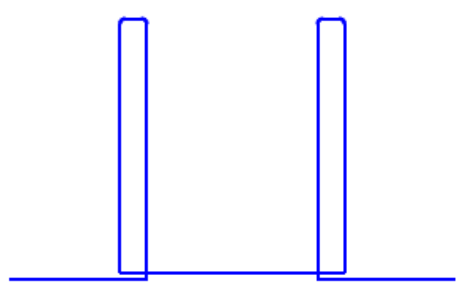

Alternativa 2

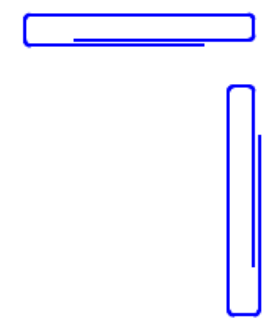

armadura disposta na direção horizontal

armadura disposta na direção vertical

Situação geral
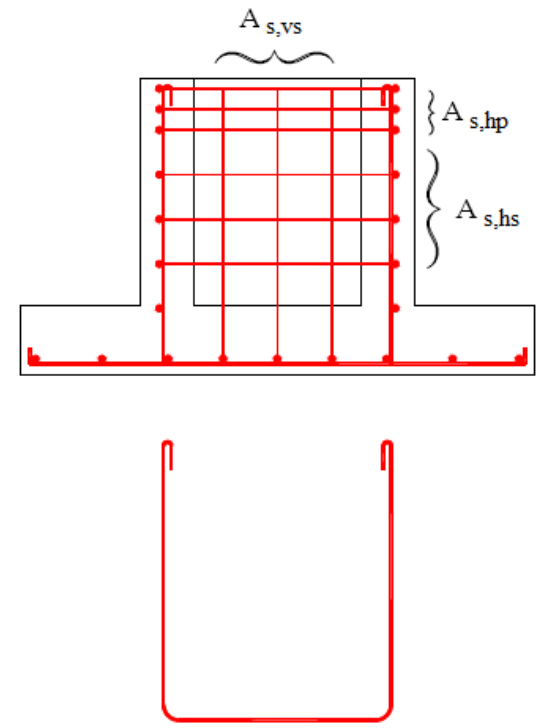

armadura disposta na direção vertical
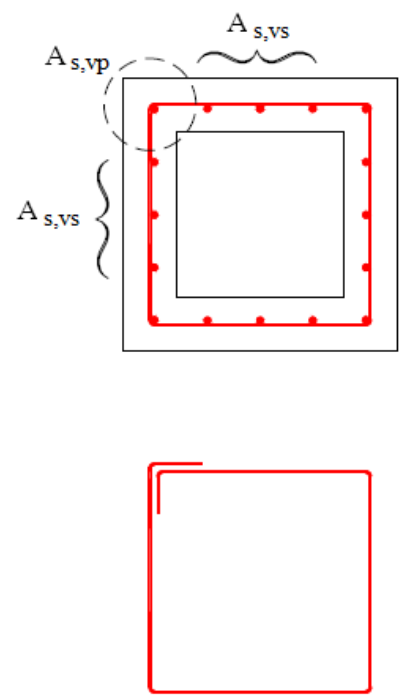

armadura disposta na direção horizontal

Situação de $\mathrm{M}_{\mathrm{d}} /\left(\mathrm{N}_{\mathrm{d}} \cdot \mathrm{h}\right)<0,15$

Figura 2.33 - Arranjo das armaduras do cálice adaptado de El Debs (2000) Fonte: Canha (2004) 
Em El Debs (2000) são feitas algumas considerações quanto à armadura do pilar na região da emenda. É recomendado a colocação de armadura transversal para resistir a uma força cortante no valor de $H_{d, \text { inf }}$ e armadura em forma de $\mathrm{U}$ na base do pilar para resistir a força $H_{d, i n f}$. A ancoragem da armadura na extremidade do pilar deve ser verificada, considerando seu início na posição da resultante $y$ e no caso de parede rugosa, deve ser verificada a emenda por traspasse entre a armadura longitudinal do pilar e a armadura vertical do colarinho.

Nos cálices de paredes lisas, a ABNT NBR 9062:2006 permite considerar que até 70\% da força normal seja transmitida pela interface, desde que se disponha de armadura de suspensão em toda a volta do encaixe e calculada para resistir a essa parcela de força normal. El Debs (2000) sugere que se possa considerar que uma parcela da força normal que atua na base seja transmitida para o colarinho, se houver armadura de suspensão calculada para tal e desde que essa parcela não supere $50 \%$ da força normal.

Com relação à verificação da punção na base do cálice, a formação da superfície de ruptura deve ser considerada formada a partir do perímetro do pilar no caso de cálice de paredes lisas e, no caso de cálice de paredes rugosas, formada a partir do perímetro externo do colarinho.

\subsubsection{OUTROS MODELOS E ESTUdOS REALIZADOS}

Willert e Kesser (1983) sugeriram um modelo teórico baseado nos resultados de pesquisa de cálices de fundação com colarinho. $\mathrm{O}$ modelo proposto considera a rugosidade da interface por meio de coeficiente de atrito, $\mu$. Sendo a interface de ligação formada por paredes lisas, é indicado o valor $2 / 3$. Nos casos de interface rugosa, não foram feitas indicações de valores para $\mu$, entretanto pode-se utilizar este modelo para interfaces rugosas desde que seja feito o ajuste adequado deste coeficiente. $\mathrm{O}$ comprimento de embutimento deve atender a Expressão 2.28 e, ao contrário do que especifica os modelos da ABNT NBR 9062:2006 e de Leonhardt e Mönnig (1977), não depende da conformação superficial das paredes da ligação.

$$
1,5 \cdot h \leq l_{e m b} \leq 3,0 \cdot h
$$


No modelo de Willert e Kesser (1983), o braço de alavanca entre as forças resultantes horizontais, superior e inferior, varia em função da excentricidade do carregamento. Para pequenas excentricidades, ao se desprezar o coeficiente de atrito na interface obtém-se a expressão de força horizontal resultante equivalente àquela sugerida por Leonhardt e Mönnig (1977) para ligações de interface rugosa. Para excentricidade muito grande, pilar submetido à flexão pura, ao se desprezar o coeficiente de atrito, se obtém a expressão de Leonhardt e Mönnig (1977) para ligações de interface lisa.

Olin et al. (1985) apresentaram um modelo que considera a atuação de tensões de aderência na interface de ligação e a excentricidade da resultante de compressão na base do pilar. Essas considerações contribuem para uma maior capacidade resistente da ligação em relação aos outros modelos que não as consideram. Os pesquisadores consideram a excentricidade da resultante de compressão na base do pilar, em razão da atuação do momento, de valor igual à $h_{p i l} / 6$, sendo $h_{p i l}$ a maior dimensão da seção transversal do pilar. $\mathrm{O}$ comprimento de embutimento do pilar deve ser igual a $1,3 \cdot h_{p i l}$.

A força de atrito abaixo do pilar é desconsiderada pelos pesquisadores por entenderem que a força de compressão na base do pilar nem sempre se distribui perpendicularmente à superfície inferior do cálice. O dimensionamento é feito para duas condições de interface de ligação: interface de conformação lisa, $\mu=0,3$, e interface de conformação rugosa, $\mu=0,6$.

Bruggeling e Huyghe (1991) distinguem o funcionamento da ligação e o modo de transmissão das ações de acordo com o comprimento de embutimento do pilar no cálice de fundação. Se o comprimento de embutimento for inferior aos valores sugeridos por Leonhardt e Mönnig (1977) para paredes rugosas, a transferência do momento fletor $M_{d}$ do pilar para a fundação será por meio de bielas situadas entre a face da coluna e a face da parede do cálice, ambos com superfície rugosa. As forças resultantes de tração nas paredes do cálice precisam ser resistidas por armaduras suficientemente dimensionadas e são transmitidas ao elemento de fundação por intermédio de bielas diagonais. Já a força vertical $N_{d}$ é transferida por duas bielas diagonais formadas entre o topo do cálice e a base fundação. O comprimento de embutimento é limitado pelo comprimento de ancoragem da armadura do pilar e as forças cortantes que atuam no pilar. A ilustração desse modelo de transferência para ações verticais centradas e excêntricas encontram-se respectivamente na Figura 2.34-a e Figura 2.34-b. 


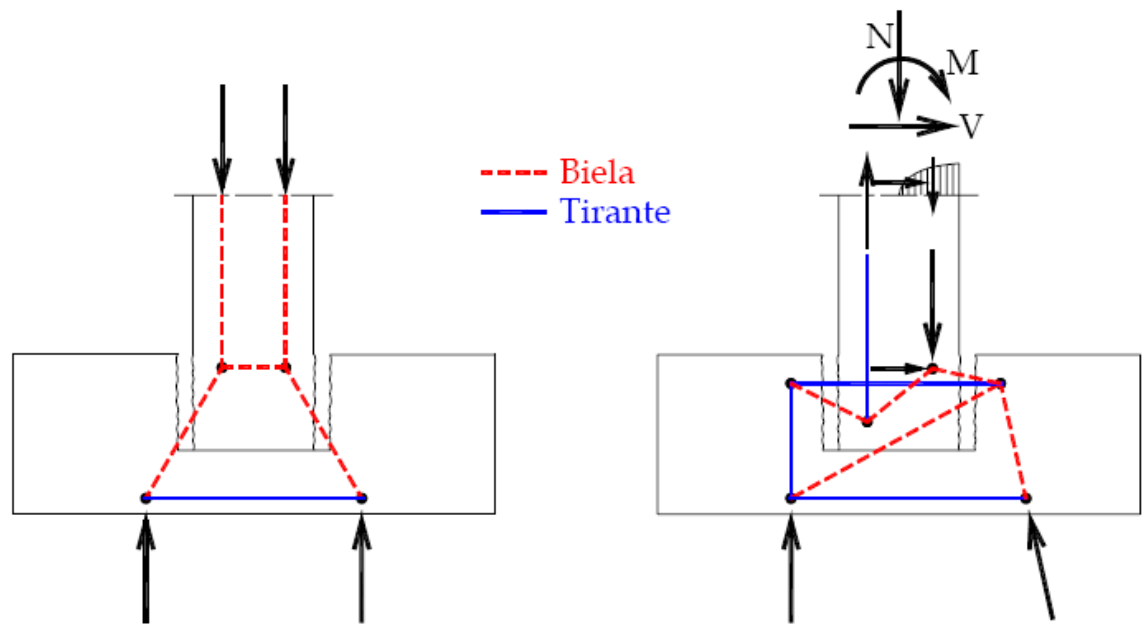

a)

b)

Figura 2.34 - Modelos para a transferência das tensões em cálices de comprimento de embutimento menores que os de Leonhardt e Mönnig (1977)

Fonte: Bruggeling e Huyghe (1991) adaptado por Canha (2004)

Para cálices cujo comprimento de embutimento atenda aos valores presentes em Leonhardt e Mönnig (1977) para paredes rugosas, o momento $M_{d}$ é transferido às paredes transversais do cálice por forças horizontais, de intensidade $M_{d} /\left(0,75 \cdot \ell_{e m b}\right)$, e a transmissão para a fundação ocorre mediante bielas diagonais formadas nas paredes situadas na direção da força horizontal. A força vertical $N_{d}$ é transferida pela base do pilar para a base do cálice. A ilustração desse modelo no caso de ações centradas e excêntricas encontra-se respectivamente na Figura 2.35-a e Figura 2.35-b.

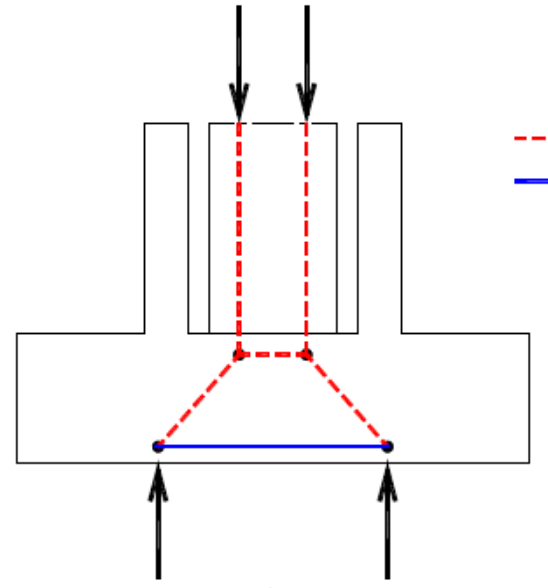

a)

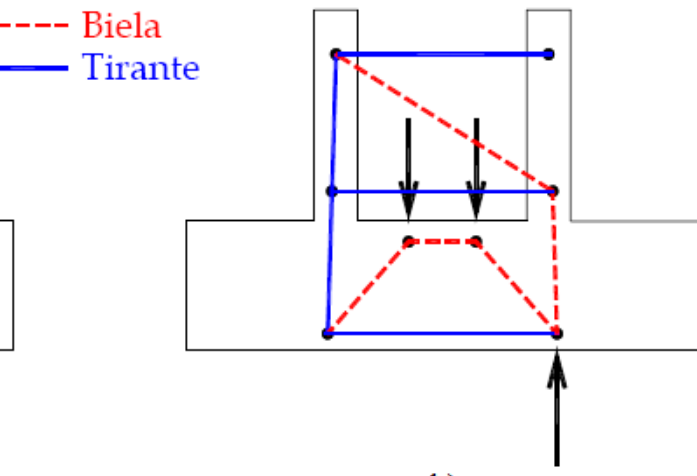

b)

Figura 2.35 - Modelos para a transferência das tensões em cálices de comprimento de embutimento iguais ao mínimo de Leonhardt e Mönnig (1977) Fonte: Bruggeling e Huyghe (1991) adaptado por Canha (2004) 
Elliott (1996) apresenta dois modelos para a ligação mediante cálice de fundação, ambos considerando a excentricidade da força normal, sendo que em um deles é considerada a atuação de força horizontal. Para ambos os modelos o autor recomenda um comprimento de embutimento não inferior a uma vez e meia a maior dimensão da seção transversal do pilar, $1,5 \cdot h$. Apesar de admitir a existência de forças de atrito na base do pilar, o autor não considera essas forças em seus modelos. Elliot (1996) recomenda que a distância entre as paredes do cálice e do pilar seja no mínimo de $75 \mathrm{~mm}$ no topo do colarinho e de $50 \mathrm{~mm}$ na base do colarinho. A pressão de contato é limitada a $40 \%$ da resistência à compressão de cálculo do concreto utilizado para preenchimento da ligação.

Osanai et al. (1996) propuseram um modelo para o dimensionamento de cálices de fundação depois de terem realizado ensaios em seis modelos de escala 1:2 submetidos à ação cíclica. Foram variados o comprimento de embutimento, $\ell_{e m b}$, entre $1,0 \cdot h$ e $1,5 \cdot h$, e a conformação das paredes da interface de ligação, rugosa ou lisa. No modelo proposto, é considerada a presença de forças de atrito nas interfaces laterais e inferior, além da excentricidade da reação vertical inferior, que surgem quando forças verticais e horizontais atuam no pilar.

Os resultados experimentais indicaram que para valores de $\ell_{e m b}$ de $1,5 \cdot h$, a ligação teve comportamento rígido mesmo para cálices de interface lisa, entretanto as ligações com interface lisa não apresentaram rigidez aceitável quando o comprimento de embutimento foi menor que $1,25 \cdot h$. Os pesquisadores observaram também que é possível manter a ligação com comportamento rígido ao se reduzir $\ell_{e m b}$ desde que as superfícies da interface de ligação possuam rugosidade adequada. Nestes ensaios as superfícies rugosas foram conseguidas mediante chaves de cisalhamento.

Para o desenvolvimento do modelo de dimensionamento, Osanai et al. (1996) utilizaram-se de dois modelos parciais, cujos equilíbrios foram feitos separadamente, e por fim a solução foi encontrada por meio da superposição. Os coeficientes de atrito indicados neste modelo são: 1,0 , para interface rugosa quando $\ell_{e m b} \geq 1,25 \cdot h$ e para interface lisa quando $\ell_{e m b} \geq 1,5 \cdot h$; e 0,5 para interface rugosa onde $\ell_{e m b}=1,0 \cdot h$. O modelo proposto pelos pesquisadores obteve melhor aproximação dos resultados experimentais quando comparados com as proposições da norma alemã DIN 1045, utilizando os mesmos coeficientes de atrito.

Em Silva (1998) são propostos modelos para a transferência de ações em ligações com cálice embutido e externo. Quanto ao cálice externo, para a situação de ação vertical centrada, 
é sugerido que o cálculo seja feito como em uma ligação monolítica, sendo a força normal transferida à fundação por um modelo de bielas e tirantes formados a partir da base do pilar.

Para pilares solicitados por ação excêntrica, a eficácia da ligação depende do comprimento de embutimento, da resistência do material de preenchimento e do conjunto cálice-fundação. A determinação do comprimento de embutimento precisa ser feita de tal forma que não ocorra ruptura por compressão do graute ou concreto de ligação. Silva (1998) propõe a limitação da tensão de contato a $60 \%$ de $f_{c d}$, por considerar que essa ligação apresenta dificuldade de vibração e compactação. A Figura 2.36 apresenta modelo de forças internas no pilar considerando a reação vertical na base do pilar centrada enquanto a Figura 2.37 apresenta o modelo para a situação de reação vertical na base do pilar excêntrica.

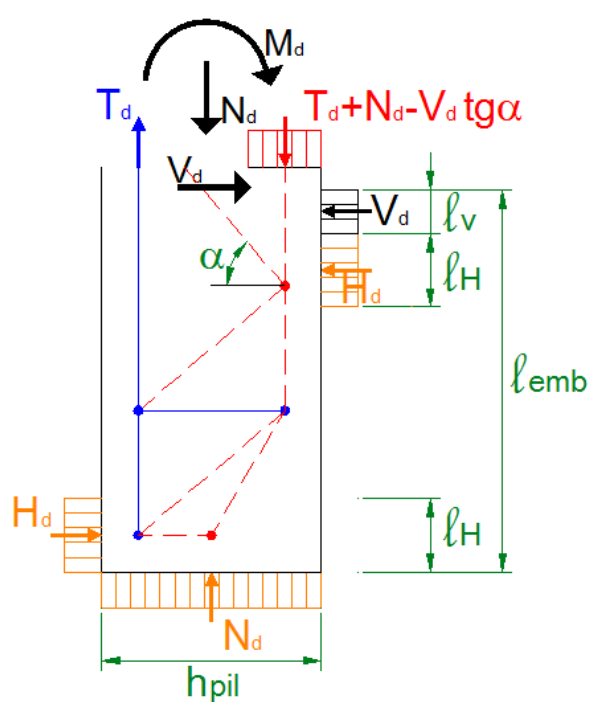

a) $\ell_{e m b}>2 \cdot h_{\text {pil }}$

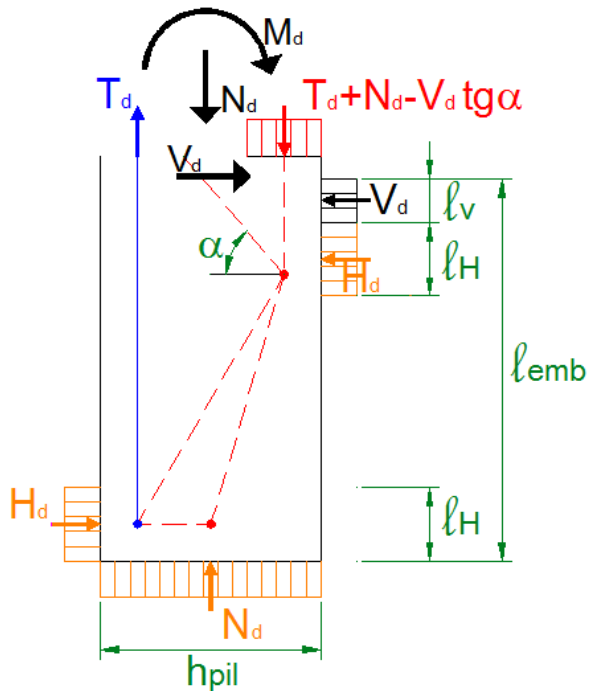

b) $\ell_{\text {emb }} \leq 2 \cdot h_{\text {pil }}$

Figura 2.36 - Modelo de forças internas no pilar com a transmissão da reação vertical centrada Fonte: Adaptação de Silva (1998)

Considerando as Figura 2.36 e Figura 2.37 e respeitando o limite da tensão de contato, tem-se que:

$$
V_{d}=0,6 \cdot f_{c d} \cdot l_{v} \cdot b_{p i l}
$$

Como as forças $V_{d}$ não são colineares, estas formam um binário que provoca um acréscimo no momento fletor que solicita a ligação. O momento solicitante, já com este acréscimo, é descrito pela Expressão 2.29:

$$
M_{d}^{\prime}=M_{d}+V_{d} \cdot \frac{l_{v}}{2}
$$


O momento $M_{d}^{\prime}$ é equilibrado pelo binário de forças de compressão $H_{d}$ calculado pela Expressão 2.30:

$$
H_{d}=0,6 \cdot f_{c d} \cdot l_{H} \cdot b_{\text {pil }}
$$

Equilibrando o binário de forças horizontais resultantes com o momento da Expressão 2.29, tem-se:

$$
H_{d} \cdot\left(l_{e m b}-l_{v}-l_{H}\right)=M_{d}+V_{d} \cdot \frac{l_{v}}{2}
$$

Fazendo a substituição da Expressão 2.30 na Expressão 2.31, tem-se a expressão:

$$
l_{H}^{2}-\left(l_{e m b}-l_{v}\right) \cdot l_{H}+\frac{M_{d}+V_{d} \cdot \frac{l_{v}}{2}}{0,6 \cdot f_{c d} \cdot b_{p i l}}=0
$$

Resolvendo a equação dada pela Expressão 2.32, tem-se que:

$$
\left(l_{e m b}-l_{v}\right)^{2}-4 \cdot \frac{M_{d}+V_{d} \cdot \frac{l_{v}}{2}}{0,6 \cdot f_{c d} \cdot b_{p i l}} \geq 0
$$

Portanto:

$$
l_{e m b} \geq 2 \cdot \sqrt{\frac{M_{d}+V_{d} \cdot \frac{l_{v}}{2}}{0,6 \cdot f_{c d} \cdot b_{p i l}}}+l_{v}
$$

Substituindo o valor de $\ell_{\mathrm{v}}$ da Expressão 2.28 na Expressão 2.34, tem-se que o comprimento de embutimento é:

$$
l_{\text {emb }} \geq 2 \cdot \sqrt{\frac{M_{d}+\frac{V_{d}^{2}}{1,2 \cdot f_{c d} b_{p i l}}}{0,6 \cdot f_{c d} \cdot b_{p i l}}}+\frac{V_{d}}{0,6 \cdot f_{c d} \cdot b_{p i l}}
$$




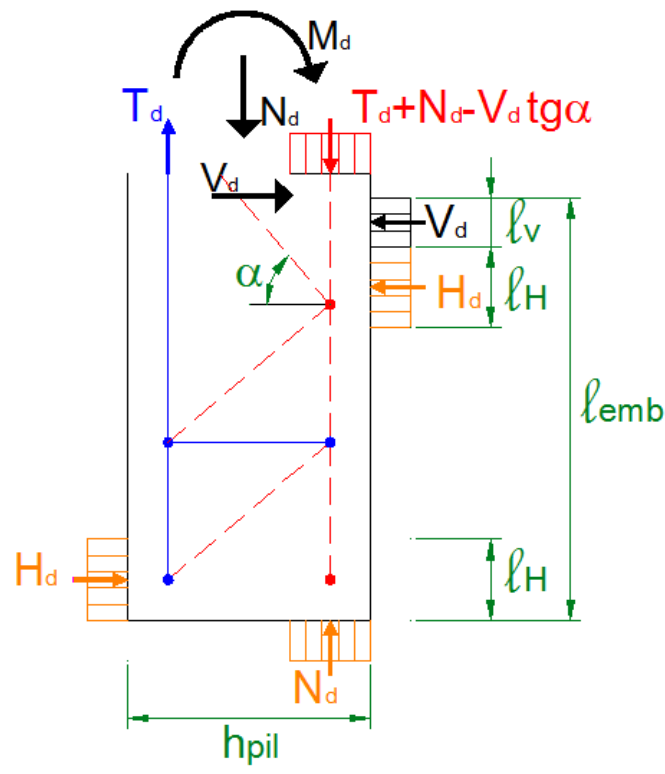

a) $\ell_{e m b}>2 \cdot h_{\text {pil }}$

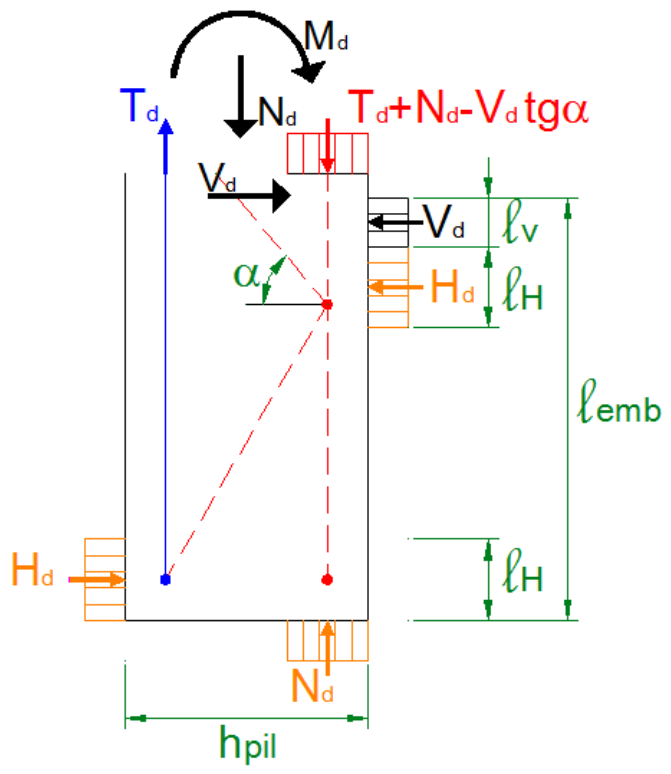

b) $\ell_{\text {emb }} \leq 2 \cdot h_{\text {pil }}$

Figura 2.37 - Modelo de forças internas no pilar com a transmissão da reação vertical excêntrica

Fonte: Adaptação de Silva (1998)

Silva (1998) observa que o comprimento de embutimento do pilar é função de $b_{p i l}$, diferentemente das expressões propostas por Leonhardt e Mönnig (1977) sendo que o comprimento de embutimento é função de $h_{\text {pil }}$. Os pesquisadores ainda fornecem modelos de bielas e tirantes para a determinação das armaduras de sapatas com cálice embutido, a Figura 2.38 representa um desses modelos, nesse caso para ação excêntrica. 

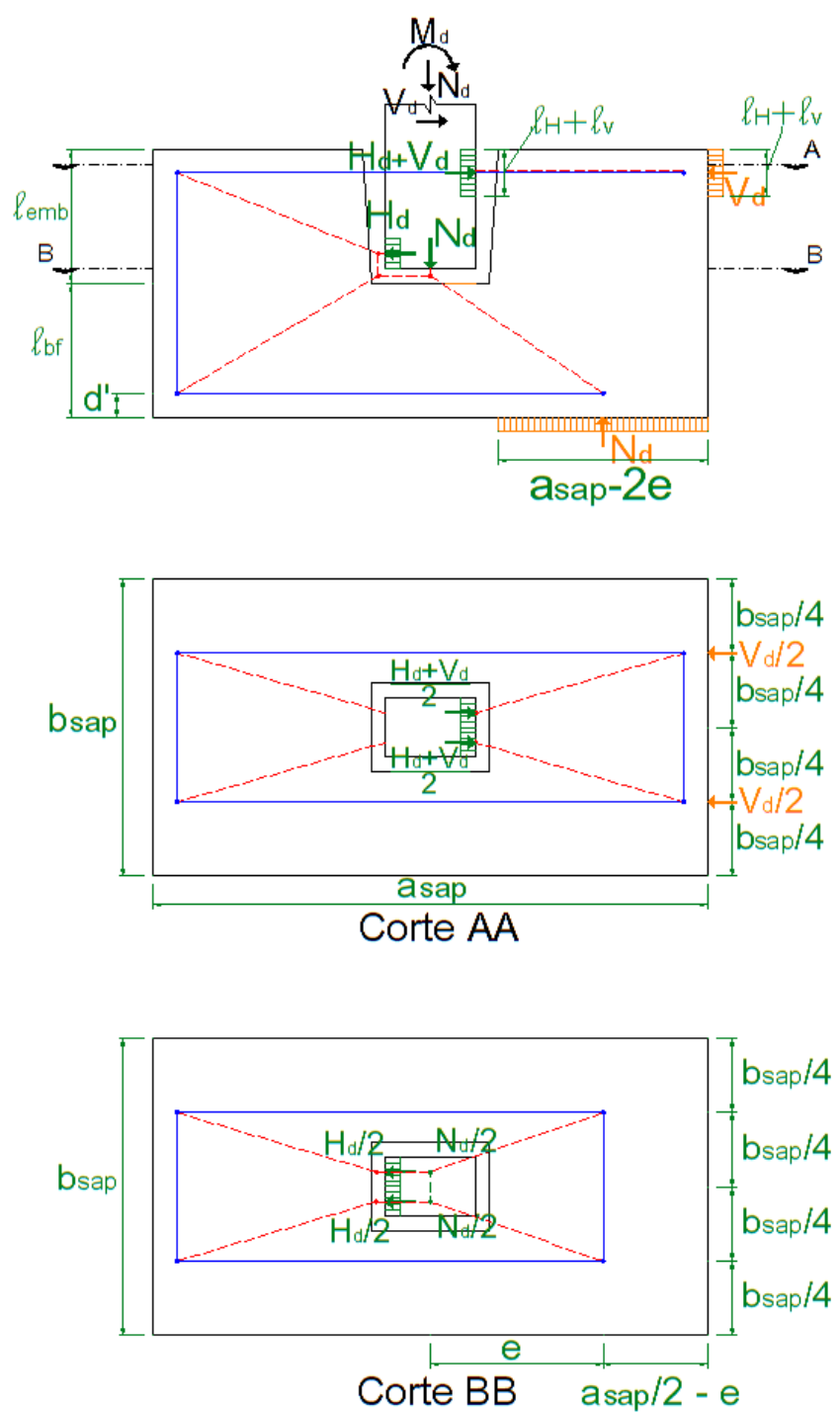

Figura 2.38 - Modelo de Bielas e Tirantes para sapata com ação vertical de excentricidade $e \geq a_{\text {sap }} / 4$

Fonte: Adaptação de Silva (1998)

Canha (2004) em sua pesquisa realizou ensaios experimentais e numéricos. A fase experimental consistiu de ensaio de cinco modelos em escala natural de cálice de ligação com atuação de força normal de grande excentricidade sendo três desses modelos com paredes de interface lisas e dois modelos com paredes de interface rugosa. Em ambos os modelos foi aplicado desmoldante na superfície das paredes de interface com a intenção de eliminar a adesão entre os concretos. A fase numérica consistiu de análise pelo Método dos Elementos Finitos com auxílio do programa computacional ANSYS 5.5. Este estudo permitiu averiguar a hipótese de que os métodos usuais de dimensionamento, baseados na ABNT NBR 9062:1985 e em Leonhardt e Mönnig (1977), conduzem a soluções conservadoras. 
Além dos ensaios, foi realizada uma avaliação de alguns modelos encontrados na literatura técnica e finalmente foi proposto um modelo de cálculo para cálices de paredes lisas que leva em consideração as forças de atrito mobilizadas pela pressão do pilar nas paredes do cálice e o comportamento de consolo para o cálculo das paredes longitudinais. Para os cálices de paredes rugosas, Canha (2004) constatou que a resistência experimental atingiu valores próximos aos de uma ligação monolítica, portanto foi indicado o dimensionamento das armaduras verticais do cálice considerando a transferência total dos esforços solicitantes e das armaduras superiores considerando o comportamento de consolo das paredes longitudinais.

As recomendações quanto à geometria do cálice são as mesmas feitas por Leonhardt e Mönnig (1977) e pela ABNT NBR 9062:2006, desse modo o comprimento de embutimento, $\ell_{e m b}$, é o mesmo fornecido pela Tabela 2.3. A representação das forças atuantes nas paredes do cálice e as reações desenvolvidas estão representadas na Figura 2.39. O modelo proposto por Canha (2004) considera o desenvolvimento de forças de atrito $F_{a t, s u p, d}$ e $F_{a t, i n f, d}$, provenientes da pressão exercida pelo pilar nas paredes transversais do cálice, e $F_{a t, b f, d}$ oriunda da pressão da força normal reduzida na base do pilar, $N_{b f, d}$, atuando com excentricidade igual a $e_{n b}$.

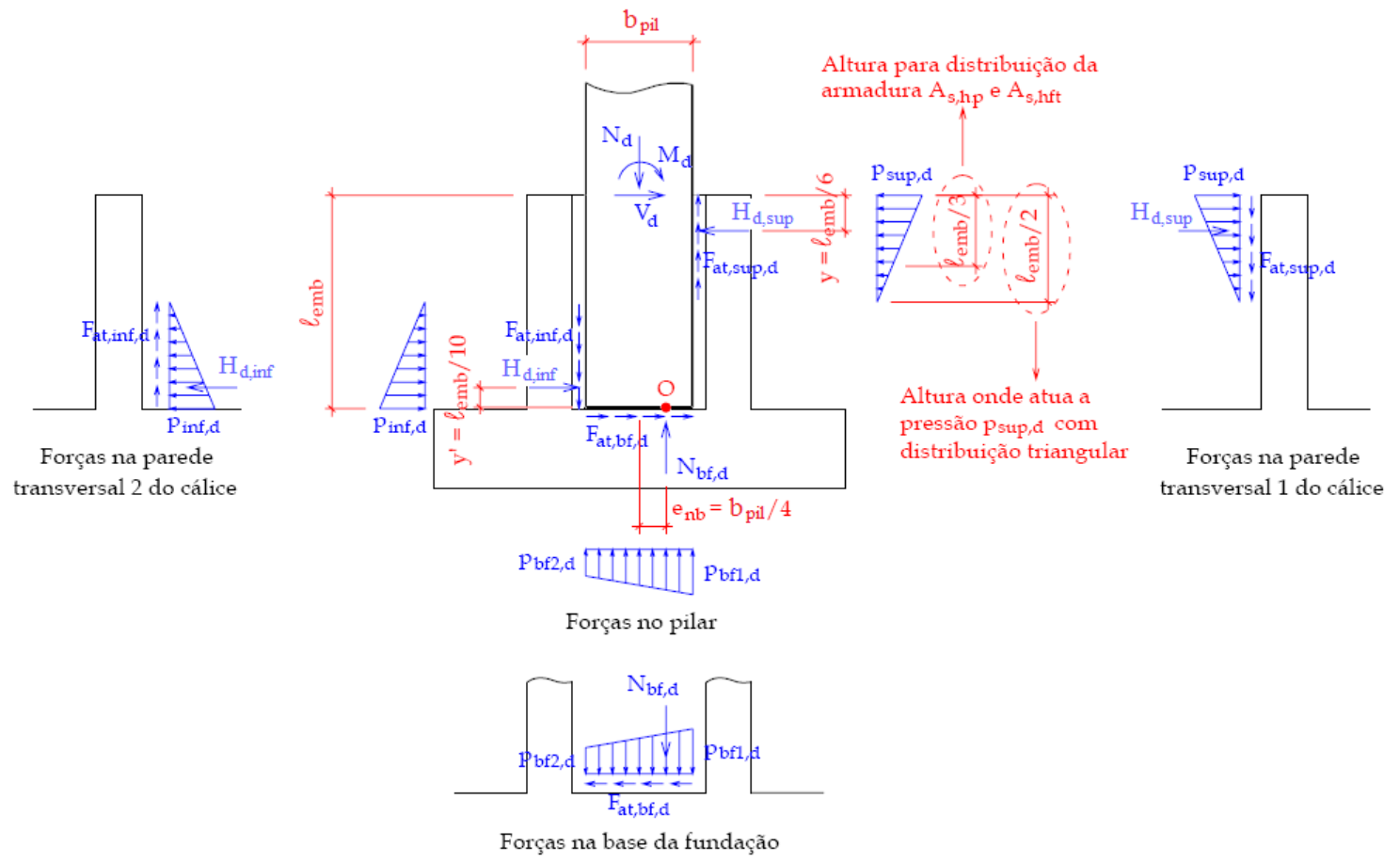

VISTA FRONTAL

Figura 2.39 - Esquema de forças solicitantes e resistentes no cálice de fundações Fonte: Adaptação de Canha (2004)

Por meio das equações de equilíbrio de forças verticais, horizontais e de momento em relação ao ponto $\mathrm{O}$, escrevendo as forças de atrito em função da forças normais que as 
mobiliza e fazendo as substituições adequadas chegou-se a Expressão 2.36, que descreve a intensidade da força $H_{d, \text { sup }}$ :

$$
H_{d, \text { sup }}=\frac{M_{d}-N_{d} \cdot\left[e_{n b}+\frac{\mu \cdot y^{\prime}-\mu^{2} \cdot\left(0,5 \cdot b_{p i l}+e_{n b}\right)}{1+\mu^{2}}\right]+V_{d} \cdot\left[l_{e m b}-\frac{y^{\prime}-\mu \cdot\left(0,5 \cdot b_{p i l}+e_{n b}\right)}{1+\mu^{2}}\right]}{l_{e m b}+\mu \cdot b_{p i l}-y-y^{\prime}}
$$

Canha (2004) calibrou a Expressão 2.36 com os resultados experimentais por meio da variação dos parâmetros $y, y^{\prime}$ e $e_{n b}$. O valor recomendado para $e_{n b}$ é de $b_{p i l} / 4$, que satisfaz à situação da linha neutra do pilar próxima do limíte entre os domínios 3 e 4 correspondendo ao caso de pilares dimensionados de forma mais econômica, valor este também favorável à segurança. Para $y$ ' foi recomendado $\ell_{e m b} / 10$. Mesmo sabendo que a força $H_{d, \text { inf }}$ é praticamente transmitida diretamente à base da fundação, foi indicado a utilização de valor diferente de zero por achar que fosse mais prudente. Considerando a distribuição triangular de esforços na parede do cálice, e considerando a posição da resultante dessa distribuição, tem-se que y é igual a $\ell_{e m b} / 6$ mesmo assim a armadura superior deverá ser distribuída, conforme indica El Debs (2000), até $\ell_{e m b} / 3$ do topo do colarinho. O coeficiente de atrito, $\mu$, indicado é de 0,6.

Como os resultados das ligações de paredes rugosas foram próximos aos de ligações monolíticas, Canha (2004) sugeriu o dimensionamento da ligação com cálices de paredes rugosas admitindo a transferência do momento, da força normal e da força cortante para o cálice de tal maneira que o dimensionamento do cálice é feito com base na Teoria de Flexão, considerando a seção conjunta cálice-pilar flexo-comprimido e a contribuição de todas as armaduras verticais principais tracionadas presentes no colarinho, incluindo as armaduras secundárias.

Prosseguindo nos estudos dos cálices de fundação com colarinho, Jaguaribe Júnior (2005) estudou dois modelos experimentais com comprimento de embutimento reduzidos, um com interface lisa e outro com interface rugosa. Comparando as resistências obtidas nos ensaios com os modelos téoricos da ABNT NBR 9062:1985, de Canha (2004) e outros modelos, o pesquisador observou que a maioria dos modelos teóricos superestimaram a capacidade da ligação quando se utilizou valores de comprimento de embutimento inferiores aos prescritos na norma brasileira de concreto pré-moldado. Para o modelo possuindo interface rugosa e comprimento de embutimento reduzido a aplicação da teoria de flexão composta, sugerida por Canha (2004), conduziu a valores de resistência superiores. Jaguaribe 
Júnior (2005) adverte que, apesar do comportamento do cálice rugoso ter sido próximo de uma ligação monolítica, é necessário um modelo de cálculo mais coerente para cálices de interfaces rugosas e comprimento de embutimento inferiores a $1,6 \cdot h$.

Ebeling (2006) estudou o comportamento da base dos pilares em ligações por cálice de fundação mediante análise experimental e numérica. A análise foi realizada em dois modelos de cálices com interface lisa sendo que foram reaproveitados modelos utilizados nas pesquisas de Canha (2004) e Jaguaribe Júnior (2005) empregando-se reforço com fibra de carbono nas paredes do cálice.

O pesquisador constatou que a base dos pilares, na ligação com o cálice de fundação, apresenta segurança, uma vez que a ruína dos modelos aconteceu pelo escoamento da armadura longitudinal tracionada, fora da região de embutimento. Também foi verificado que o comprimento de embutimento influenciou na rigidez das ligações tornando as ligações com menores comprimentos de embutimento mais deformáveis. Além disso, Ebeling (2006) verificou que a armadura transversal não sofreu grandes solicitações, mesmo com ela possuindo valores mínimos indicados pela norma.

Nunes (2009) estudou ligações por cálice externo com enfoque no comportamento das paredes transversais do cálice. Nesta pesquisa foram realizados ensaios em dois modelos experimentais, um com interface rugosa e outro lisa, sendo avaliadas as armaduras verticais principais, localizadas no encontro das paredes longitudinais com as transversais.

A comparação dos resultados experimentais com as previsões feitas pelo modelo proposto do Canha (2004), indica que a parede transversal encontra-se submetida a flexotração, sendo que os melhores resultados foram alcançados ao se considerar $15 \%$ de flexão e $85 \%$ de tração.

Outros códigos normativos fazem recomendações quanto ao dimensionamento de ligações por meio de cálices, tal como o Eurocode 2 (2002). Segundo esta norma, os cálices devem ser capazes de transmitir a força axial, força cortante e momento fletor do pilar à fundação. Para o cálice com interface rugosa, pode-se considerar que a transferência de esforços é semelhante à da ligação monolítica, de tal forma que as recomendações são as mesmas. A Figura 2.40 ilustra esse caso. 


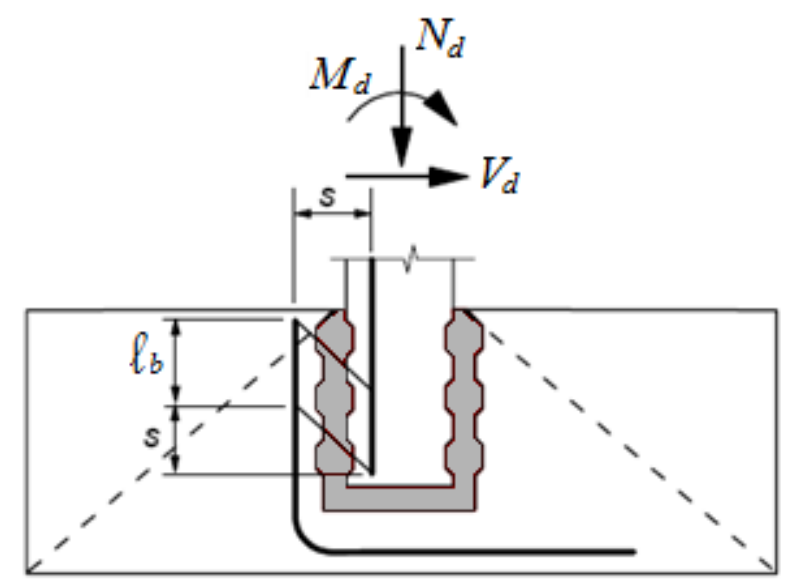

Figura 2.40 - Cálice com chave de cisalhamento. Fonte: Eurocode 2 (2002).

É imprescindível um detalhamento cauteloso da armadura que se sobrepõe na região da ligação. O comprimento de traspasse comum deve sofrer acréscimo de no mínimo a distância entre as barras de armadura do pilar e da fundação conforme indica a Figura 2.40.

A verificação da punção deve ser igual à feita para situação de ligação monolítica entre pilar e fundação, caso ocorra à transferência de cisalhamento na interface. Caso contrário a verificação é igual para ligação com cálice de parede lisa.

Em cálices de interface lisa, o Eurocode 2 supõe que a transferência de esforços é feita mediante as forças $H_{d, s u p}, H_{d, \text { inf }}$ e $N_{b f, d}$ e as correspondentes forças de atrito no concreto de preenchimento, Figura 2.41. O coeficiente de atrito, $\mu$, não deve ser maior que 0,3 . Neste modelo o comprimento de embutimento, $\ell_{e m b}$, deve ser maior ou igual a $1,2 \cdot h_{p i l}$.

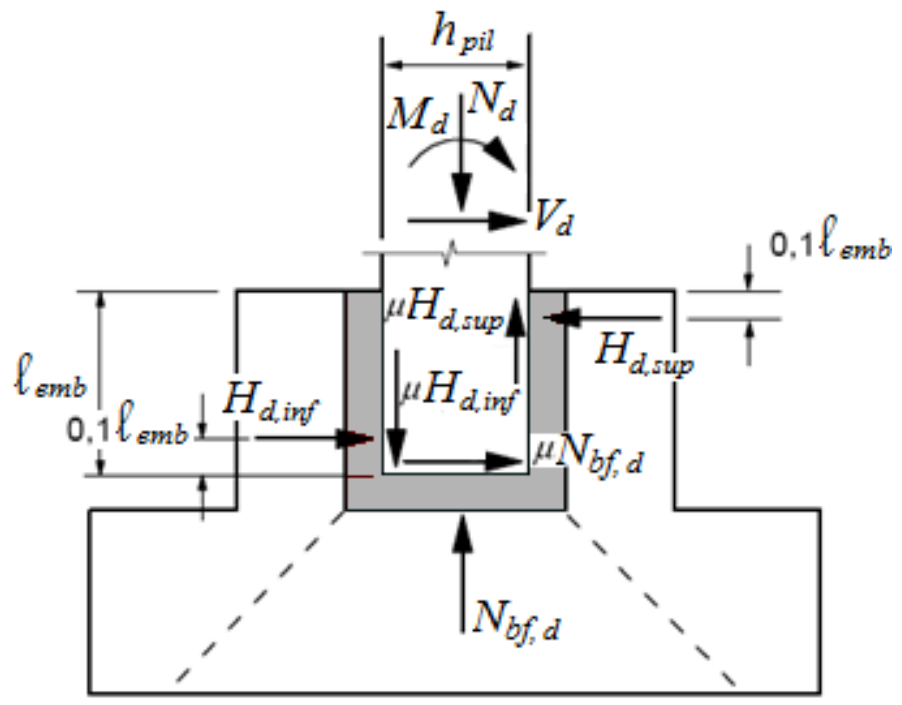

Figura 2.41 - Cálice com paredes lisas. Fonte: Eurocode 2 (2002). 
Segundo a norma, deve-se prestar atenção especial no detalhamento da armadura de $H_{d \text { sup }}$ no topo das paredes do cálice e na transferência dessa força por meio das paredes laterais até a fundação. Ainda, é preciso verificar a ancoragem da armadura principal no pilar nas paredes do cálice e a resistência ao cisalhamento da coluna com o cálice.

\subsubsection{CONSIDERAÇõES FINAIS}

Pela análise dos modelos de cálices apresentados e pelo estudo feito por Canha (2004), percebe-se que a não consideração das forças de atrito desenvolvidas na interface, como ocorre no modelo de Leonhardt e Mönnig (1977) para paredes lisas, conduz a resultados conservadores. Além disso, os modelos que consideram a excentricidade da reação da força vertical fornecem resultados mais econômicos uma vez que essa excentricidade reduz uma parcela do momento atuante na ligação.

A flexão das paredes do cálice em razão da pressão exercida pelo pilar não é preponderante uma vez que, como foi observado no estudo de paredes do cálice realizado por Nunes (2009), o dimensionamento da armadura do topo do cálice considerando a flexo-tração com $85 \%$ de tração e $15 \%$ de flexão conduz a resultados mais próximos dos valores observados nos ensaios. Para os cálices embutidos em blocos sobre quatro estacas, acredita-se que a ocorrência de flexão da parede não seja relevante uma vez que as paredes do cálice são formadas pelo próprio bloco possuindo uma grande rigidez.

Nos cálices embutidos com interface rugosa, em razão dos resultados encontrados no estudo de Canha (2004) e na recomendação feita pelo Eurocode 2 (2002), acredita-se que o comportamento da ligação será de monolitismo sendo necessário observar o comprimento de ancoragem e de traspasse da armadura do pilar. A quantidade reduzida de recomendações de modelos de bielas e tirantes para o elemento de fundação com cálice embutido de paredes lisas faz com que seja difícil o dimensionamento do bloco, Bruggeling e Huyghe (1991) ilustram um modelo privado de detalhes e Silva (1998) apresenta um modelo desenvolvido para sapatas com cálice embutido. Percebe-se também que o modelo de forças internas ao pilar proposto por Silva (1998) prevê um bloco de tensões de compressão que só pode ser considerado válido no caso de pequenos valores de excentricidade da força vertical. 


\section{|caprtrulo 3 \\ ESTUDO E ANÁLISE DOS MOdELOS NumÉRICOS

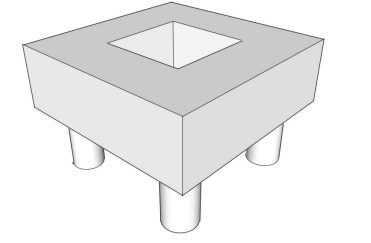

\subsection{CONSIDERAÇõES INICIAIS}

Em meados da metade do século XX, o desenvolvimento computacional estimulou o uso dos métodos numéricos, em especial o Método dos Elementos Finitos, para a análise de problemas complexos de engenharia. O concreto é um dos materiais mais consumidos no planeta, em grande parte das obras de engenharia com finalidade estrutural. A sua simulação numérica é complexa em razão da modelagem das fissuras e do comportamento não-linear induzido pela fissuração do concreto. Ao longo dos anos, foram desenvolvidos programas computacionais baseadas no Método dos Elementos Finitos cuja finalidade é simular e analisar materiais, tais como o concreto, quando submetidos a carregamentos, tensões impostas por deformações e deslocamentos de apoios, e variações de temperatura. Dentre os programas disponíveis optou-se nesse estudo pelo DIANA.

\subsection{Programa Computacional DIANA}

\subsubsection{INTRODUÇÃO}

O programa computacional DIANA, DIsplacement method ANAlyzer, é destinado a análises por meio do Método dos Elementos Finitos baseado no método dos deslocamentos. Esse programa vem sendo desenvolvido, desde 1972, pela Delft University of Technology na Holanda e possui uma biblioteca vasta de elementos e materiais que foi apontada por pesquisadores, como Souza (2004) e Barros (2009), apropriada para a análise de estruturas formadas por elementos de concreto armado. Além de efetuar vários tipos de análise, salientase a possibilidade de considerar efeitos dependentes do tempo, temperatura, instabilidade, 
plasticidade e fissuração do concreto, dos quais interessam às análises deste estudo apenas os dois últimos.

Amparando-se na potencialidade e na capacidade de simular o comportamento de elementos de concreto armado pelos modelos inclusos no programa e na sua disponibilidade para o Departamento de Engenharia de Estruturas da Escola de Engenharia de São Carlos, optou-se por sua utilização para o desenvolvimento das análises numéricas desta pesquisa.

\subsubsection{Modelos Constitutivos}

As estruturas de concreto, após certa intensidade de tensão, apresentam um acréscimo das deformações. Esse comportamento também denominado por strain softening, ou amolecimento, tende a ser mais acentuado em algumas regiões da estrutura de tal modo que, para conseguir uma boa representação, seria necessária uma malha mais refinada nessas regiões. A discretização da malha de elementos finitos eleva o número de elementos e, conseqüentemente, o número de equações do sistema, gerando maior tempo de processamento computacional podendo até inviabilizar a análise. A solução alternativa do DIANA é a utilização dos parâmetros da Mecânica da Fratura para descrever esse comportamento do concreto. Para isso o programa dispõe do modelo de fissuras distribuídas, Smeared Crack Model, e de fissuras discretas, Discrete Crack Model.

O modelo de fissura discreta busca representar a fissura por meio da geração de uma nova malha de elementos finitos a cada incremento de carregamento, de modo a representar a descontinuidade ocasionada pela fissura. Essa estratégia busca representar o processo de fissuração do concreto, entretanto, segundo Rots e Blaauwendraad (1989), esta alternativa apresenta a inconveniência de gerar mudanças contínuas na conectividade dos nós dos elementos finitos e de obrigar a fissura a seguir por um caminho pré-definido pelas interfaces dos elementos adjacentes à mesma. Por outro lado, o modelo de fissuras distribuídas trata $\mathrm{o}$ fraturamento do concreto mantendo a continuidade do material sem alterar a malha original de elementos finitos em razão da propagação das fissuras. Rots e Blaauwendraad (1989) também citam a vantagem do modelo de fissuras distribuídas não impor restrições quanto à orientação das fissuras. 
Por motivo de simplificação, optou-se nesta pesquisa pelo modelo de fissuras distribuídas. Os parâmetros necessários para a análise considerando o modelo de fissuras distribuídas são: energia de fraturamento na tração $G_{f}$, energia de fraturamento na compressão $G_{c}$, resistências à tração e compressão, fator de retenção ao cisalhamento $\beta$ e a largura de banda das fissuras $h_{c r}$.

A energia de fraturamento, conforme procedimento da RILEM Draft Recommendation TC50-FMC ${ }^{11}$, pode ser obtida em ensaio à flexão de corpo-de-prova entalhado sendo que $G_{f}$ é dado pela área abaixo da curva força-deslocamento dividida pela área da seção efetiva do corpo-de-prova no plano do entalhe. Na ausência deste ensaio, o CEB-FIP 1990 (1993) permite a estimativa da energia de fraturamento por meio da Expressão 3.1:

$$
G_{f}=G_{F 0} \cdot\left(\frac{f_{c m}}{f_{c m 0}}\right)^{0,7}\left[\mathrm{~N} \cdot \mathrm{mm} / \mathrm{mm}^{2}\right]
$$

Sendo que $f_{c m 0}$ é igual a $10 M P a$ e $f_{c m}$ é dado pela Expressão 3.2. O parâmetro $G_{F 0}$ é o valor básico da energia de fraturamento, fornecido na Tabela 3.1 em função do diâmetro máximo do agregado do concreto.

$$
f_{c m}=f_{c k}+8\left[\mathrm{~N} / \mathrm{mm}^{2}\right]
$$

Tabela 3.1 - $\boldsymbol{G}_{\boldsymbol{F} \text { o }}$ em função do diâmetro máximo do agregado
\begin{tabular}{cc}
$\mathbf{d}_{\text {máx }}(\mathbf{m m})$ & $\mathbf{G}_{\boldsymbol{F} \mathbf{0}}\left(\mathbf{N} \cdot \mathbf{m m} / \mathbf{m m}^{\mathbf{2}}\right)$ \\
\hline 8 & 0,025 \\
\hline 16 & 0,030 \\
\hline 32 & 0,058 \\
\hline
\end{tabular}

Já o $G_{c}$, segundo Feenstra ${ }^{12}$, encontra-se no intervalo entre 10 e $25 \mathrm{~N} \cdot \mathrm{mm} / \mathrm{mm}^{2}$ que corresponde a um valor entre 50 e 100 vezes o $G_{f}$.

\footnotetext{
${ }^{11}$ RILEM, Draft Recommendation, 50-FMC Committee Fracture Mechanics of Concrete, Determination of the Fracture Energy of Mortar and Concrete by means of Three-Point Bending Tests on Notched Beams, Materials and Structures, v. 85, n. 85, p. 285-290, 1985.

12 FEENSTRA, P. H. Computational Aspects of Biaxial Stress in Plain and Reinforced Concrete. PhD thesis, Delft University of Technology, 1993.
} 


\subsubsection{Modelos Total StRain}

São modelos desenvolvidos sobre a teoria do campo de compressão modificado, apresentada por Vecchio e Collins ${ }^{13}$ e que posteriormente foi estendida para problemas tridimensionais por Selby e Vecchio ${ }^{14}$

Segundo TNO DIANA (2005c), estes modelos descrevem o comportamento do concreto sob tensões de compressão e de tração por meio de relações tensão-deformação, entretanto não podem ser combinados com outros modelos constitutivos. Estes modelos são adequados para análises de ELS (Estado Limite de Serviço) e ELU (Estado Limite Último) por serem estes estados limites governados pela fissuração e pela ruptura do concreto.

O DIANA disponibiliza dois modelos Total Strain: o Total Strain Rotating Crack Model, ou seja, modelo de fissuras rotacionais e o Total Strain Fixed Crack Model, ou modelo de fissuras fixas. O primeiro modelo corresponde a uma aproximação sendo que as relações tensão-deformação são avaliadas nas direções principais do vetor deformação. As aproximações obtidas são adequadas para estruturas de concreto armado, permitindo que a orientação das fissuras co-rotacionem com os eixos da deformação principal de tal forma que a direção da fissura coincida com a direção das deformações principais. Ainda, quanto ao modelo de fissuras rotacionais, a transferência de cisalhamento não irá desempenhar um papel relevante, de tal modo que não é necessário especificar um fator de retenção ao cisalhamento. Maekawa et al. (2003) afirmam que, uma vez que as tensões de cisalhamento desaparecem nos planos principais continuamente atualizados, nenhum modelo de transferência de cisalhamento é necessário. Nesse modelo, a inclinação das tensões principais permanece sempre coincidente com a inclinação das deformações principais. Por esse motivo, essa aproximação não considera explicitamente o deslizamento e a transferência de tensões cisalhantes motivadas pelo intertravamento do agregado. Esse tipo de tratamento traz benefícios computacionais e respostas satisfatórias para estruturas submetidas a carregamentos monotônicos ou cíclicos nos quais os ciclos de carregamento não ocasionem muitas rotações nas direções das tensões principais.

\footnotetext{
${ }^{13}$ VECCHIO, F. J.; COLLINS, M. P. The Modified Compression Field Theory for Reinforced Concrete Elements Subjected to Shear. ACI Journal, v. 83, n. 2, p. 219-231, mar.-abr. 1986.

14 SELBY, R. G.; VECCHIO, F. J. Three-dimensional Constitutive Relations for Reinforced Concrete. Technical Report, n. 93-02, University of Toronto, Department of Civil Engineering, Canada, 1993.
} 
O segundo modelo possui maior apelo na natureza física da fissura sendo que as relações tensão-deformação são avaliadas segundo um sistema de coordenadas fixo sobre a fissura, conservando a sua orientação inicial nos estágios subseqüentes. Conforme Maekawa et al. (2003), no modelo de fissuras fixas a anisotropia é levada em consideração em consequiência do tratamento independente dispensado para o modelo de transferência de tensões normais e de cisalhamento. Nesse caso o vetor de tensões principais não coincide com o das deformações principais, e a modelagem da fissura é geometricamente próxima a realidade. Nesse modelo, a descrição do comportamento quanto ao cisalhamento torna-se necessária.

Os dados de entrada são compostos por duas partes: os dados básicos, tais como o módulo de elasticidade, o coeficiente de Poisson e as resistências à compressão e à tração, e por definições quanto ao comportamento do concreto sob compressão, tração e cisalhamento.

Os dados podem ser fornecidos diretamente ao DIANA ou escolhendo um modelo já inserido na biblioteca do programa, como o Model Code CEB-FIP 1990. Quando inseridos diretamente, os dados referentes ao comportamento do concreto sob tração e compressão serão compostos pelas características das curvas que relacionam tensão e deformação e pelos parâmetros necessários para descrever cada curva. A Figura 3.1 e a Figura 3.2 descrevem os modelos disponíveis para representar o comportamento do concreto sob tração e compressão respectivamente. 


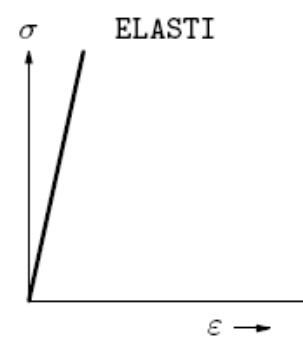

(a) elastic

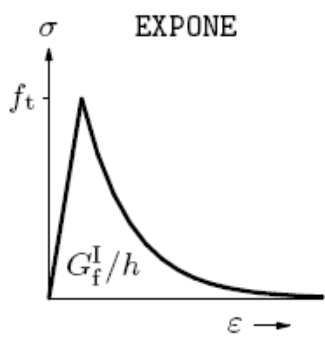

(e) exponential

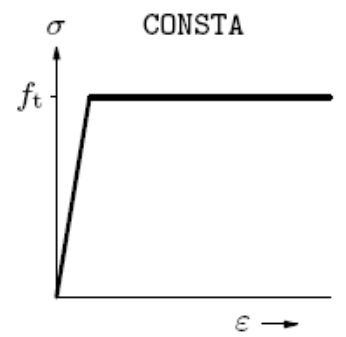

(b) ideal

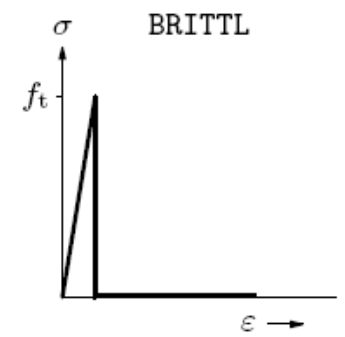

(c) brittle

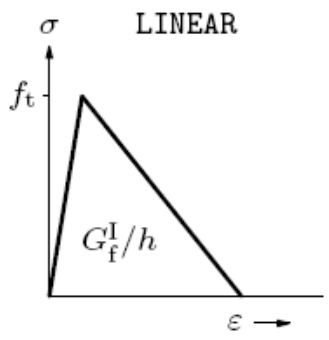

(d) linear

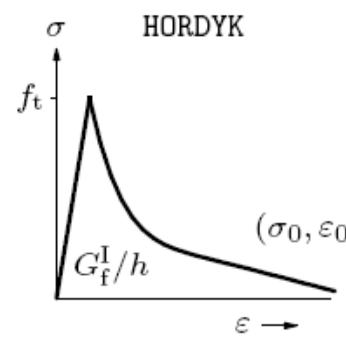

(f) Hordijk

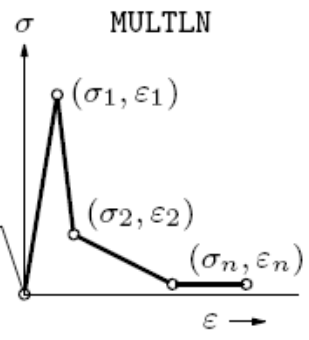

(g) multi-linear

Figura 3.1 - Modelos de comportamento Tensão x Deformação disponíveis para o concreto tracionado

Fonte: DIANA (2005c)

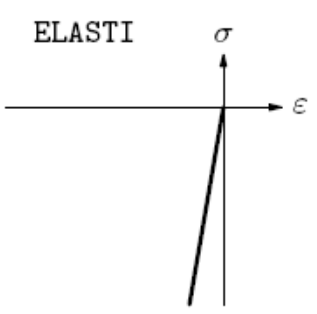

(a) elastic

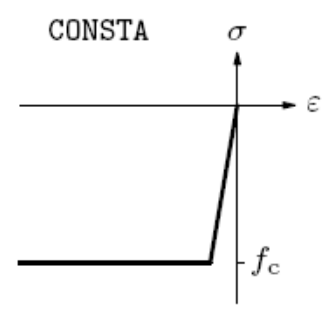

(b) ideal

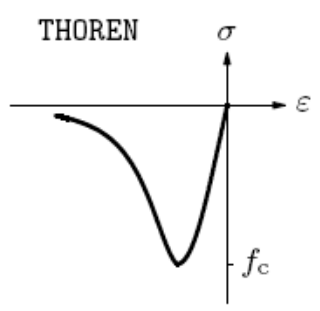

(c) Thorenfeldt

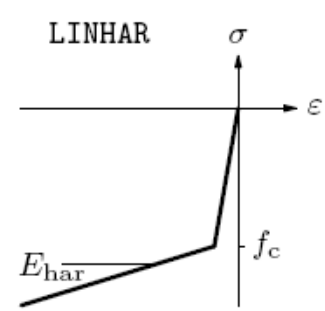

(d) linear

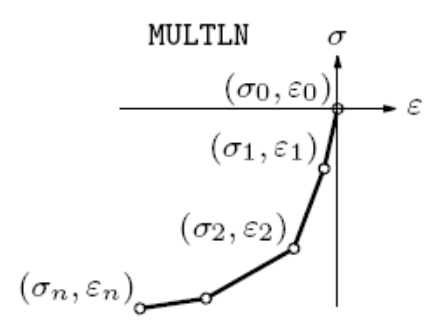

(e) multi-linear

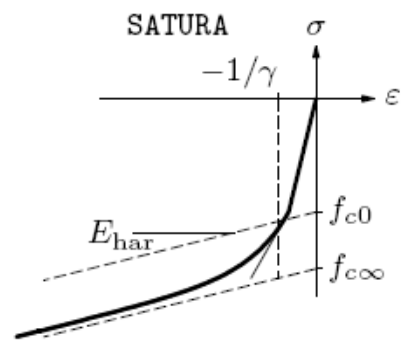

(f) saturation type

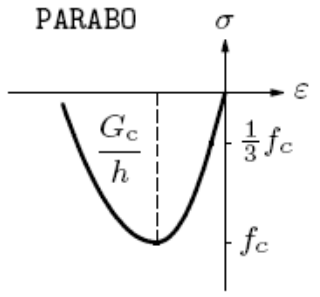

(g) parabolic

Figura 3.2 - Modelos de comportamento Tensão x Deformação disponíveis para o concreto sob compressão

Fonte: DIANA (2005c) 
Nos modelos Total Strain de fissura fixa o comportamento quanto ao cisalhamento é avaliado por meio do fator de retenção ao cisalhamento $\beta$, que será constante nos caso do Total Strain Fixed Crack, e constante ou variável para o caso do Non-orthogonal Crack Model. Para o modelo Total Strain Rotating Crack Model o valor de $\beta$ pode ser assumido igual a um, uma vez que esse fator é dispensável no comportamento deste modelo. $\mathrm{O}$ coeficiente $\beta$ promove a minoração do módulo de elasticidade transversal $G$, em razão da elevação da intensidade das tensões e conseqüente fissuração do concreto. Este coeficiente pode ser visto como uma forma de representar os mecanismos de transferência de cisalhamento entre interfaces de concreto.

Segundo Rots e Blaauwendraad (1989), os modelos de fissuras rotacionais diferem dos modelos de fissuras fixas por não preservarem uma memória permanente da orientação dos danos, ou seja, implicando que os defeitos inativos não possam ser reativados nos estágios seguintes de carregamento, e por não necessitar de parâmetros que descrevam a relação entre a fissura e a transferência de cisalhamento na mesma.

No concreto, os efeitos laterais provocados pela fissuração e pelo confinamento induzem a redução e elevação da resistência à compressão respectivamente. Em TNO DIANA (2005c) é descrito que o efeito lateral de fissuração pode ser considerado por meio da relação dada por Collins e Vecchio ${ }^{15}$, Figura 3.3, e o efeito do confinamento por meio do modelo de Selby e Vecchio.

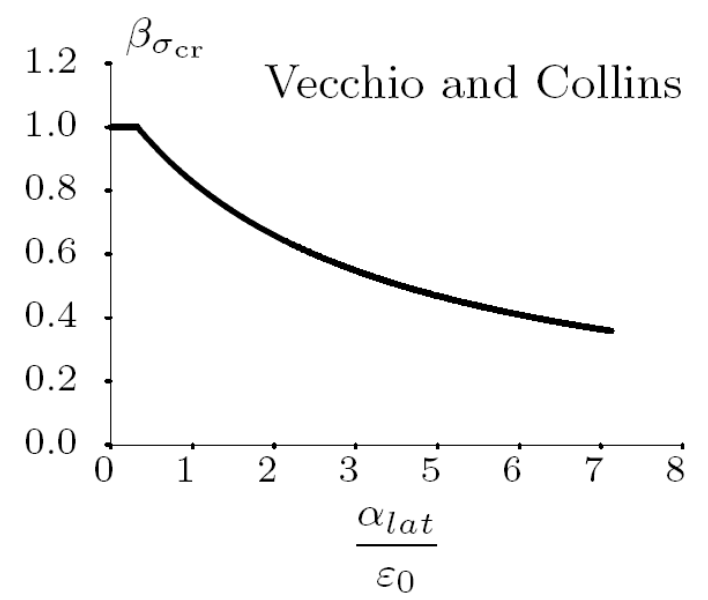

Figura 3.3 - Fator de redução por causa da fissuração lateral Fonte: DIANA (2005c)

\footnotetext{
${ }^{15}$ VECCHIO, F. J.; COLLINS, M. P. Compression Response of Cracked Reinforced Concrete. Journal of Structural Engineering, v. 119, n. 12, p. 3590-3610, dez. 1993.
} 


\subsubsection{MODELOS INCREMENTAIS OU PLÁSTICOS}

Esses modelos são representados no DIANA por meio do modelo de fissuras fixas multi-direcionais, Multi-Directional Fixed Crack Model, que considera os conceitos da Teoria da Plasticidade. A deformação do material é dividida em uma parcela elástica - reversível - e outra plástica - irreversível. A ruptura por tração ocorrerá quando em algum ponto do material a máxima tensão principal de tração ultrapassar o valor limite da resistência do material. Na compressão, pode-se recorrer aos critérios de Von Mises, Tresca, Drucker-Prager e Mohr-Coulomb para determinar a ruptura.

Segundo TNO DIANA (2005c) e Rots e Blaauwendraad (1989), em razão da decomposição da parcela de deformação plástica, é possível a abertura de várias fissuras em direções diferentes, simultaneamente, num mesmo ponto da malha de elementos finitos. No programa computacional DIANA este modelo é disponibilizado para os problemas de estado plano de tensão, de deformação e em elementos axissimétricos. Sua formulação não está disponível para elementos sólidos tornando o inútil para as análises propostas neste trabalho.

\subsubsection{Modelo MaEkaWA Modificado}

O Modified Maekawa Concrete Model, ou Modelo Maekawa Modificado, combina um modelo plástico multi-axial de dano para representar o efeito de ruptura do concreto sob compressão e um modelo de fissuração baseado nos modelos Total Strain para representar o concreto sob tração. A vantagem desse modelo é referente ao uso de parâmetros como resistência à tração, à compressão e energia de fraturamento que possibilitam uma boa representação do concreto para várias situações, ao contrário de modelos mais específicos que não representam satisfatoriamente situações de solicitação diferentes daquelas para as quais foram formulados.

Este modelo pode ser empregado tanto para elementos sólidos, de viga, de casca, de treliça e de estado plano de tensão. Segundo TNO DIANA (2005c), o modelo de dano na plasticidade foi desenvolvido pelo grupo de pesquisa do professor Koichi Maekawa na Universidade de Tóquio e o modelo de fissuração é diretamente relacionado aos modelos de 
fissuração Total Strain, já descritos. Este modelo também descreve o efeito de histerese em ciclos de carregamento e descarregamento.

Maekawa et al. (2003) afirmam que a não-linearidade do concreto não pode ser descrita unicamente pela plasticidade porque a teoria da plasticidade não postula um amolecimento da curva tensão - deformação total ao longo do caminho de descarregamento. Esse amolecimento no ramo de carregamento e de descarregamento é observado experimentalmente até mesmo em situações em que o concreto encontra-se altamente confinado. Ainda segundo os pesquisadores, o amolecimento e a redução da rigidez no descarregamento são atribuídos ao dano contínuo causado pelas micro-fissuras dispersas que degradam a capacidade de absorção de energia.

Neste modelo de dano elastoplástico, em conseqüência da danificação do concreto, é assumido que o módulo de elasticidade transversal é reduzido por um parâmetro $K$ que varia de 0 a 1 correspondendo à completa deterioração até o concreto sem danos. $\mathrm{O}$ parâmetro $K$ é um parâmetro de fratura que é calculado como função dos invariantes do tensor de deformações elásticas e é utilizado para quantificar a intensidade de dano deviatórico. Este parâmetro representa a taxa de volume de concreto não danificado que pode absorver completamente a energia de deformação elástica, ocasionada pelas forças tangenciais, sobre todo o volume.

Quando ocorre a fissuração no Modelo Maekawa Modificado, verificada pela superação da resistência à tração do concreto nas direções principais de deformação, se processa a mudança do modelo de dano elastoplástico para um modelo de concreto fissurado. Neste modelo as tensões são avaliadas com as deformações em cada direção principal de deformação. Nos casos de carregamento, descarregamento e recarregamento, o comportamento do modelo é descrito pela Figura 3.4. 


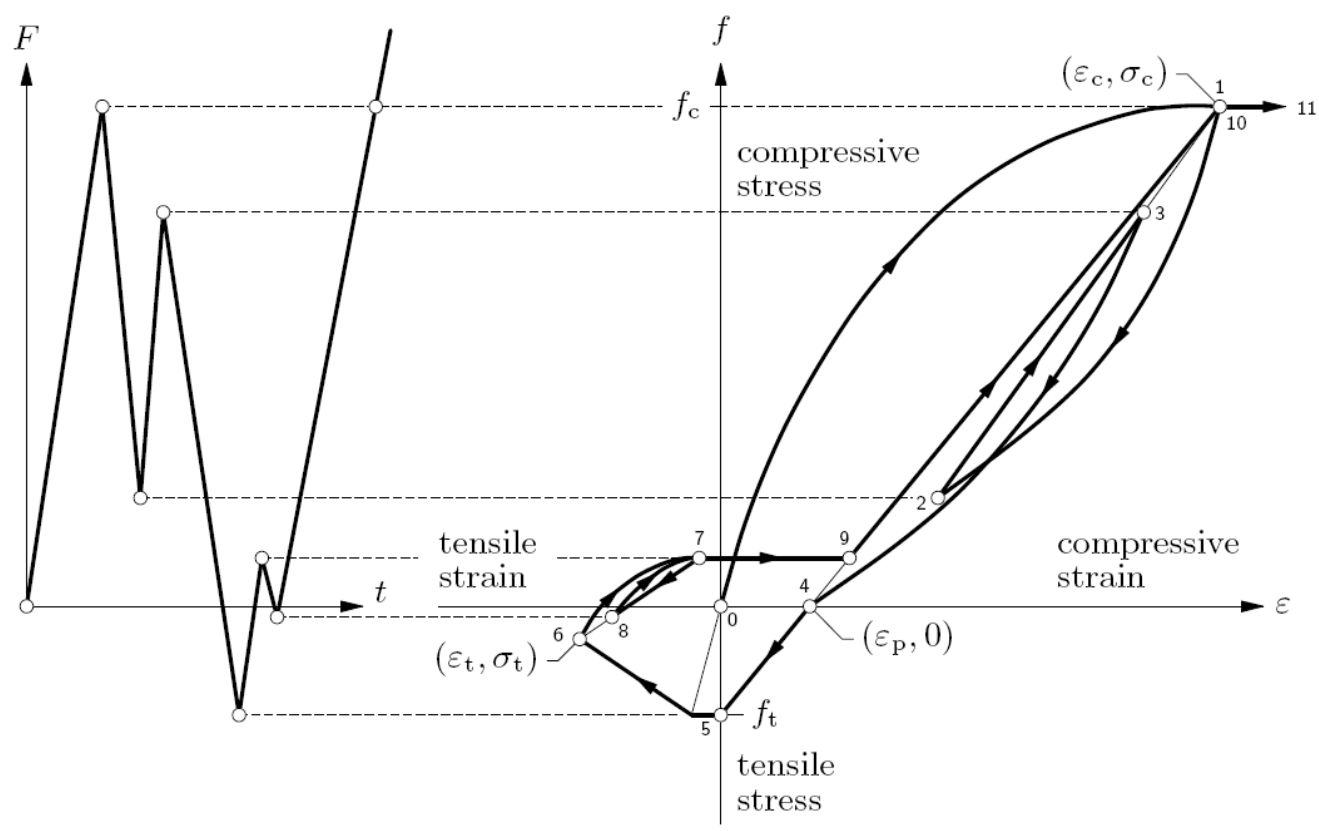

Figura 3.4 - Comportamento de histerese do Modelo Maekawa

Existem três modelos disponíveis para tratar a fissuração no "Maekawa": fissuras fíxas, fissuras rotacionais e fissuras não ortogonais, ou non-orthogonal crack. Para os dois primeiros valem os mesmos comentários feitos no item 3.2.2.1. O modelo de fissuras não ortogonais assume que as direções das fissuras não são ortogonais entre si. Neste modelo, a primeira direção da fissura é determinada conforme os modelos ortogonais, de fissura fixa ou rotacional, e as demais direções das fissuras são determinadas com base nas direções das deformações principais.

Para isto, sempre que o ângulo entre a fissura existente e das atuais direções das tensões principais superar um ângulo limite, denominado threshold angle, terá início uma nova fissura. Considerando que esse ângulo seja nulo, a cada estágio do carregamento incremental surgirá uma nova fissura fixa tornando o modelo relativamente semelhante ao princípio do modelo de fissuras rotacionais.

\subsubsection{ELEMENTOS FINITOS UTILIZADOS}

Este trabalho fez uso da análise não-linear considerando o modelo de plasticidade e a fissuração do concreto. Foram utilizados elementos finitos sólidos e de interface para a 
representação dos modelos. O elemento finito sólido é capaz de representar diversos tipos de problemas estruturais com boa qualidade de resultados, em contrapartida a sua utilização demanda maior tempo de processamento computacional para a resolução dos grandes sistemas de equações. A opção pelo elemento finito tridimensional em blocos sobre estacas é justificada pela incapacidade de representação do problema por meio de outros tipos de elementos.

Em meio aos elementos finitos sólidos disponíveis, utilizaram-se os hexaédricos ou cúbicos que podem ser do tipo HX24L, CHX60 ou CHX96. Conforme indica TNO DIANA (2005b) o primeiro é um elemento isoparamétrico de oito nós baseado em aproximação linear para os deslocamentos, o segundo é um elemento isoparamétrico de 20 nós baseado em aproximação quadrática e o último é um elemento isoparamétrico de 32 nós que utiliza função aproximadora de $3^{\circ}$ grau para os deslocamentos. Todos esses elementos possuem três graus de liberdade por nó, translação em x, y e z, e integração numérica pelo método de Gauss. Dentre os três tipos citados optou-se pelo CHX60, Figura 3.5, uma vez que em TNO DIANA (2005a) é recomendado não se empregar elementos isoparamétricos com aproximação linear para geração de modelos em análises não-lineares por motivo de limitações intrínsecas ao elemento como cisalhamento parasítico e travamento volumétrico que ocorre em elementos que não conseguem descrever deformações isocóricas, e assim podem superestimar a força última em até $30 \%$.

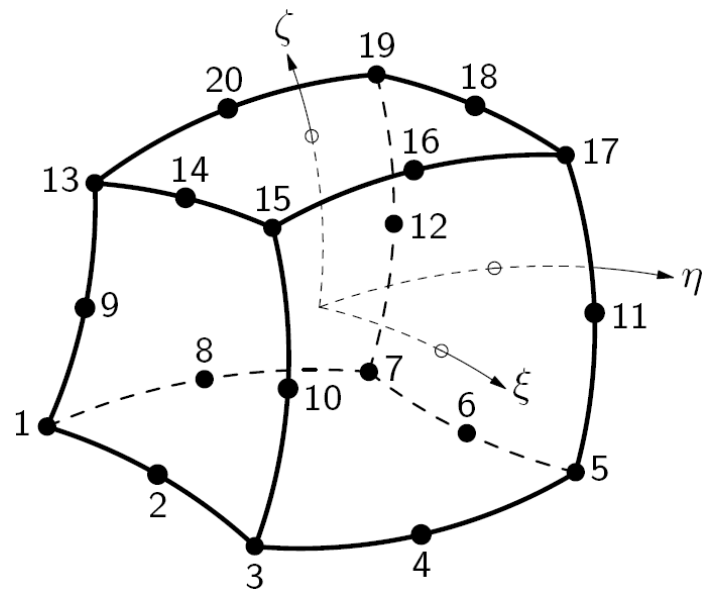

Figura 3.5 - Elemento CHX60

Fonte: DIANA (2005b) 
A formulação do elemento finito isoparamétrico CHX60 é apresentada na Expressão 3.3 .

$$
\begin{aligned}
& \mathrm{u}_{\mathrm{i}}(\xi, \eta, \zeta)=a_{0}+a_{1} \cdot \xi+a_{2} \cdot \eta+a_{3} \cdot \zeta+a_{4} \cdot \xi \cdot \eta+a_{5} \cdot \eta \cdot \\
& \zeta+a_{6} \cdot \xi \cdot \zeta+a_{7} \cdot \xi^{2}+a_{8} \cdot \eta^{2}+a_{9} \cdot \zeta^{2}+a_{10} \cdot \xi \cdot \eta \cdot \zeta+a_{11} \cdot \xi^{2} \cdot \\
& \eta+a_{12} \cdot \xi^{2} \cdot \zeta+a_{13} \cdot \xi \cdot \eta^{2}+a_{14} \cdot \xi \cdot \zeta^{2}+a_{15} \cdot \eta^{2} \cdot \zeta+a_{16} \cdot \eta \cdot \\
& \zeta^{2}+a_{17} \cdot \xi^{2} \cdot \eta \cdot \zeta+a_{18} \cdot \xi \cdot \eta^{2} \cdot \zeta+a_{19} \cdot \xi \cdot \eta \cdot \zeta^{2}
\end{aligned}
$$

Para a representação das armaduras, o DIANA dispõe de elementos chamados Embedded Reinforcement cuja finalidade é enrijecer os elementos finitos do modelo. Por meio do embutimento deste elemento na malha de elementos finitos que representam o concreto, o programa computacional simula a presença da armadura naquela específica região. Este elemento caracteriza-se por não possuir graus de liberdade próprios e, como padrão, apresenta deformações contabilizadas a partir do campo de deformações dos elementos em que se encontra inserido. Em razão destas características, ele não pode ser considerado um elemento finito.

Esta estratégia implica em uma aderência perfeita entre a armadura e o concreto, que é impróprio para a análise de alguns tipos de elementos estruturais quando se deseja avaliar o escorregamento das barras da armadura. Todavia nos modelos em que esta estratégia mostrase adequada, os Embeddeds Reinforcements favorecem a rapidez e simplificação da geração da rede de elementos finitos conferindo praticidade à criação do modelo.

Os dados de entrada para a definição destes elementos são a sua localização e as suas propriedades materiais e dimensionais. Dentre as opções disponíveis no DIANA para este tipo de armadura, em forma de barras e em forma de malha, utilizaram-se as armaduras em forma de barras. Esta técnica de embutimento de armaduras permite que as linhas que representam as armaduras desviem das linhas da malha de elementos finitos ao qual estão inseridas, permitindo que a malha seja criada sem a necessidade da antecipação da localização das barras, Figura 3.6.

Para o aço das armaduras formadas por estes elementos, foi adotado o comportamento elasto-plástico perfeito com critério de ruptura de Von Mises. 


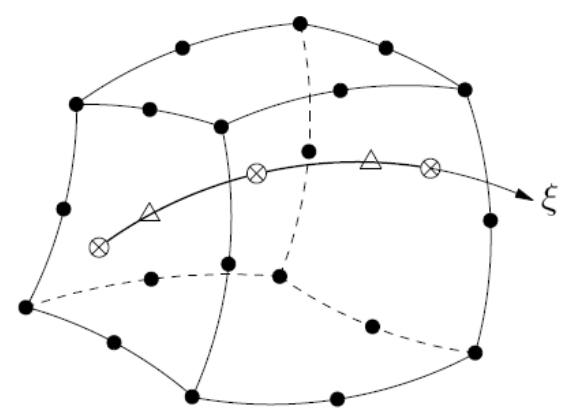

element node

$\otimes$ location point

$\triangle$ integration point

Figura 3.6 - Armadura em barra embutida em elemento sólido do tipo CHX60

Para os modelos desta pesquisa, foi necessário utilizar os elementos planos quadrilaterais de interface para que pudessem ser representadas as interfaces pilar-graute e graute-bloco da ligação. Os elementos de interface são freqüentemente aplicados na representação de fissuras discretas, na representação do escorregamento da armadura imersa no concreto, nas ligações existentes entre rochas e entre alvenarias e para representar o atrito entre duas superfícies. O programa DIANA dispõe de duas famílias de elementos de interface, os elementos de interfaces estruturais e os elementos de contato.

A primeira família de elementos de interface descreve o comportamento da interface em termos da relação entre força e deslocamentos normal e tangencial relativos à interface. Em razão da utilização de elementos CHX60 de vinte nós, o elemento de interface que possui número de nós compatíveis é o CQ48I, Figura 3.7.

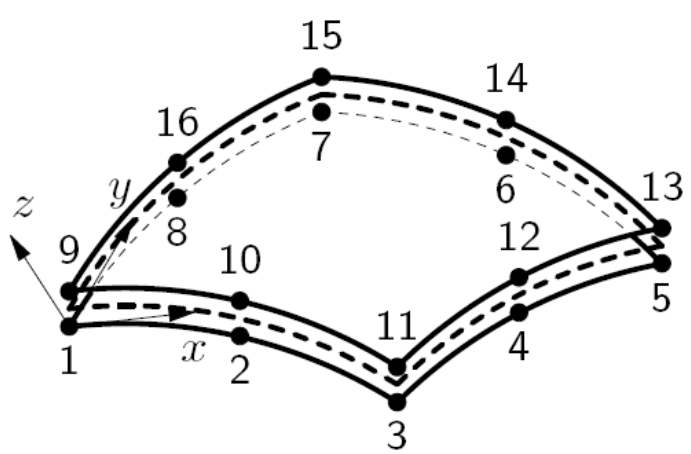

(a) topology

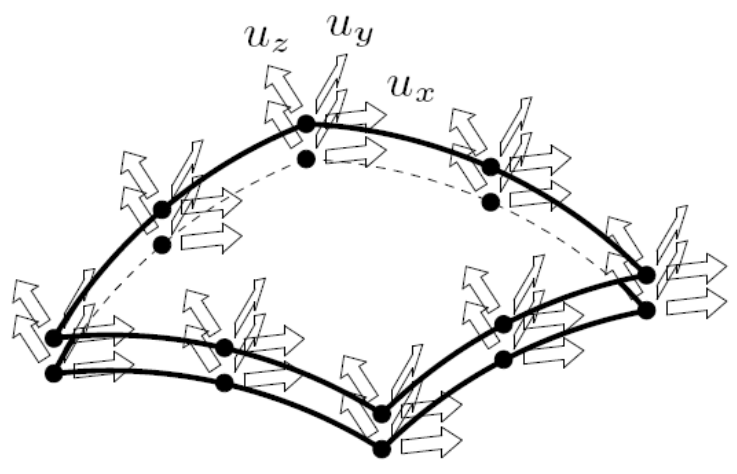

(b) displacements

Figura 3.7 - Elemento de interface plano quadrilateral CQ48I, 8+8 nós

O elemento CQ48I apresenta função quadrática para a aproximação dos deslocamentos. 
A segunda família de elementos de interface são os elementos de contato. Na análise de contato, em uma das interfaces da ligação os elementos do contato serão definidos como contacter (contato), e na outra interface os elementos serão definidos como target (alvo). Os nós do elemento definido como contacter não podem penetrar um elemento target.

Nestas análises, optou-se por modelar a ligação pilar-fundação utilizando elementos de interface CQ48I. Estes elementos já foram utilizados em análises semelhantes por Barros (2009).

\subsubsection{MÉTOdos DE SOLUÇão Do SISTEMA DE EQUAÇõES NÃO-LINEARES}

Em análises não-lineares por meio de elementos finitos, a relação entre os vetores força e deslocamento não é linear e dependerá dos deslocamentos nos estágios precedentes sendo assim, para determinar o equilíbrio do elemento estrutural, é necessário não só discretizar o problema no espaço, mas também no tempo por meio de incrementos. Para chegar ao equilíbrio em cada incremento é utilizado um algoritmo iterativo de solução de tal forma que o procedimento de solução pode ser denominado incremental-iterativo.

Os métodos iterativos disponíveis no DIANA são: rigidez constante, rigidez linear, Newton-Raphson ou tangente e Quasi-Newton ou secante.

O método de Newton-Raphson tem por base a idéia de que o resíduo seja uma função contínua nas proximidades da solução e, desse modo se for admitido que na iteração $r$ seja encontrada a solução, o valor do resíduo será nulo. O método de Newton-Raphson pode ser classificado em Regular ou Modificado.

O método iterativo de Newton-Raphson Regular atualiza a matriz de rigidez a cada iteração de tal modo que os deslocamentos são obtidos para o último estado conhecido, mesmo que esse não corresponda a um estado de equilíbrio, dessa forma conduz à convergência em poucas iterações, caso a estimativa esteja próxima da solução final, caso contrário o método pode falhar por divergência. Embora a convergência possa ocorrer em poucas iterações, a atualização da matriz de rigidez em cada iteração demandará um elevado tempo de processamento. 
O método de Newton-Raphson Modificado, segundo Proença (2007), consiste na aproximação da rigidez tangente apenas na primeira iteração de cada incremento, mantendose fixa a rigidez ao longo das iterações. Geralmente esse método apresenta uma convergência mais lenta quando comparado ao processo de Newton-Raphson Regular, em razão do elevado número de iterações necessárias para o equilíbrio, em contrapartida, para cada iteração apenas a estimativa incremental dos deslocamentos e o vetor de forças internas precisam ser calculados consumindo um menor tempo de processamento para cada iteração. Além disso, segundo TNO DIANA (2005a) em situações onde o processo iterativo anterior não converge mais é possível que o processo de Newton-Raphson Modificado ainda apresente convergência, entretanto Proença (2007) afirma que este método pode divergir em situações de não-linearidade mais pronunciada.

O método Quasi-Newton ou secante, ou ainda, direto usa as informações prévias dos vetores de solução e do vetor de forças não equilibrado durante a aplicação dos incrementos para chegar a uma melhor aproximação e, diferentemente do Método Newton-Raphson Regular, não altera completamente a matriz de rigidez do sistema a cada iteração. Segundo Proença (2007), nesse método admite-se que tenha sido determinada a solução na iteração ( $r$ 1), então se utiliza desta informação para atualizar a matriz de rigidez e determinar a nova estimativa para a solução na iteração $r$, a qual substituirá a estimativa da iteração anterior. Segundo TNO DIANA (2005a), a taxa de convergência e o tempo consumido geralmente encontram-se entre aqueles dos Métodos Newton-Raphson Regular e Modificado.

O método da Rigidez Linear utiliza a matriz de rigidez linear durante todo o processo. Esse método apresenta a convergência mais lenta, entretanto as iterações são mais rápidas uma vez que a matriz de rigidez é definida apenas uma vez.

Já o método da Rigidez Constante utiliza a matriz de rigidez do incremento anterior e pode ser utilizado quando ocorrer falha na utilização dos métodos Newton-Raphson e QuasiNewton após um número de incrementos com resultados satisfatórios. Segundo TNO DIANA (2005a), ambos os métodos da Rigidez Linear e Constante poderão ser utilizados quando os demais métodos tornarem-se instáveis.

Pode ocorrer em análises com forte não-linearidade, tais como as que consideram a fissuração, a divergência durante o processo iterativo em razão de a estimativa estar longe do equilíbrio. Para minimizar esse problema e para reduzir o tempo gasto para a convergência de cada iteração, existe no DIANA um algoritmo chamado Line Search que faz com que seja 
adotado como aproximação inicial para o incremento de deslocamento da iteração, um dos vetores deslocamentos dos algoritmos de iteração multiplicados por um valor.

Além do recurso Line Search, existe o recurso Arc Length Control, controle do comprimento de arco, cuja função é obter o comportamento pós-pico da estrutura analisada. Por meio da restrição da norma dos deslocamentos incrementais a um valor prescrito, juntamente com a adaptação do tamanho do incremento, é possível analisar o comportamento Snap-Through e Snap-Back do modelo, Figura 3.8. O comportamento Snap-Back não pode ser capturado por meio de análise efetuada com controle de deslocamentos e tanto o comportamento Snap-Back quanto Snap-Through, em análise não-linear, só podem ser obtidos adequadamente mediante o uso do Arc Length Control.

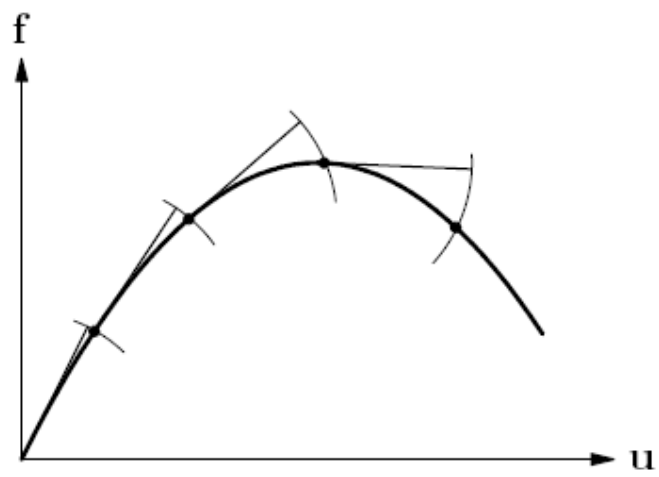

(a) Snap-through

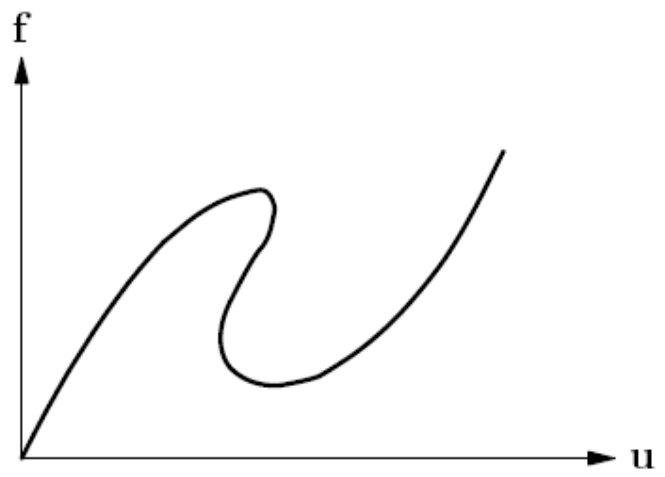

(b) Snap-back

Figura 3.8 - Comportamentos Snap-Through e Snap-Back Fonte: DIANA (2005a)

\subsection{ANÁliSE PARAMÉTRICA}

Antes de qualquer análise numérica é conveniente a realização de análise paramétrica a fim de avaliar quais as combinações de parâmetros levam os modelos numéricos a fornecer respostas mais próximas do comportamento do modelo experimental equivalente. Para esse tipo de análise é necessário contar com as respostas experimentais uma vez que, em razão da complexidade dos modelos, não existem soluções analíticas ou, mesmo quando existem, fornecem resultados com desvios consideráveis em relação aos valores observados experimentalmente. 
Levando em consideração a inexistência de pesquisas de caráter experimental envolvendo blocos com cálice embutido e apoiados sobre quatro estacas, recorreu-se à utilização de resultados de trabalhos experimentais envolvendo blocos convencionais apoiados sobre quatro estacas, ligados monoliticamente ao pilar. Essa medida é conveniente uma vez que permite validar o modelo constitutivo do concreto.

Para a análise paramétrica, optou-se por valer dos modelos ensaiados experimentalmente por Adebar et al. (1990), Suzuki et al. (1998) e Chan e Poh (2000). Dentre os blocos ensaiados por Adebar et al. (1990), optou-se por ensaiar os modelos D e E, apresentados em detalhes no Quadro 3.1 e no Quadro 3.2.

Quadro 3.1- Detalhes do modelo D ensaiado por Adebar et al. (1990)

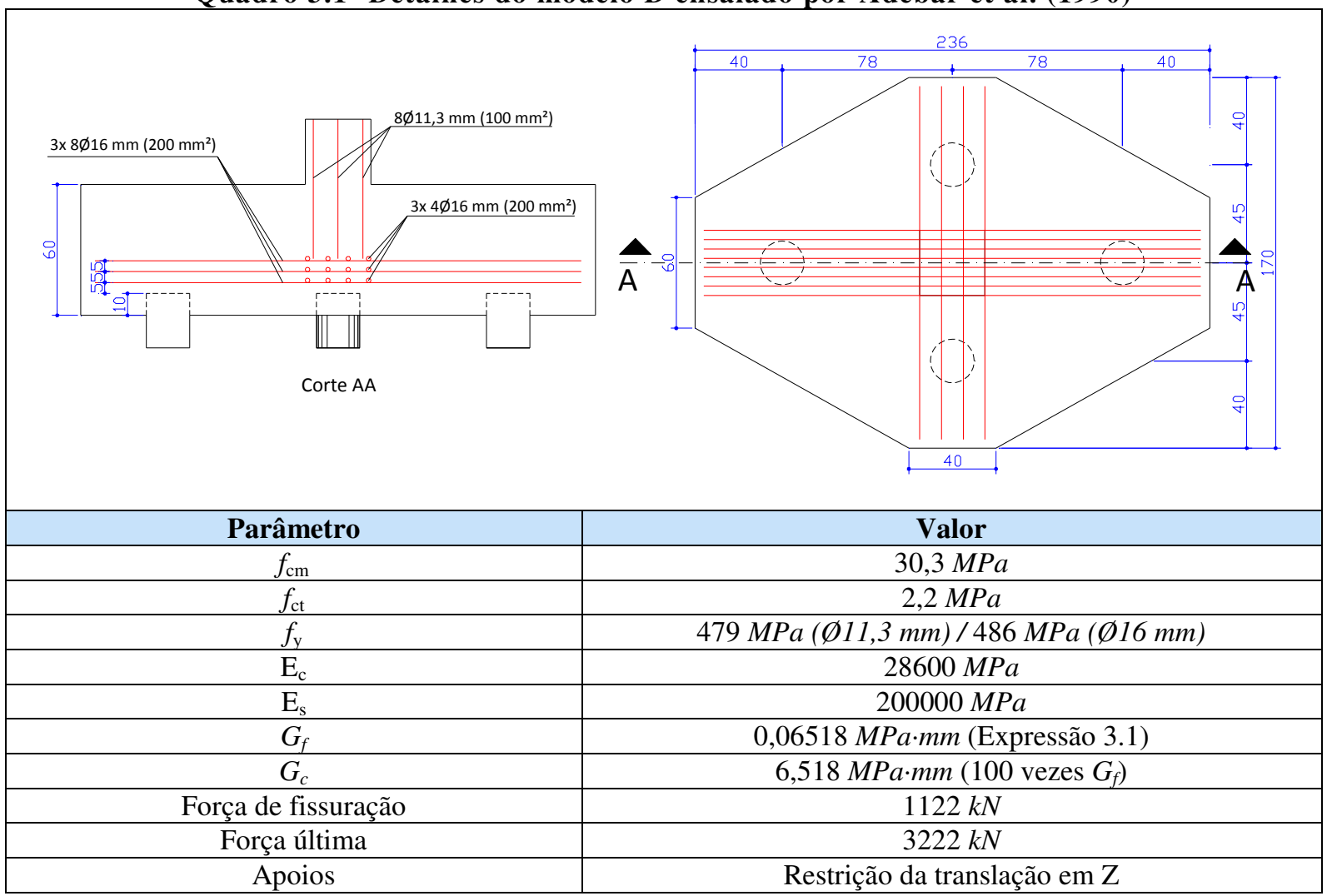


Quadro 3.2 - Detalhes do modelo E ensaiado por Adebar et al. (1990)

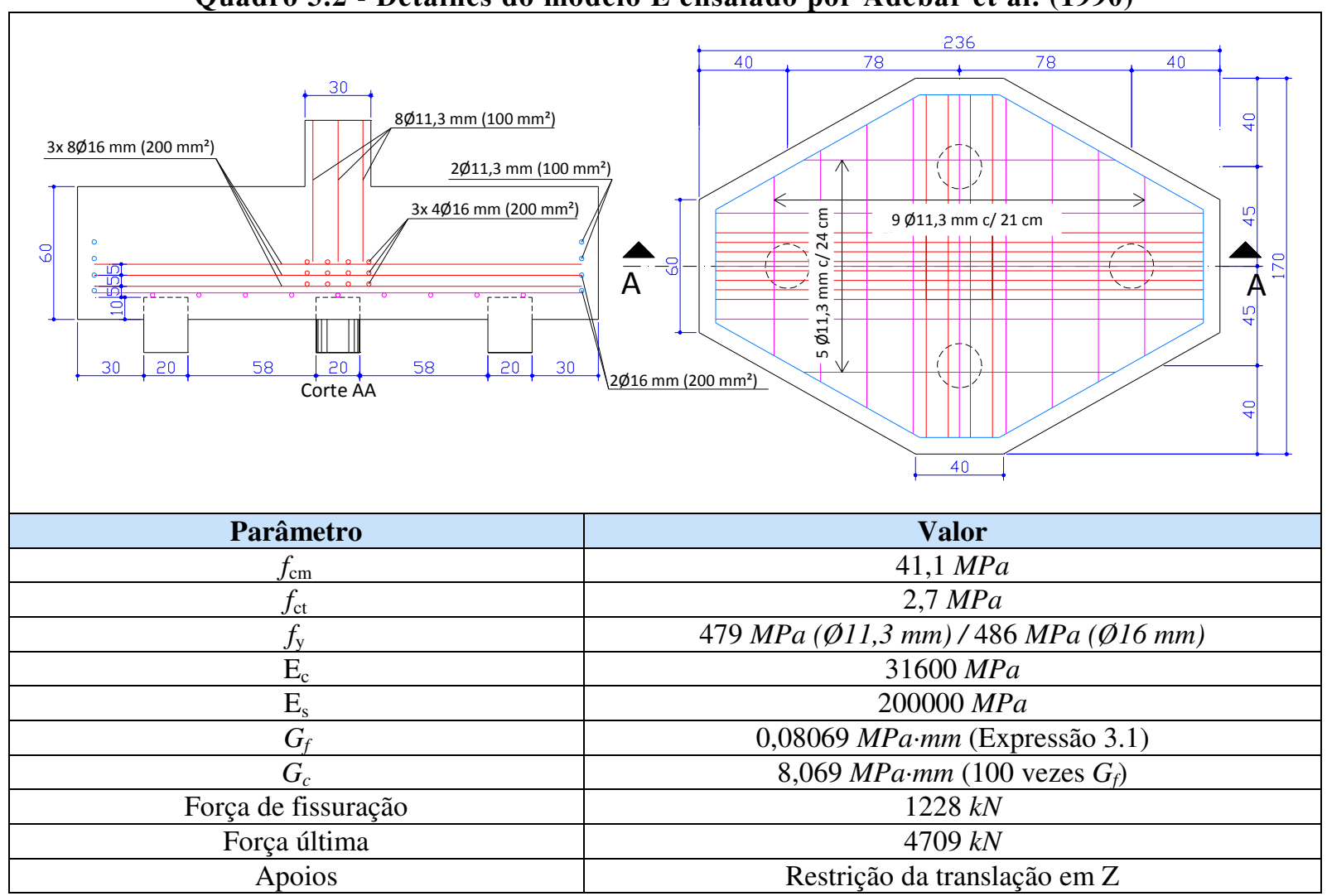

Suzuki et al. (1998) ensaiou uma série de blocos sobre quatro estacas, o modelo escolhido para ser utilizado nessa análise numérica encontra-se descrito no Quadro 3.3. 
Quadro 3.3 - Detalhes do modelo BPC-30-30-1 ensaiado por Suzuki et al. (1998)

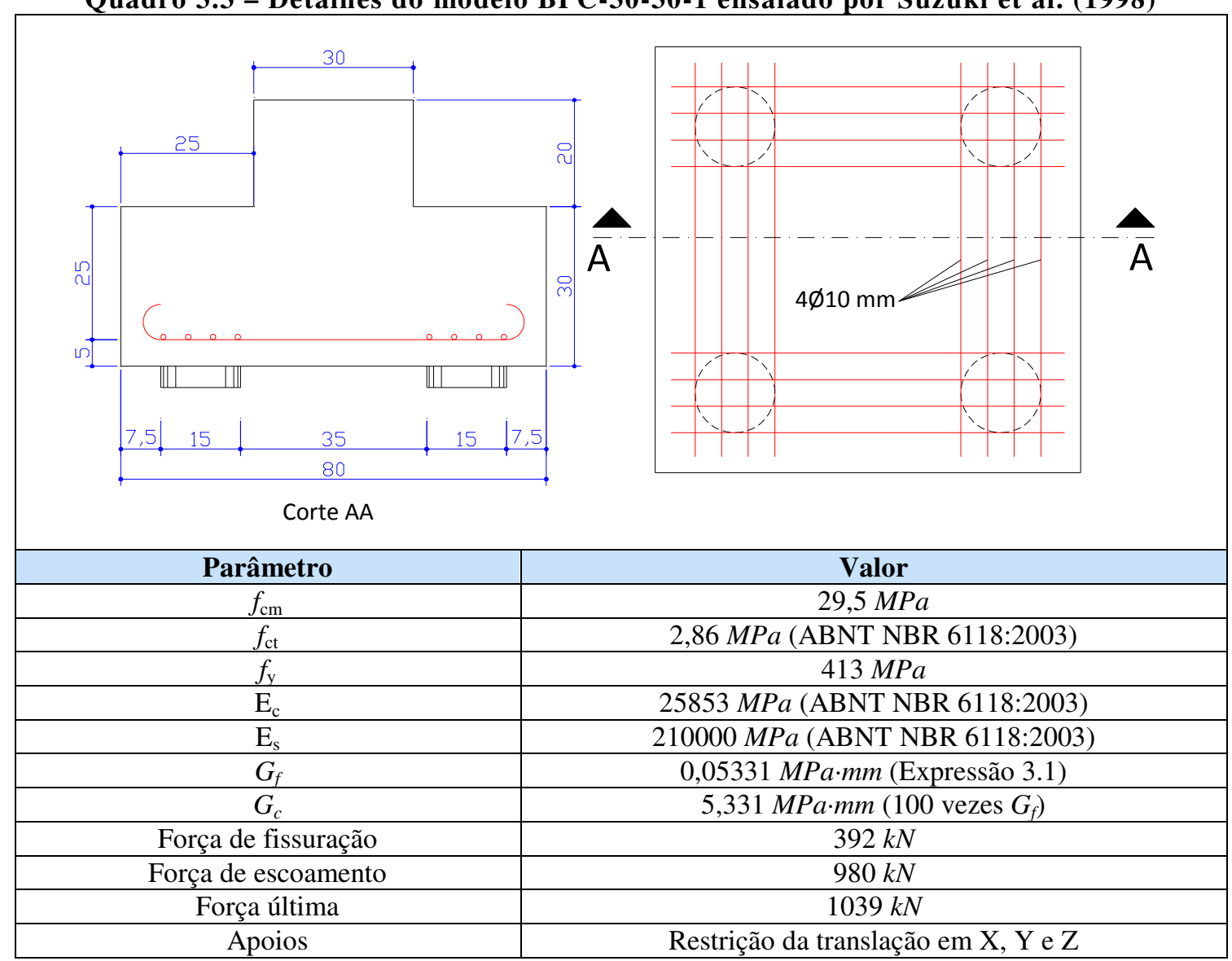

Dentre os três modelos avaliados por Chan e Poh (2000), optou-se por analisar numericamente o bloco A. As características do modelo A estão descritas no Quadro 3.4. 
Quadro 3.4 - Características do modelo A ensaiado por Chan e Poh (2000)

\begin{tabular}{|c|c|c|c|c|}
\hline \\
\hline Parâmetro
\end{tabular}

Em razão da utilização de elementos hexaédricos, a construção da malha de elementos na proximidade de estacas circulares ocasionou o surgimento de elementos irregulares, com ângulos entre as arestas excessivamente agudos ou obtusos. Poderiam ser utilizados outros elementos, entretanto optou-se pela substituição das estacas circulares por estacas de seção quadrada equivalente sem prejuízo ao comportamento do modelo.

Nas análises que seguem, foram variados os parâmetros que definem os modelos constitutivos do concreto, o modo de aplicação da força, os critérios de convergência e o método iterativo.

Considerando que a combinação das alternativas de diferentes parâmetros resulta em um número elevado de análises, foi tomada a decisão de adotar um modelo com combinações de parâmetros padrão e analisar o efeito da variação de cada parâmetro isoladamente. Este procedimento reduziu o tempo de processamento computacional e o tempo dispensado nesta etapa da pesquisa. $\mathrm{O}$ modelo padrão adotado e as variações analisadas encontram-se descritas no Quadro 3.5. 
Quadro 3.5 - Fatores avaliados na análise paramétrica

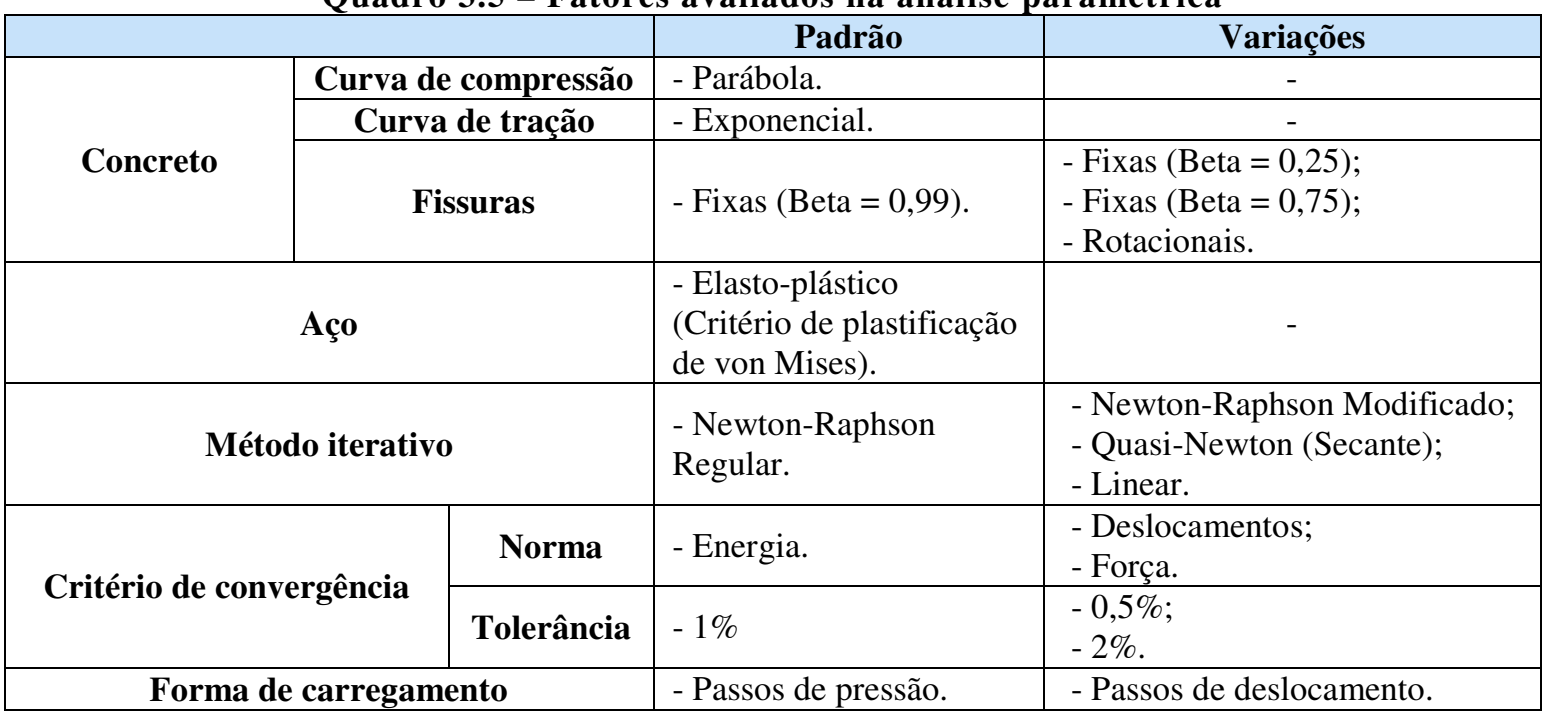

Para o comportamento do concreto tracionado admitiu-se que a relação tensãodeformação fosse descrita pela curva de amolecimento de característica exponencial, apresentada na Figura 3.1 - (e). Visando encontrar o melhor modelo para o comportamento do concreto dos blocos estudados, foram avaliados os seguintes modelos para o comportamento do concreto comprimido: relação tensão-deformação descrita por curva parabólica e o modelo descrito em Maekawa Modificado. Entretanto os resultados obtidos com o modelo Maekawa Modificado foram insatisfatórios no trecho não-linear das curvas que relacionam força e deslocamentos para os blocos analisados, então foram descartados.

Quanto à influência lateral de confinamento e fissuração, Barros (2009) observou que quando ativado o efeito de confinamento, conforme o modelo de Selby e Vecchio, os valores de força última foram muito superiores aos experimentais, esse efeito também foi observado em algumas das análises preliminares realizadas nesta pesquisa. Desse modo, considerou-se apenas a redução da resistência em razão da fissuração, dada pelo modelo de Collins e Vecchio. Não se considerou o efeito de confinamento dado por Selby e Vecchio. A ativação destes modelos de influência lateral só pode ser feita diretamente no arquivo de extensão DAT que contem as características geométricas, físicas e condições de contorno do modelo gerado pelo pré-processador.

Antes de proceder com a variação dos parâmetros dos modelos constitutivos e demais parâmetros de análise foram realizados testes de malha para o bloco $D$ de Adebar et al. (1990) com a finalidade de determinar o refinamento mais adequado da malha. As malhas estudadas estão ilustradas na Figura 3.9. 


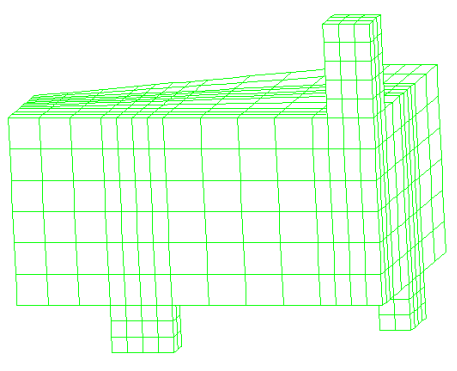

(a)

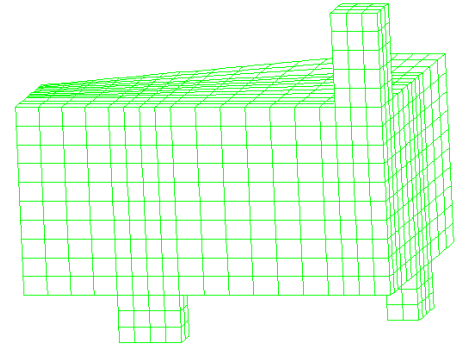

(b)

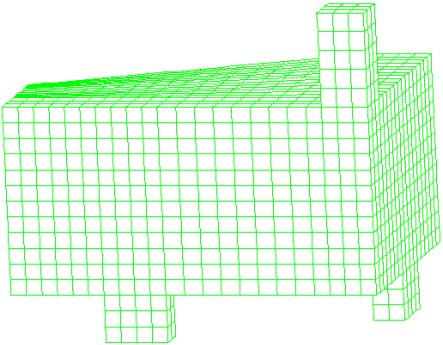

(c)

Figura 3.9 - Três malhas de elementos finitos analisadas

A Tabela 3.2 ilustra os resultados obtidos para as três diferentes malhas utilizando a configuração padrão para os parâmetros e métodos de análise.

Tabela 3.2 - Resultados obtidos para três malhas diferentes

\begin{tabular}{cccccc}
\hline Malha & $\begin{array}{c}\text { Número de } \\
\text { nós }\end{array}$ & $\begin{array}{c}\text { Força última } \\
(\mathbf{k N})\end{array}$ & $\begin{array}{c}\text { Deslocamento } \\
(\mathbf{m m})\end{array}$ & $\mathbf{F}_{\text {últ,num }} / \mathbf{F}_{\text {últ,exp }}$ & $\begin{array}{c}\text { Tempo de processamento } \\
(\mathbf{m i n})\end{array}$ \\
\hline $\mathrm{a}$ & 6316 & 2994,3 & 1,14 & 0,93 & 103 \\
\hline $\mathrm{b}$ & 12403 & 3109,5 & 1,22 & 0,97 & 363 \\
\hline $\mathrm{c}$ & 21909 & 3136,5 & 1,16 & 0,97 & 1663 \\
\hline
\end{tabular}

Este teste foi realizado em um modelo considerando a simetria, entretanto a determinação da superfície de simetria conforme indica o manual do DIANA pode provocar problemas. O DIANA tenta restringir a translação na direção da simetria e a rotação em torno das duas outras direções, no entanto alguns elementos não possuem graus de liberdade de rotação originando uma série de avisos que atrapalham o desenvolvimento da análise. Para contornar este problema, a simetria foi estabelecida pela imposição adequada das restrições dos deslocamentos nas superfícies de simetria, conforme procedimento adotado para a definição dos apoios. Considerando que os blocos analisados possuem simetria em duas direções, optou-se por modelar apenas um quarto do bloco obtendo em contrapartida, um menor custo computacional.

Os resultados da verificação da malha fundamentaram a decisão pelo uso de malhas similares à "b" nos demais modelos. Esta malha corresponde a elementos finitos cujas distâncias entre nós são de aproximadamente quarenta milímetros.

Quanto aos modelos que representam a fissuração, foram avaliados os diferentes tipos de modelo "Total Strain". Os modelos "Total Strain" foram variados entre fissuras fixas e rotacionais sendo que, para os modelos de fissuras fixas, o fator de retenção ao cisalhamento, $\beta$, foi considerado constante durante as análises. Nestas análises avaliaram-se três valores de $\beta: 0,99,0,75$ e 0,25 . 
A Figura 3.10 apresenta as curvas que relacionam força aplicada e deslocamento para os blocos analisados considerando cada um dos modelos de fissuração.
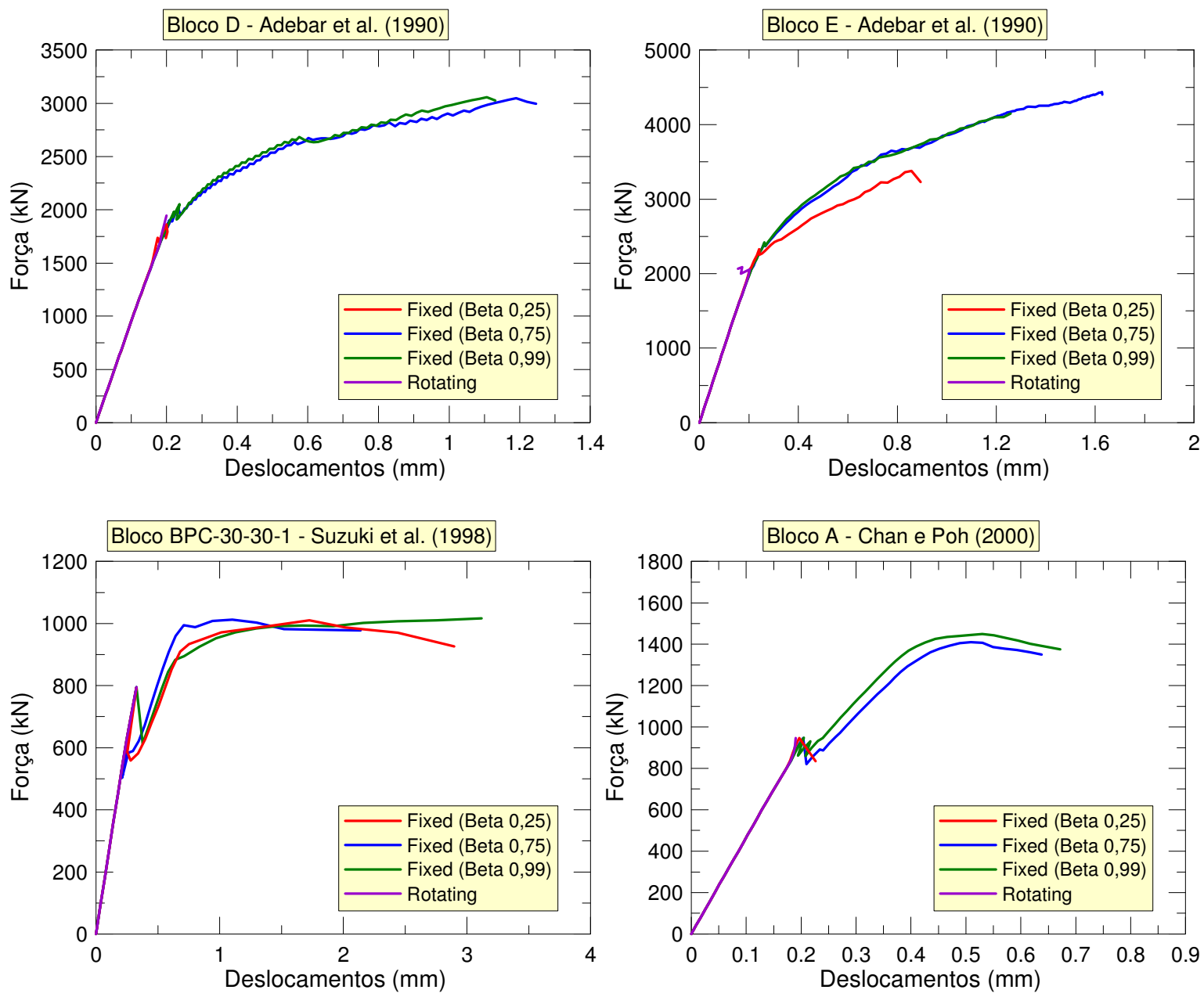

Figura 3.10 - Curvas Força x Deslocamentos dos blocos para diferentes modelos de fissuras distribuídas

Em todos os blocos, o modelo de fissuras rotacionais não permitiu a observação do comportamento do bloco no regime não-linear sendo a análise interrompida após o aumento da fissuração. Este comportamento pode ser atribuído ao fato de que neste modelo, após a fissuração, a transmissão dos esforços pelas fissuras fica impossibilitada e não é mais encontrado o equilíbrio do sistema de equações. Exceto o bloco BPC 30-30-1, os demais que utilizaram modelos de fissuras fixas com fator de retenção ao cisalhamento de 0,25 não conseguiram ultrapassar o regime elástico linear satisfatoriamente sendo a ruína do bloco prematura. Estes comportamentos relacionados aos modelos de fissuras corroboram as observações de Barros (2009) em blocos sobre duas estacas, e contrasta com os resultados relatados em Souza (2004) que obteve comportamentos semelhantes entre os modelos de fissuras fixas e rotacionais em blocos sobre duas e quatro estacas. O comportamento 
observado já era esperado, pois a própria descrição do modelo de fissuras rotacionais indica que são obtidos valores inferiores de força última em relação aos modelos de fissuras fixas.

Depois de analisados os modelos de fissuração do concreto, foram analisados os critérios de convergência em energia, deslocamentos e força, variando-se também a tolerância para a norma da variação das mesmas. Nesse caso foram avaliados apenas o Bloco $D$ de Adebar et al. (1990) e o Bloco BPC-30-30-1 de Suzuki et al. (1998), Figura 3.11.
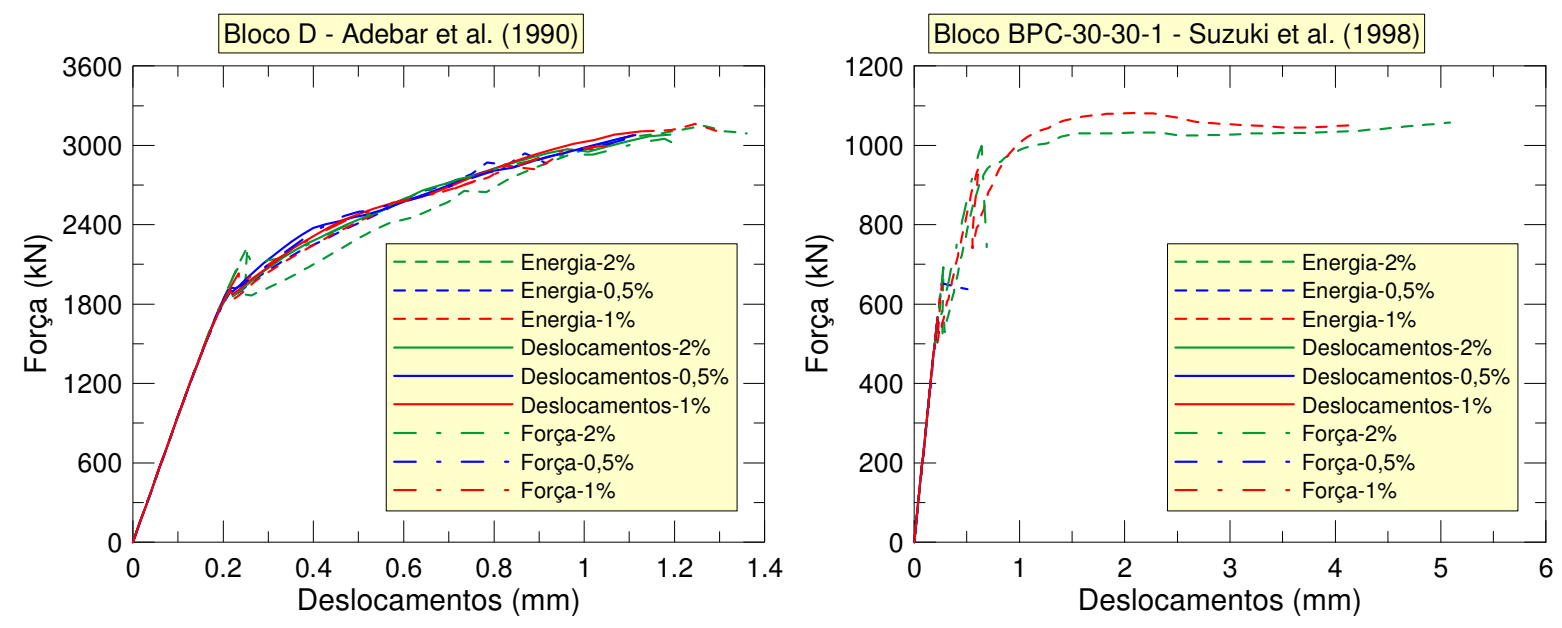

Figura 3.11 - Curvas Força x Deslocamentos dos blocos obtidas utilizando diferentes critérios de convergência

As curvas obtidas utilizando os critérios de energia apresentaram oscilação no trecho não-linear enquanto as curvas obtidas utilizando critérios de convergência em forças e em deslocamentos foram mais suaves. Para o bloco D de Adebar et al. (1990) as curvas apresentaram comportamento equivalente para todos tipos de critérios, entretanto no bloco BPC-30-30-1 de Suzuki et al. (1998) apenas se obteve comportamento próximo ao experimental quando utilizado critério de convergência em energia. Quanto aos valores das tolerâncias, foi observado que não influenciou significativamente nos resultados apresentados, entretanto, quando utilizados critérios com $0,5 \%$ de tolerância, houve acréscimo do número de iterações necessárias em cada passo e, conseqüentemente, o tempo de processamento.

Depois de analisados os critérios de convergência, foram estudados a forma de carregamento dos modelos: por imposição de deslocamentos e por aplicação de pressão, Figura 3.12. 

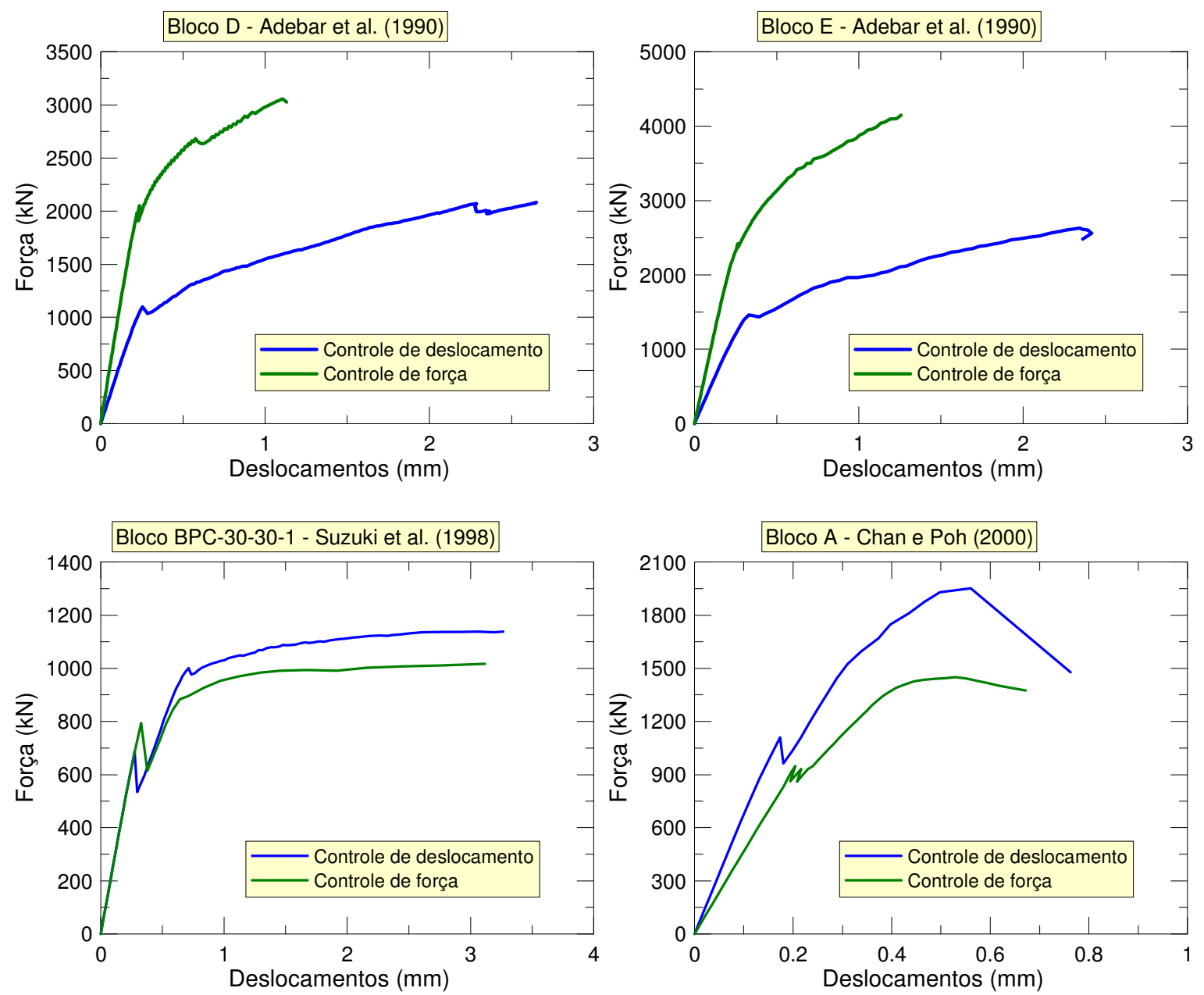

Figura 3.12 - Curvas Força x Deslocamentos dos blocos obtidas variando a estratégia de controle do carregamento

As análises conduzidas com controle de incrementos de força resultaram mais próximas das observadas nos ensaios experimentais principalmente em termos de força máxima resistente. Embora os resultados não tenham sido satisfatórios com o controle de deslocamentos, não prevaleceu um comportamento para todos os modelos. Observa-se que para os blocos de Adebar et al. (1990) o comportamento caracterizou-se pelo maior amolecimento enquanto para os outros dois blocos o comportamento foi mais rígido.

Em seguida a Figura 3.13 ilustra os resultados das análises utilizando os seguintes métodos de resolução dos sistemas de equações não-lineares: rigidez linear, secante, NewtonRaphson Regular e Newton-Raphson Modificado. Os métodos da rigidez linear, secante e Newton-Raphson Modificado forneceram respostas muito aquém da força última sendo que os resultados para todos os métodos foram semelhantes quando os blocos se encontravam em regime elástico-linear, mas apenas o método Newton-Raphson Regular foi capaz de representar satisfatoriamente o comportamento não-linear. 

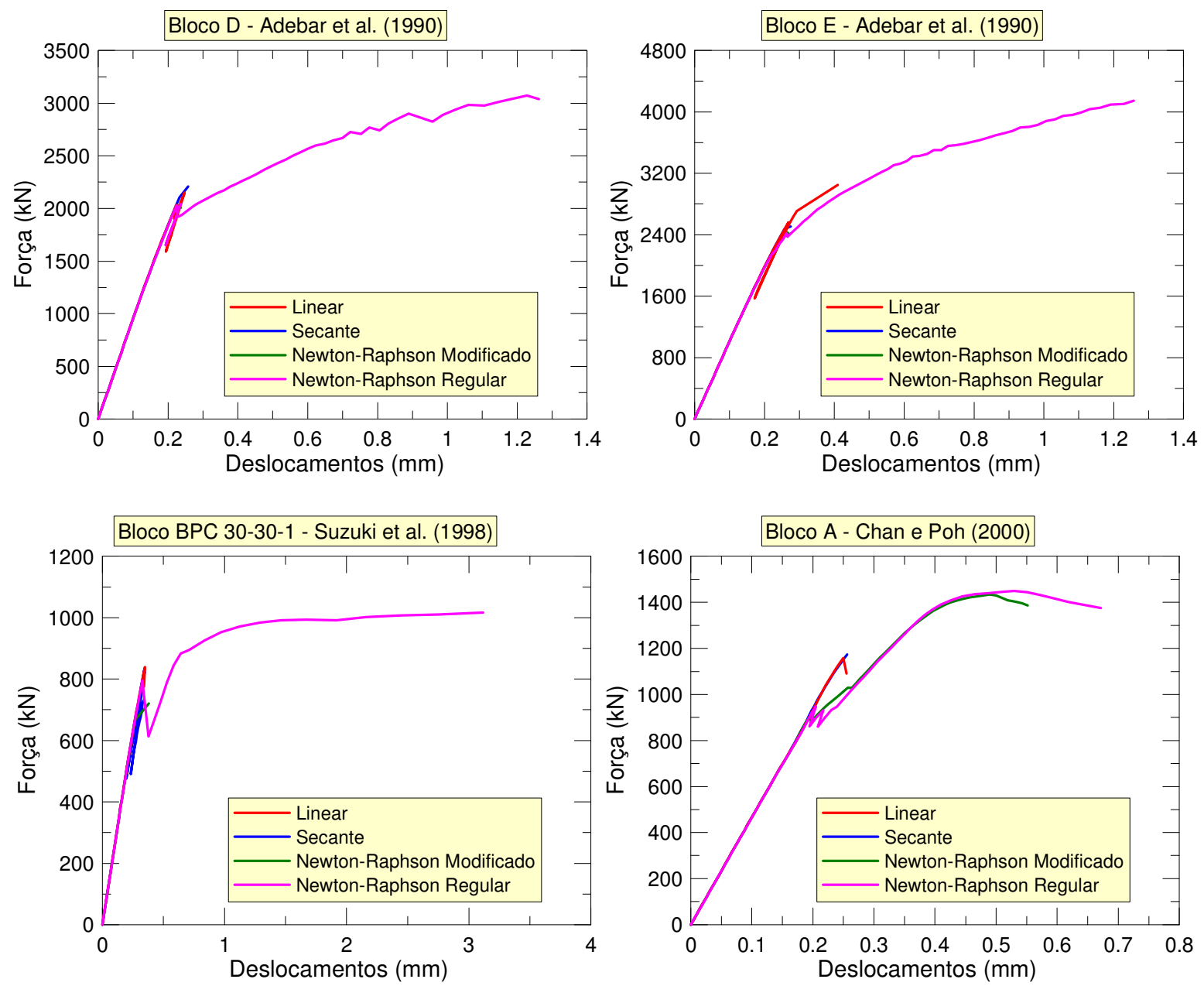

Figura 3.13 - Curvas Força x Deslocamentos dos blocos obtidas para diferentes métodos iterativos

Pode-se atribuir o comportamento mais satisfatório do método Newton-Raphson Regular ao fato deste atualizar a matriz de rigidez a cada iteração, fazendo com que as iterações consumam um maior tempo, mas apresentem convergência em um número menor de iterações. Em razão de terem sido permitidas no máximo cinqüienta iterações para cada passo, é provável que se obtenha convergência em mais passos nos demais métodos se for permitido um número maior de iterações. Para checar esta hipótese, foram feitos mais duas análises nos blocos $D$ e $E$ de Adebar et al. (1990) utilizando um número máximo de cem iterações, Figura 3.14 . 

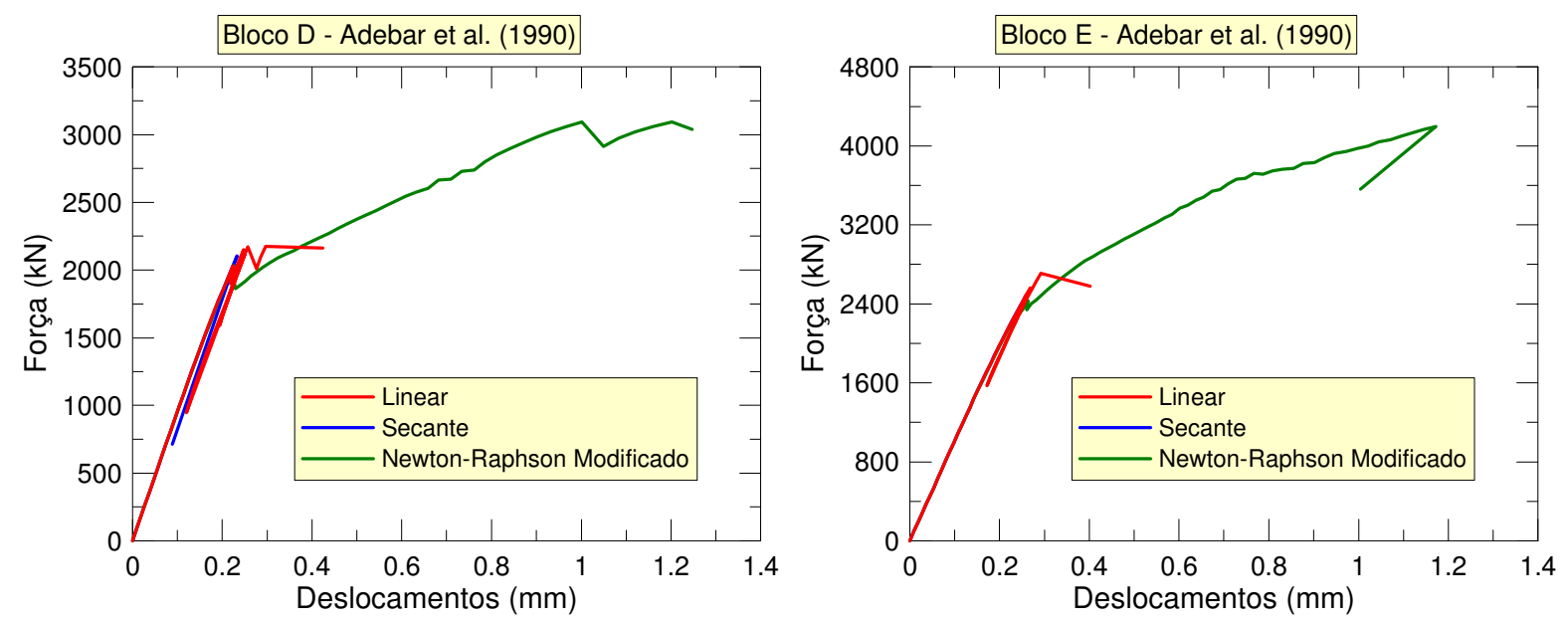

Figura 3.14 - Curvas Força x Deslocamentos dos blocos obtidas para diferentes métodos iterativos com número máximo de cem iterações por passo

A partir das curvas da Figura 3.14 é possível observar que, após o aumento do número máximo de iterações, foi obtida a convergência em um número maior de passos no método Newton-Raphson Modificado. Os métodos de rigidez linear e secante continuam apresentando a mesma resposta, portanto pode ser que os incrementos de carga precisem ser diminuídos. As melhores respostas continuam sendo as obtidas mediante o uso do método Newton-Raphson Regular, assim como observou Barros (2009) em blocos sobre duas estacas.

A fim de esclarecer a influência do número de incrementos de força, foi realizado um teste em um dos modelos variando o número de passos de carga. Os resultados ilustrados na Figura 3.15 indicam que pode haver influência significativa nos resultados quando se varia o número de incrementos de força, principalmente quando se busca representar o comportamento do modelo no regime não-linear. 


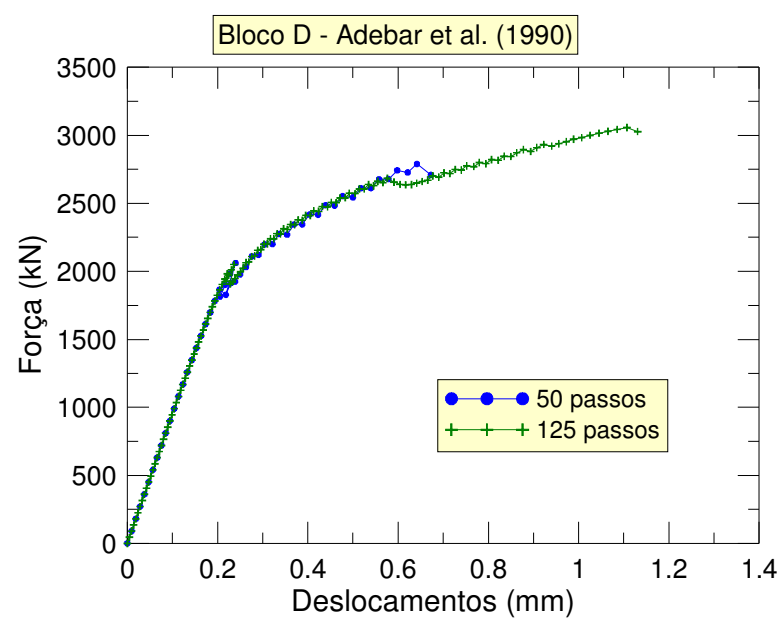

Figura 3.15 - Curva Força x Deslocamentos obtidas variando o numero de incrementos de força

A partir dos resultados obtidos nas análises das variáveis citadas no Quadro 3.5 decidiu-se que as análises numéricas propostas nesta pesquisa fossem conduzidas mediante utilização do método iterativo de Newton-Raphson Regular, pois utilizando este método todas as análises avançaram mais que quando utilizando os demais métodos disponíveis no DIANA.

Optou-se por solicitar o bloco mediante a aplicação de incrementos de força no pilar, avaliando a convergência por meio do cálculo da norma da variação de energia com tolerância de $1 \%$. Para o concreto adotou-se, o modelo constitutivo de fissuras fixas e $\beta$ de 0,99 com comportamento na compressão descrita por curva tensão-deformação parabólica e curva de amolecimento exponencial na tração.

\subsection{RESULTADOS DAS ANÁliSES}

Ao realizar as análises utilizando os parâmetros definidos no item 3.3, chegaram-se aos resultados em termos de força última, tensões principais no bloco, tensão e deformação nas armaduras e panoramas de fissuração para os quatro blocos estudados na análise paramétrica. 


\subsubsection{Bloco D DE AdEBAR et al. (1990)}

O bloco D de Adebar et al. (1990) apresentou força última experimental de $3222 \mathrm{kN}$, enquanto nesta análise numérica a força última foi de 3138,3 $\mathrm{kN}$. As primeiras fissuras surgiram na porção central da face inferior do bloco e se estenderam pelo vão entre as estacas até atingirem as faces laterais, da mesma forma como relataram os pesquisadores. As primeiras fissuras surgiram para uma força de $990 \mathrm{kN}$ enquanto no ensaio experimental os pesquisadores observaram as primeiras fissuras para uma força de $1122 \mathrm{kN}$. Como a observação das fissuras a olho nu possui limitações, acredita-se que a resposta numérica foi adequada à experimental. O panorama de fissuração é ilustrado na Figura 3.16.

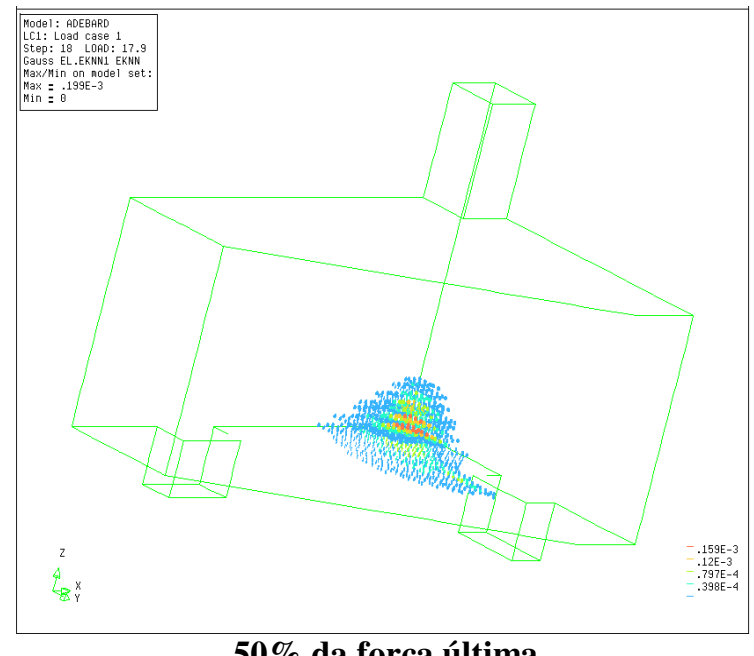

$50 \%$ da força última

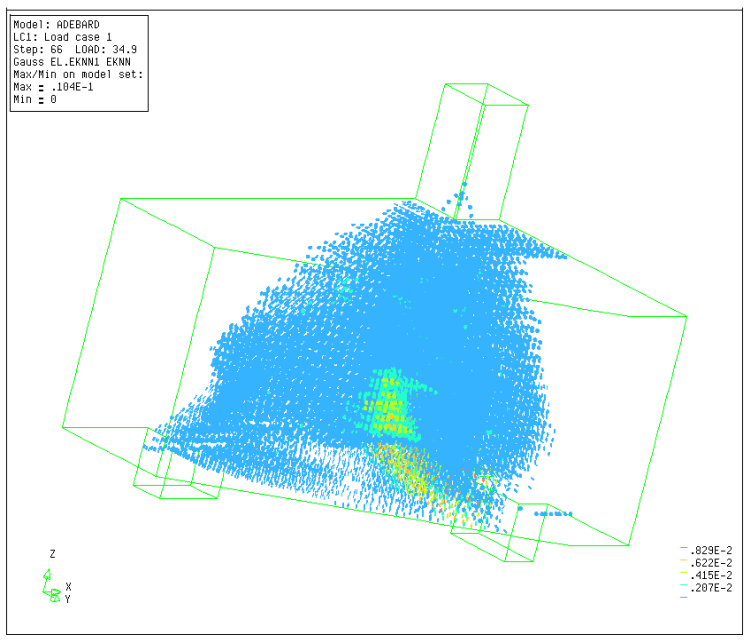

$100 \%$ da força última

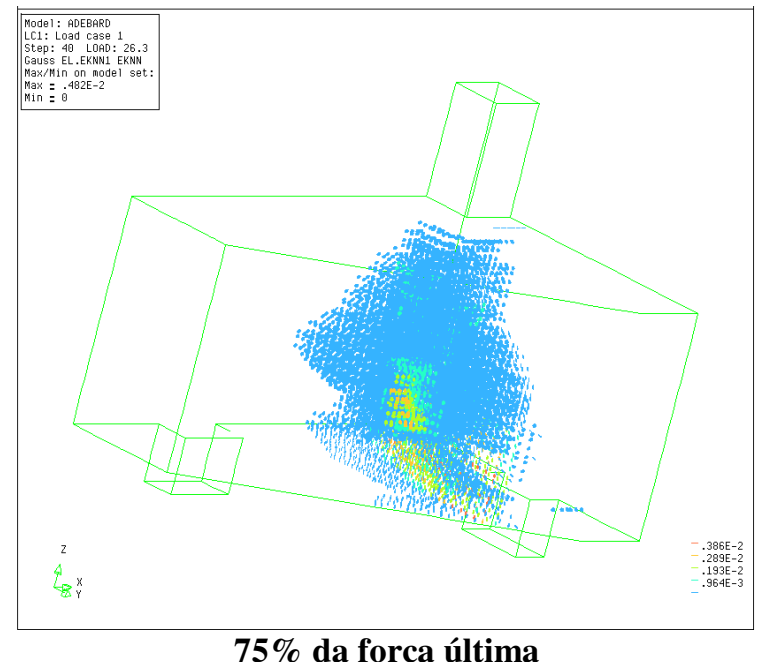

$\mathbf{7 5 \%}$ da força última

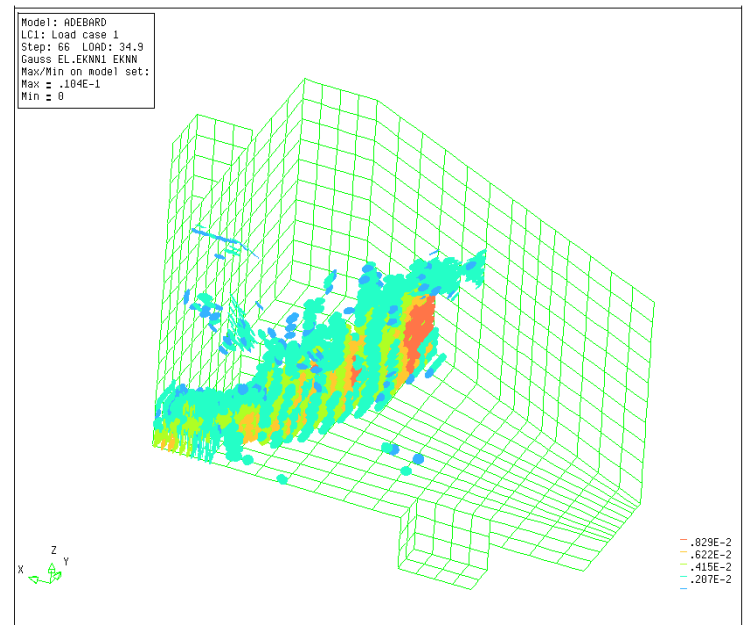

Fissuras na superfície inferior na ruína

Figura 3.16 - Panorama de fissuração do bloco D de Adebar et al. (1990)

A Figura 3.17 e a Figura 3.18 indicam a formação de bielas comprimidas e que a maior parcela dos esforços solicitantes provenientes do pilar dirigem-se para a estaca cujo 
eixo encontra-se a menor distância do eixo do pilar. Esse fato também foi observado durante os ensaios. Ao surgirem tensões de compressão, cujo fluxo indica a formação de uma biela, apareceram também tensões transversais de tração conforme ilustram as figuras das tensões principais de tração.

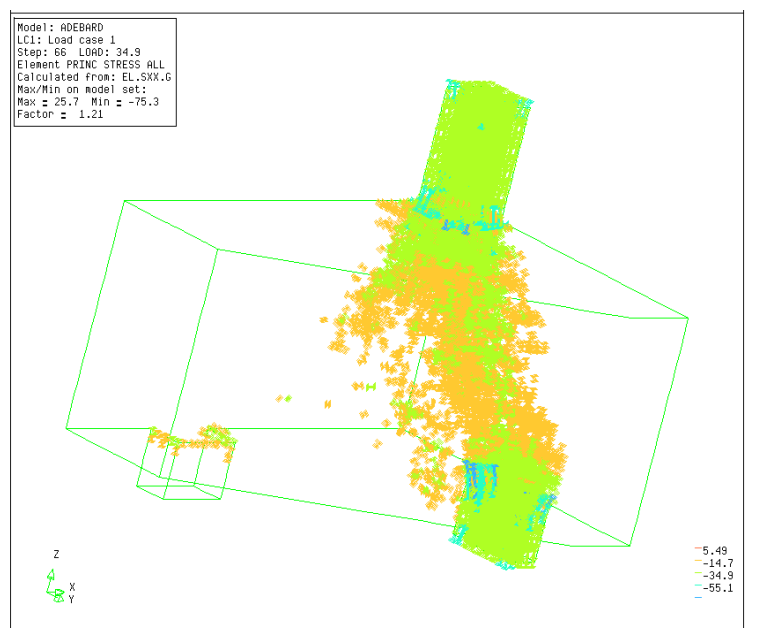

Tensões principais de compressão

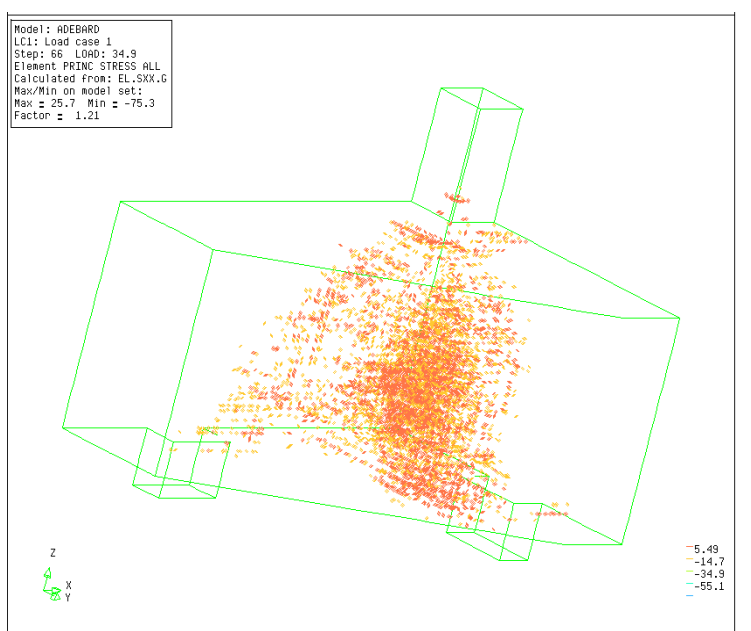

Tensões principais de tração

Figura 3.17 - Tensões principais no bloco D de Adebar et al. (1990)

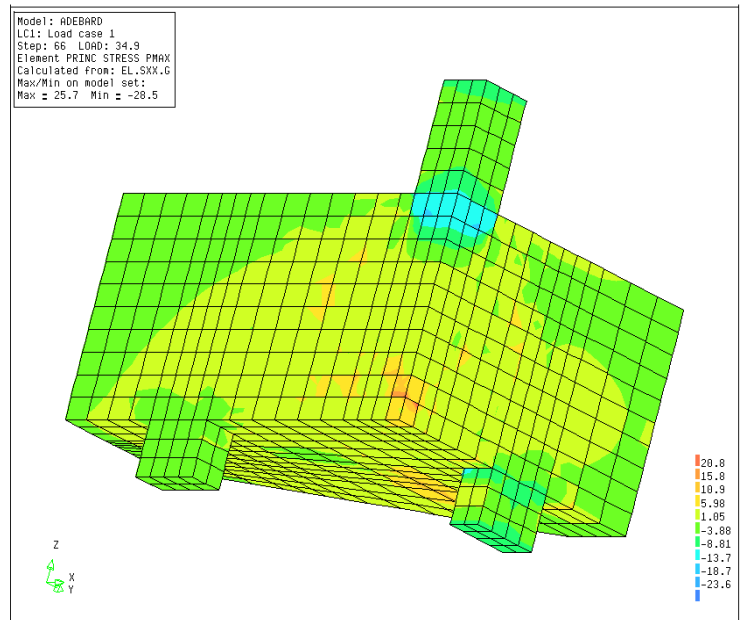

Tensões principais máximas

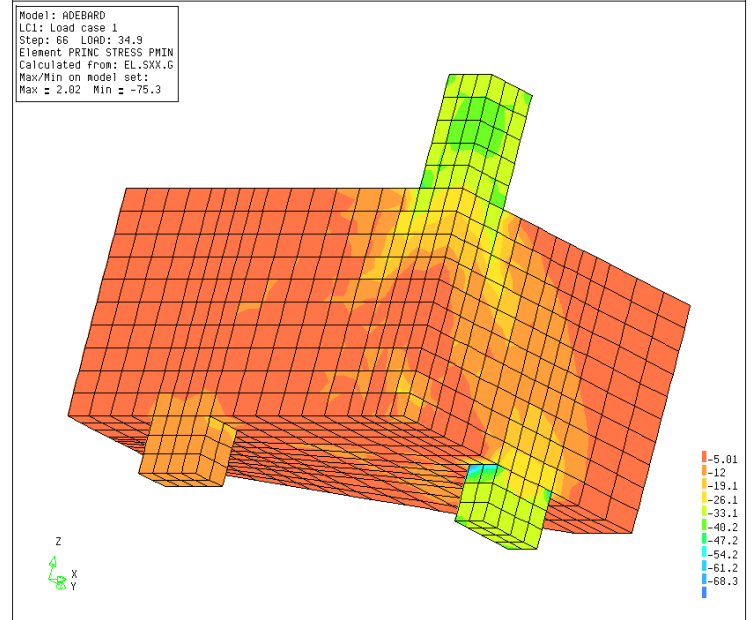

Tensões principais mínimas

Figura 3.18 - Tensões principais máximas e mínimas no bloco D de Adebar et al. (1990)

Para a força última, a deformação máxima das armaduras localizadas entre as duas estacas mais próximas foi de $1,1 \mathrm{~mm} / \mathrm{m}$ enquanto no ensaio foi registrada $1,9 \mathrm{~mm} / \mathrm{m}$. Já para as armaduras localizadas entre as duas estacas mais afastadas, a deformação máxima da armadura foi de $0,9 \mathrm{~mm} / \mathrm{m}$ enquanto no ensaio foi registrada $1,3 \mathrm{~mm} / \mathrm{m}$. A Figura 3.19 ilustra a distribuição de deformações ao longo das barras da armadura do bloco. 


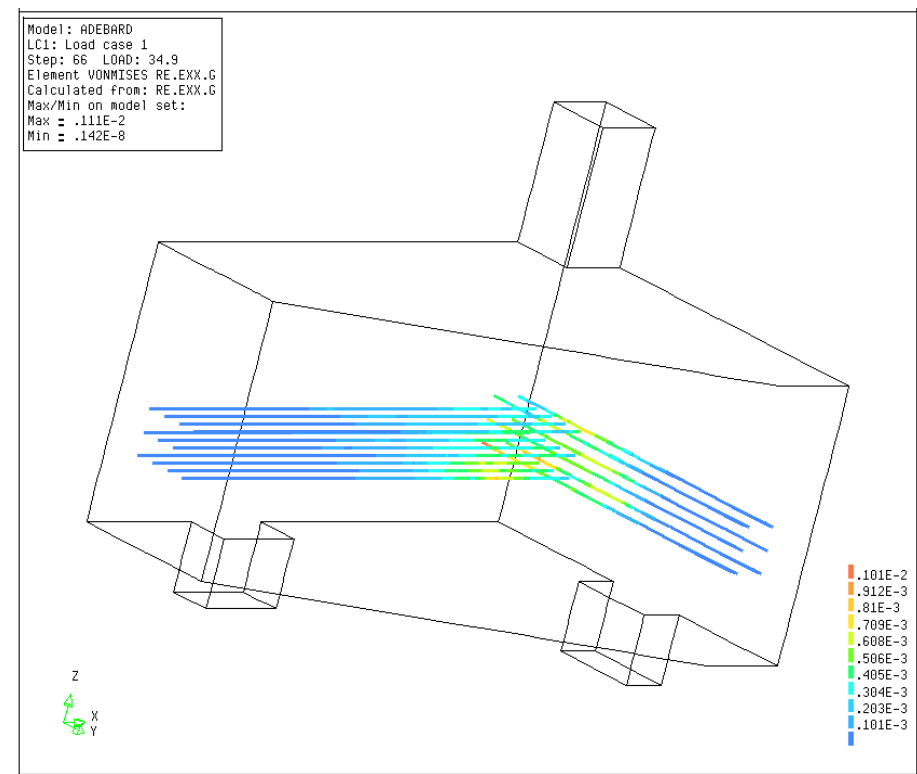

Figura 3.19 - Deformações nas barras da armadura principal do bloco D de Adebar et al. (1990)

A curva que relaciona a força aplicada no pilar com o deslocamento na face inferior do bloco está ilustrada na Figura 3.20. Nota-se o comportamento mais rígido do modelo numérico com amolecimento menos acentuado que o modelo experimental.

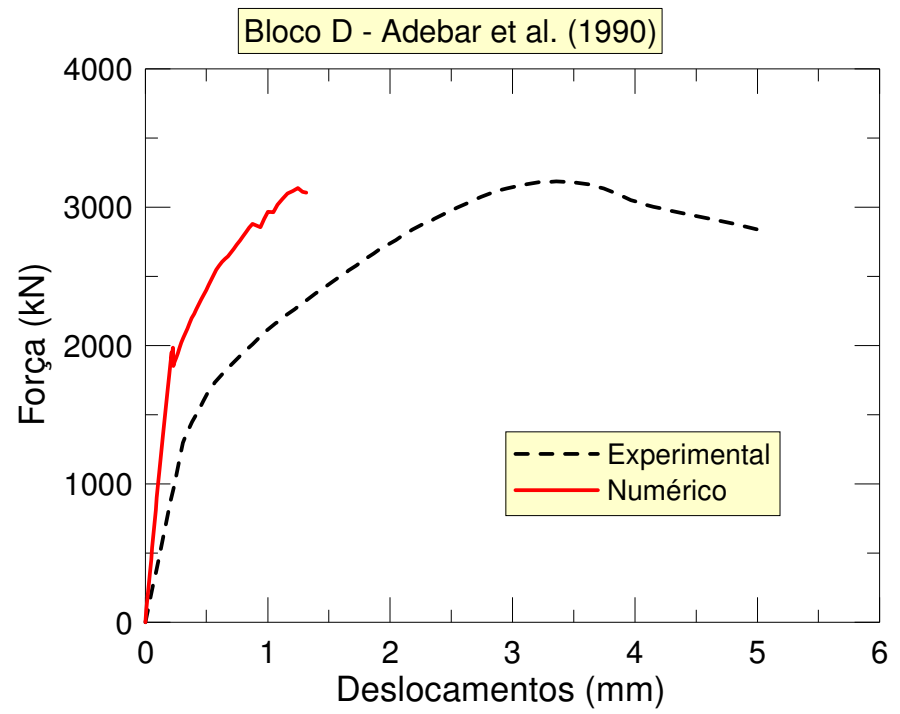

Figura 3.20 - Curvas força-deslocamento numérica e experimental do bloco D de Adebar et al. (1990) 


\subsubsection{Bloco E DE AdEBAR et al. (1990)}

O bloco E de Adebar et al. (1990) apresentou força última experimental de $4709 \mathrm{kN}$, enquanto a força última numérica foi de $4248 \mathrm{kN}$. As primeiras fissuras surgiram na porção central da face inferior do bloco e se estenderam pelo vão entre as estacas até atingirem as faces laterais, da mesma forma como relataram os pesquisadores. As primeiras fissuras surgiram para uma força de $1350 \mathrm{kN}$ enquanto no ensaio experimental os pesquisadores observaram as primeiras fissuras para uma força de $1228 \mathrm{kN}$. O panorama de fissuração é ilustrado na Figura 3.21 e pode ser comparado na Figura $3.22 \mathrm{com}$ um dos modelos experimentais que apresentou fissuras de mesmo aspecto.

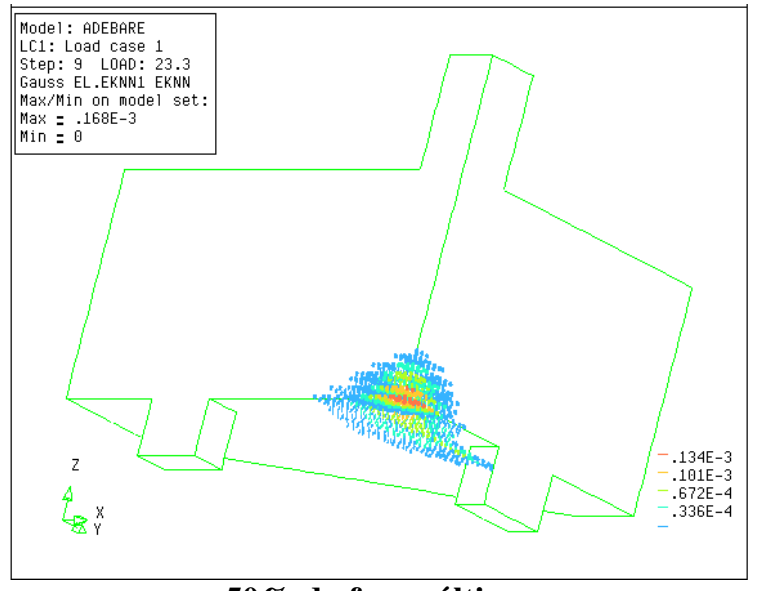

$50 \%$ da força última

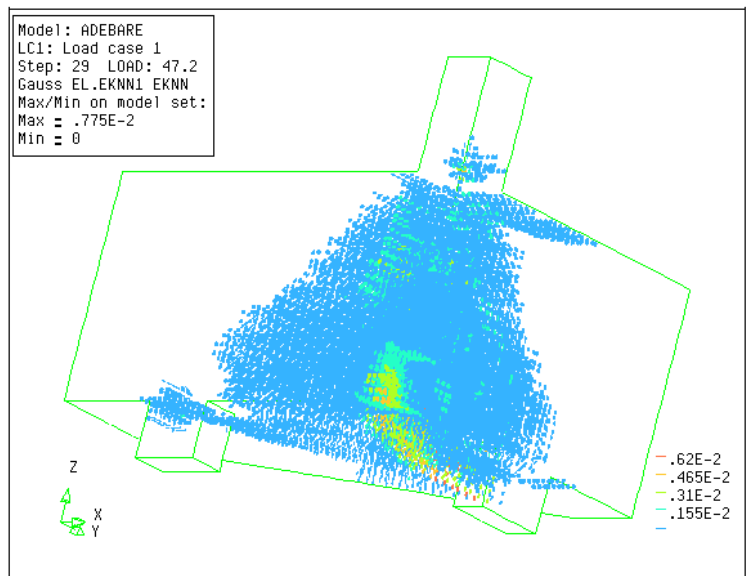

$100 \%$ da força última

Figura 3.21 - Panorama de fissuração do bloco E de Adebar et al. (1990)

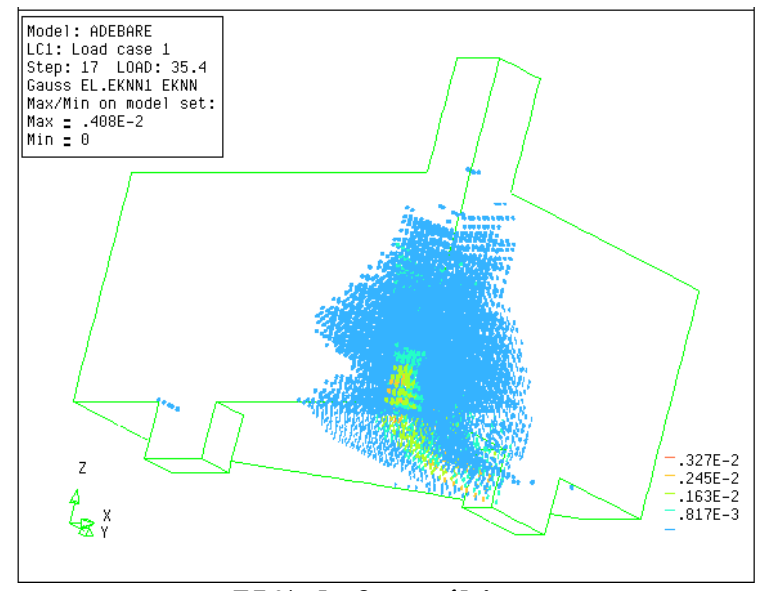

$75 \%$ da força última

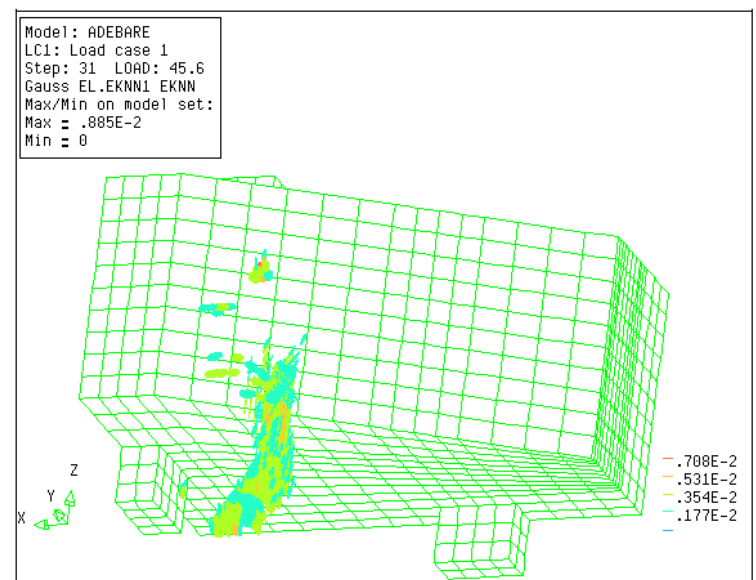

Fissuras na face inferior e lateral na ruína 


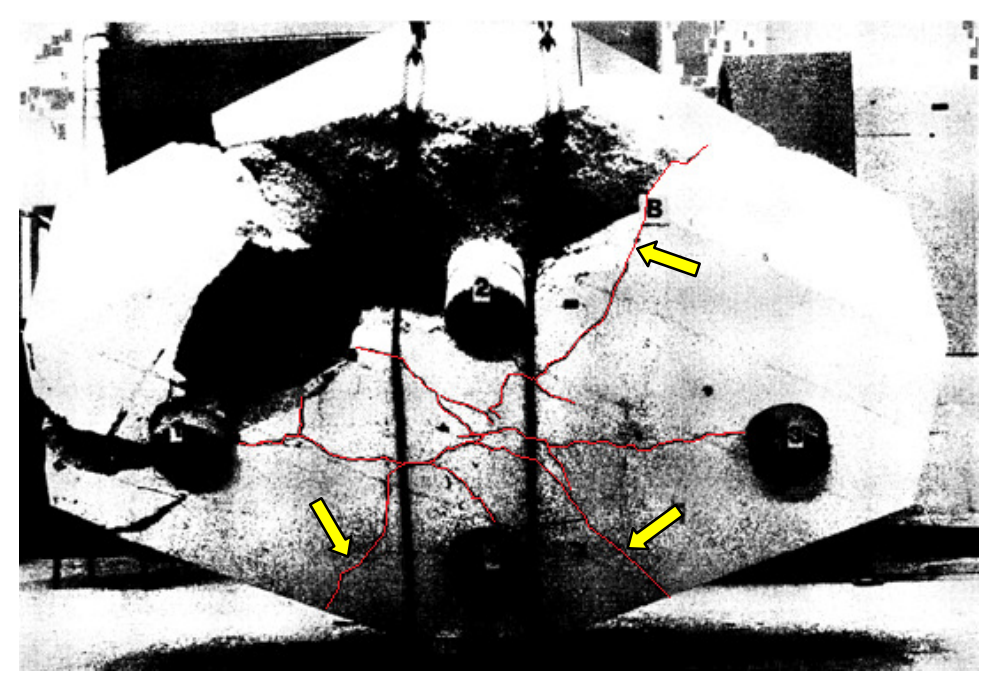

Figura 3.22 - Panorama de fissuras de bloco após o ensaio, adaptado de Adebar et al. (1990)

As tensões principais, indicando a formação das bielas, podem ser visualizadas na Figura 3.23 e na Figura 3.24.

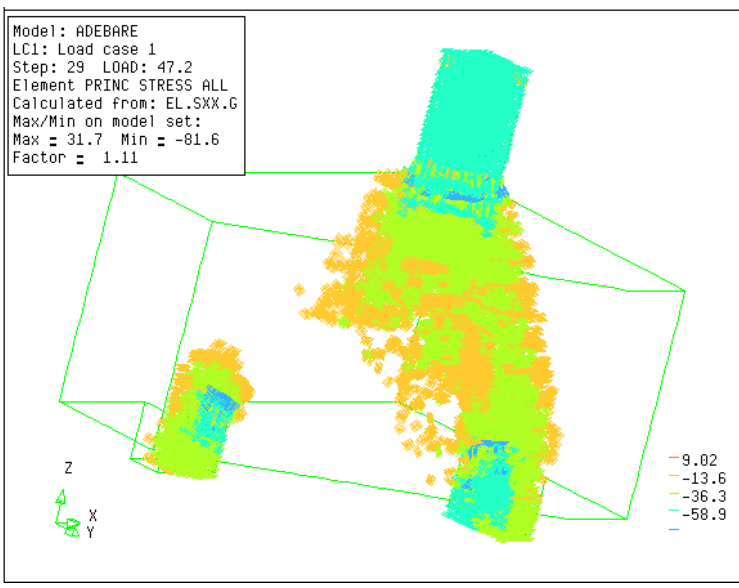

Tensões principais de compressão

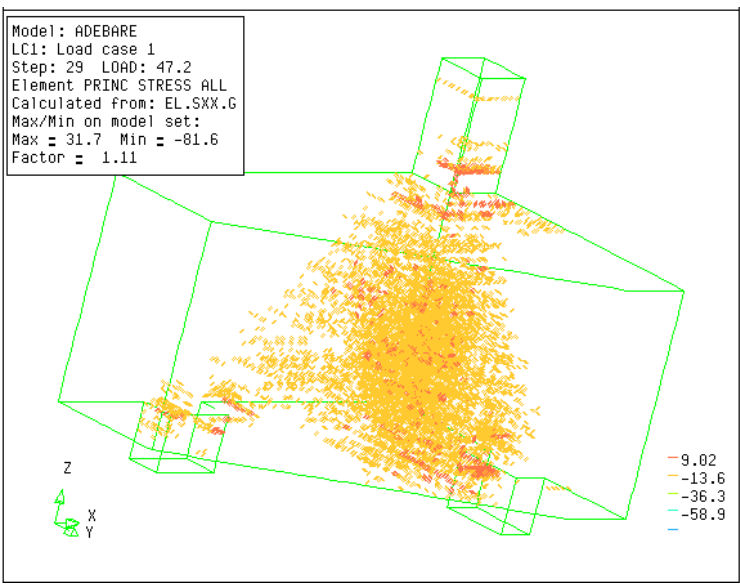

Tensões principais de tração

Figura 3.23 - Tensões principais no bloco E de Adebar et al. (1990) 


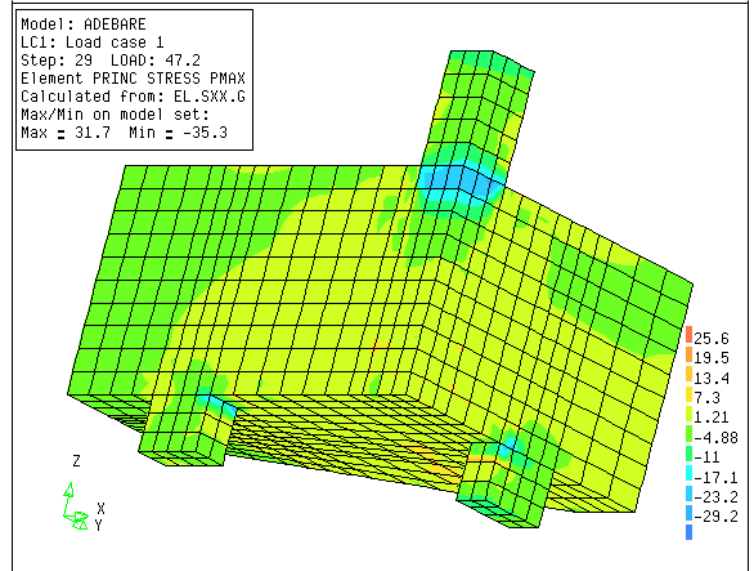

Tensões principais máximas

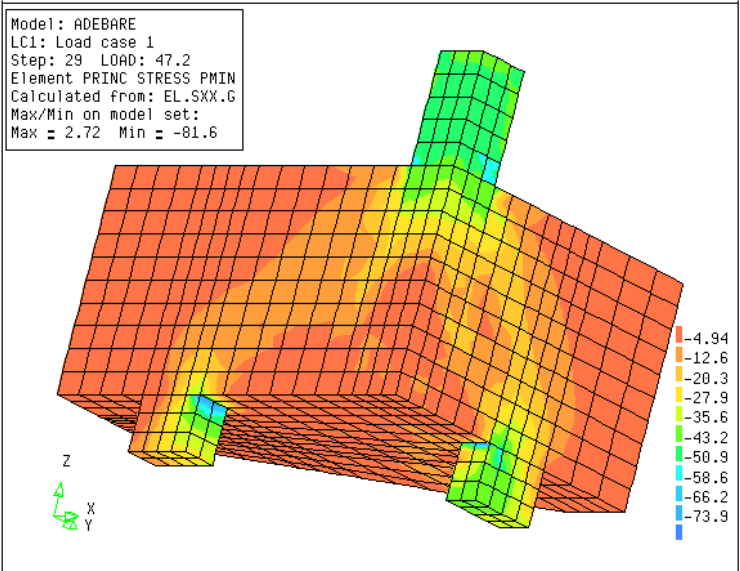

Tensões principais mínimas

Figura 3.24 - Tensões principais máximas e mínimas no bloco E de Adebar et al. (1990)

Para a força última, a deformação máxima dentre as armaduras localizadas entre as duas estacas mais próximas foi de $0,8 \mathrm{~mm} / \mathrm{m}$ enquanto no ensaio foi registrado o mesmo valor. Já para as armaduras localizadas entre as duas estacas mais afastadas, a deformação máxima da armadura foi de $0,7 \mathrm{~mm} / \mathrm{m}$ enquanto no ensaio foi registrada $0,4 \mathrm{~mm} / \mathrm{m}$. Essa diferença pode ser em parte atribuída ao fato de que as medidas das deformações no ensaio foram feitas no centro das barras, enquanto esses valores numéricos máximos não se encontram na região central e sim na região atravessada pela fissura apresentada na ruína. A Figura 3.25 evidencia a maior intensidade das tensões nas barras que atravessam a região da fissura mais relevante.

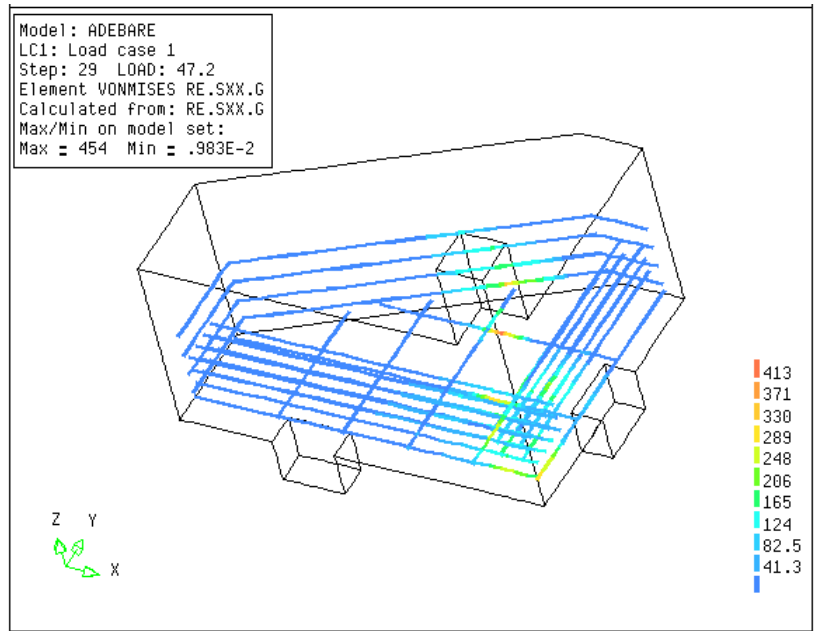

Figura 3.25 - Tensões nas armaduras do bloco E de Adebar et al. (1990)

Adebar et al. (1990) aferiram as reações nas estacas durante o ensaio e esses valores podem ser comparados com os numéricos. Para a força última experimental, $69 \%$ da força 
foram resistidas pelas estacas mais próximas do pilar enquanto nesta análise numérica, para a força última, $67,1 \%$ da força aplicada foi resistida pelas estacas mais próximas ao pilar.

As curvas que relacionam forças e deslocamentos do modelo numérico e experimental são apresentadas na Figura 3.26. Nota-se um comportamento mais rígido da curva numérica em comparação com a curva experimental, isso se deve ao fato do modelo numérico não conseguir percorrer o caminho de equilíbrio pós-pico após a fissuração do concreto.

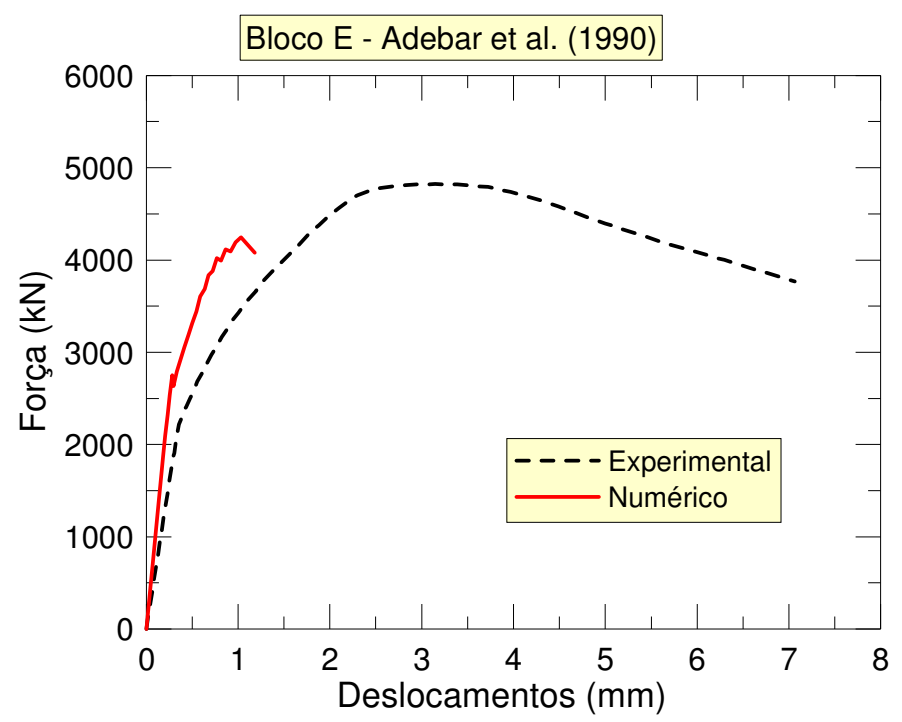

Figura 3.26 - Curvas força-deslocamento numérica e experimental do bloco E de Adebar et al. (1990)

\subsubsection{Bloco BPC-30-30-1 De SuzuKi et al. (1998)}

O bloco BPC-30-30-1 de Suzuki et al. (1998) apresentou força última experimental de $1039 k N$, enquanto nesta análise numérica a força última foi de 993,6 kN. As primeiras fissuras surgiram para uma força de $360 \mathrm{kN}$ enquanto no ensaio experimental os pesquisadores observaram as primeiras fissuras para uma força de 392 kN. A Figura 3.27 ilustra o panorama de fissuração sendo que é possível visualizar que o bloco encontra-se totalmente fissurado, sendo que as fissuras mais notáveis na ruína tiveram a formação iniciada na face inferior do bloco e progrediram até as faces laterais, no meio do vão entre as estacas, conforme foi observado pelos pesquisadores durante o ensaio, Figura 3.28. 


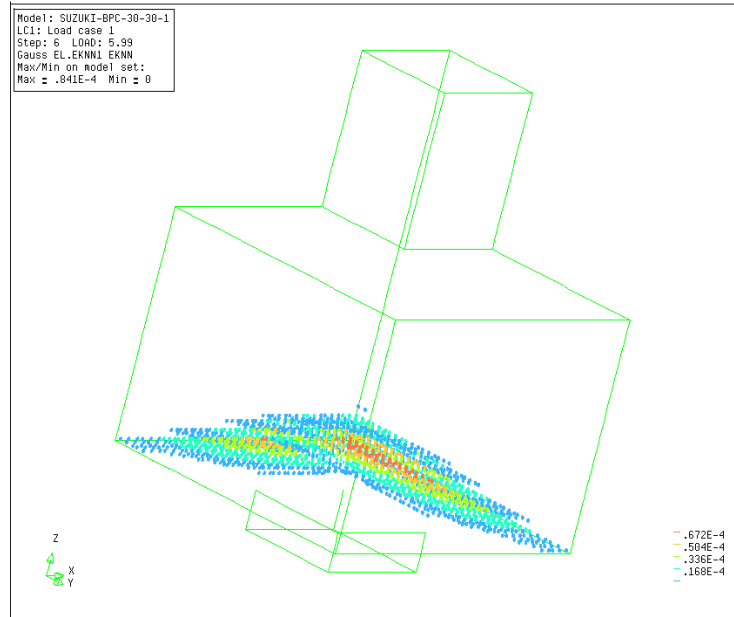

$50 \%$ da força última

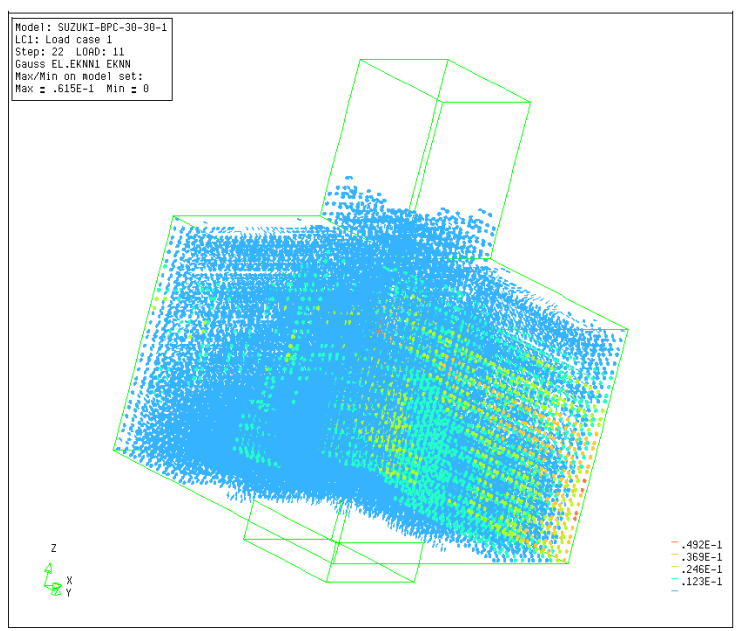

$100 \%$ da força última

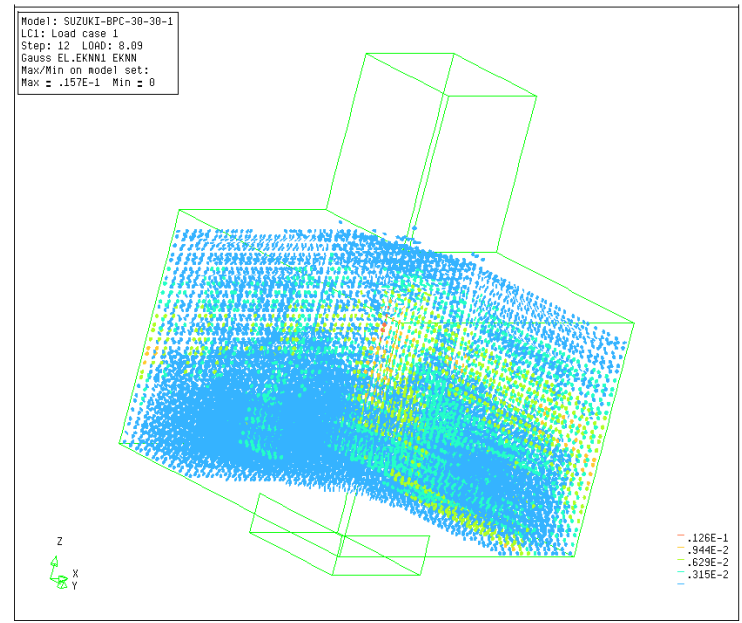

$75 \%$ da força última

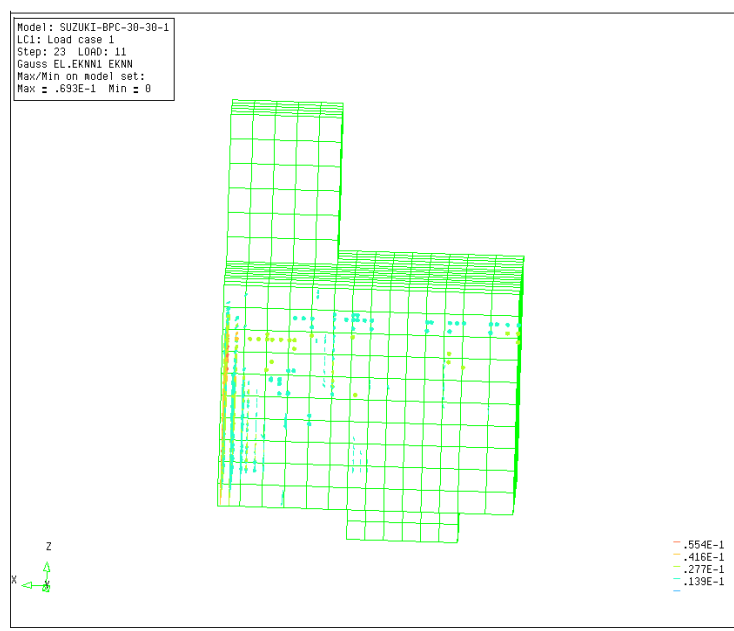

Fissuras na face lateral na ruína

Figura 3.27 - Panorama de fissuração do bloco BPC-30-30-1 de Suzuki et al. (1998)

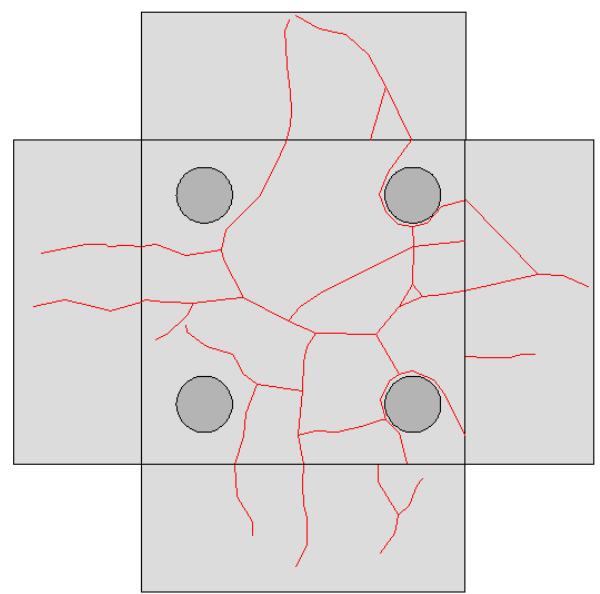

Figura 3.28 - Fissuras das faces do bloco BPC-30-30-1, adaptado de Suzuki et al. (1998)

Na Figura 3.29 e na Figura 3.30 estão indicadas as tensões principais de compressão e de tração causadas pela força última. As tensões de compressão claramente indicam a 
formação da biela de compressão e em decorrência desse fluxo de tensões de compressão nas bielas, surgem tensões de tração que também estão indicadas nas figuras. As maiores intensidades de compressão estão situadas na região nodal superior, junto ao pilar.

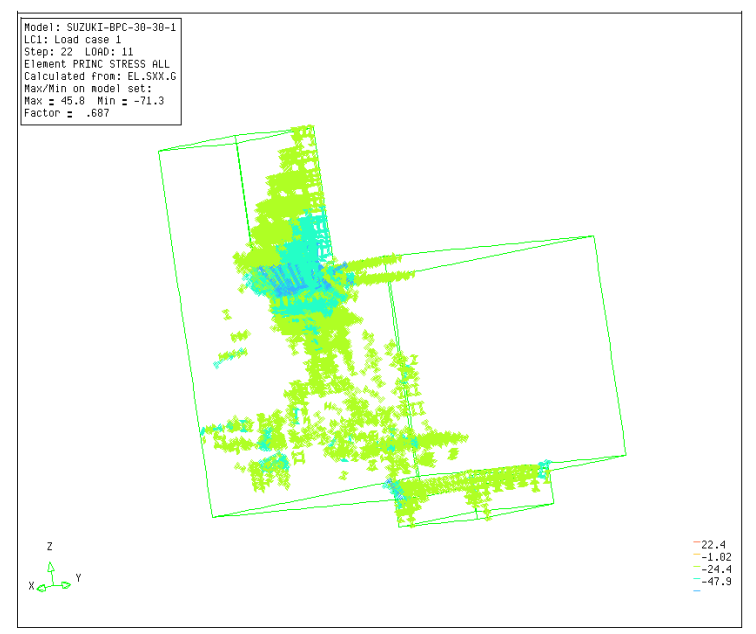

Tensões principais de compressão

Figura 3.29 - Tensões principais no bloco BPC-30-30-1 de Suzuki et al. (1998)

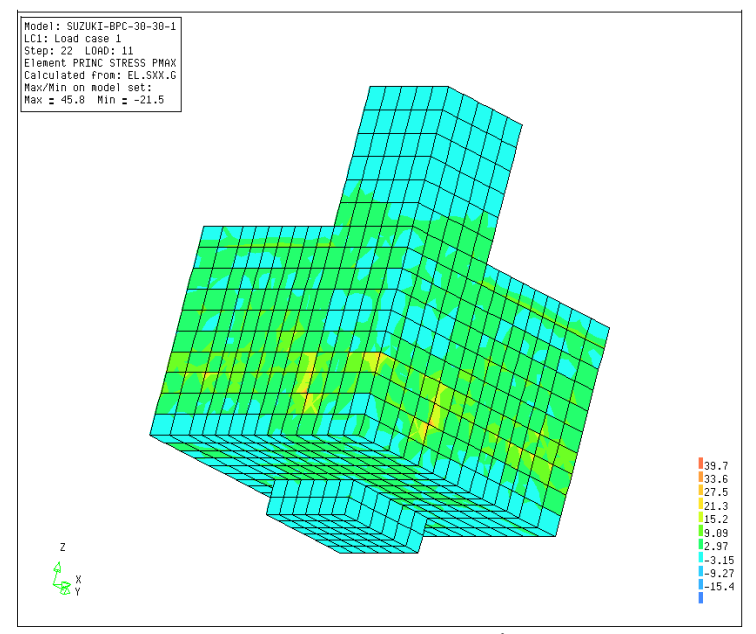

Tensões principais máximas

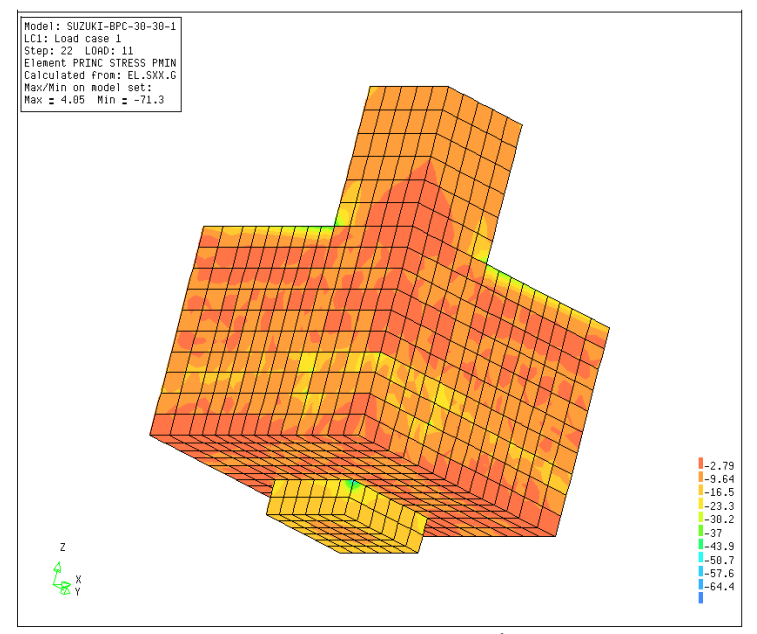

Tensões principais mínimas

Figura 3.30 - Tensões principais máximas e mínimas no bloco BPC-30-30-1 de Suzuki et al. (1998)

Analisando uma seção que atravesse o bloco diagonalmente, é possível visualizar a formação da biela comprimida assim como a grande intensidade das tensões compressivas na região nodal superior, Figura 3.31. 


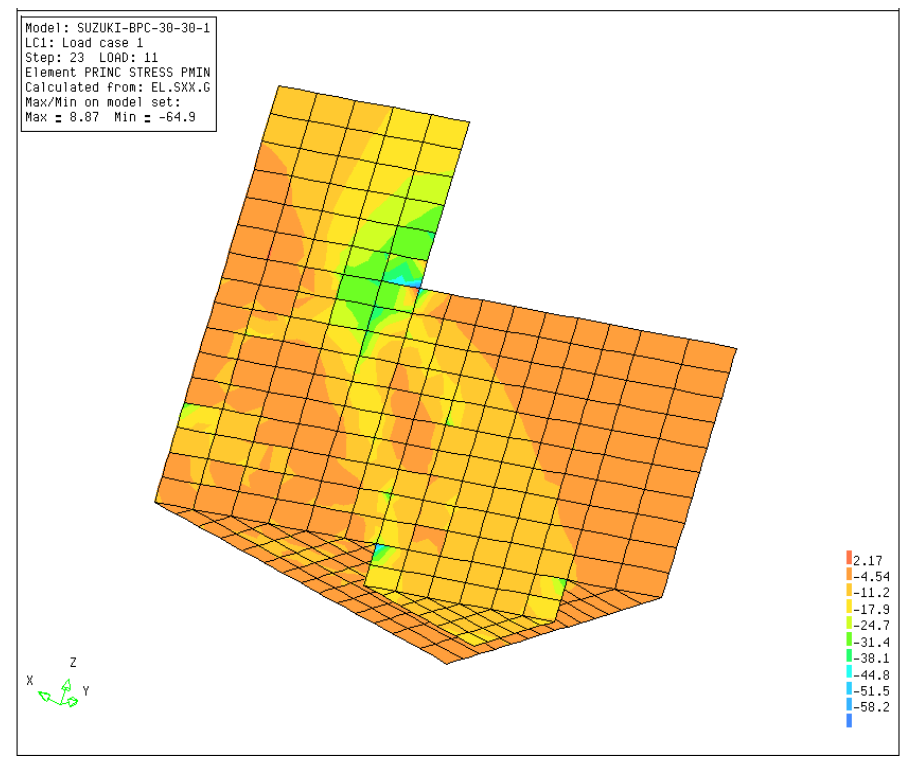

Figura 3.31 - Fluxo de tensões de compressão no bloco BPC-30-30-1 de Suzuki et al. (1998)

A força correspondente ao escoamento da armadura principal no modelo numérico foi de 953,1 $k N$ enquanto no modelo experimental foi de $980 \mathrm{kN}$. A Figura 3.32 ilustra a distribuição de tensão ao longo das barras da armadura do bloco e mostra que a tensão não varia expressivamente ao longo do vão entre as estacas, somente reduzindo ao atravessar a região das estacas.

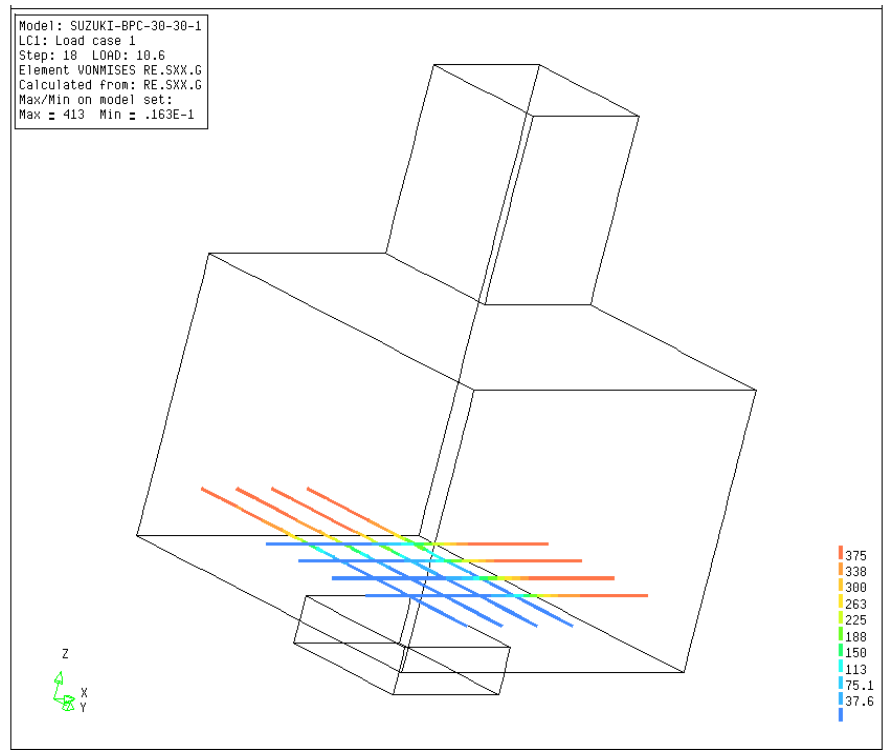

Figura 3.32 - Tensão nas barras da armadura principal do bloco BPC-30-30-1 de Suzuki et al. (1998) para uma força de $953,1 \mathrm{kN}$

A distribuição de tensões na armadura caracteriza as barras como tirantes e não como armaduras de flexão. Além disso, as tensões nas barras diminuem significativamente próximo 
às estacas de tal modo que legitima as indicações da CSA A23.3 (2004) de ancoragem reta, sem gancho.

A Figura 3.33 ilustra as curvas que relacionam a força aplicada com o deslocamento da face inferior do bloco. O comportamento do modelo numérico foi semelhante ao experimental. O equilíbrio do modelo no trecho pós-pico foi mais bem capturado em razão deste modelo estar com a armadura escoando na situação de ruína.

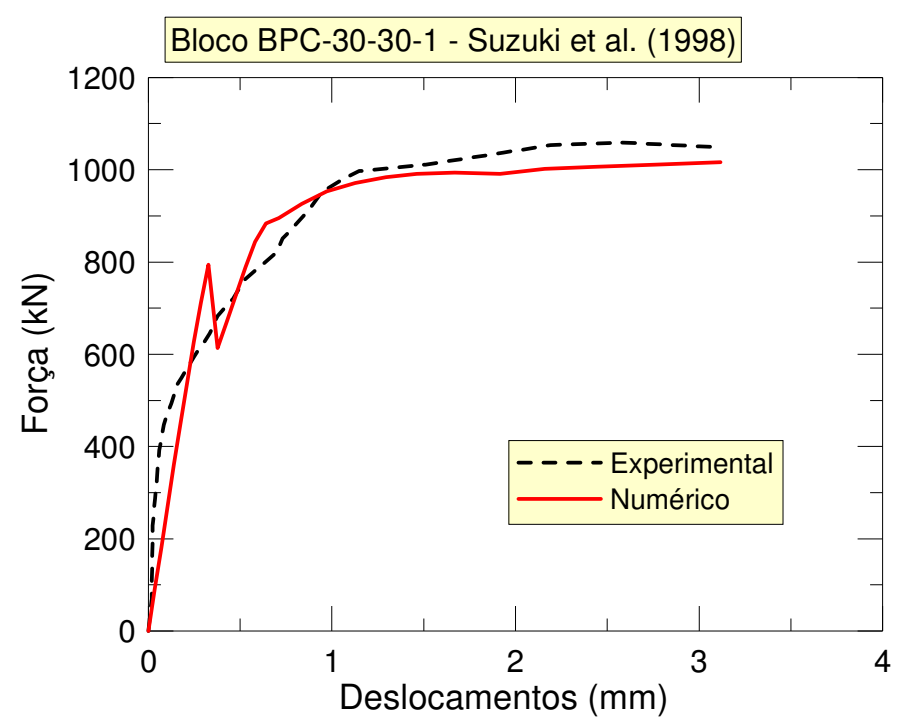

Figura 3.33 - Curvas força-deslocamento numérica e experimental do bloco BPC-30-30-1 de Suzuki et al. (1998)

\subsubsection{Bloco A de Chan e Poh (2000)}

Este bloco apresentou força última experimental de $1230 \mathrm{kN}$, enquanto nesta análise numérica a força última foi de 1197,6 $k N$. As primeiras fissuras surgiram para uma força de $560 \mathrm{kN}$ enquanto no ensaio experimental os pesquisadores observaram as primeiras fissuras para uma força de $840 \mathrm{kN}$. A Figura 3.34 ilustra o panorama de fissuração. 


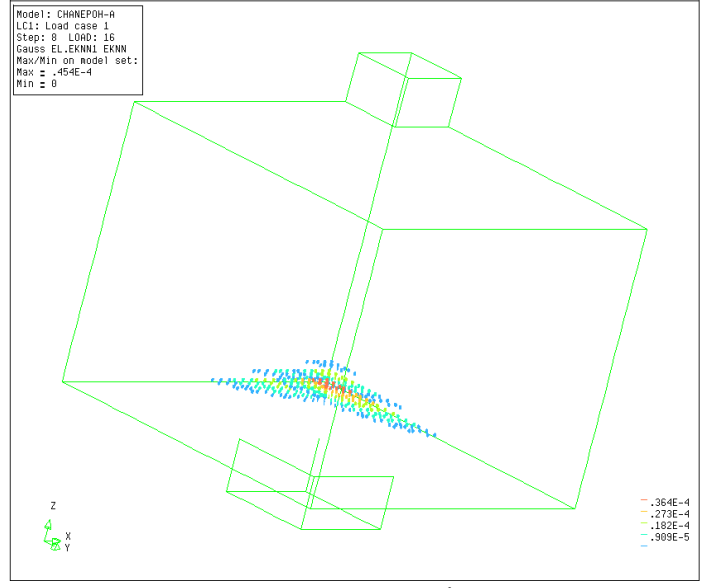

$\mathbf{5 0 \%}$ da força última

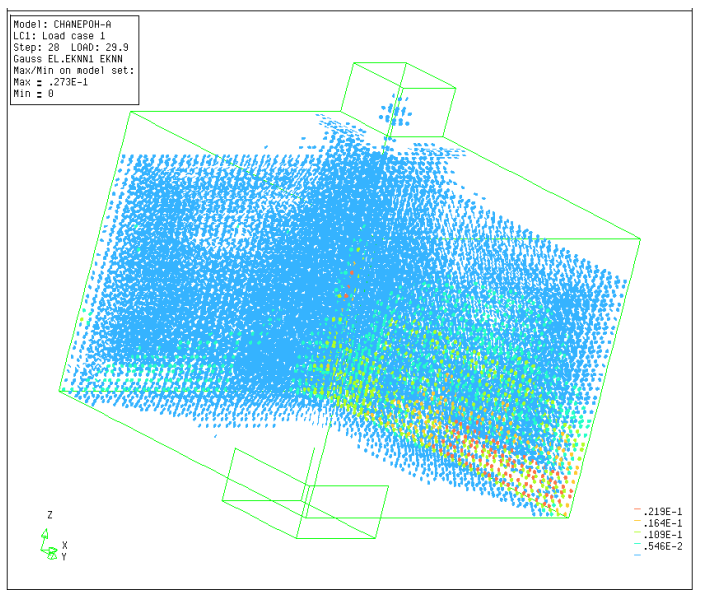

$100 \%$ da força última

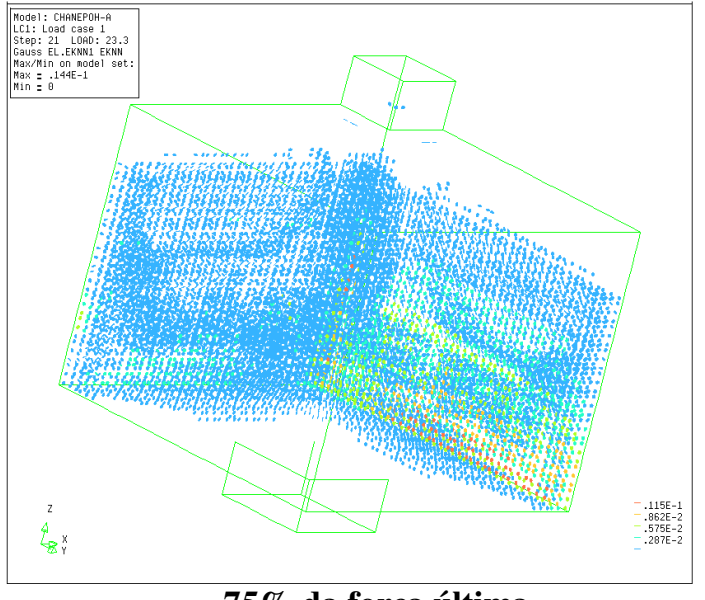

$75 \%$ da força última

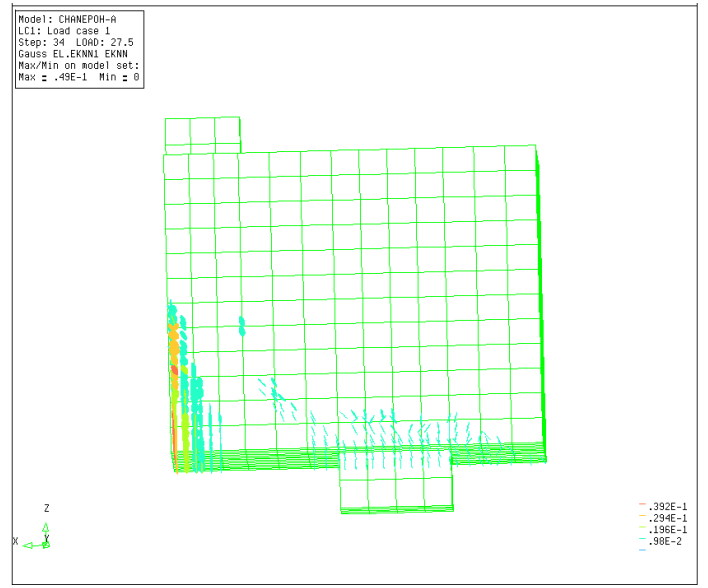

Fissuras na face lateral na ruína Figura 3.34 - Panorama de fissuração do bloco A de Chan e Poh (2000)

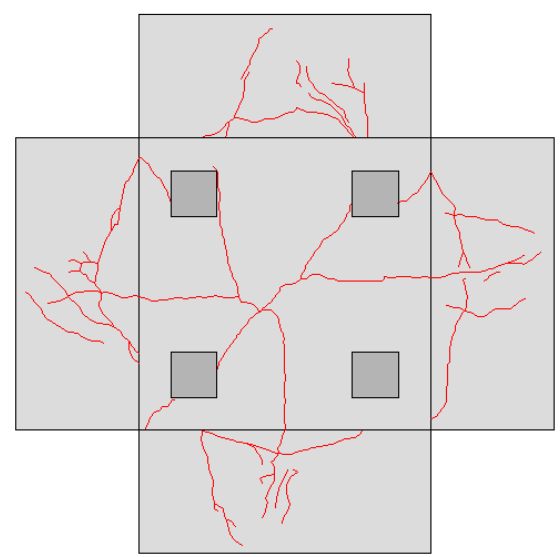

Figura 3.35 - Fissuras nas faces do bloco A, adaptado de Chan e Poh (2000)

O fluxo de tensões principais ilustrados na Figura 3.36 e na Figura 3.37 não indicam claramente a formação da biela. Pode-se justificar pelo fato do ângulo de inclinação da biela encontrar-se no limite inferior de $40^{\circ}$ definido por Blévot e Frémy (1967). 


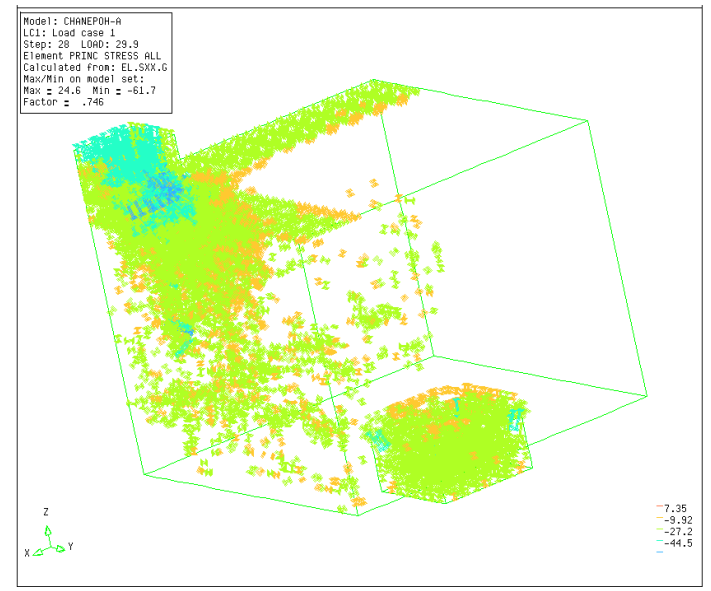

Tensões principais de compressão

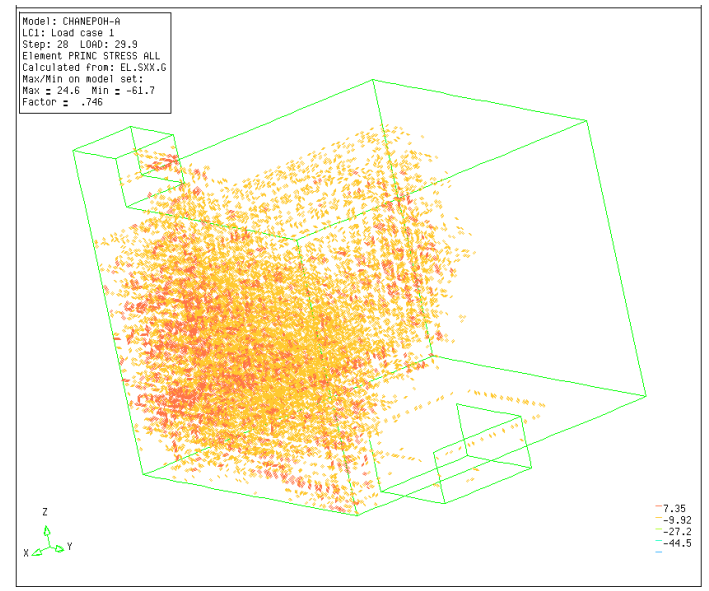

Tensões principais de tração Figura 3.36 - Tensões principais no bloco A de Chan e Poh (2000)

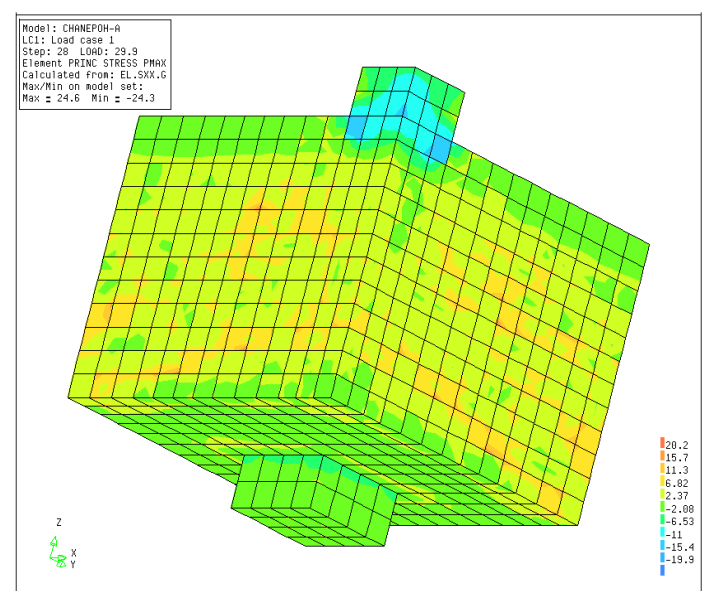

Tensões principais máximas

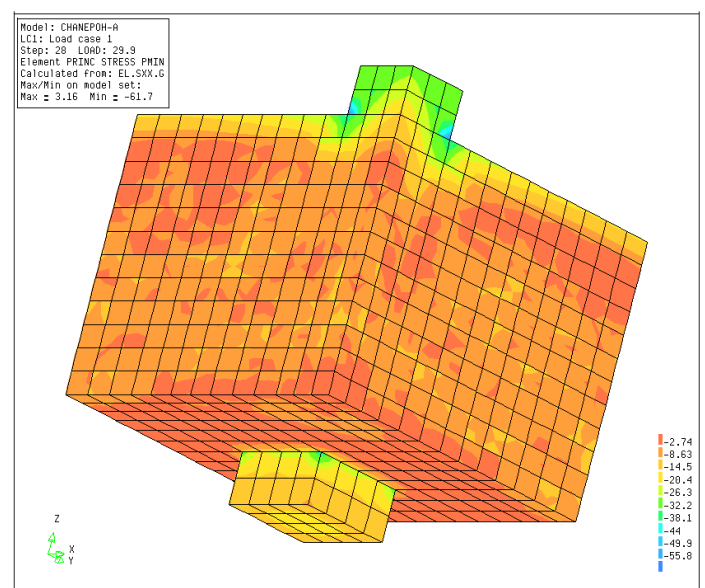

Tensões principais mínimas

Figura 3.37 - Tensões principais máximas e mínimas no bloco A de Chan e Poh (2000)

Quando se faz um corte diagonal no bloco, Figura 3.38, fica mais clara a formação de uma biela comprimida. O distúrbio de tensões logo abaixo da região nodal superior pode ser atribuído à presença da armadura longitudinal do pilar que, ao enrijecer os elementos adjacentes, ocasionou o surgimento de tensões de compressão maiores em alguns destes elementos. 


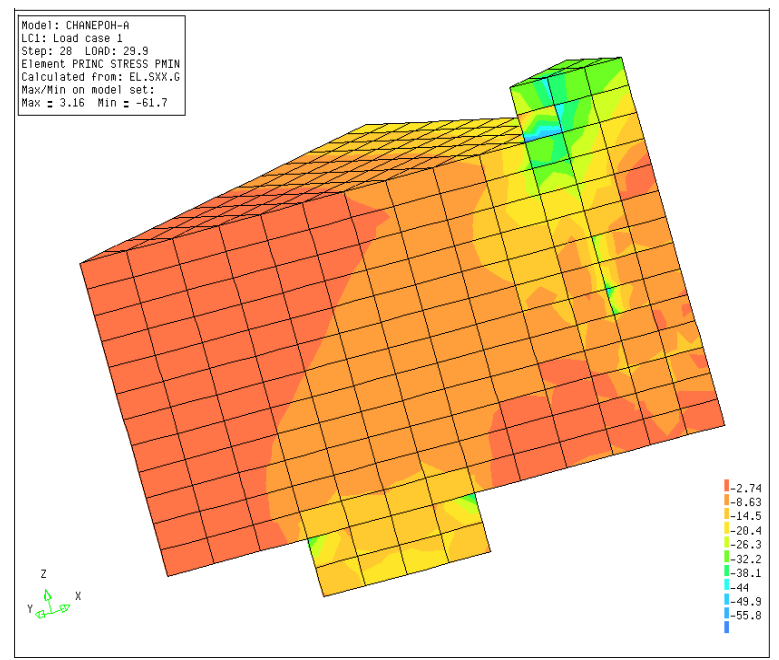

Figura 3.38 - Fluxo de tensões de compressão no bloco A de Chan e Poh (2000)

A partir da Figura 3.39 verifica-se que a curva força-deslocamento obtida numericamente apresentou comportamento mais rígido que a obtida experimentalmente. Apesar de esta tendência ter se repetido nos outros modelos, o comportamento no regime elástico-linear ficou aquém do esperado. Uma das hipóteses para justificar este tipo de comportamento são os valores dos módulos de elasticidade do aço e do concreto, uma vez que, na ausência destes dados, foram atribuídos valores recomendados pela norma brasileira.

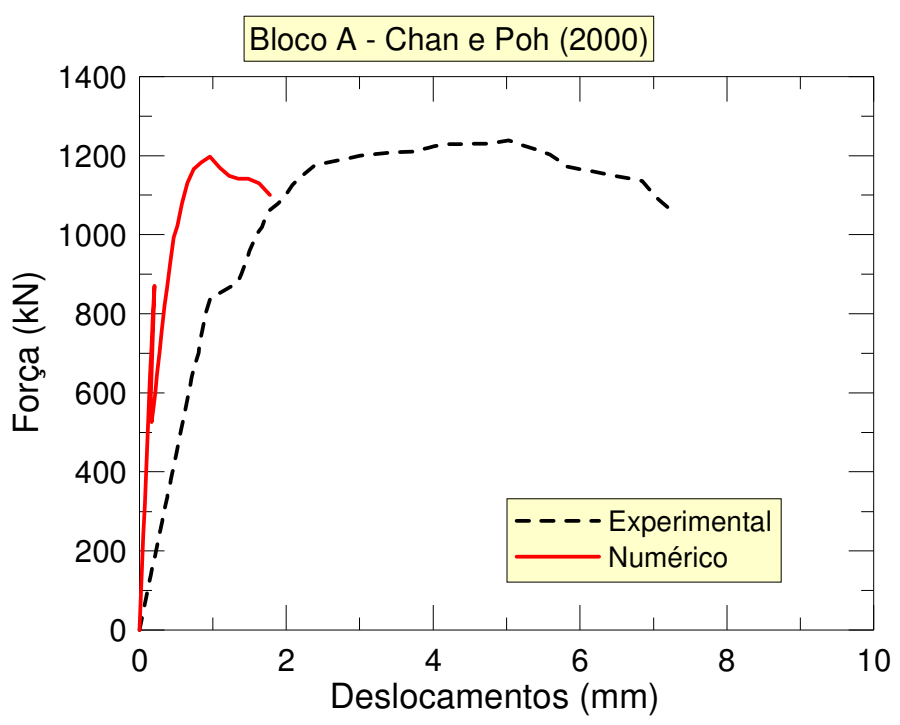

Figura 3.39 - Curvas força-deslocamento numérica e experimental do bloco A de Chan e Poh (2000) 


\subsubsection{CONSIDERAÇÕES FINAIS}

O ajuste dos parâmetros dos modelos numéricos mediante validação com resultados experimentais permitiu a aproximação adequada do comportamento dos blocos em termos de capacidade resistente, força de fissuração, panorama de fissuração e distribuição de esforços. As deformações das armaduras, quando medidas, tiveram boa aproximação, assim como a força de escoamento da armadura do bloco BPC-30-30-1 de Suzuki et al. (1998). Os modelos apresentaram comportamento mais rígido, com o trecho de amolecimento menos acentuado que os demonstrados nas curvas força-deslocamento experimentais, excetuando-se o bloco BPC-30-30-1 onde a obtenção de comportamento pós-pico foi facilitada pela ocorrência de escoamento da armadura.

A Tabela 3.3 resume alguns dos resultados obtidos. Acredita-se que, utilizando estes mesmos parâmetros em análises numéricas de blocos sobre quatro estacas com cálice embutido, é possível obter respostas satisfatórias quanto ao comportamento destes elementos.

Tabela 3.3 - Comparação das forças experimentais e numéricas para os blocos analisados

\begin{tabular}{|c|c|c|c|c|c|c|c|c|c|}
\hline Modelo & $\begin{array}{l}\boldsymbol{F}_{c, \exp } \\
(\mathbf{k N})^{*}\end{array}$ & $\begin{array}{c}F_{c, \text { num }} \\
(\mathbf{k N})\end{array}$ & $\begin{array}{c}\boldsymbol{F}_{y, \exp } \\
(\mathbf{k N})^{* *}\end{array}$ & $\begin{array}{c}F_{y, \text { num }} \\
(\mathbf{k N})\end{array}$ & $\begin{array}{c}F_{u, \exp } \\
(\mathbf{k N})\end{array}$ & $\begin{array}{c}F_{u, n u m} \\
(\mathbf{k N})\end{array}$ & $\frac{F_{y, \text { num }}}{F_{y, \exp }}$ & $\frac{F_{c, \text { num }}}{F_{c, \exp }}$ & $\frac{F_{u, \text { num }}}{F_{u, \exp }}$ \\
\hline $\begin{array}{c}\text { D } \\
\text { Adebar et al. (1990) }\end{array}$ & 1122 & 990 & - & - & 3222 & 3138,3 & - & 0,88 & 0,97 \\
\hline $\begin{array}{l}\mathrm{E} \\
\text { Adebar et al. (1990) }\end{array}$ & 1228 & 1350 & - & - & 4709 & 4248 & - & 1,10 & 0,90 \\
\hline $\begin{array}{c}\text { BPC-30-30-1 } \\
\text { Suzuki et al. (1998) }\end{array}$ & 392 & 360 & 980 & 953,1 & 1039 & 993,6 & 0,97 & 0,92 & 0,92 \\
\hline \multirow[t]{3}{*}{$\stackrel{\text { A }}{\text { Chan e Poh (2000) }}$} & 840 & 560 & - & - & 1230 & 1197,6 & - & 0,67 & 0,97 \\
\hline & & & & & & \multicolumn{2}{|c|}{ Desvio padrão } & 0,18 & 0,03 \\
\hline & & & & & & \multicolumn{2}{|c|}{ Coef. de variação } & 0,20 & 0,04 \\
\hline
\end{tabular}





\section{Capítulo 4 \\ BLOCOS SOBRE QUATRO ESTACAS COM CÁLICE \\ EMBUTIDO

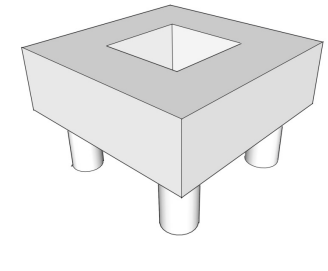

\subsection{CONSIDERAÇõES INICIAIS}

A partir dos resultados obtidos na análise paramétrica, foi definida a combinação de parâmetros que melhor representou o comportamento de blocos sobre quatro estacas e, com o ajuste desses parâmetros, foram realizadas análises numéricas em vinte e quatro blocos sobre quatro estacas com cálice embutido, por intermédio da versão 9.2 do programa computacional DIANA cuja licença está registrada para o Departamento de Estruturas da Escola de Engenharia de São Carlos - USP.

A combinação de parâmetros que levou aos melhores resultados consistiu de modelo Total Strain de fissuras fixas com fator de retenção ao cisalhamento de 0,99 , sendo analisado pelo método iterativo de Newton-Raphson regular, considerando como critério de convergência a norma de energia com tolerância de $1 \%$.

Os resultados em termos de fluxos de tensões principais, panorama da fissuração, tensões nas barras das armaduras e diagramas força aplicada versus deslocamento, permitiram avaliar o comportamento dos blocos sobre quatro estacas com cálice totalmente embutido quando solicitados por força vertical e momentos em duas direções.

\subsection{Modelos ANALiSAdos}

Os modelos foram idealizados considerando aspectos de projeto e propriedades físicas dos materiais especificados nas normas ABNT NBR 6118:2003, ABNT NBR 9062:2006 e ABNT NBR 7480:2007. Além dessas normas, serviram de apoio as recomendações de Moraes (1976), Alonso (1983) e Montoya (2000). 


\subsubsection{PARÂMETROS ANALISADOS}

Nestas análises variaram-se o comprimento de embutimento do pilar no bloco, a espessura da "laje de fundo" do bloco, o tipo de interface da ligação pilar-fundação e as solicitações. O comprimento de embutimento do pilar no bloco variou de acordo com os valores propostos na ABNT NBR 9062:2006 e em El Debs (2000) para cálices externos, uma vez que não foram encontradas recomendações específicas para cálices embutidos.

A altura do fundo do cálice ao fundo do bloco, denominada em alguns trabalhos por "laje de fundo", foi avaliada respeitando o mínimo estabelecido pela ABNT NBR 9062:2006 de $20 \mathrm{~cm}$. A rugosidade da interface da ligação, formada pelas paredes internas do cálice e do pilar, também foram variadas entre rugosas e lisas. A altura do bloco foi variada indiretamente, uma vez que a altura corresponde à soma do comprimento de embutimento e da espessura da laje de fundo.

O estudo também contemplou o efeito de diferentes ações atuantes no topo do bloco: força vertical centrada, força vertical excêntrica em uma direção e força vertical excêntrica em duas direções.

\subsubsection{DESCRIÇÃO DOS MODELOS}

A partir da variação dos parâmetros descritos no item 4.2.1, 24 modelos foram elaborados. Estes modelos foram divididos em dois grupos, A e B, sendo o primeiro constituído de blocos cujos cálices apresentam interfaces de ligação rugosas e o segundo constituído de blocos com cálices de interfaces lisas.

Admitindo pilares de seção transversal quadrada de $40 \mathrm{~cm}$ x $40 \mathrm{~cm}$ - usualmente empregados em estruturas de galpões com modulação de $15 \mathrm{~m}$ - e estacas pré-moldadas de seção transversal quadrada de $30 \mathrm{~cm} \times 30 \mathrm{~cm}$ e apreciando as recomendações da norma ABNT NBR 6118:2003 e da bibliografia referida nos itens anteriores, foram calculadas as demais dimensões do bloco.

O espaçamento entre eixos de estacas, $l_{e}$, de $110 \mathrm{~cm}$, resultou maior que três vezes o lado da estaca, respeitando as recomendações de Moraes (1976), Alonso (1983) e da ABNT 
NBR 6118:2003. A distância de $25 \mathrm{~cm}$ da face mais externa da estaca à face do bloco está de acordo com o valor mínimo sugerido em Montoya (2000) e Calavera (2000).

Assumindo estes valores, o bloco resultou com dimensões em planta de $190 \mathrm{~cm}$ x 190 cm. Sendo a solicitação na base do pilar composta por força vertical e momentos nas duas direções, tem-se que o comprimento de embutimento do pilar no bloco, $\ell_{e m b}$, de acordo com a ABNT NBR 9062:2006, variou com o valor da excentricidade, a largura do pilar e a rugosidade da interface de ligação. Os valores sugeridos pela norma brasileira de concreto pré-moldado que estão apresentados na Tabela 2.3 são destinados a cálices externos, todavia, na falta de estudos para blocos com cálices embutidos, adotaram-se os valores sugeridos na referida norma.

O comprimento de embutimento variou entre $48 \mathrm{~cm}$ e $64 \mathrm{~cm}$ para os blocos do grupo A (interface rugosa) e entre $60 \mathrm{~cm}$ e $80 \mathrm{~cm}$ para os blocos do grupo B (interface lisa). Esses valores foram obtidos a partir das recomendações contidas na ABNT NBR 9062:2006 para cálices lisos e rugosos considerando que serão estudados blocos solicitados por forças verticais axiais e também excêntricas $(e=10 \mathrm{~cm})$. Os valores inferiores de comprimento de embutimento são referentes àqueles sugeridos para excentricidades menores que $0,15 \cdot b_{\text {pil }}$ e os superiores são referentes àqueles sugeridos para excentricidades maiores que $2,00 \cdot b_{\text {pil }}$. Neste estudo a excentricidade encontra-se no intervalo entre esses dois valores, ou seja, é recomendada a interpolação linear para a obtenção do comprimento de embutimento, entretanto optou-se por analisar os dois valores, pois o comprimento de embutimento pertence ao conjunto de variáveis das quais se estudou.

Foram estudados dois valores para a altura da "laje de fundo", $20 \mathrm{~cm}$ e $30 \mathrm{~cm}$, com o propósito de avaliar a influência desta altura na resistência do bloco, em especial a segurança à punção.

A Figura 4.1 ilustra os dois grupos de blocos analisados numericamente. Na Tabela 4.1 e na Tabela 4.2 estão presentes, respectivamente, as descrições geométricas de cada modelo que compõem o grupo A e o grupo B. 

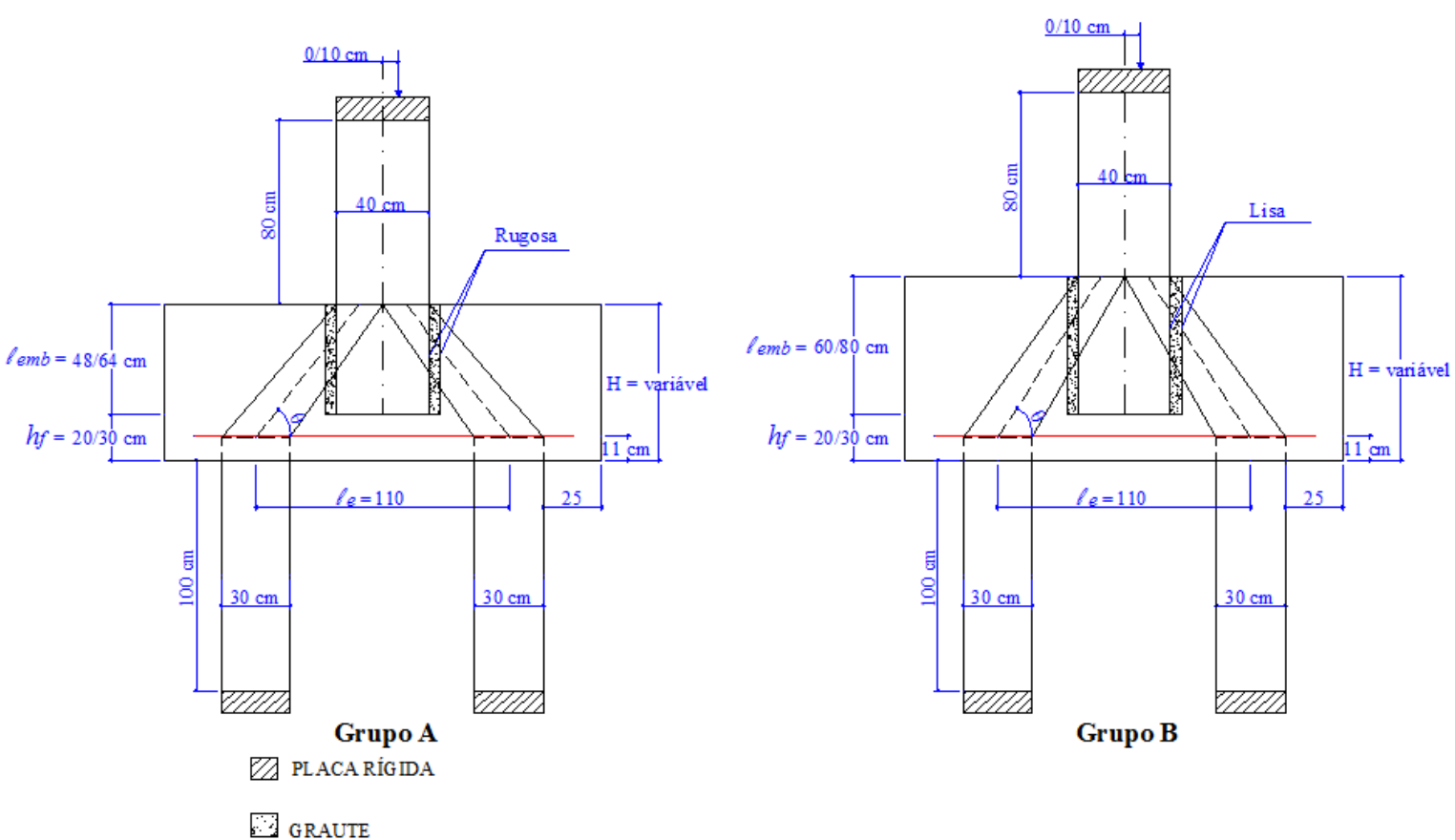

Figura 4.1 - Detalhes dos modelos do grupo A e do grupo B

Os comprimentos da estaca e do pilar foram escolhidos de tal modo que permitisse a visualização das tensões nas regiões de perturbações como as ligações, a região de apoio ou de aplicação da força.

Tabela 4.1 - Propriedades geométricas dos modelos do grupo A (interface rugosa)

\begin{tabular}{lcccccccc}
\hline \multicolumn{1}{c}{ Modelo } & $\begin{array}{c}\mathbf{A}_{\text {est }} \times \mathbf{B}_{\text {est }} \\
(\mathbf{c m})\end{array}$ & $\begin{array}{c}\mathbf{A}_{\text {pil }} \times \mathbf{B}_{\text {pil }} \\
(\mathbf{c m})\end{array}$ & $\begin{array}{c}\mathbf{A}_{\text {blo }} \times \mathbf{B}_{\text {blo }} \\
(\mathbf{c m})\end{array}$ & $\begin{array}{c}\boldsymbol{l}_{\mathbf{e}} \\
(\mathbf{c m})\end{array}$ & $\begin{array}{c}\boldsymbol{H} \\
(\mathbf{c m})\end{array}$ & $\begin{array}{c}\boldsymbol{\ell}_{\text {emb }} \\
(\mathbf{c m})\end{array}$ & $\begin{array}{c}\boldsymbol{h}_{\boldsymbol{s}} \\
(\mathbf{c m})\end{array}$ & $\begin{array}{c}\boldsymbol{\theta} \\
(\mathbf{g r a u s})\end{array}$ \\
\hline IR-E48-HS20-N & $30 \times 30$ & $40 \times 40$ & $190 \times 190$ & 110 & 68 & 48 & 20 & 41,8 \\
\hline IR-E48-HS20-NM & $30 \times 30$ & $40 \times 40$ & $190 \times 190$ & 110 & 68 & 48 & 20 & 41,8 \\
\hline IR-E48-HS20-NMM & $30 \times 30$ & $40 \times 40$ & $190 \times 190$ & 110 & 68 & 48 & 20 & 41,8 \\
\hline IR-E48-HS30-N & $30 \times 30$ & $40 \times 40$ & $190 \times 190$ & 110 & 78 & 48 & 30 & 46,5 \\
\hline IR-E48-HS30-NM & $30 \times 30$ & $40 \times 40$ & $190 \times 190$ & 110 & 78 & 48 & 30 & 46,5 \\
\hline IR-E48-HS30-NMM & $30 \times 30$ & $40 \times 40$ & $190 \times 190$ & 110 & 78 & 48 & 30 & 46,5 \\
\hline IR-E64-HS20-N & $30 \times 30$ & $40 \times 40$ & $190 \times 190$ & 110 & 84 & 64 & 20 & 48,9 \\
\hline IR-E64-HS20-NM & $30 \times 30$ & $40 \times 40$ & $190 \times 190$ & 110 & 84 & 64 & 20 & 48,9 \\
\hline IR-E64-HS20-NMM & $30 \times 30$ & $40 \times 40$ & $190 \times 190$ & 110 & 84 & 64 & 20 & 48,9 \\
\hline IR-E64-HS30-N & $30 \times 30$ & $40 \times 40$ & $190 \times 190$ & 110 & 94 & 64 & 30 & 52,5 \\
\hline IR-E64-HS30-NM & $30 \times 30$ & $40 \times 40$ & $190 \times 190$ & 110 & 94 & 64 & 30 & 52,5 \\
\hline IR-E64-HS30-NMM & $30 \times 30$ & $40 \times 40$ & $190 \times 190$ & 110 & 94 & 64 & 30 & 52,5 \\
\hline
\end{tabular}


Tabela 4.2 - Propriedades geométricas dos modelos do grupo B (interface lisa)

\begin{tabular}{lcccccccc}
\hline \multicolumn{1}{c}{ Modelo } & $\begin{array}{c}\mathbf{A}_{\text {est }} \times \mathbf{B}_{\text {est }} \\
(\mathbf{c m})\end{array}$ & $\begin{array}{c}\mathbf{A}_{\text {pil }} \times \mathbf{B}_{\text {pil }} \\
(\mathbf{c m})\end{array}$ & $\begin{array}{c}\mathbf{A}_{\text {blo }} \times \mathbf{B}_{\text {blo }} \\
(\mathbf{c m})\end{array}$ & $\begin{array}{c}\boldsymbol{l}_{\mathbf{e}} \\
(\mathbf{c m})\end{array}$ & $\begin{array}{c}\boldsymbol{H} \\
(\mathbf{c m})\end{array}$ & $\begin{array}{c}\boldsymbol{\ell}_{\text {emb }} \\
(\mathbf{c m})\end{array}$ & $\begin{array}{c}\boldsymbol{h}_{\mathbf{s}} \\
(\mathbf{c m})\end{array}$ & $\begin{array}{c}\boldsymbol{\theta} \\
(\mathbf{g r a u s})\end{array}$ \\
\hline IL-E60-HS20-N & $30 \times 30$ & $40 \times 40$ & $190 \times 190$ & 110 & 80 & 60 & 20 & 47,3 \\
\hline IL-E60-HS20-NM & $30 \times 30$ & $40 \times 40$ & $190 \times 190$ & 110 & 80 & 60 & 20 & 47,3 \\
\hline IL-E60-HS20-NMM & $30 \times 30$ & $40 \times 40$ & $190 \times 190$ & 110 & 80 & 60 & 20 & 47,3 \\
\hline IL-E60-HS30-N & $30 \times 30$ & $40 \times 40$ & $190 \times 190$ & 110 & 90 & 60 & 30 & 51,1 \\
\hline IL-E60-HS30-NM & $30 \times 30$ & $40 \times 40$ & $190 \times 190$ & 110 & 90 & 60 & 30 & 51,1 \\
\hline IL-E60-HS30-NMM & $30 \times 30$ & $40 \times 40$ & $190 \times 190$ & 110 & 90 & 60 & 30 & 51,1 \\
\hline IL-E80-HS20-N & $30 \times 30$ & $40 \times 40$ & $190 \times 190$ & 110 & 100 & 80 & 20 & 54,4 \\
\hline IL-E80-HS20-NM & $30 \times 30$ & $40 \times 40$ & $190 \times 190$ & 110 & 100 & 80 & 20 & 54,4 \\
\hline IL-E80-HS20-NMM & $30 \times 30$ & $40 \times 40$ & $190 \times 190$ & 110 & 100 & 80 & 20 & 54,4 \\
\hline IL-E80-HS30-N & $30 \times 30$ & $40 \times 40$ & $190 \times 190$ & 110 & 110 & 80 & 30 & 57,3 \\
\hline IL-E80-HS30-NM & $30 \times 30$ & $40 \times 40$ & $190 \times 190$ & 110 & 110 & 80 & 30 & 57,3 \\
\hline IL-E80-HS30-NMM & $30 \times 30$ & $40 \times 40$ & $190 \times 190$ & 110 & 110 & 80 & 30 & 57,3 \\
\hline
\end{tabular}

Os nomes dos modelos foram atribuídos tendo em vista o fácil reconhecimento das informações geométricas e físicas dos modelos nas etapas seguintes. A nomenclatura segue o padrão descrito na Figura 4.2.

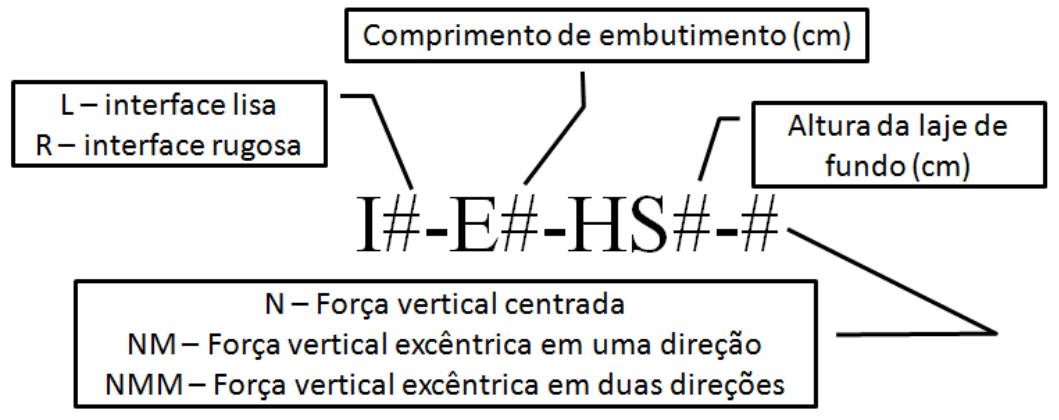

Figura 4.2 - Designação dos modelos

A partir da geometria dos modelos e considerando que os blocos sejam moldados por um concreto de $25 \mathrm{MPa}$ de resistência característica à compressão, foram feitas estimativas das forças últimas para cada um dos blocos. As estimativas foram feitas baseadas nas previsões de Blévot e Frémy (1967) para a ruptura das bielas comprimidas e encontram-se descritas na Tabela 4.3 e na Tabela 4.4. 
Tabela 4.3 - Força última dos modelos do grupo A (interface rugosa)

\begin{tabular}{lccccccc}
\hline \multicolumn{1}{c}{ Modelo } & $\begin{array}{c}\mathbf{A}_{\text {est }} \mathbf{x} \mathbf{B}_{\text {est }} \\
(\mathbf{c m})\end{array}$ & $\begin{array}{c}\mathbf{A}_{\text {pil }} \mathbf{x} \mathbf{B}_{\text {pil }} \\
(\mathbf{c m})\end{array}$ & $\begin{array}{c}\mathbf{A}_{\mathbf{b l o}} \mathbf{x} \mathbf{B}_{\text {blo }} \\
(\mathbf{c m})\end{array}$ & $\begin{array}{c}\boldsymbol{l}_{\mathbf{e}} \\
(\mathbf{c m})\end{array}$ & $\begin{array}{c}\boldsymbol{H} \\
(\mathbf{c m})\end{array}$ & $\begin{array}{c}\boldsymbol{\theta} \\
(\mathbf{g r a u s})\end{array}$ & $\begin{array}{c}\mathbf{F}_{\mathbf{u}}^{*} \\
(\mathbf{k N})\end{array}$ \\
\hline IR-E48-HS20-N & $30 \times 30$ & $40 \times 40$ & $190 \times 190$ & 110 & 68 & 41,8 & 1602,47 \\
\hline IR-E48-HS20-NM & $30 \times 30$ & $40 \times 40$ & $190 \times 190$ & 110 & 68 & 41,8 & 1602,47 \\
\hline IR-E48-HS20-NMM & $30 \times 30$ & $40 \times 40$ & $190 \times 190$ & 110 & 68 & 41,8 & 1602,47 \\
\hline IR-E48-HS30-N & $30 \times 30$ & $40 \times 40$ & $190 \times 190$ & 110 & 78 & 46,5 & 1892,54 \\
\hline IR-E48-HS30-NM & $30 \times 30$ & $40 \times 40$ & $190 \times 190$ & 110 & 78 & 46,5 & 1892,54 \\
\hline IR-E48-HS30-NMM & $30 \times 30$ & $40 \times 40$ & $190 \times 190$ & 110 & 78 & 46,5 & 1892,54 \\
\hline IR-E64-HS20-N & $30 \times 30$ & $40 \times 40$ & $190 \times 190$ & 110 & 84 & 48,9 & 2045,46 \\
\hline IR-E64-HS20-NM & $30 \times 30$ & $40 \times 40$ & $190 \times 190$ & 110 & 84 & 48,9 & 2045,46 \\
\hline IR-E64-HS20-NMM & $30 \times 30$ & $40 \times 40$ & $190 \times 190$ & 110 & 84 & 48,9 & 2045,46 \\
\hline IR-E64-HS30-N & $30 \times 30$ & $40 \times 40$ & $190 \times 190$ & 110 & 94 & 52,5 & 2267,15 \\
\hline IR-E64-HS30-NM & $30 \times 30$ & $40 \times 40$ & $190 \times 190$ & 110 & 94 & 52,5 & 2267,15 \\
\hline IR-E64-HS30-NMM & $30 \times 30$ & $40 \times 40$ & $190 \times 190$ & 110 & 94 & 52,5 & 2267,15 \\
\hline
\end{tabular}

* - Força última obtida considerando os critérios de Blévot e Frémy (1967): Formação das bielas no topo do bloco; força vertical centrada; e tensão limite de compressão da biela de $0,9 \cdot f_{\mathrm{ck}}$.

Tabela 4.4 - Força última dos modelos do grupo B (interface lisa)

\begin{tabular}{|c|c|c|c|c|c|c|c|}
\hline Modelo & $\begin{array}{c}\mathbf{A}_{\text {est }} \times B_{\text {est }} \\
\quad(\mathbf{c m})\end{array}$ & $\begin{array}{l}\mathbf{A}_{\text {pil }} \times B_{\text {pil }} \\
\quad(\mathbf{c m})\end{array}$ & $\begin{array}{c}\mathbf{A}_{\text {blo }} \times \mathbf{B}_{\text {blo }} \\
\quad(\mathbf{c m})\end{array}$ & $\begin{array}{c}l_{\mathrm{e}} \\
(\mathrm{cm})\end{array}$ & $\begin{array}{c}H \\
(\mathbf{c m})\end{array}$ & $\begin{array}{c}\theta \\
\text { (graus) }\end{array}$ & $\begin{array}{c}\mathbf{F}_{\mathbf{u}} * \\
(\mathbf{k N})\end{array}$ \\
\hline IL-E60-HS20-N & $30 \times 30$ & $40 \times 40$ & $190 \times 190$ & 110 & 80 & 47,3 & 1945,25 \\
\hline IL-E60-HS20-NM & $30 \times 30$ & $40 \times 40$ & $190 \times 190$ & 110 & 80 & 47,3 & 1945,25 \\
\hline IL-E60-HS20-NMM & $30 \times 30$ & $40 \times 40$ & $190 \times 190$ & 110 & 80 & 47,3 & 1945,25 \\
\hline IL-E60-HS30-N & $30 \times 30$ & $40 \times 40$ & $190 \times 190$ & 110 & 90 & 51,1 & 2183,23 \\
\hline IL-E60-HS30-NM & $30 \times 30$ & $40 \times 40$ & $190 \times 190$ & 110 & 90 & 51,1 & 2183,23 \\
\hline IL-E60-HS30-NMM & $30 \times 30$ & $40 \times 40$ & $190 \times 190$ & 110 & 90 & 51,1 & 2183,23 \\
\hline IL-E80-HS20-N & $30 \times 30$ & $40 \times 40$ & $190 \times 190$ & 110 & 100 & 54,4 & 2382,06 \\
\hline IL-E80-HS20-NM & $30 \times 30$ & $40 \times 40$ & $190 \times 190$ & 110 & 100 & 54,4 & 2382,06 \\
\hline IL-E80-HS20-NMM & $30 \times 30$ & $40 \times 40$ & $190 \times 190$ & 110 & 100 & 54,4 & 2382,06 \\
\hline IL-E80-HS30-N & $30 \times 30$ & $40 \times 40$ & $190 \times 190$ & 110 & 110 & 57,3 & 2547,37 \\
\hline IL-E80-HS30-NM & $30 \times 30$ & $40 \times 40$ & $190 \times 190$ & 110 & 110 & 57,3 & 2547,37 \\
\hline IL-E80-HS30-NMM & $30 \times 30$ & $40 \times 40$ & $190 \times 190$ & 110 & 110 & 57,3 & 2547,37 \\
\hline
\end{tabular}

A armadura dos modelos foi dimensionada de modo a evitar que a ruína do pilar ou estacas preceda a ruptura do bloco. Considerando que a armadura do bloco não faz parte dos parâmetros que são objetos de análise, as armaduras do bloco foram dimensionadas de tal 
modo que, ao final, foram adotadas as mesmas quantidades de armaduras para todos os modelos. Esse procedimento fez com que a armadura efetiva dos tirantes para alguns modelos resultassem $25 \%$ maiores que as calculadas. Considerando estas premissas, a Figura 4.3 ilustra a armadura utilizada nos modelos do grupo A e B.

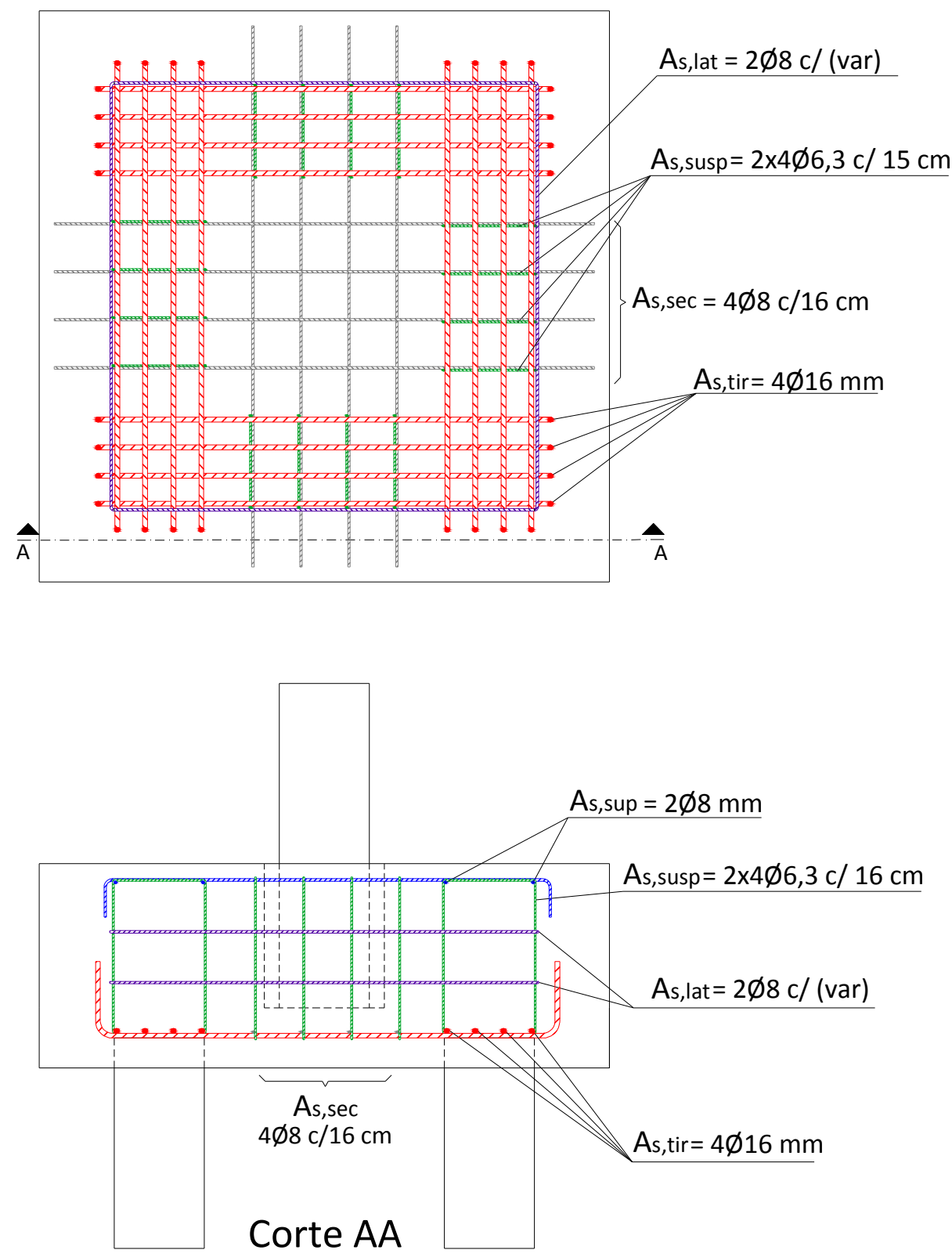

Figura 4.3 - Disposição das armaduras do bloco dos modelos analisados

A armadura principal, correspondente aos tirantes foi disposta em faixas laterais de largura igual à medida do lado da estaca e posicionada sobre as mesmas. A armadura secundária foi calculada para $25 \%$ da capacidade mecânica das armaduras principais 
colocadas em faixas, para cada direção, como é recomendado por Calavera (2000). A armadura superior adotada foi de $10 \%$ da armadura principal em faixa, conforme indica o Boletim 73 do CEB-FIP (1970). A armadura lateral foi obtida conforme recomendação de Alonso (1983), 1/8 da armadura principal. A armadura de suspensão foi dimensionada para resistir a uma força total igual à força atuante no pilar dividida por uma vez e meia o número de estacas, de acordo com as indicações de Leonhardt e Mönnig (1978).

A Tabela 4.5 indica a armadura principal, superior e lateral dos modelos do grupo A. Já a Tabela 4.6 indica a armadura secundária e de suspensão dos modelos do grupo A.

Tabela 4.5 - Armaduras principal, superior e lateral dos modelos do grupo A

\begin{tabular}{|c|c|c|c|c|c|c|c|}
\hline \multirow{2}{*}{ Modelos } & \multicolumn{3}{|c|}{ Armadura Principal } & \multicolumn{2}{|c|}{$\begin{array}{l}\text { Armadura } \\
\text { Superior }\end{array}$} & \multicolumn{2}{|c|}{ Armadura Lateral } \\
\hline & $\begin{array}{c}\mathbf{A}_{\text {s,tir,calc }} \\
\left(\mathbf{c m}^{2}\right)\end{array}$ & Adotada & $\begin{array}{c}A_{\text {s,tir,ef }} \\
\left(\mathbf{c m}^{2}\right)\end{array}$ & Adotada & $\begin{array}{c}\mathbf{A}_{\mathrm{s}, \text { sup,ef }} \\
\left(\mathrm{cm}^{2}\right)\end{array}$ & Adotada & $\begin{array}{r}\mathbf{A}_{\text {s,lat,e }} \\
\left(\mathbf{c m}^{2}\right)\end{array}$ \\
\hline IR-E48-HS20-N & 6,68 & $4 \varnothing 16 \mathrm{~mm}$ & 8,04 & $2 \varnothing 8 \mathrm{~mm}$ & 1,01 & $2 \varnothing 8 \mathrm{~mm}$ & 1,01 \\
\hline IR-E48-HS20-NM & 6,68 & $4 \varnothing 16 \mathrm{~mm}$ & 8,04 & $2 \varnothing 8 \mathrm{~mm}$ & 1,01 & $2 \varnothing 8 \mathrm{~mm}$ & 1,01 \\
\hline IR-E48-HS20-NMM & 6,68 & $4 \varnothing 16 \mathrm{~mm}$ & 8,04 & $2 \varnothing 8 \mathrm{~mm}$ & 1,01 & $2 \varnothing 8 \mathrm{~mm}$ & 1,01 \\
\hline IR-E48-HS30-N & 6,61 & $4 \varnothing 16 \mathrm{~mm}$ & 8,04 & $2 \varnothing 8 \mathrm{~mm}$ & 1,01 & $2 \varnothing 8 \mathrm{~mm}$ & 1,01 \\
\hline IR-E48-HS30-NM & 6,61 & $4 \varnothing 16 \mathrm{~mm}$ & 8,04 & $2 \varnothing 8 \mathrm{~mm}$ & 1,01 & $2 \varnothing 8 \mathrm{~mm}$ & 1,01 \\
\hline IR-E48-HS30-NMM & 6,61 & $4 \varnothing 16 \mathrm{~mm}$ & 8,04 & $2 \emptyset 8 \mathrm{~mm}$ & 1,01 & $2 \varnothing 8 \mathrm{~mm}$ & 1,01 \\
\hline IR-E64-HS20-N & 6,56 & $4 \varnothing 16 \mathrm{~mm}$ & 8,04 & $2 \emptyset 8 \mathrm{~mm}$ & 1,01 & $2 \varnothing 8 \mathrm{~mm}$ & 1,01 \\
\hline IR-E64-HS20-NM & 6,56 & $4 \varnothing 16 \mathrm{~mm}$ & 8,04 & $2 \varnothing 8 \mathrm{~mm}$ & 1,01 & $2 \varnothing 8 \mathrm{~mm}$ & 1,01 \\
\hline IR-E64-HS20-NMM & 6,56 & $4 \varnothing 16 \mathrm{~mm}$ & 8,04 & $2 \varnothing 8 \mathrm{~mm}$ & 1,01 & $2 \varnothing 8 \mathrm{~mm}$ & 1,01 \\
\hline IR-E64-HS30-N & 6,41 & $4 \varnothing 16 \mathrm{~mm}$ & 8,04 & $2 \varnothing 8 \mathrm{~mm}$ & 1,01 & $2 \varnothing 8 \mathrm{~mm}$ & 1,01 \\
\hline IR-E64-HS30-NM & 6,41 & $4 \varnothing 16 \mathrm{~mm}$ & 8,04 & $2 \varnothing 8 \mathrm{~mm}$ & 1,01 & $2 \varnothing 8 \mathrm{~mm}$ & 1,01 \\
\hline IR-E64-HS30-NMM & 6,41 & $4 \varnothing 16 \mathrm{~mm}$ & 8,04 & $2 \varnothing 8 \mathrm{~mm}$ & 1,01 & $2 \varnothing 8 \mathrm{~mm}$ & 1,01 \\
\hline
\end{tabular}


Capítulo 4: Blocos sobre Quatro Estacas com Cálice Embutido

Tabela 4.6 - Armaduras secundária e de suspensão dos modelos do grupo A

\begin{tabular}{|c|c|c|c|c|}
\hline \multirow{2}{*}{ Modelos } & \multicolumn{2}{|c|}{ Armadura Secundária } & \multicolumn{2}{|c|}{ Armadura de Suspensão } \\
\hline & $\begin{array}{c}\text { Adotada } \\
\text { (em cada direção) }\end{array}$ & $\begin{array}{c}\mathbf{A}_{\mathrm{s}, \mathrm{sec}, \mathrm{ef}} \\
\left(\mathbf{c m}^{2}\right)\end{array}$ & Adotada & $\begin{array}{c}\mathbf{A}_{\text {s,lat,ef }} \\
\left(\mathbf{c m}^{2}\right)\end{array}$ \\
\hline IR-E48-HS20-N & $4 \varnothing 8 \mathrm{c} / 16 \mathrm{~cm}$ & 2,01 & $2 \times 16 \varnothing 6,3 \mathrm{c} / 16 \mathrm{~cm}$ & 9,96 \\
\hline IR-E48-HS20-NM & $4 \varnothing 8 \mathrm{c} / 16 \mathrm{~cm}$ & 2,01 & $2 \times 16 \varnothing 6,3 \mathrm{c} / 16 \mathrm{~cm}$ & 9,96 \\
\hline IR-E48-HS20-NMM & $4 \varnothing 8 \mathrm{c} / 16 \mathrm{~cm}$ & 2,01 & $2 \times 16 \varnothing 6,3 \mathrm{c} / 16 \mathrm{~cm}$ & 9,96 \\
\hline IR-E48-HS30-N & $4 \emptyset 8 \mathrm{c} / 16 \mathrm{~cm}$ & 2,01 & $2 \times 16 \varnothing 6,3 \mathrm{c} / 16 \mathrm{~cm}$ & 9,96 \\
\hline IR-E48-HS30-NM & $4 \varnothing 8 \mathrm{c} / 16 \mathrm{~cm}$ & 2,01 & $2 \times 16 \varnothing 6,3 \mathrm{c} / 16 \mathrm{~cm}$ & 9,96 \\
\hline IR-E48-HS30-NMM & $4 \emptyset 8 \mathrm{c} / 16 \mathrm{~cm}$ & 2,01 & $2 \times 16 \varnothing 6,3 \mathrm{c} / 16 \mathrm{~cm}$ & 9,96 \\
\hline IR-E64-HS20-N & $4 \varnothing 8 \mathrm{c} / 16 \mathrm{~cm}$ & 2,01 & $2 \times 16 \varnothing 6,3 \mathrm{c} / 16 \mathrm{~cm}$ & 9,96 \\
\hline IR-E64-HS20-NM & $4 \varnothing 8 \mathrm{c} / 16 \mathrm{~cm}$ & 2,01 & $2 \times 16 \varnothing 6,3 \mathrm{c} / 16 \mathrm{~cm}$ & 9,96 \\
\hline IR-E64-HS20-NMM & $4 \varnothing 8 \mathrm{c} / 16 \mathrm{~cm}$ & 2,01 & $2 \times 16 \varnothing 6,3 \mathrm{c} / 16 \mathrm{~cm}$ & 9,96 \\
\hline IR-E64-HS30-N & $4 \varnothing 8 \mathrm{c} / 16 \mathrm{~cm}$ & 2,01 & $2 \times 16 \varnothing 6,3 \mathrm{c} / 16 \mathrm{~cm}$ & 9,96 \\
\hline IR-E64-HS30-NM & $4 \varnothing 8 \mathrm{c} / 16 \mathrm{~cm}$ & 2,01 & $2 \times 16 \varnothing 6,3 \mathrm{c} / 16 \mathrm{~cm}$ & 9,96 \\
\hline IR-E64-HS30-NMM & $4 \varnothing 8 \mathrm{c} / 16 \mathrm{~cm}$ & 2,01 & $2 \times 16 \varnothing 6,3 \mathrm{c} / 16 \mathrm{~cm}$ & 9,96 \\
\hline
\end{tabular}

As armaduras que compõem os blocos do grupo B estão indicadas na Tabela 4.7 e na Tabela 4.8.

Tabela 4.7 - Armaduras principal, superior e lateral dos modelos do grupo B

\begin{tabular}{|c|c|c|c|c|c|c|c|}
\hline \multirow{2}{*}{ Modelos } & \multicolumn{3}{|c|}{ Armadura Principal } & \multicolumn{2}{|c|}{$\begin{array}{l}\text { Armadura } \\
\text { Superior }\end{array}$} & \multicolumn{2}{|c|}{ Armadura Lateral } \\
\hline & $\begin{array}{c}\mathbf{A}_{\mathrm{s}, \mathrm{tir}, \mathrm{calc}} \\
\left(\mathrm{cm}^{2}\right)\end{array}$ & Adotada & $\begin{array}{c}\mathbf{A}_{\mathrm{s}, \mathrm{tir}, \mathrm{ef}} \\
\left(\mathbf{c m}^{2}\right)\end{array}$ & Adotada & $\begin{array}{c}\mathbf{A}_{\text {s,sup,ef }} \\
\left(\mathbf{c m}^{2}\right)\end{array}$ & Adotada & $\begin{array}{c}\mathbf{A}_{\text {s,lat,ef }} \\
\left(\mathbf{c m}^{2}\right)\end{array}$ \\
\hline IL-E60-HS20-N & 6,60 & $4 \varnothing 16 \mathrm{~mm}$ & 8,04 & $2 \varnothing 8 \mathrm{~mm}$ & 1,01 & $2 \varnothing 8 \mathrm{~mm}$ & 1,01 \\
\hline IL-E60-HS20-NM & 6,60 & $4 \varnothing 16 \mathrm{~mm}$ & 8,04 & $2 \varnothing 8 \mathrm{~mm}$ & 1,01 & $2 \varnothing 8 \mathrm{~mm}$ & 1,01 \\
\hline IL-E60-HS20-NMM & 6,60 & $4 \varnothing 16 \mathrm{~mm}$ & 8,04 & $2 \varnothing 8 \mathrm{~mm}$ & 1,01 & $2 \varnothing 8 \mathrm{~mm}$ & 1,01 \\
\hline IL-E60-HS30-N & 6,48 & $4 \varnothing 16 \mathrm{~mm}$ & 8,04 & $2 \varnothing 8 \mathrm{~mm}$ & 1,01 & $2 \varnothing 8 \mathrm{~mm}$ & 1,01 \\
\hline IL-E60-HS30-NM & 6,48 & $4 \varnothing 16 \mathrm{~mm}$ & 8,04 & $2 \varnothing 8 \mathrm{~mm}$ & 1,01 & $2 \emptyset 8 \mathrm{~mm}$ & 1,01 \\
\hline IL-E60-HS30-NMM & 6,48 & $4 \varnothing 16 \mathrm{~mm}$ & 8,04 & $2 \varnothing 8 \mathrm{~mm}$ & 1,01 & $2 \varnothing 8 \mathrm{~mm}$ & 1,01 \\
\hline IL-E80-HS20-N & 6,29 & $4 \varnothing 16 \mathrm{~mm}$ & 8,04 & $2 \varnothing 8 \mathrm{~mm}$ & 1,01 & $2 \varnothing 8 \mathrm{~mm}$ & 1,01 \\
\hline IL-E80-HS20-NM & 6,29 & $4 \varnothing 16 \mathrm{~mm}$ & 8,04 & $2 \varnothing 8 \mathrm{~mm}$ & 1,01 & $2 \varnothing 8 \mathrm{~mm}$ & 1,01 \\
\hline IL-E80-HS20-NMM & 6,29 & $4 \varnothing 16 \mathrm{~mm}$ & 8,04 & $2 \varnothing 8 \mathrm{~mm}$ & 1,01 & $2 \emptyset 8 \mathrm{~mm}$ & 1,01 \\
\hline IL-E80-HS30-N & 6,05 & $4 \varnothing 16 \mathrm{~mm}$ & 8,04 & $2 \varnothing 8 \mathrm{~mm}$ & 1,01 & $2 \varnothing 8 \mathrm{~mm}$ & 1,01 \\
\hline IL-E80-HS30-NM & 6,05 & $4 \varnothing 16 \mathrm{~mm}$ & 8,04 & $2 \varnothing 8 \mathrm{~mm}$ & 1,01 & $2 \varnothing 8 \mathrm{~mm}$ & 1,01 \\
\hline IL-E80-HS30-NMM & 6,05 & $4 \emptyset 16 \mathrm{~mm}$ & 8,04 & $2 \varnothing 8 \mathrm{~mm}$ & 1,01 & $2 \varnothing 8 \mathrm{~mm}$ & 1,01 \\
\hline
\end{tabular}


Tabela 4.8 - Armaduras secundária e de suspensão dos modelos do grupo B

\begin{tabular}{|c|c|c|c|c|}
\hline \multirow{2}{*}{ Modelos } & \multicolumn{2}{|c|}{ Armadura Secundária } & \multicolumn{2}{|c|}{ Armadura de Suspensão } \\
\hline & $\begin{array}{c}\text { Adotada } \\
\text { (em cada direção) }\end{array}$ & $\begin{array}{c}\mathbf{A}_{\text {s,sec,ef }} \\
\left(\mathbf{c m}^{2}\right)\end{array}$ & Adotada & $\begin{array}{l}\mathbf{A}_{\text {s,lat,ef }} \\
\left(\mathbf{c m}^{2}\right)\end{array}$ \\
\hline IL-E60-HS20-N & $4 \varnothing 8 \mathrm{c} / 16 \mathrm{~cm}$ & 2,01 & $2 \times 16 \varnothing 6,3 \mathrm{c} / 16 \mathrm{~cm}$ & 9,96 \\
\hline IL-E60-HS20-NM & $4 \varnothing 8 \mathrm{c} / 16 \mathrm{~cm}$ & 2,01 & $2 \times 16 \varnothing 6,3 \mathrm{c} / 16 \mathrm{~cm}$ & 9,96 \\
\hline IL-E60-HS20-NMM & $4 \varnothing 8 \mathrm{c} / 16 \mathrm{~cm}$ & 2,01 & $2 \times 16 \varnothing 6,3 \mathrm{c} / 16 \mathrm{~cm}$ & 9,96 \\
\hline IL-E60-HS30-N & $4 \varnothing 8 \mathrm{c} / 16 \mathrm{~cm}$ & 2,01 & $2 \times 16 \varnothing 6,3 \mathrm{c} / 16 \mathrm{~cm}$ & 9,96 \\
\hline IL-E60-HS30-NM & $4 \varnothing 8 \mathrm{c} / 16 \mathrm{~cm}$ & 2,01 & $2 \times 16 \varnothing 6,3 \mathrm{c} / 16 \mathrm{~cm}$ & 9,96 \\
\hline IL-E60-HS30-NMM & $4 \varnothing 8 \mathrm{c} / 16 \mathrm{~cm}$ & 2,01 & $2 \times 16 \varnothing 6,3 \mathrm{c} / 16 \mathrm{~cm}$ & 9,96 \\
\hline IL-E80-HS20-N & $4 \varnothing 8 \mathrm{c} / 16 \mathrm{~cm}$ & 2,01 & $2 \times 16 \varnothing 6,3 \mathrm{c} / 16 \mathrm{~cm}$ & 9,96 \\
\hline IL-E80-HS20-NM & $4 \varnothing 8 \mathrm{c} / 16 \mathrm{~cm}$ & 2,01 & $2 \times 16 \varnothing 6,3 \mathrm{c} / 16 \mathrm{~cm}$ & 9,96 \\
\hline IL-E80-HS20-NMM & $4 \varnothing 8 \mathrm{c} / 16 \mathrm{~cm}$ & 2,01 & $2 \times 16 \varnothing 6,3 \mathrm{c} / 16 \mathrm{~cm}$ & 9,96 \\
\hline IL-E80-HS30-N & $4 \varnothing 8 \mathrm{c} / 16 \mathrm{~cm}$ & 2,01 & $2 \times 16 \varnothing 6,3 \mathrm{c} / 16 \mathrm{~cm}$ & 9,96 \\
\hline IL-E80-HS30-NM & $4 \varnothing 8 \mathrm{c} / 16 \mathrm{~cm}$ & 2,01 & $2 \times 16 \varnothing 6,3 \mathrm{c} / 16 \mathrm{~cm}$ & 9,96 \\
\hline IL-E80-HS30-NMM & $4 \varnothing 8 \mathrm{c} / 16 \mathrm{~cm}$ & 2,01 & $2 \times 16 \varnothing 6,3 \mathrm{c} / 16 \mathrm{~cm}$ & 9,96 \\
\hline
\end{tabular}

Desse modo, a armadura dos blocos foi mantida constante para possibilitar a análise dos resultados quando da variação dos parâmetros que foram objeto de estudo. Em razão da inexistência de modelos de dimensionamento de armaduras para cálices embutido, uma vez que as hipóteses consideradas para os cálculos de cálices externos não puderam ser comprovadas em cálices embutidos, optou-se por não utilizar qualquer tipo de armadura complementar à do bloco. Este procedimento visa a não perturbação do campo de tensões e do panorama de fissuras na região da ligação e se justifica pelo caráter deste trabalho.

$\mathrm{O}$ pilar e as estacas foram modelados considerando um concreto de $50 \mathrm{MPa}$ de resistência à compressão aos 28 dias. As propriedades físicas dos concretos dos pilares e das estacas, assim como o dos blocos, encontram-se na Tabela 4.9.

Tabela 4.9 - Propriedades físicas dos concretos

\begin{tabular}{lcccccc}
\hline & $\begin{array}{c}\text { Resistência à } \\
\text { compressão } \\
\boldsymbol{f}_{\mathrm{cm}}(\mathbf{M P a})\end{array}$ & $\begin{array}{c}\text { Resistência } \\
\text { à tração } \\
\boldsymbol{f}_{\text {ctm }}(\mathbf{M P a})\end{array}$ & $\begin{array}{c}\text { Módulo de } \\
\text { elasticidade } \\
\text { longitudinal } \\
\boldsymbol{E}_{\text {cs }}(\mathbf{M P a})\end{array}$ & $\begin{array}{c}\text { Coeficiente } \\
\text { de Poisson } \\
\mathbf{v n n n y y}\end{array}$ & & \multicolumn{2}{c}{$\begin{array}{c}\text { Energia de Fraturamento } \\
\left(\mathbf{N} \cdot \mathbf{m m} / \mathbf{m m}^{2}\right)\end{array}$} \\
\hline Bloco & 25 & 2,565 & 23800,00 & 0,2 & 0,056974 & 5,6974 \\
\hline Pilar & 50 & 4,072 & 33658,28 & 0,2 & 0,092555 & 9,2555 \\
\hline Estaca & 50 & 4,072 & 33658,28 & 0,2 & 0,092555 & 9,2555 \\
\hline
\end{tabular}


O aço das armaduras foi considerado com módulo de elasticidade de $210 \mathrm{GPa}$, resistência característica ao escoamento de $500 \mathrm{MPa}$ e 0,3 de coeficiente de Poisson.

As interfaces nas ligações pilar-graute e graute-bloco, Figura 4.4, foram modeladas por meio de elementos de interface CQ48I que apresentam 16 nós e três graus de liberdade por nó. É oportuno, recomendar precaução adicional para a utilização do comando MERGE, cuja função é acoplar nós da malha que estejam ocupando a mesma posição ou que estejam à distâncias inferiores que certos limites definidos pelo usuário. A utilização deste comando em malhas que possuem elementos de interface pode corromper os mesmos por estes possuírem nós distintos com coordenadas coincidentes.

O comportamento da interface foi descrito pelo modelo de atrito de Coulomb, já utilizado por Barros (2009) para representar o mesmo tipo de ligação. O manual do programa DIANA (2005c) indica que a interação entre dois elementos de concreto pode ser descrita por meio do atrito na interface entre os elementos. Este comportamento pode ser representado pelo modelo de atrito de Coulomb que possui grande semelhança com o modelo de plasticidade de Mohr-Coulomb para elementos contínuos.

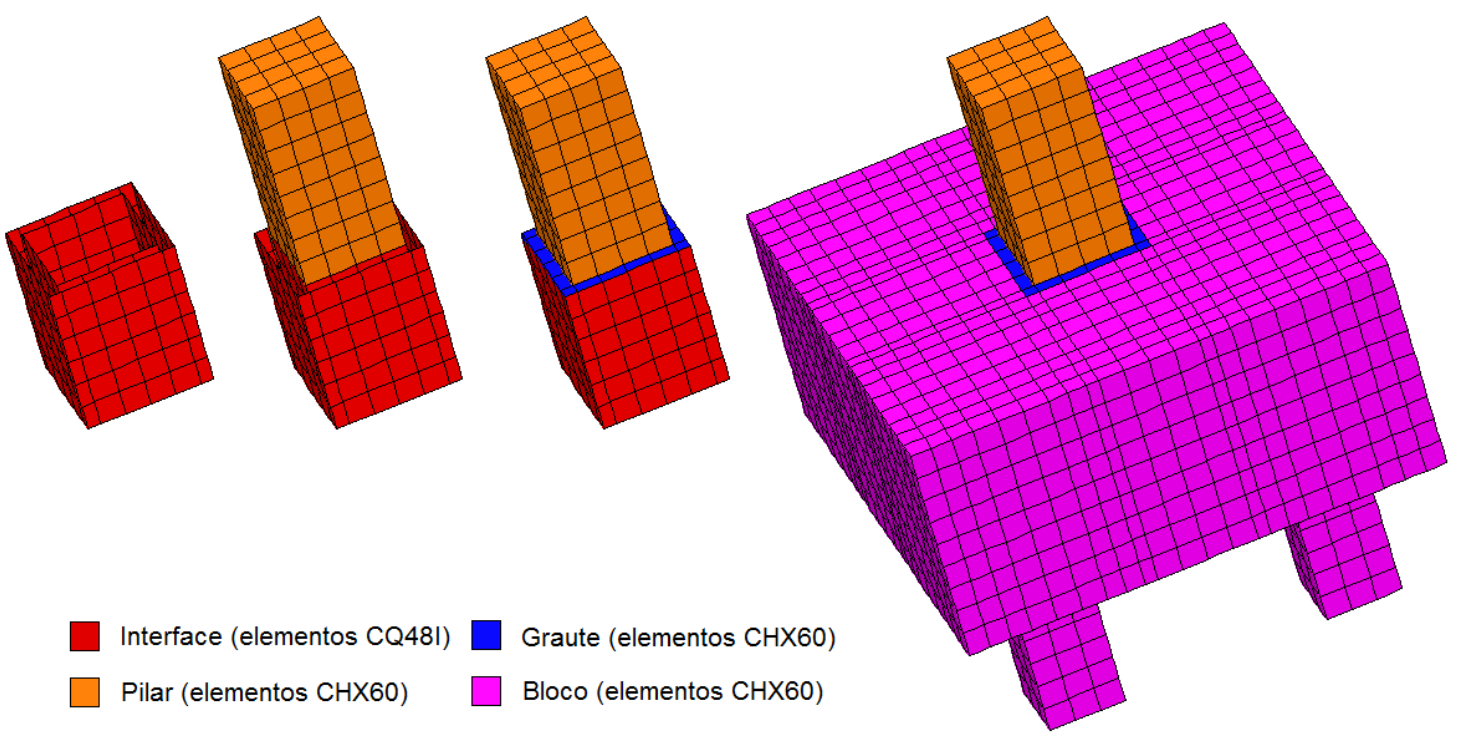

Figura 4.4 - Modelagem da ligação por meio de elementos de interface

Os parâmetros necessários para a descrição do comportamento da interface por este modelo de atrito de Coulomb são a adesão, o coeficiente de atrito e a resistência à tração.

Willert e Kesser (1983), em seu modelo teórico para o projeto de cálices de interface lisa com colarinho, sugerem um coeficiente de atrito de $2 / 3$ na interface. Olin et al. (1985) 
apresentaram um modelo para a distribuição de forças na ligação indicando valores de coeficiente de atrito de 0,3 para interfaces lisas e 0,6 para interfaces rugosas. Elliott (1996) adota coeficiente de atrito de 0,7 no caso de interfaces lisas. Canha (2004) propôs um modelo para dimensionamento de cálices com colarinho sendo que, no caso de interfaces lisas, o coeficiente de atrito é 0,6 .

O guia de ligações do boletim 43 do FIB (2008) indica valores entre 0,6 e 0,8 para o coeficiente de atrito em ligações entre superfícies de concreto em construções gerais e 1,4 para quando são adotadas medidas especiais nas superfícies da ligação, como dentes e chaves de cisalhamento. Tendo como parâmetro os valores sugeridos pela literatura, optou-se por adotar coeficientes de atrito de 0,6 para as interfaces lisas. A partir do coeficiente de atrito indicado, calcularam-se valores de adesão dados pela Expressão 4.1. A resistência à tração foi desprezada.

$$
c=\frac{f_{c}^{\prime} \cdot(1-\operatorname{sen} \emptyset)}{2 \cdot \cos \emptyset}
$$

Para as interfaces rugosas, possuindo chave de cisalhamento, Canha (2004) observou que o comportamento da ligação pode ser considerado como monolítico e, assim, também foi adotado este comportamento nas análises subseqüentes.

\subsection{ANÁlise dos ReSUltados}

\subsubsection{CURVAS FORÇA-DESLOCAMENTO}

Para cada incremento de força foi aferido o correspondente deslocamento do nó central da face inferior do bloco. Apesar dessas medidas de deslocamentos em blocos serem muito pequenas e susceptíveis a erros nos ensaios experimentais, pois a deformabilidade dos apoios e do pórtico de reação podem interferir consideravelmente nas leituras, têm sido comum a apresentação destes resultados nos trabalhos.

Na Figura 4.5 e Figura 4.6 são apresentadas as curvas que relacionam força e deslocamento para os blocos com cálice de fundação de paredes rugosas, analisados para as três diferentes variações de ações: força vertical centrada no eixo do pilar, força vertical com 
excentricidade de $10 \mathrm{~cm}$ em uma direção e força vertical com excentricidade de $10 \mathrm{~cm}$ nas duas direções.
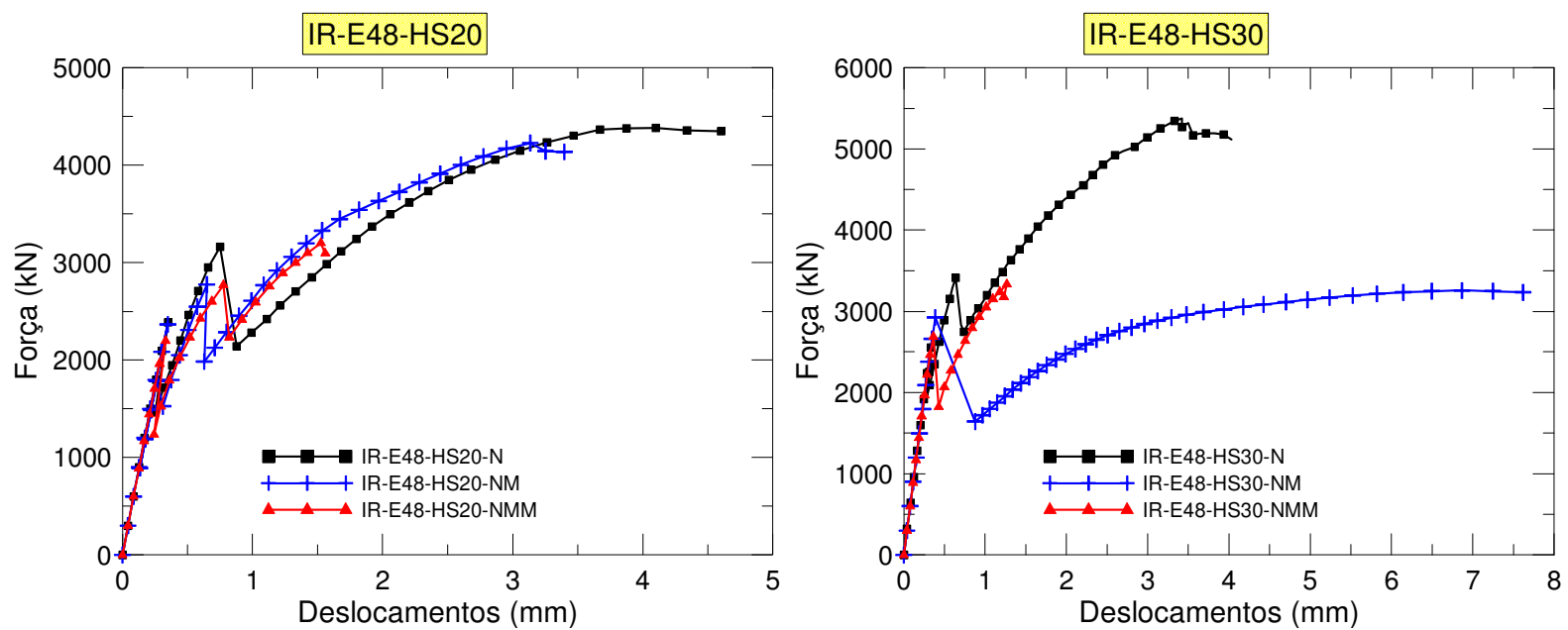

Figura 4.5 - Curvas que relacionam força e deslocamento nos blocos com cálice rugoso de $\ell_{e m b}=$ $48 \mathrm{~cm}$
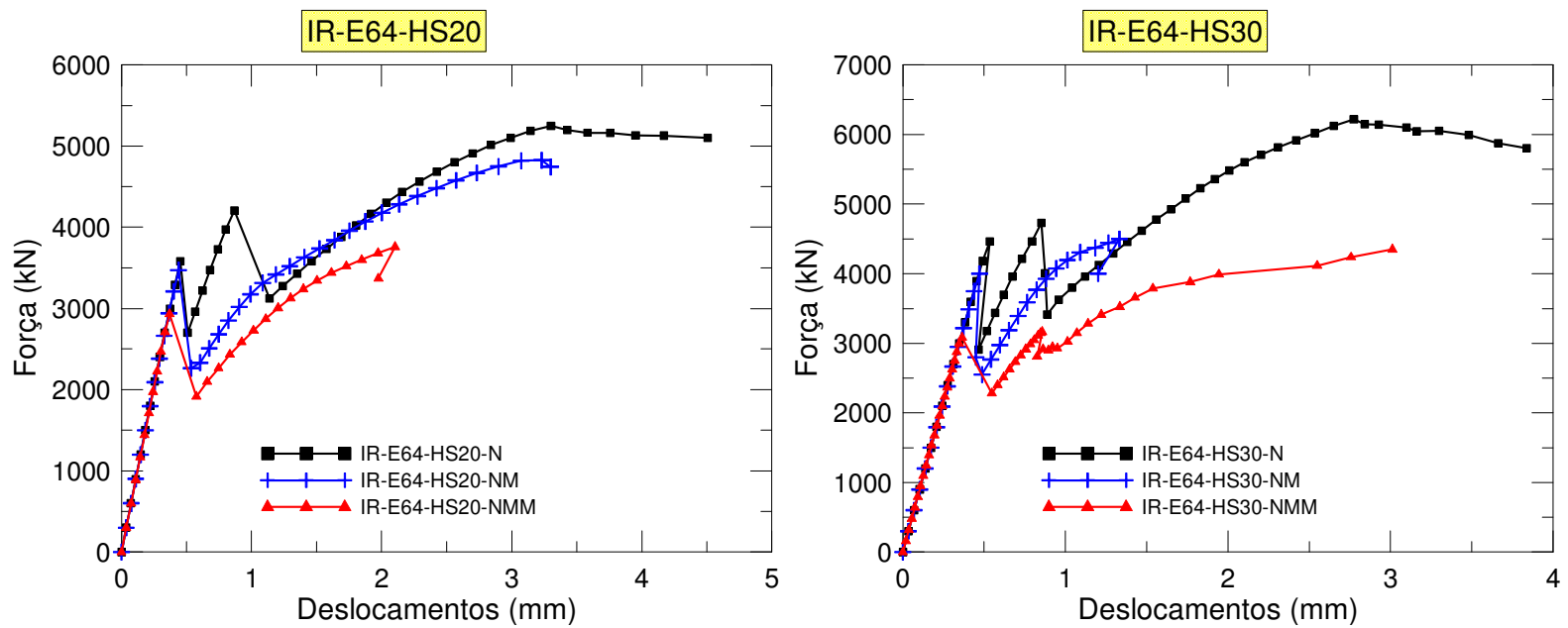

Figura 4.6 - Curvas que relacionam força e deslocamento nos blocos com cálice rugoso de $\ell_{e m b}=$ $64 \mathrm{~cm}$

Como esperado, a atuação da força vertical excêntrica promove a concentração de tensões em algumas bielas provocando a ruptura do bloco para menores valores da ação vertical. As curvas apresentaram trechos lineares seguidos de uma redução da capacidade resistente que delimita o início do ramo não-linear da curva força por deslocamento. Observou-se no panorama de fissuração dos blocos que o passo de carga em que ocorre essa mudança no diagrama corresponde a um avanço do número e tamanho das aberturas das fissuras, em geral, quando estas atingem as faces laterais do bloco. 
Os mesmos diagramas foram traçados para os blocos que possuíam interface de ligação lisa. Na Figura 4.7 e Figura 4.8 são observados os comportamentos dos blocos com interface de ligação lisa quando sob a atuação dos mesmos tipos de ação já descritos para os blocos com cálice de interface rugosa.
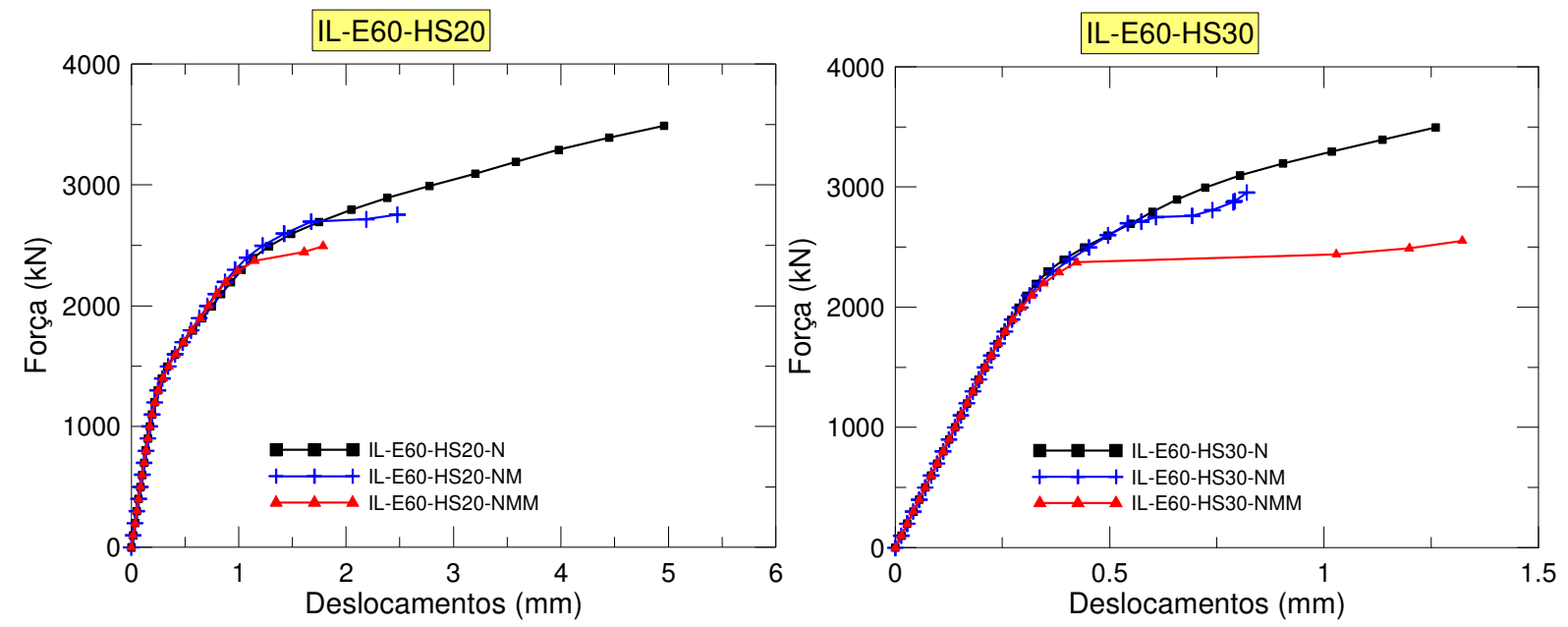

Figura 4.7 - Curvas que relacionam força e deslocamento nos blocos com cálice liso de $\ell_{e m b}=60$ cm
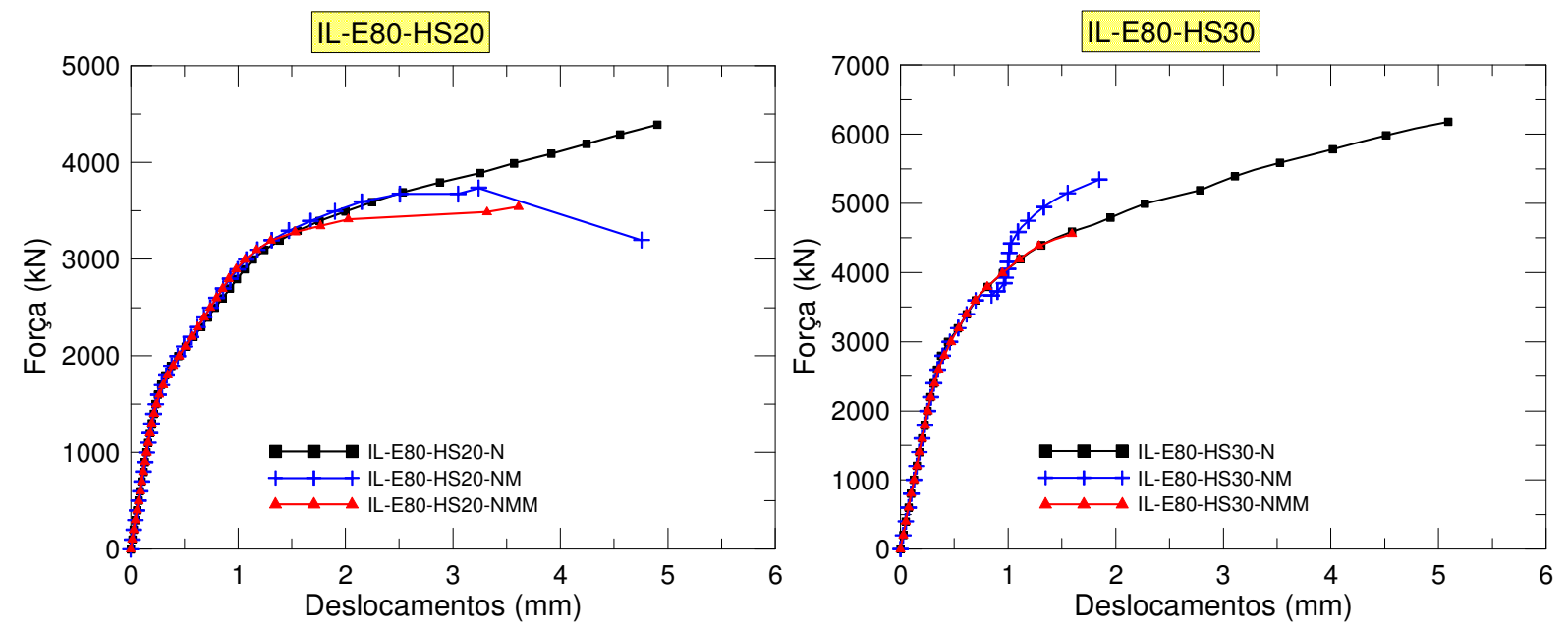

Figura 4.8 - Curvas que relacionam força e deslocamento nos blocos com cálice liso de $\ell_{e m b}=\mathbf{8 0}$ cm

Os blocos com interface de ligação lisa apresentaram curvas força-deslocamento sem grande perda de rigidez apresentada nos blocos com interface rugosa. Esse comportamento com decréscimo de rigidez mais atenuado indica que o aparecimento e abertura de novas fissuras aconteceram gradualmente com a elevação da intensidade da tensão no bloco, ao contrário dos blocos de interface rugosa nos quais o trecho linear é interrompido por uma 
diminuição repentina da resistência indicando o aparecimento de fissuras mais pronunciadas em uma orientação preferencial que coincide com o meio do vão entre as estacas.

\subsubsection{FLUXO DE TENSÕES}

Por meio dos diagramas de tensões principais de compressão foram visualizados os fluxos de tensões, possibilitando assim a delimitação da geometria das bielas nos blocos. Nos blocos do grupo A o fluxo de tensões de compressão ficou delimitado pelo pilar e estacas caracterizando a formação das bielas desde o topo do bloco.

Nos blocos submetidos à força vertical excêntrica, a formação das bielas de compressão foi mais pronunciada na região entre o local da aplicação da força vertical e a estaca de maior reação de apoio. Este fenômeno contribuiu para que a ruína destes blocos ocorresse para forças de intensidade inferiores àquelas observadas nos blocos submetidos à força vertical centrada.

Os blocos com interface lisa não apresentaram a formação de bielas e grande parte da força vertical do pilar transferiu-se para o fundo do cálice sujeitando o bloco à ruína por punção.

Os diagramas da Figura 4.9 à Figura 4.12 indicam as tensões de compressão para os blocos do grupo A, com interface de ligação rugosa, enquanto os diagramas da Figura 4.13 à Figura 4.24 mostram estes resultados para os blocos do grupo B, com interface de ligação lisa. Os modelos foram apresentados aos ternos, sendo o primeiro correspondente àquele submetido à força vertical axial, o segundo submetido à força vertical excêntrica em uma direção e o terceiro à força vertical excêntrica em duas direções. 


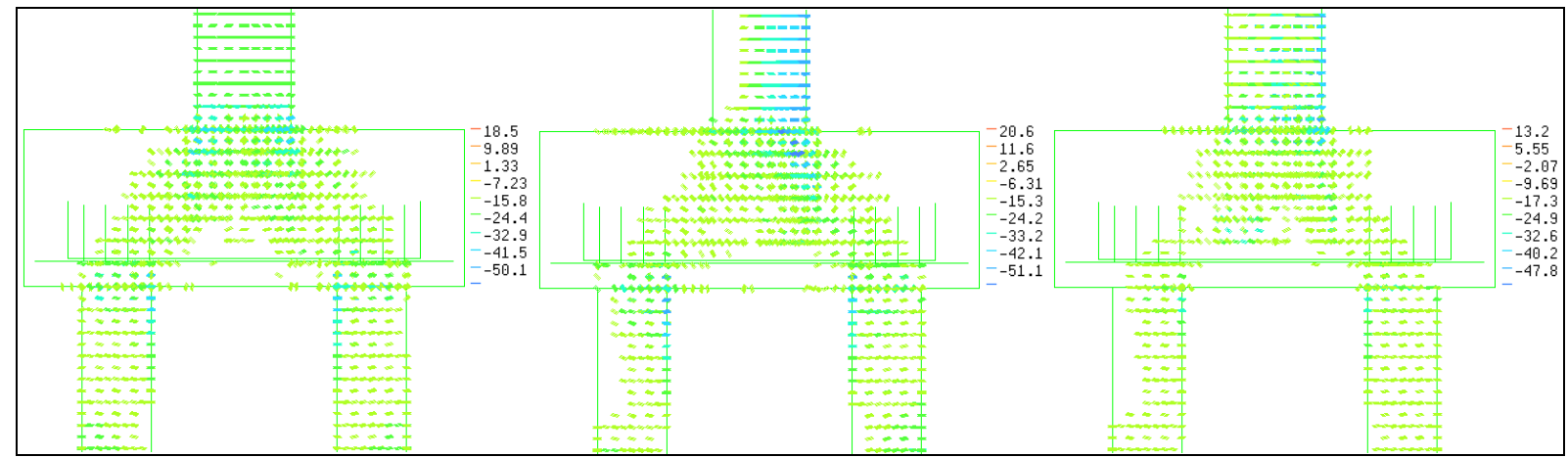

Figura 4.9 - Tensões de compressão superiores a 10 MPa nos modelos IR-E48-HS20

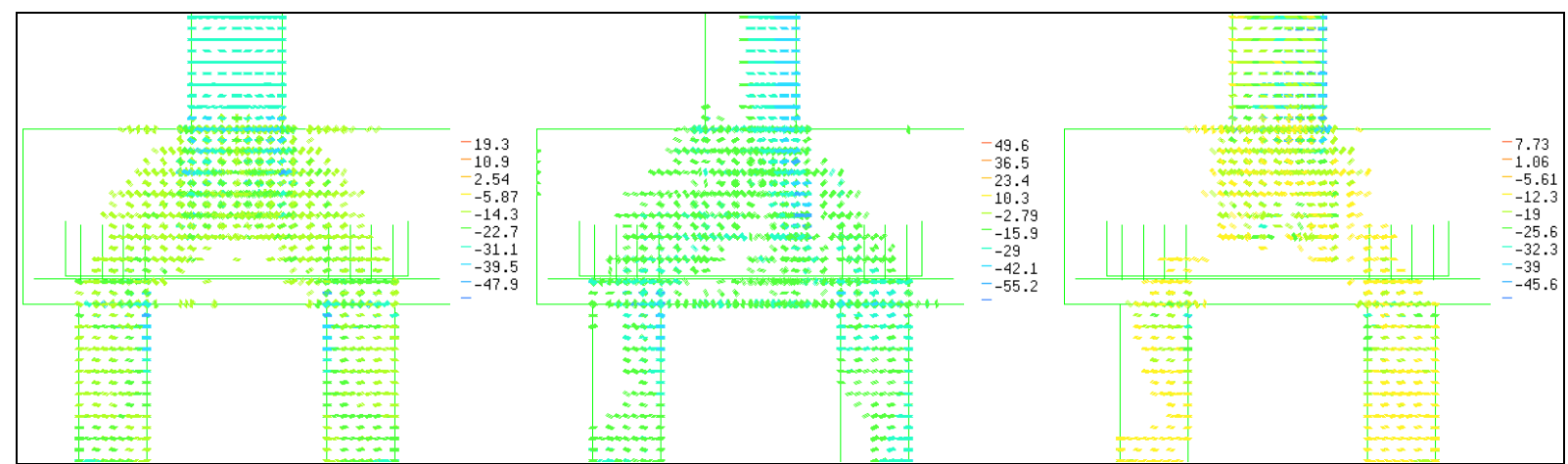

Figura 4.10 - Tensões de compressão superiores a 10 MPa nos modelos IR-E48-HS30

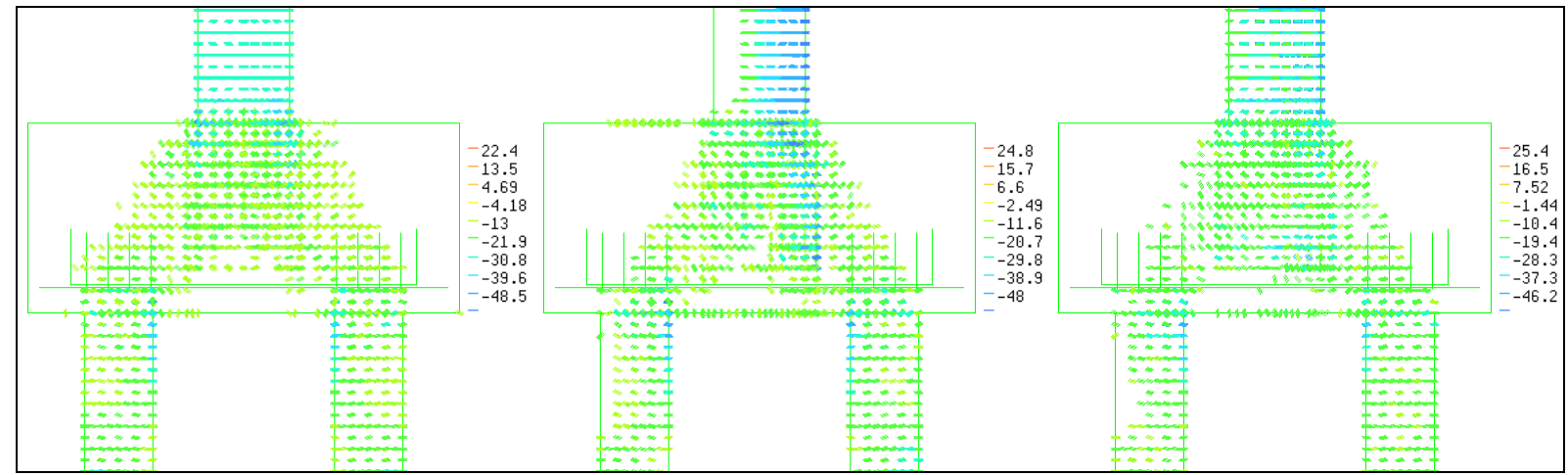

Figura 4.11 - Tensões de compressão superiores a 10 MPa nos modelos IR-E64-HS20 


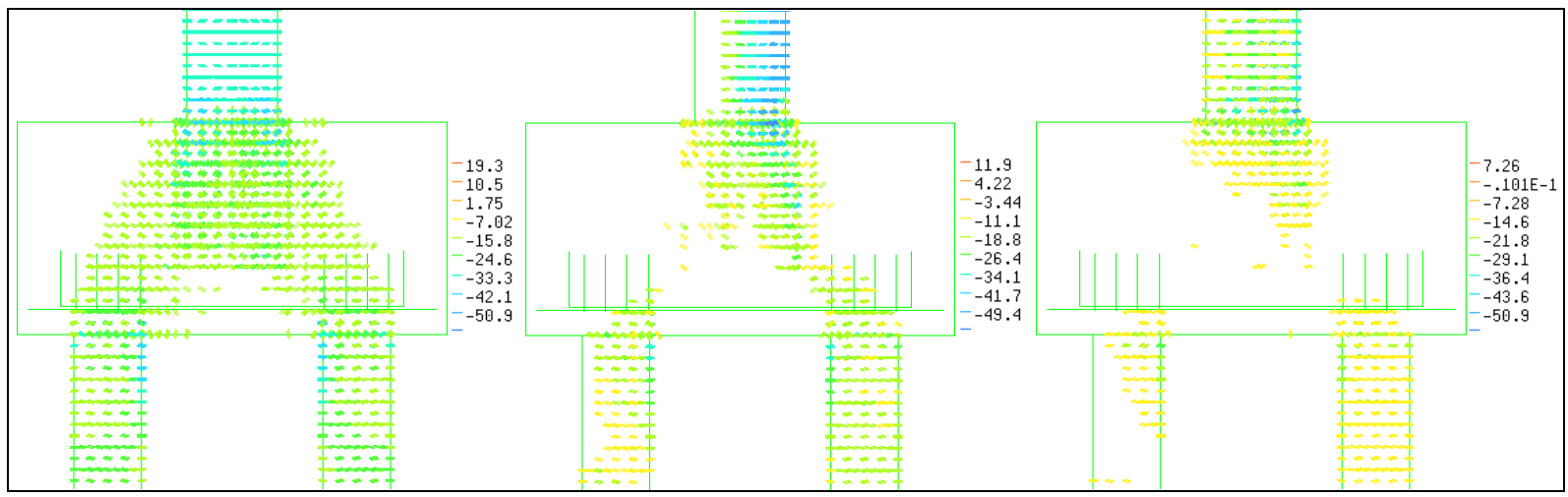

Figura 4.12 - Tensões de compressão superiores a 10 MPa nos modelos IR-E64-HS30

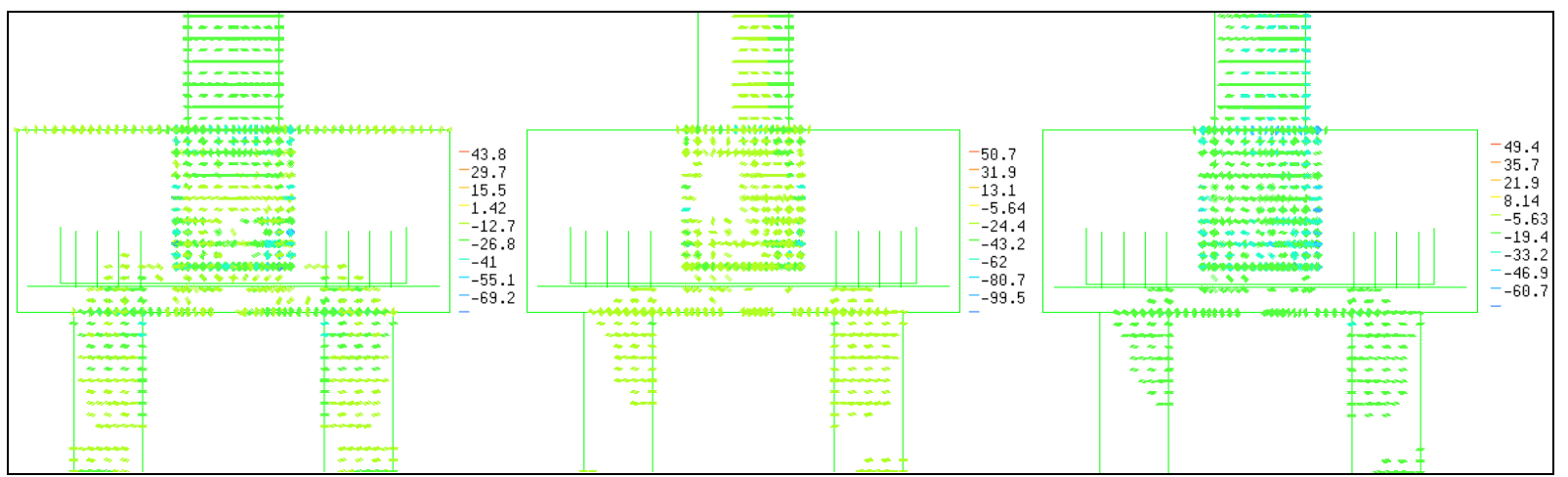

Figura 4.13 - Tensões de compressão superiores a 10 MPa nos modelos IL-E60-HS20

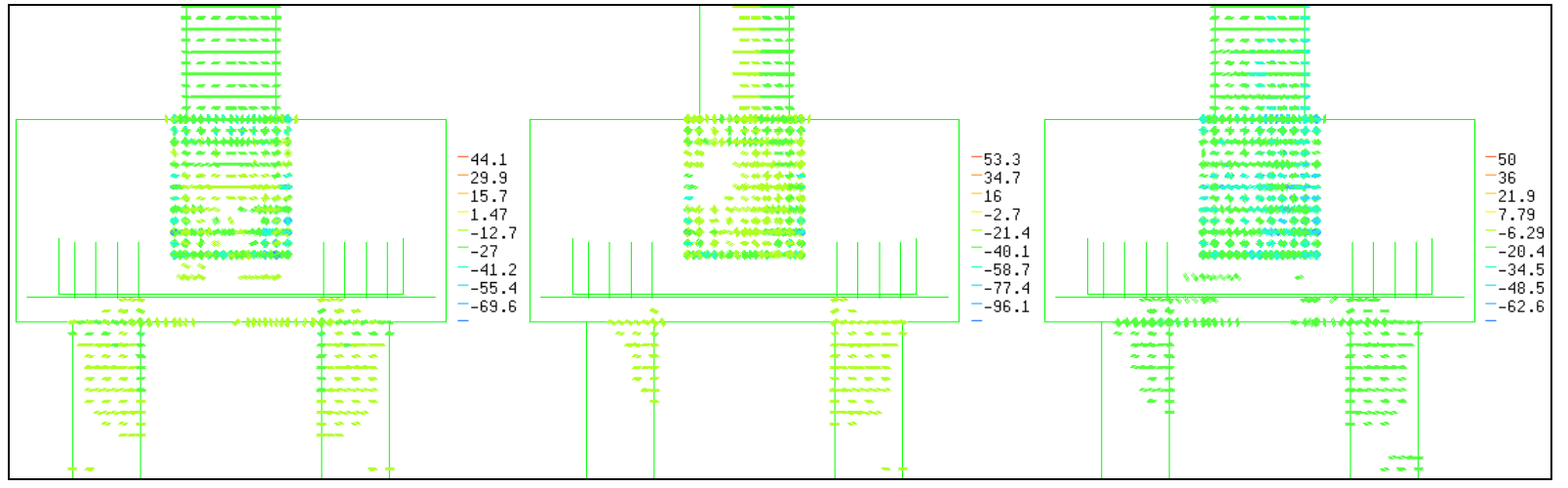

Figura 4.14 - Tensões de compressão superiores a 10 MPa nos modelos IL-E60-HS30 


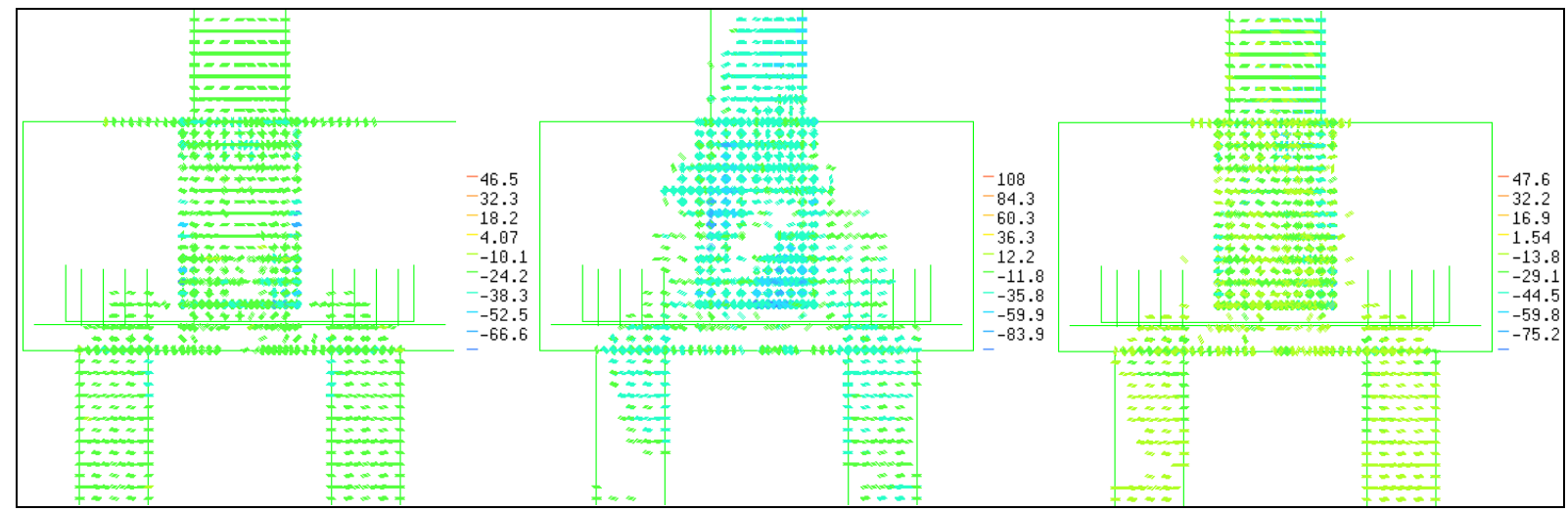

Figura 4.15 - Tensões de compressão superiores a 10 MPa nos modelos IL-E80-HS20

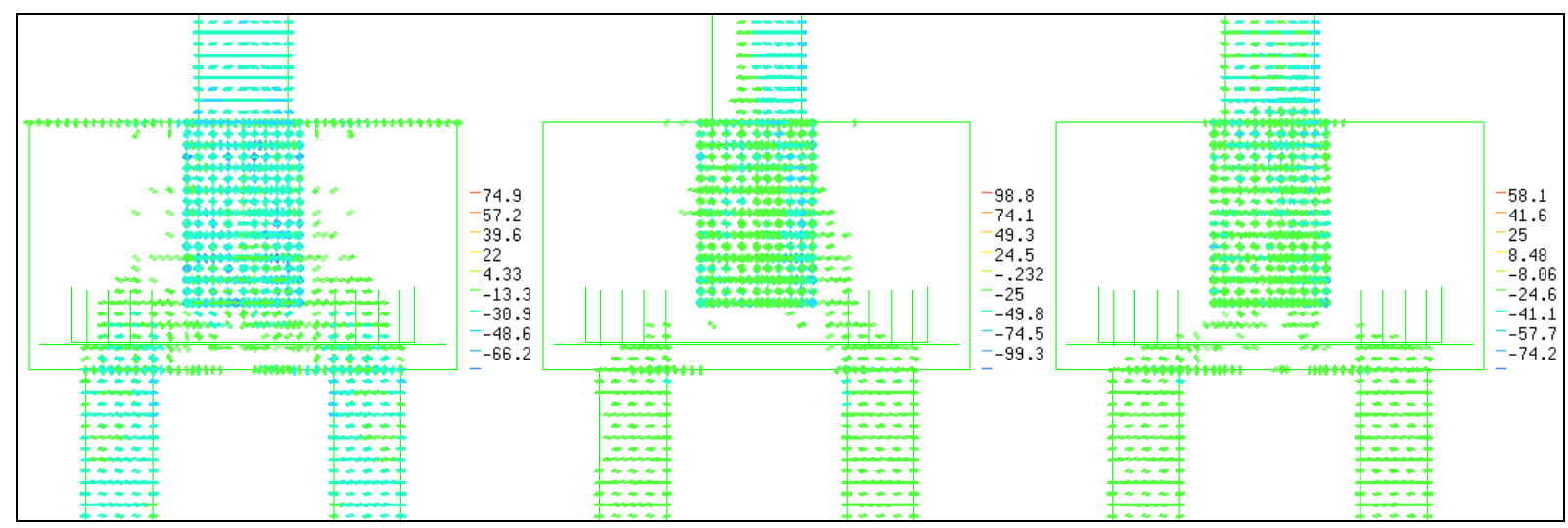

Figura 4.16 - Tensões de compressão superiores a 10 MPa nos modelos IL-E80-HS30

\subsubsection{TENSÕES PRINCIPAIS}

As tensões principais de compressão são apresentadas em diagramas de cores indicando a intensidade das tensões no domínio.

Em razão das bielas ficarem na posição diagonal no bloco, os resultados foram obtidos em uma seção transversal cujo plano contém a diagonal do bloco. Este procedimento é realizado no DIANA mediante a utilização de um algoritmo que interpola os resultados nodais, entretanto algumas pequenas imperfeições são geradas na sua visualização.

Nos blocos considerando a interface rugosa, as bielas são formadas a partir da base do pilar e comprimem as estacas de maneira não uniforme. Assim como Delalibera (2007) e Barros (2009) observaram, na parte superior, as estacas foram mais comprimidas na região próxima às faces internas sendo que, na base das estacas, as tensões de compressão se 
distribuem com mais intensidade na parte mais externa. A ocorrência deste comportamento pode ser remetida às condições de contorno que foram impostas, restrição da translação nas três direções, pois a distribuição de tensões nas estacas de alguns blocos verificados na etapa de análise dos modelos constitutivos foi mais uniforme, isto por que havia sido restringida apenas a translação vertical na base da estaca.

Com relação aos modelos submetidos à força vertical excêntrica, os modelos com excentricidade em duas direções apresentaram bielas com inclinação diferente. Esta observação é condizente com a situação de equilíbrio estático da treliça idealizada, pois uma vez que as forças nos tirantes devem ser constantes e as reações nas estacas variáveis, as bielas de compressão necessariamente terão de se adaptar para atender esta condição de equilíbrio.

Os resultados para os blocos cujas paredes do cálice foram consideradas rugosas, ligação monolítica, estão descritos aos ternos na Figura 4.17 a Figura 4.20. No primeiro bloco atua força vertical centrada, no segundo atua força vertical com excentricidade em uma direção e no terceiro, atua força vertical com excentricidade em duas direções.

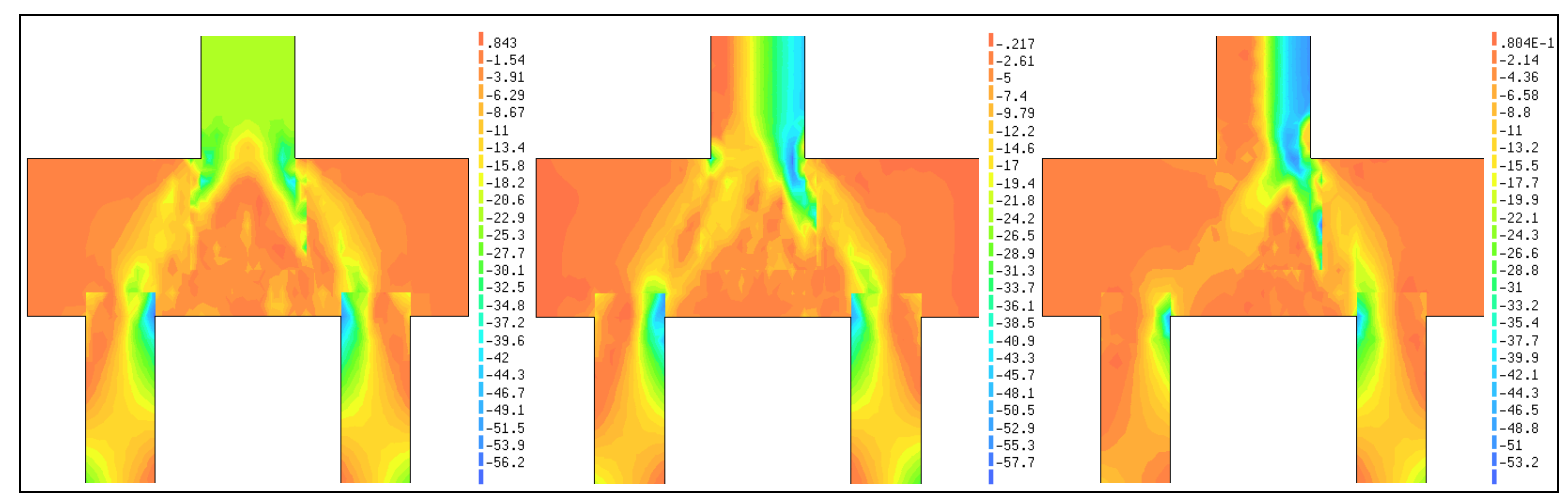

Figura 4.17 - Tensões principais de compressão nos modelos IR-E48-HS20 


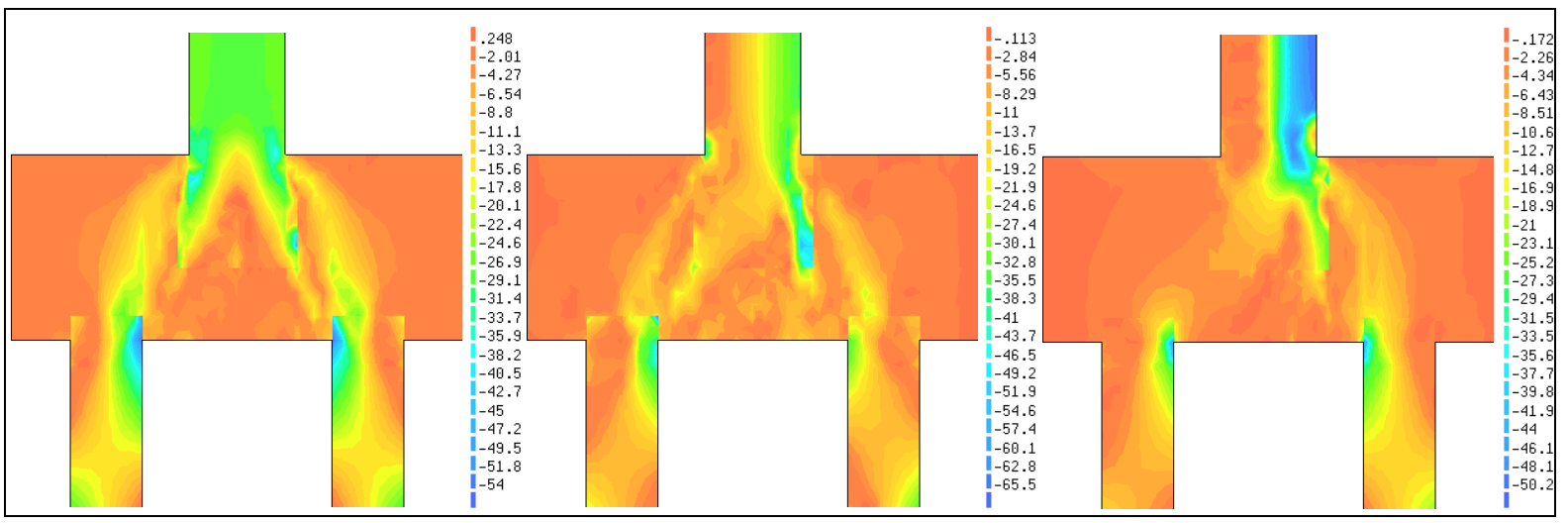

Figura 4.18 - Tensões principais de compressão nos modelos IR-E48-HS30

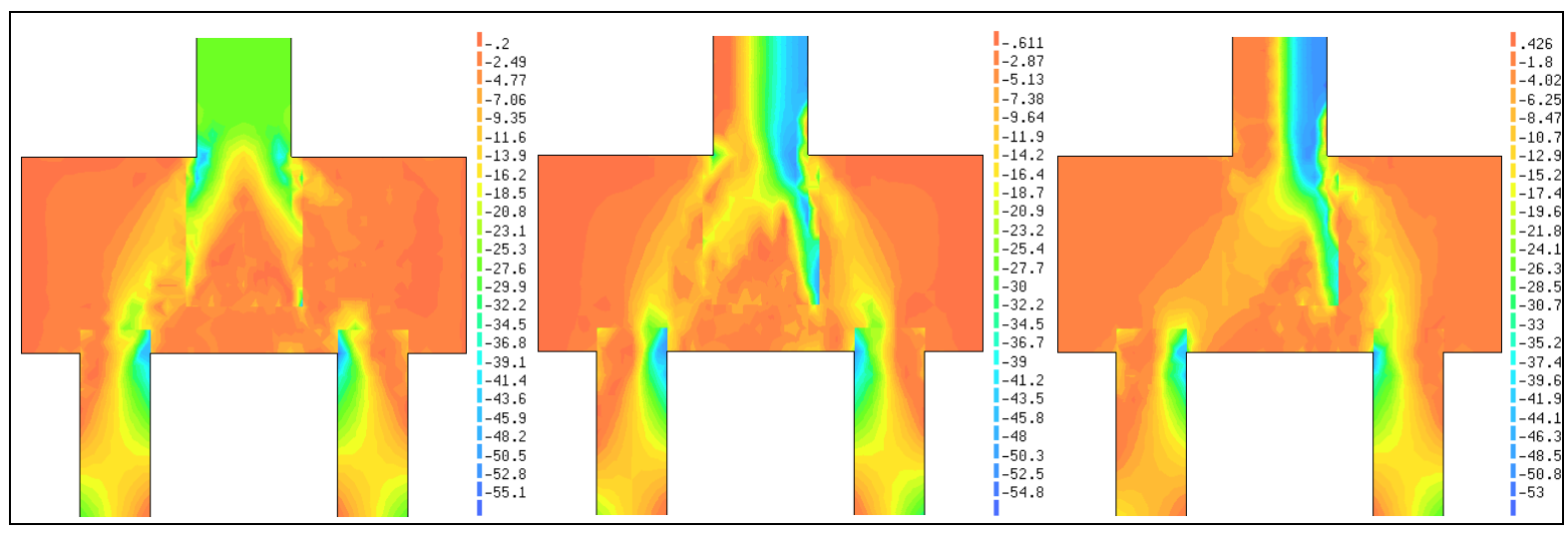

Figura 4.19 - Tensões principais de compressão nos modelos IR-E64-HS20

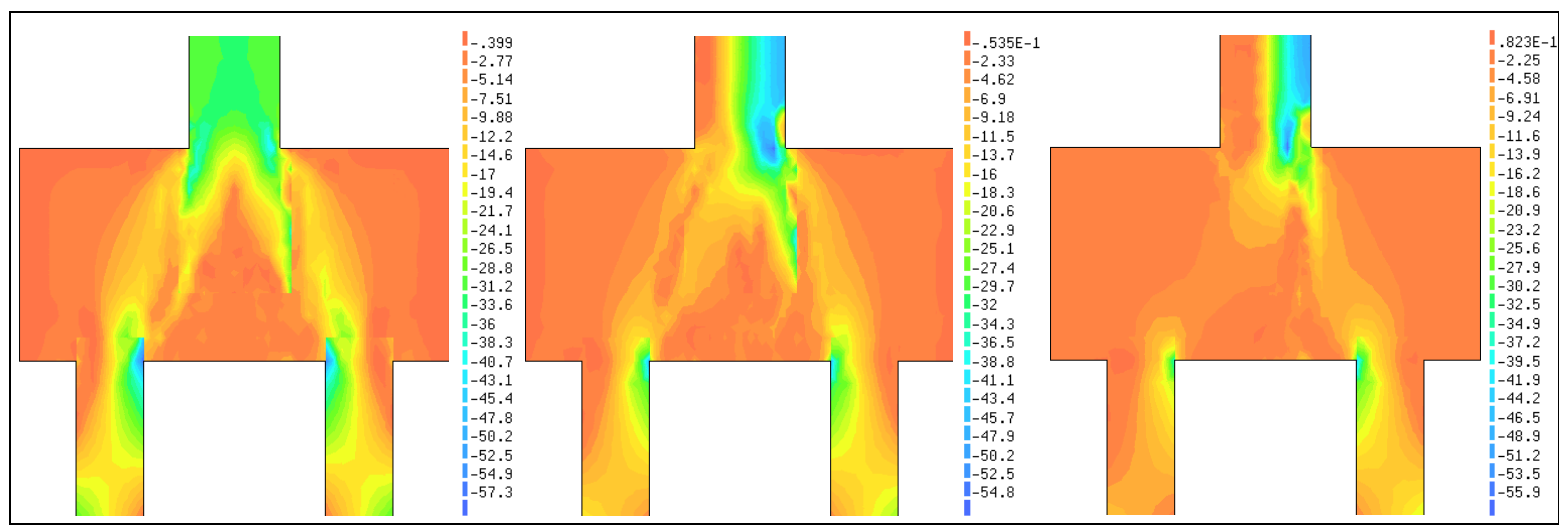

Figura 4.20 - Tensões principais de compressão nos modelos IR-E64-HS30

Nos blocos de interface lisa pôde-se perceber que não foram formadas bielas de compressão a partir do topo do bloco, entretanto constata-se que existe a transferência dos esforços solicitantes do pilar ao bloco, mas não suficientemente grande para a formação de bielas de compressão. 
Nos blocos cuja força vertical do pilar encontra-se centrada, a intensidade de tensões na base do cálice é maior que nos blocos nos quais a força vertical atua excentricamente. Este comportamento está ligado ao fato de que nos blocos em que o pilar está submetido à força vertical excêntrica, existe uma pressão maior exercida nas paredes do cálice que mobiliza também uma maior força de atrito.

Em razão da elevada intensidade de tensão que ainda atinge a base dos cálices com a interface considerada lisa, torna-se muito mais susceptível à ruína do bloco por punção. A força máxima do pilar resistida à punção do bloco pode ser calculada pela Expressão 4.2, obtida a partir do item 19.5 da ABNT NBR 6118:2003, desprezando os coeficientes majoradores da solicitação e minoradores da resistência e majorando a resistência em 20\%, em razão do estado múltiplo de tensões.

$$
F_{s k}=0,27 \cdot\left(1-\frac{f_{c k}}{250}\right) \cdot f_{c k} \cdot u \cdot d \cdot 1,2
$$

Sendo que:

$u \quad$ é a força aplicada ao fundo do bloco pelo pilar suficiente para provocar a punção $(1539,65 k N)$;

$u \quad$ é o perímetro da superfície crítica $C$, coincidente ao perímetro do pilar $160 \mathrm{~cm}$;

d é a média da altura útil do bloco nas duas direções, $\mathrm{dx}$ e dy, que no caso destes blocos, fazendo-se uma analogia à uma laje e pilar invertidos, é igual a 13,2 $\mathrm{cm}$.

Verifica-se que os valores de resistência dos blocos nos modelos analisados ultrapassaram o limite de 1539,65 kN entretanto, com base nestes resultados, não é possível conhecer precisamente o valor de pressão que o pilar exerceu no fundo do bloco. Esta incerteza ocorre em razão do espraiamento da força em uma área maior que a do perímetro do pilar e em razão de parte da força do pilar ter se dirigido para as estacas.

Os resultados para os blocos cujas paredes do cálice foram consideradas lisas estão descritos aos ternos na Figura 4.21 a Figura 4.24. No primeiro bloco atua força vertical centrada, no segundo atua força vertical com excentricidade em uma direção e no terceiro, atua força vertical com excentricidade em duas direções. 


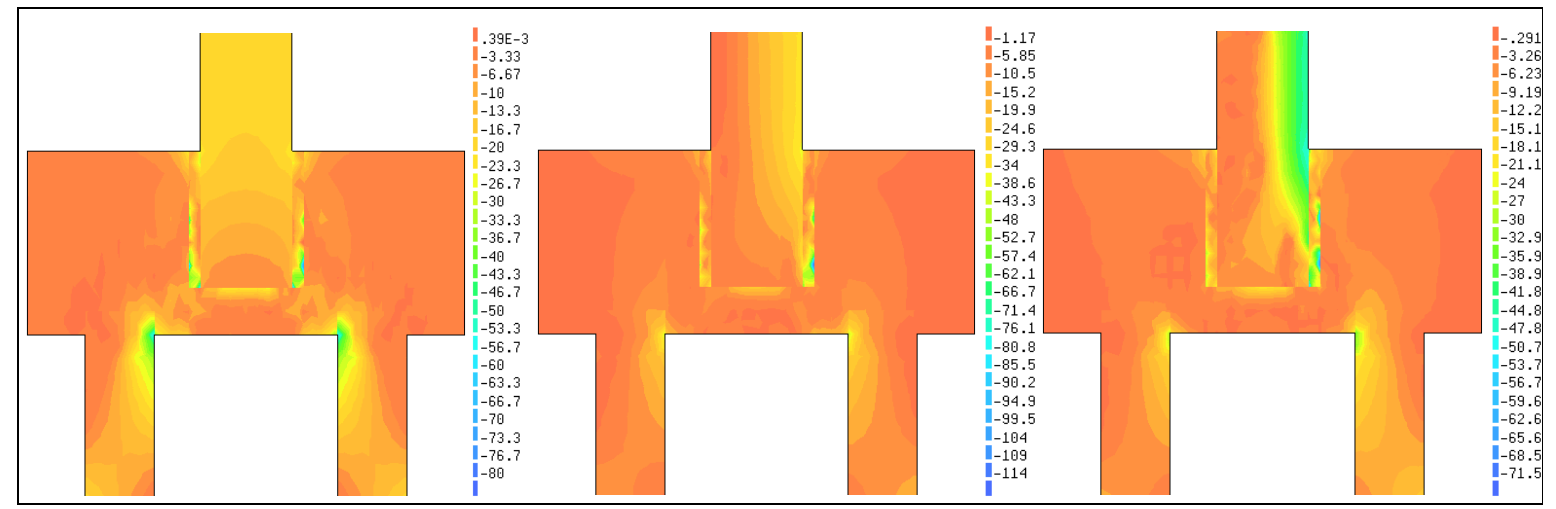

Figura 4.21 - Tensões principais de compressão nos modelos IL-E60-HS20

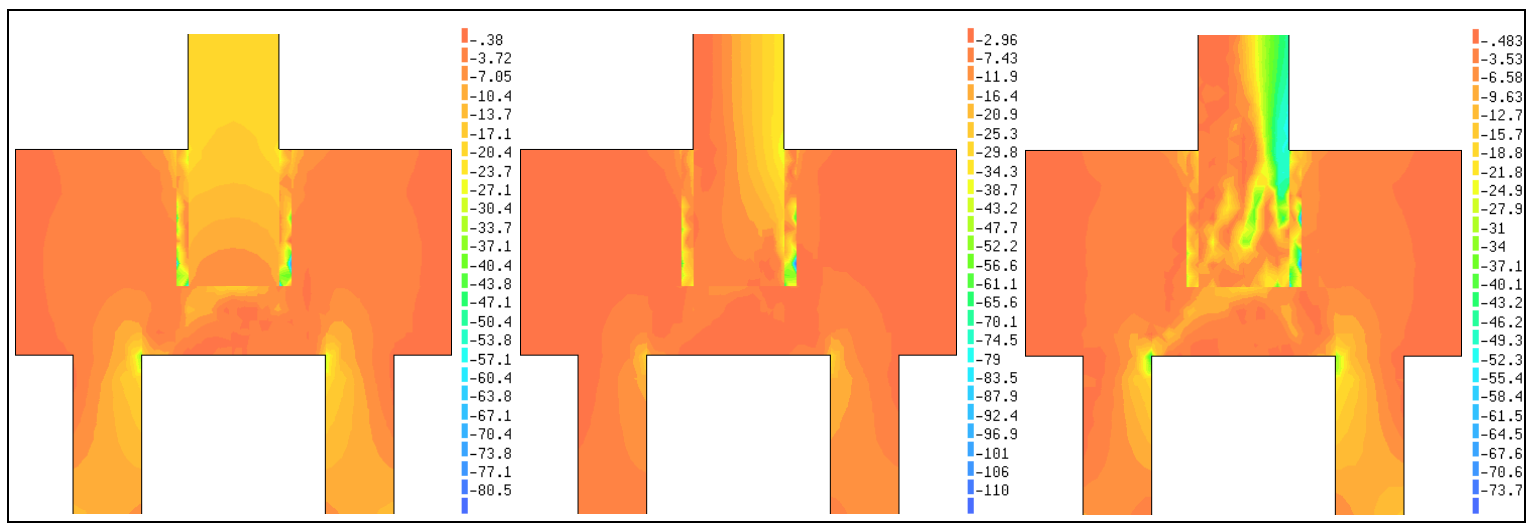

Figura 4.22 - Tensões principais de compressão nos modelos IL-E60-HS30

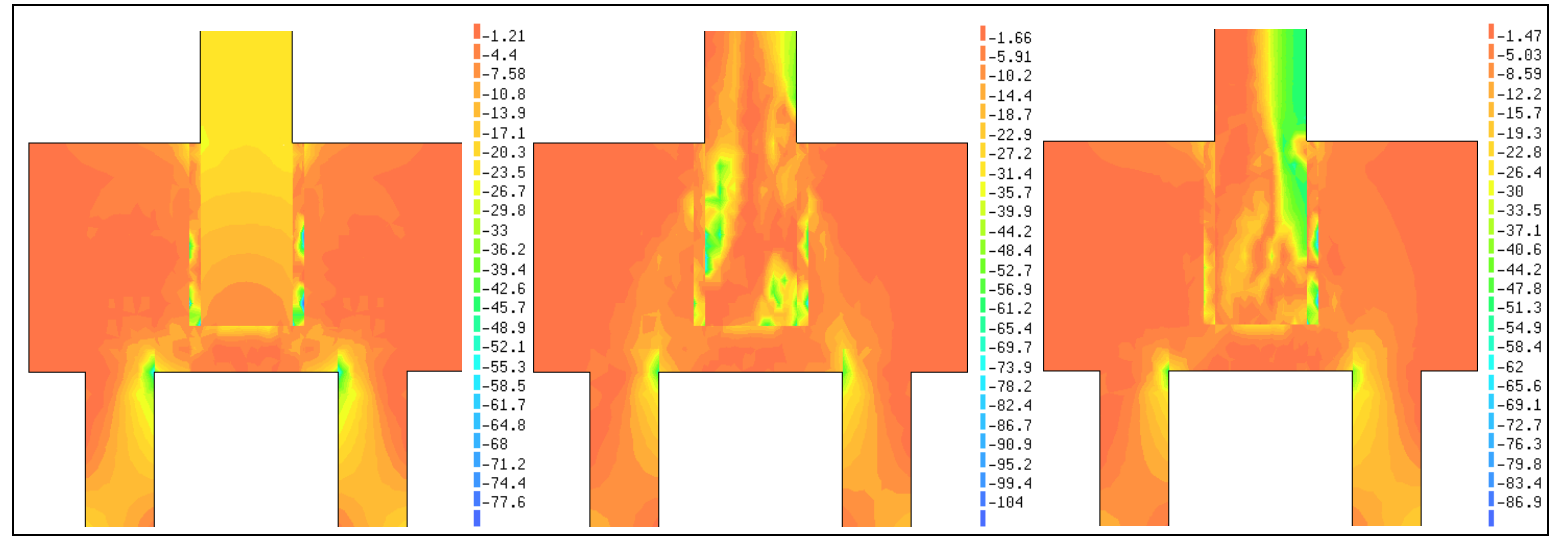

Figura 4.23 - Tensões principais de compressão nos modelos IL-E80-HS20 


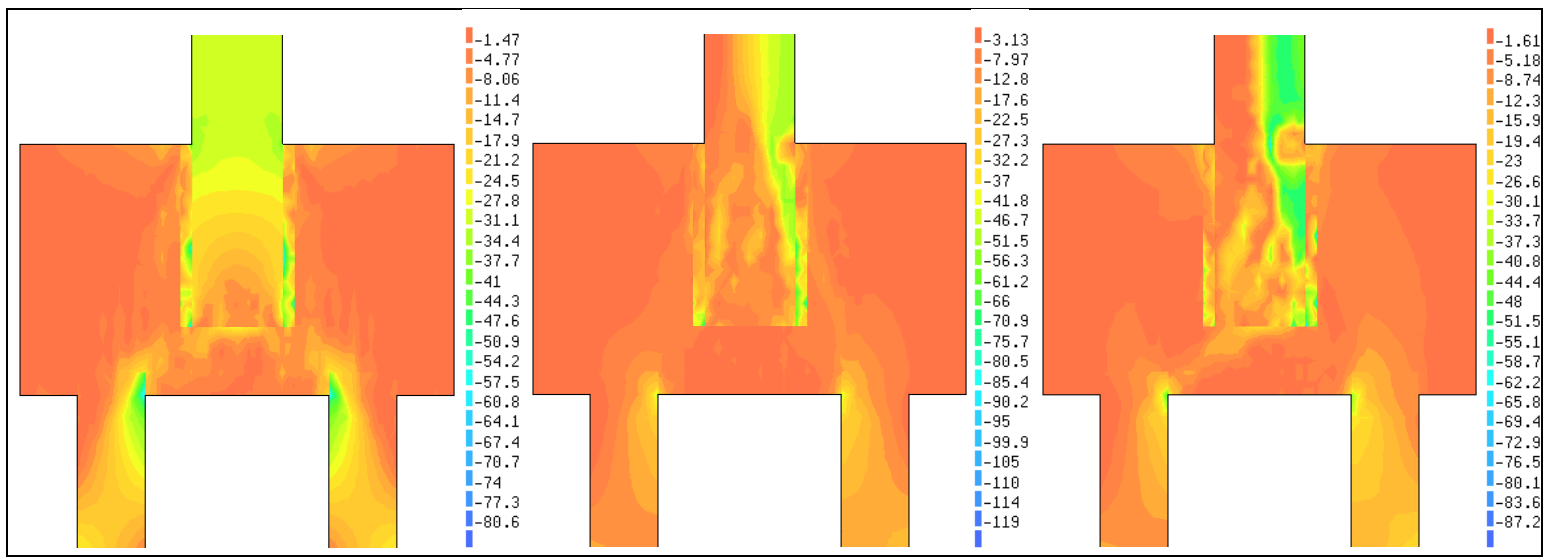

Figura 4.24 - Tensões principais de compressão nos modelos IL-E80-HS30

\subsubsection{TENSÕES NAS BARRAS DAS ARMADURAS}

Os diagramas da Figura 4.25 à Figura 4.36 referem-se às tensões equivalentes de von Mises nas barras das armaduras dos blocos com cálice de interface rugosa sendo que à esquerda encontram-se representadas as armaduras principais e secundárias e à direita as armaduras superiores e de suspensão. Os resultados indicam que a armadura principal e secundária atingiu o escoamento com a distribuição de tensões variando ao longo do comprimento das barras.

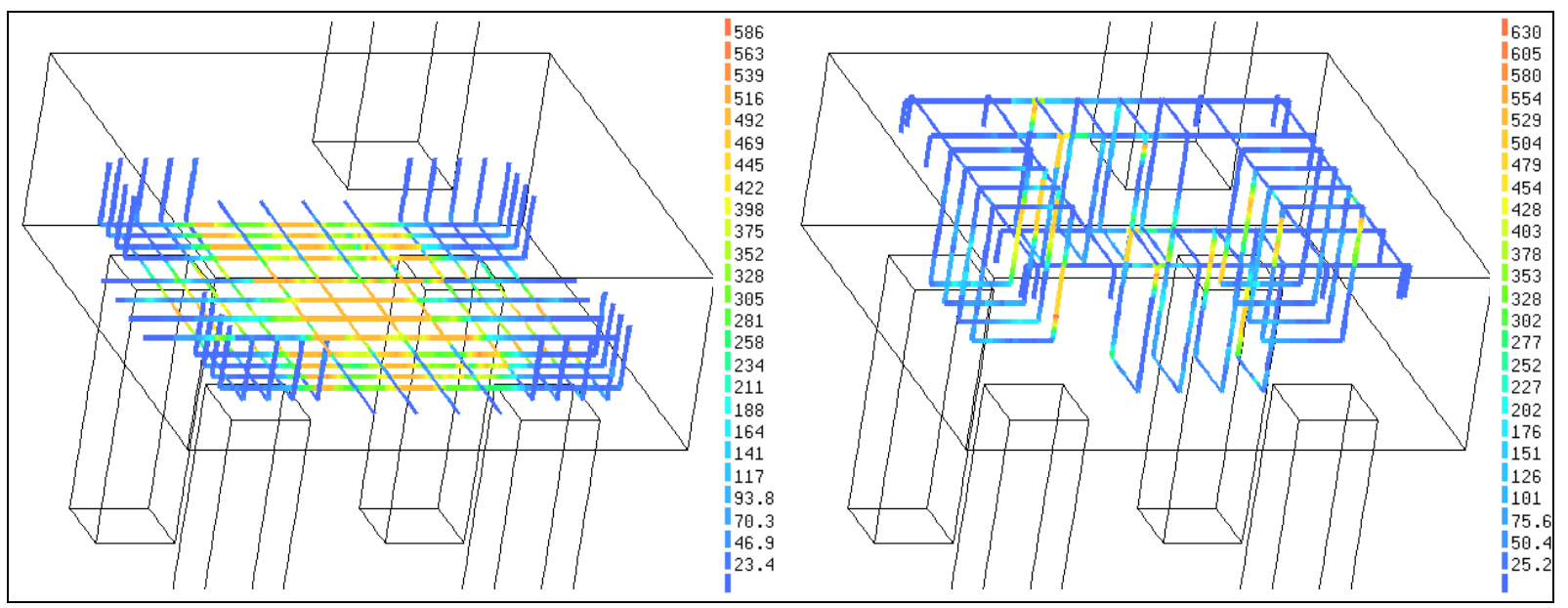

Figura 4.25 - Tensões nas armaduras dos blocos IR-E48-HS20-N 


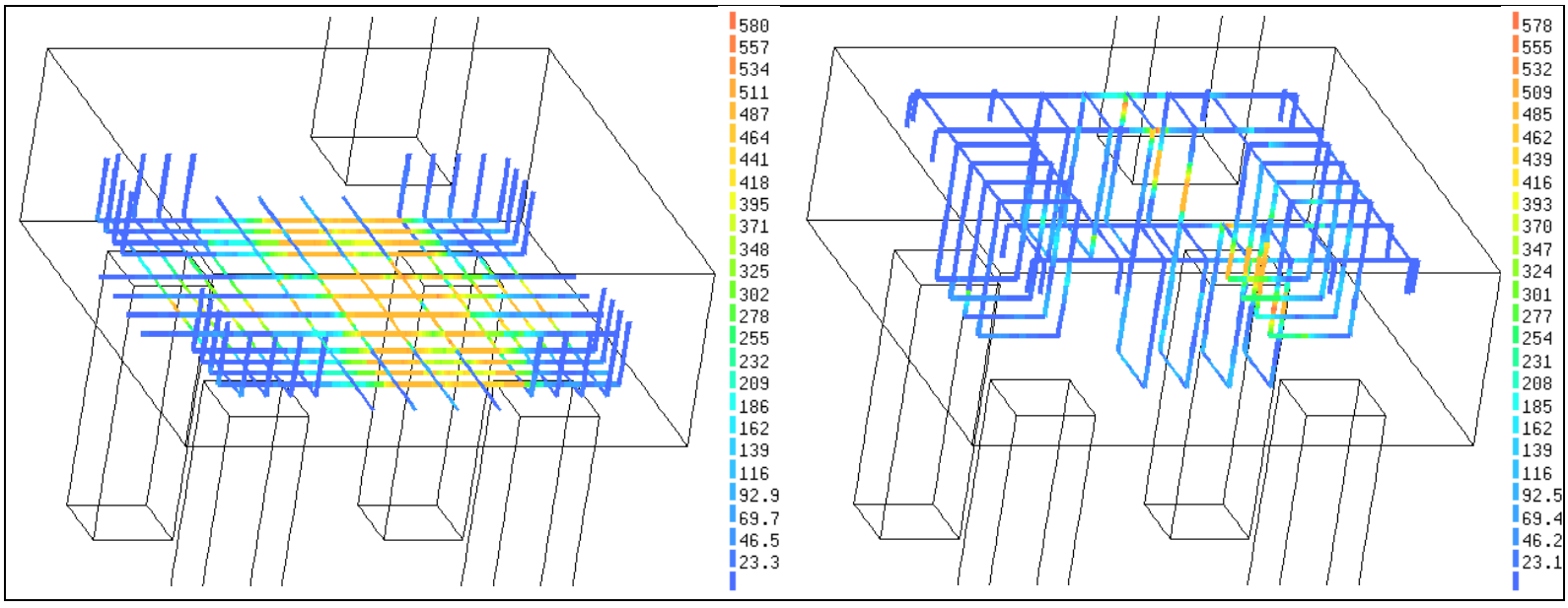

Figura 4.26 - Tensões nas armaduras dos blocos IR-E48-HS20-NM

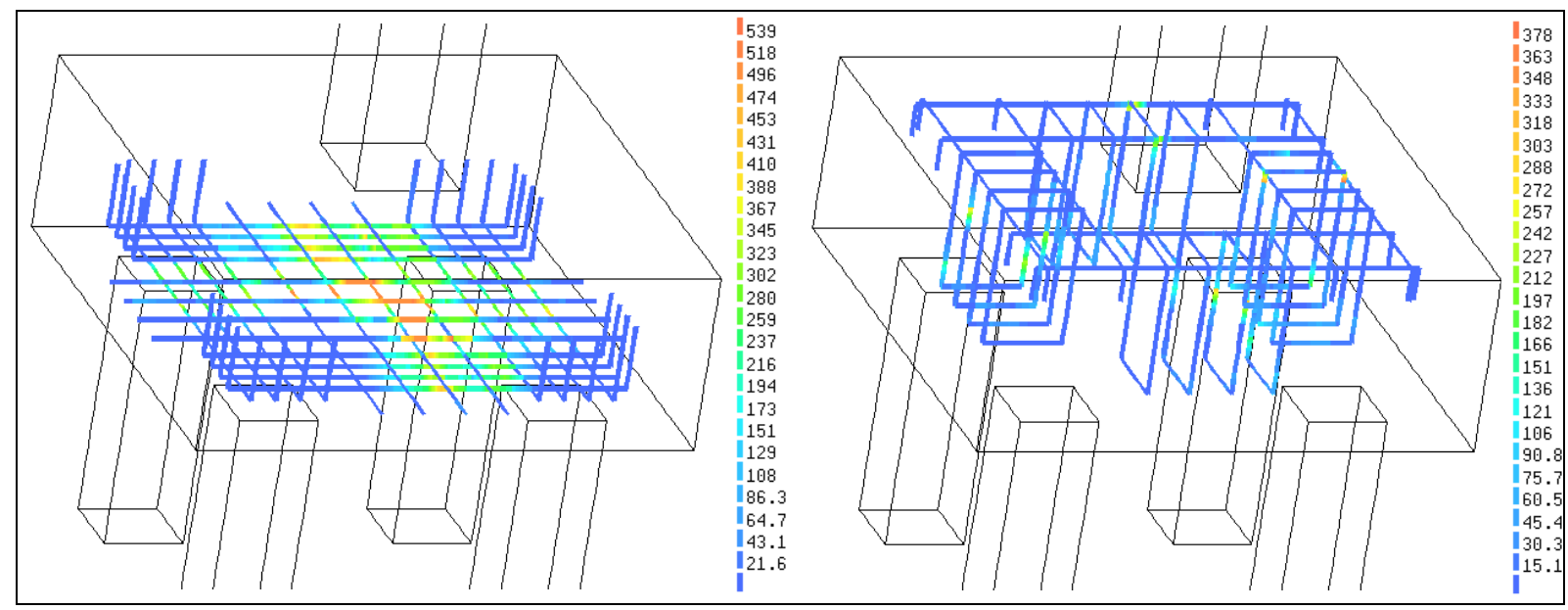

Figura 4.27 - Tensões nas armaduras dos blocos IR-E48-HS20-NMM

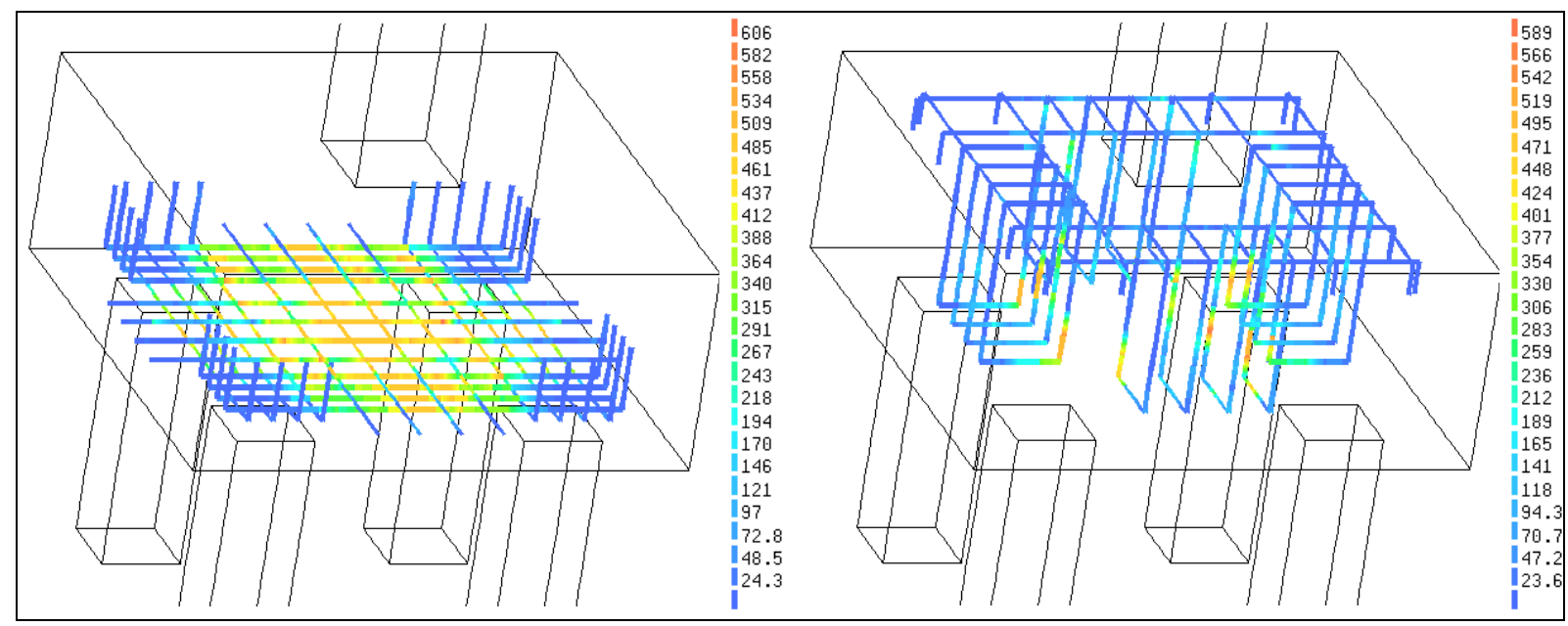

Figura 4.28 - Tensões nas armaduras dos blocos IR-E48-HS30-N 
Capítulo 4: Blocos sobre Quatro Estacas com Cálice Embutido

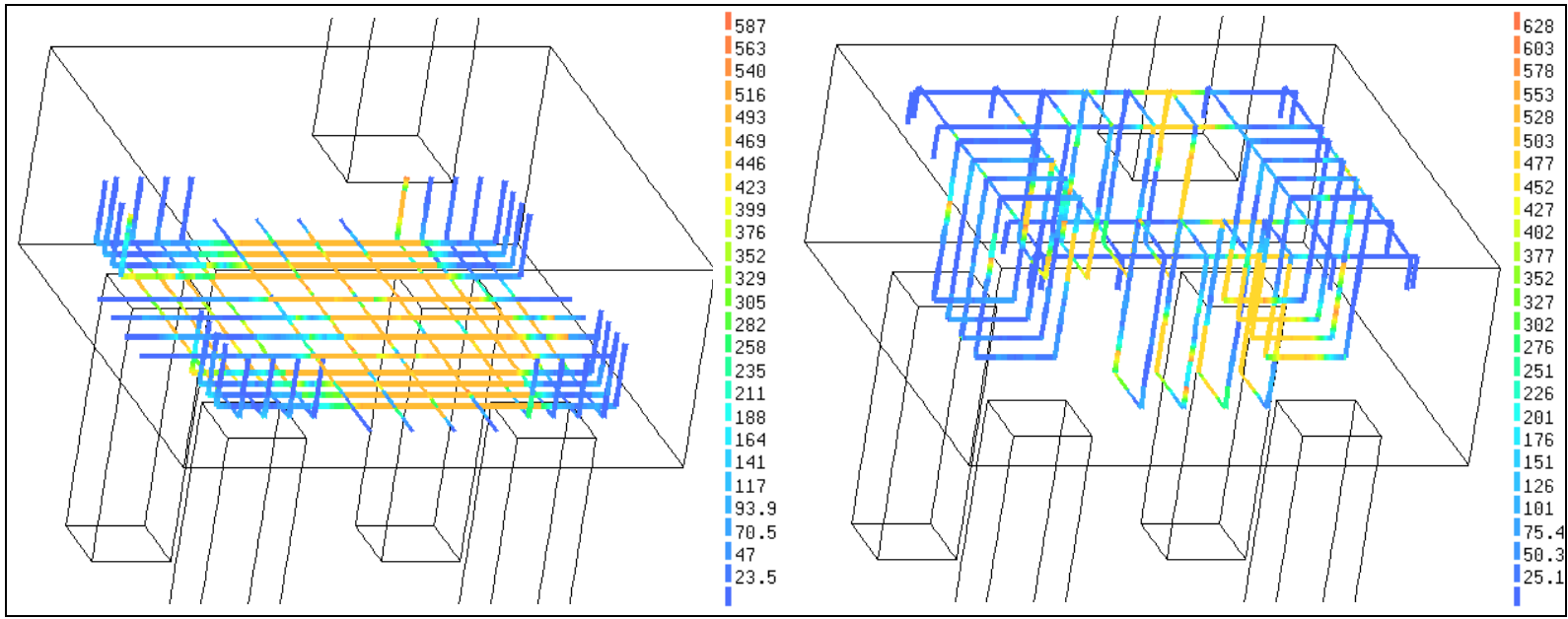

Figura 4.29 - Tensões nas armaduras dos blocos IR-E48-HS30-NM

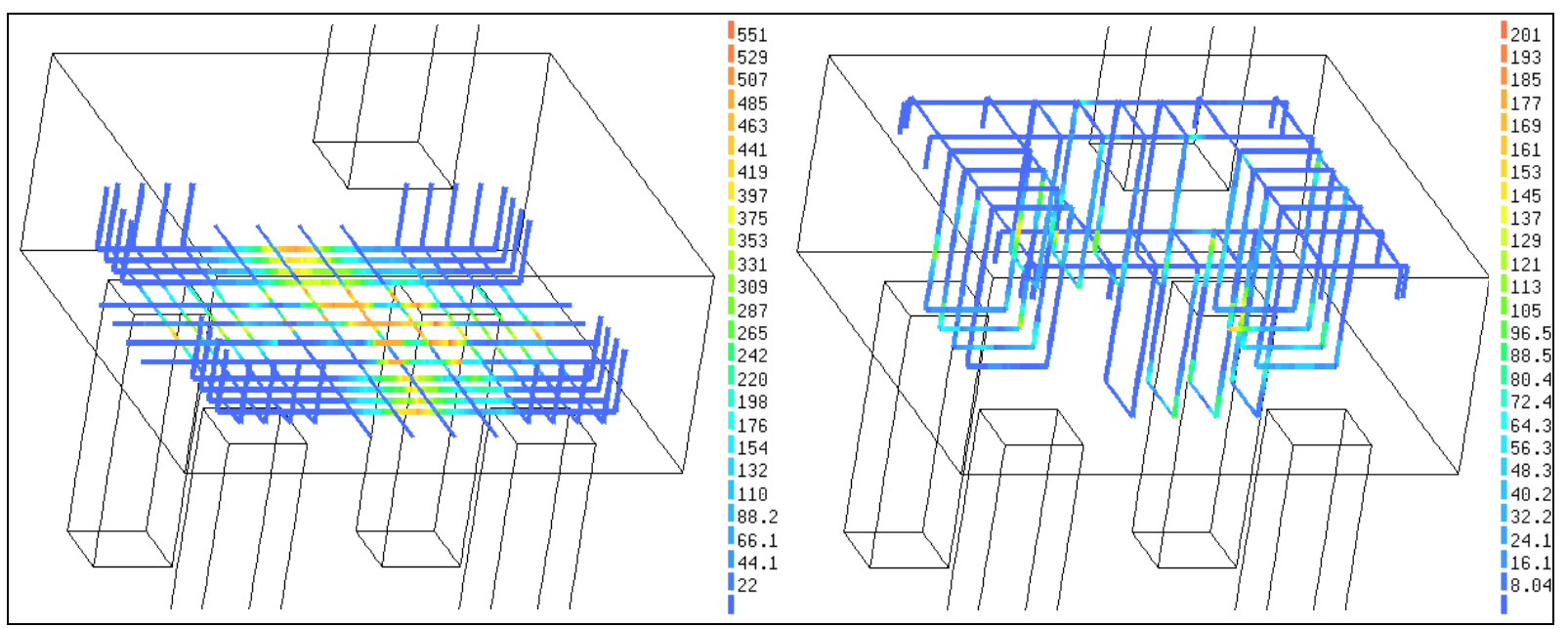

Figura 4.30 - Tensões nas armaduras dos blocos IR-E48-HS30-NMM

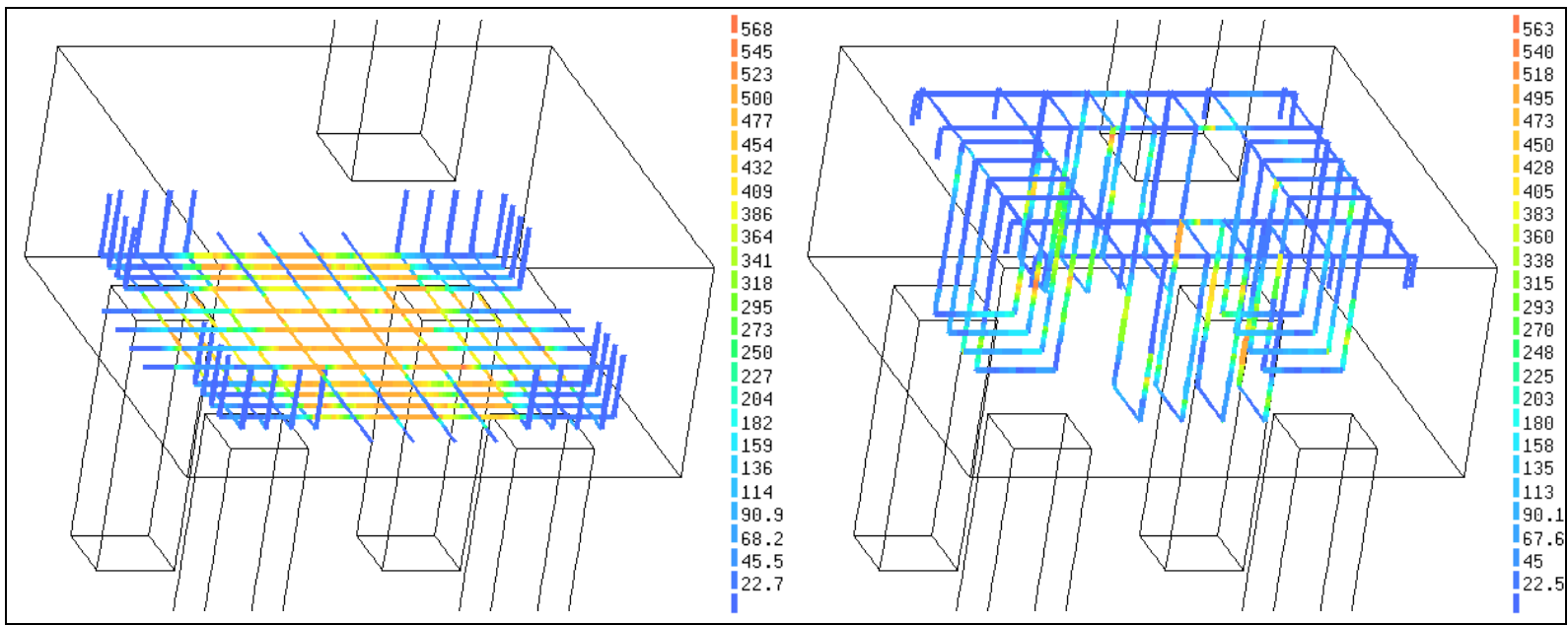

Figura 4.31 - Tensões nas armaduras dos blocos IR-E64-HS20-N 


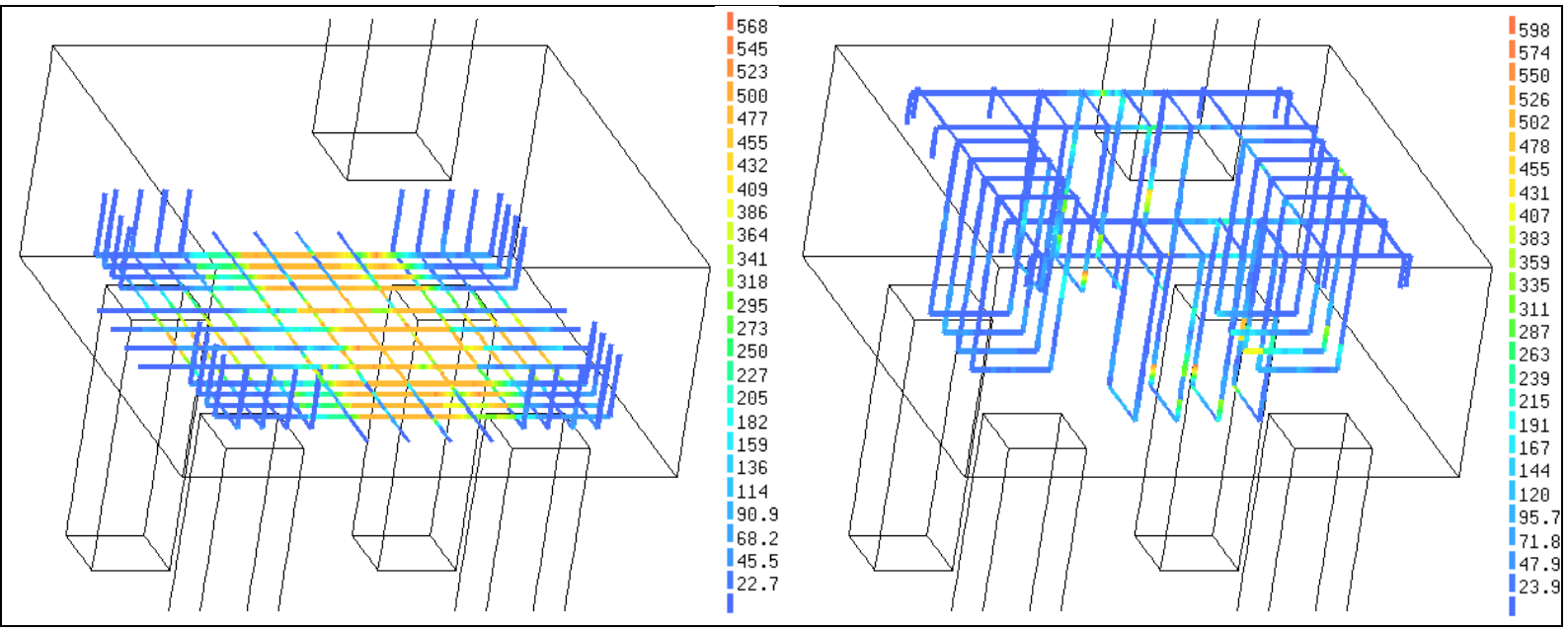

Figura 4.32 - Tensões nas armaduras dos blocos IR-E64-HS20-NM

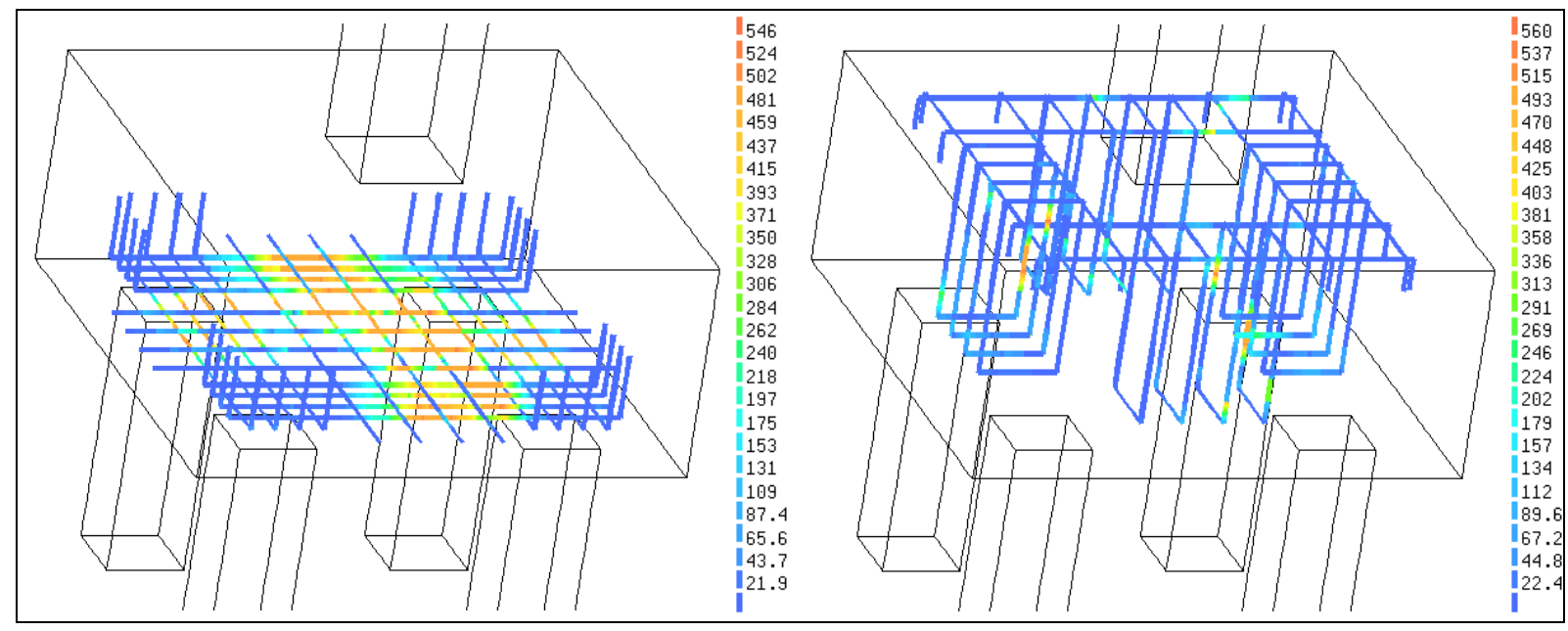

Figura 4.33 - Tensões nas armaduras dos blocos IR-E64-HS20-NMM

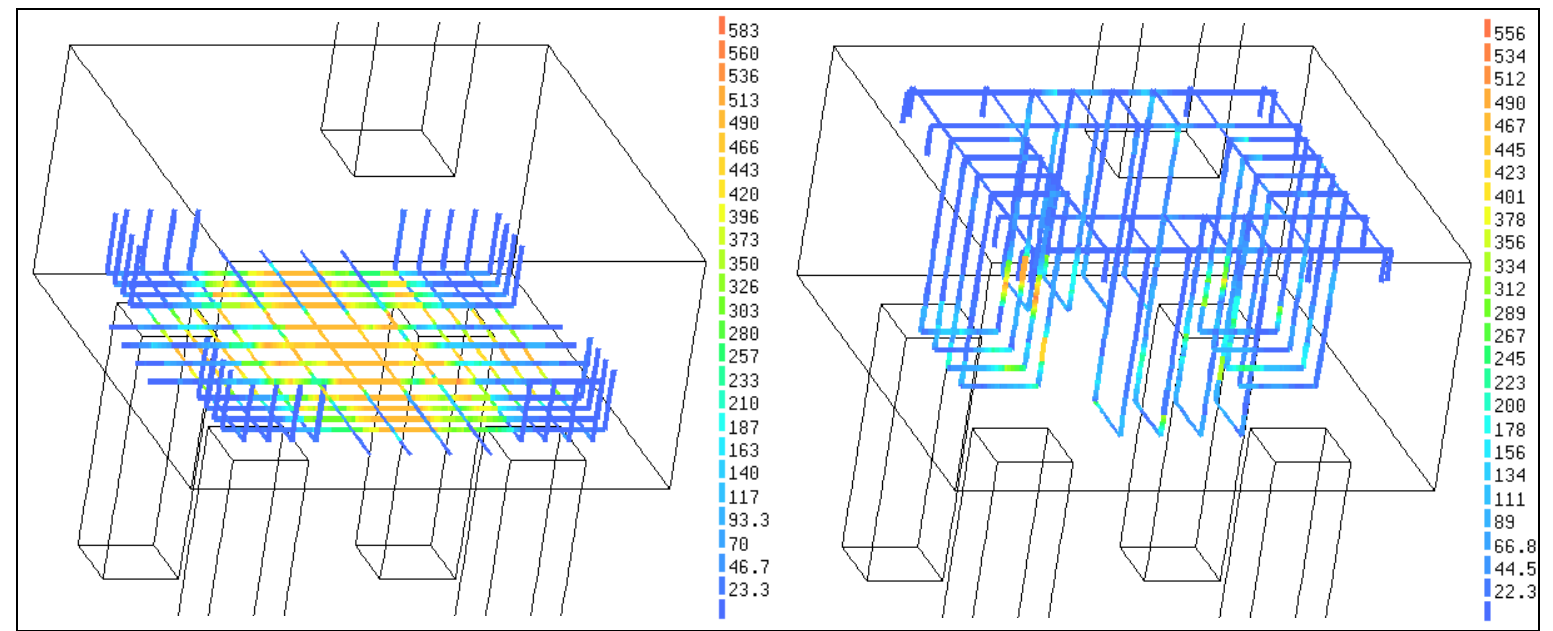

Figura 4.34 - Tensões nas armaduras dos blocos IR-E64-HS30-N 


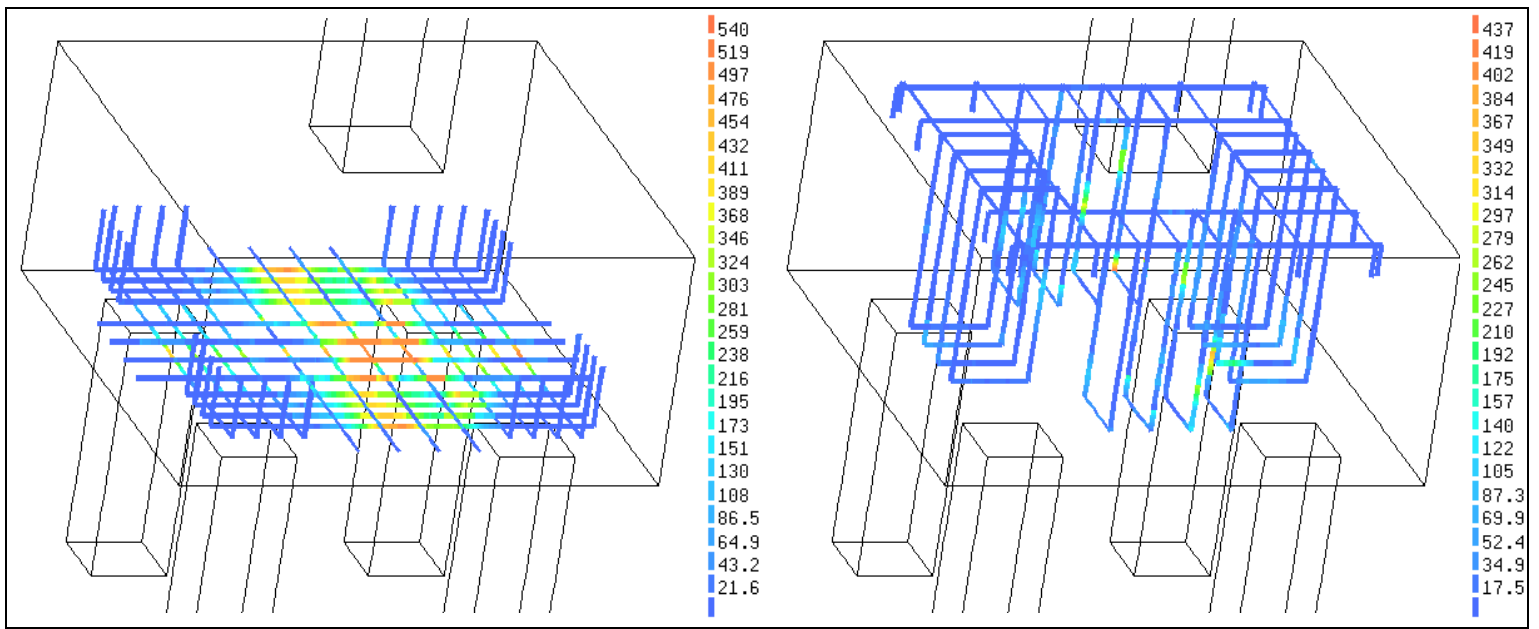

Figura 4.35 - Tensões nas armaduras dos blocos IR-E64-HS30-NM

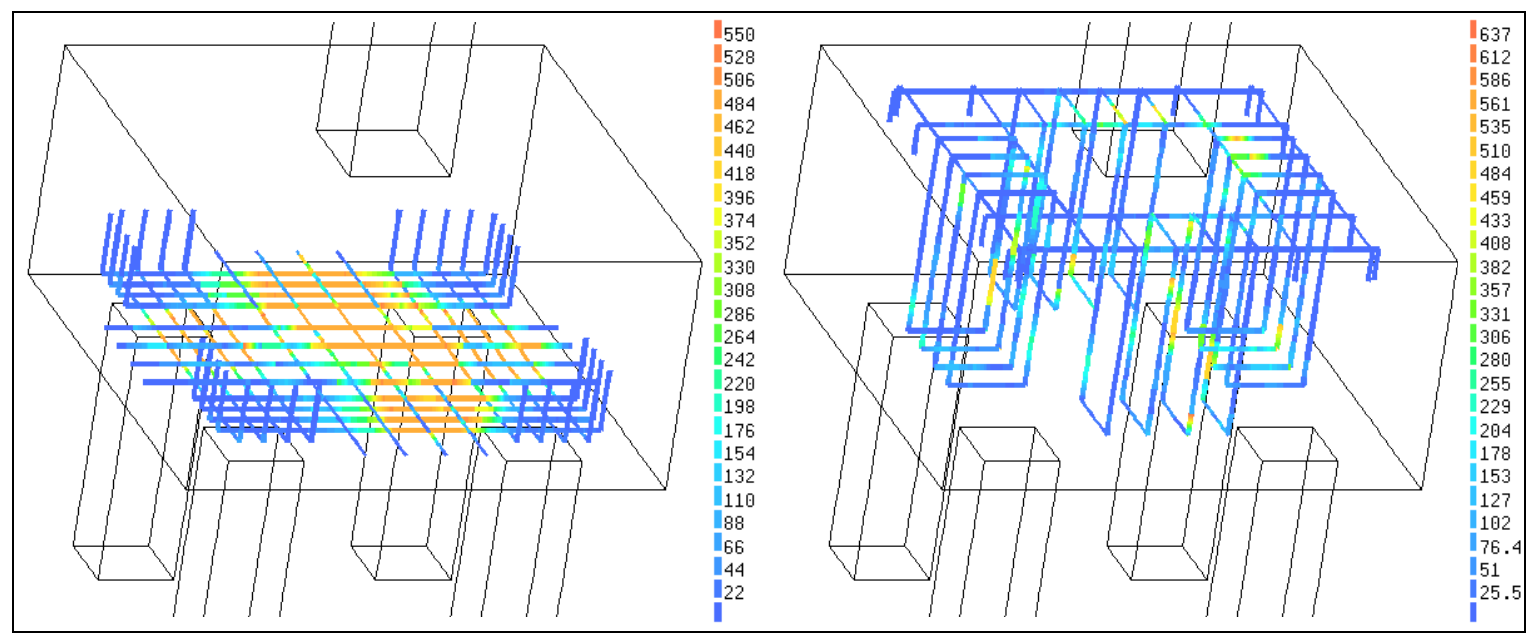

Figura 4.36 - Tensões nas armaduras dos blocos IR-E64-HS30-NMM

As armaduras superiores e laterais não influenciaram no comportamento dos modelos, pois a intensidade das tensões nas suas barras foi relativamente reduzida. Em contrapartida, a armadura secundária apresentou elevados valores de tensão ao longo de suas barras indicando que, apesar de terem sido formadas bielas de compressão entre o pilar e as estacas, parte significativa da força do pilar atua no fundo do bloco.

As tensões nas armaduras dos blocos com cálice de interface lisa estão representadas da Figura 4.37 a Figura 4.48. Percebe-se que a armadura principal não foi submetida a elevados valores de tensão, em contrapartida a armadura secundária continua sendo solicitada. As armaduras de suspensão continuam sendo solicitadas e as armaduras superiores permanecem sendo pouco solicitadas. 


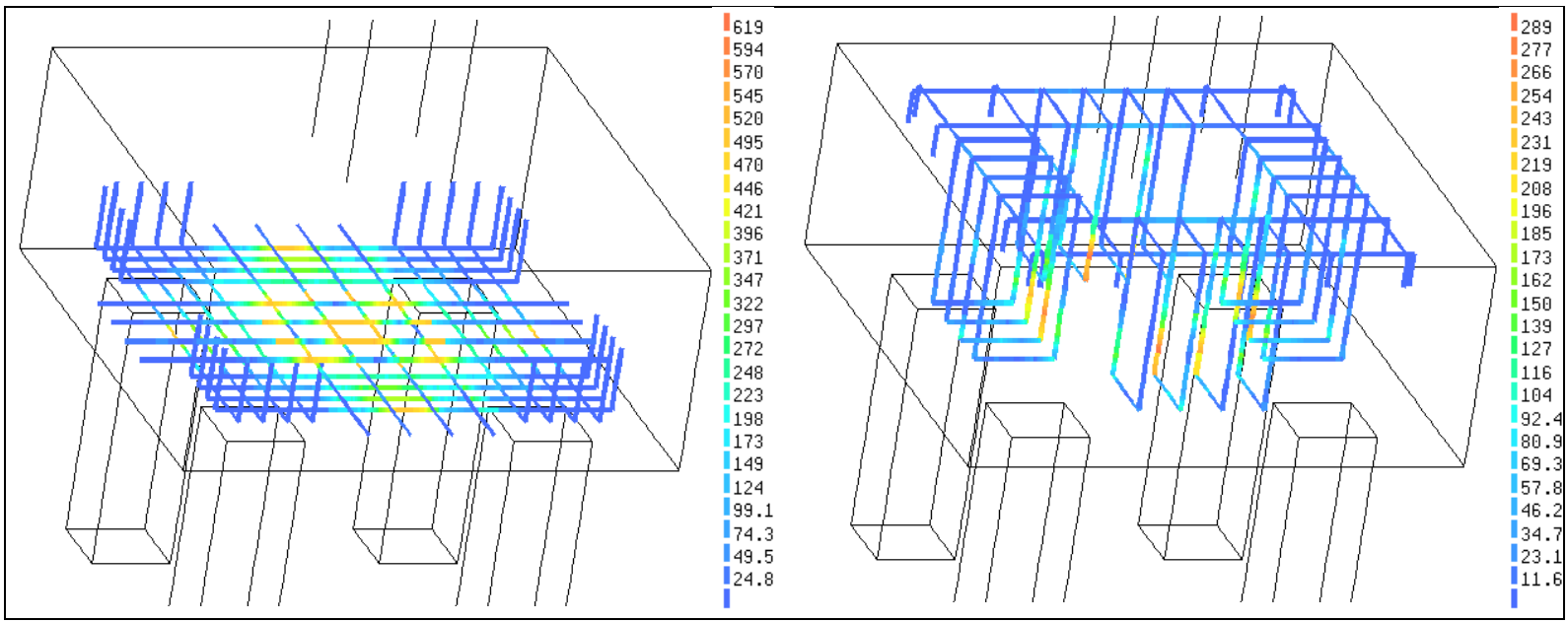

Figura 4.37 - Tensões nas armaduras dos blocos IL-E60-HS20-N

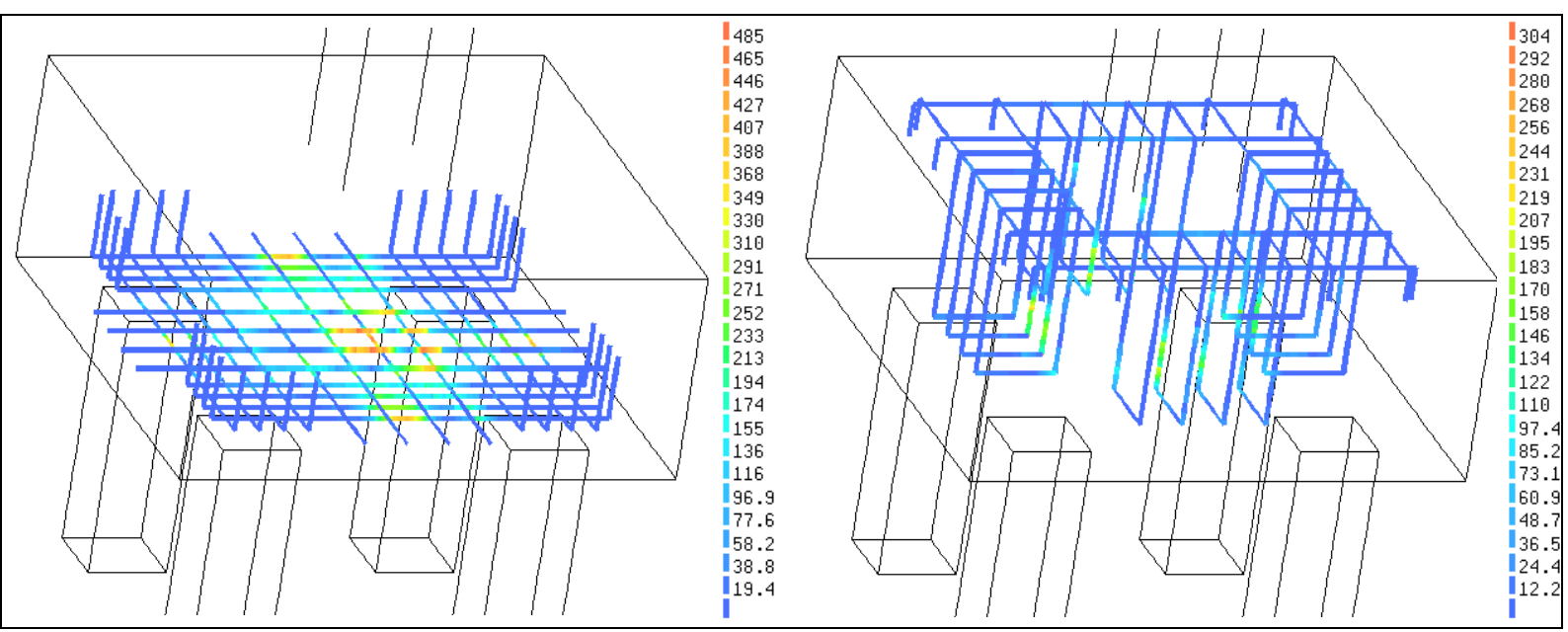

Figura 4.38 - Tensões nas armaduras dos blocos IL-E60-HS20-NM

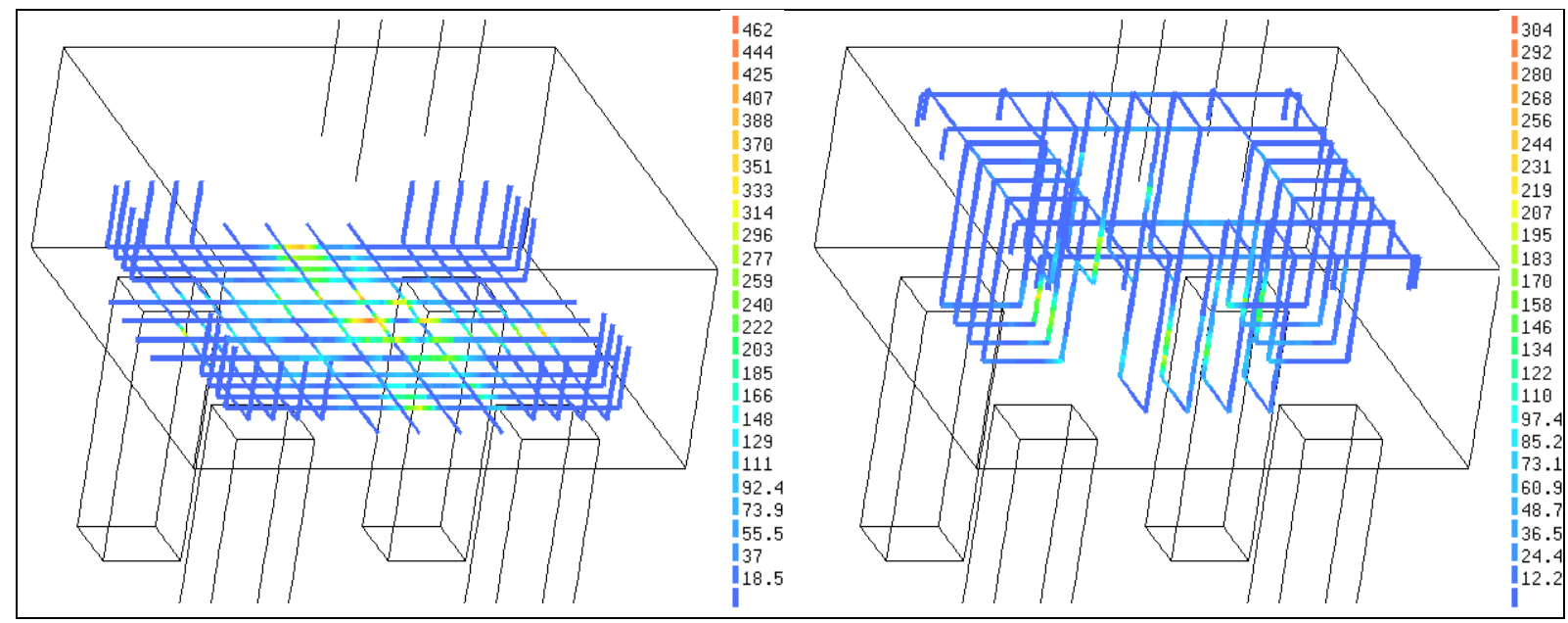

Figura 4.39 - Tensões nas armaduras dos blocos IL-E60-HS20-NMM 


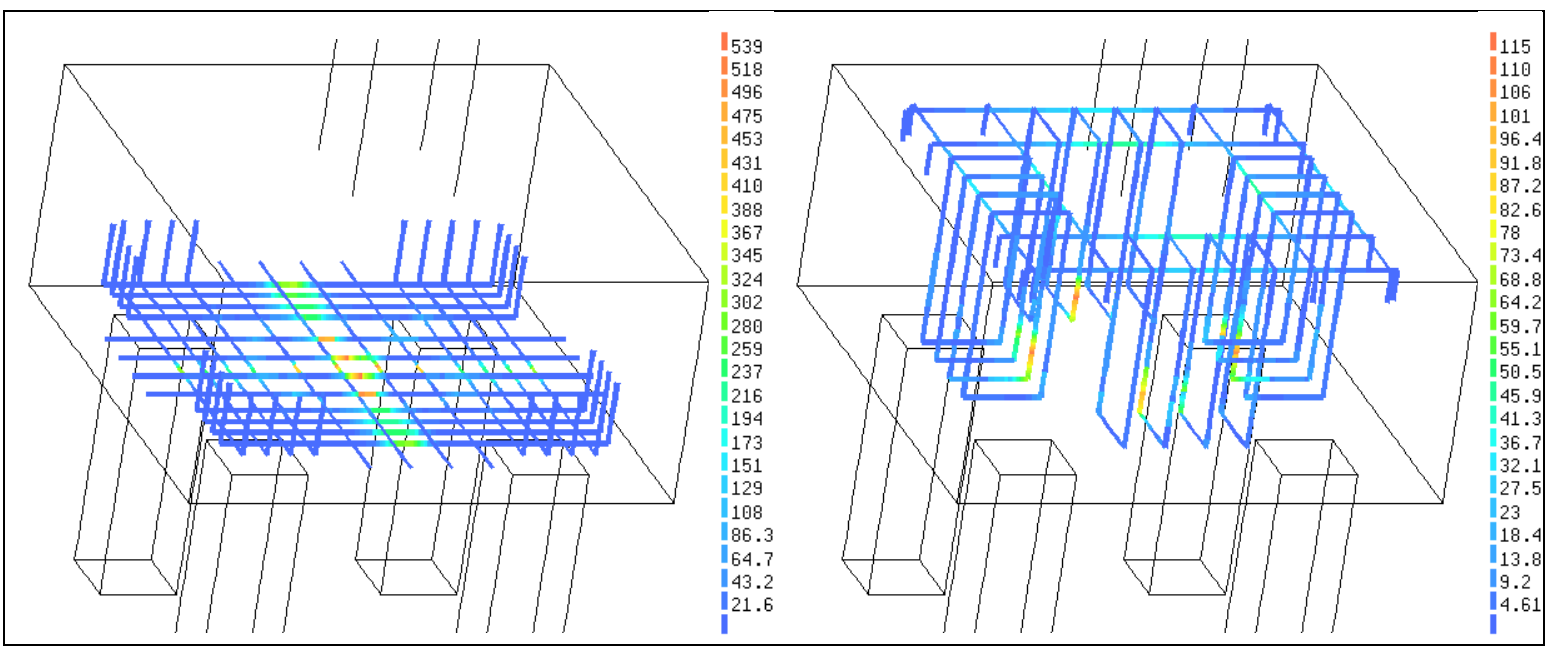

Figura 4.40 - Tensões nas armaduras dos blocos IL-E60-HS30-N

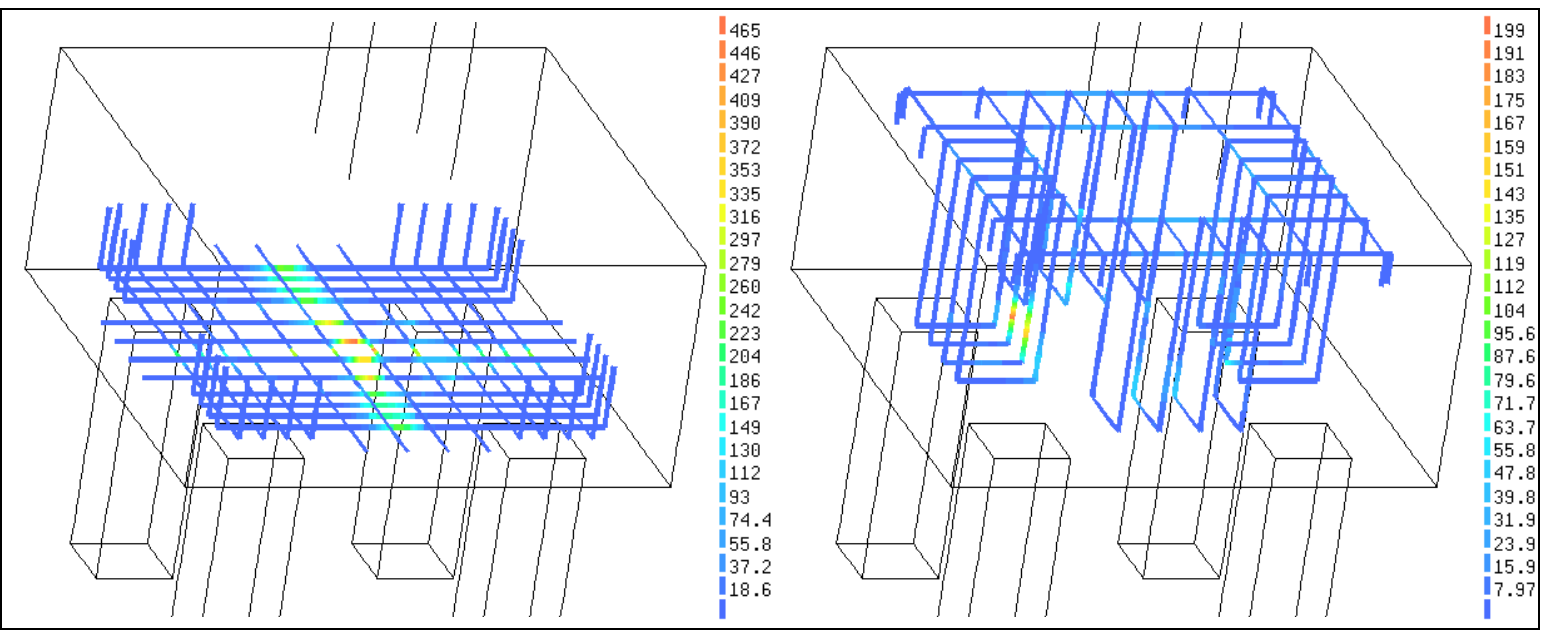

Figura 4.41 - Tensões nas armaduras dos blocos IL-E60-HS30-NM

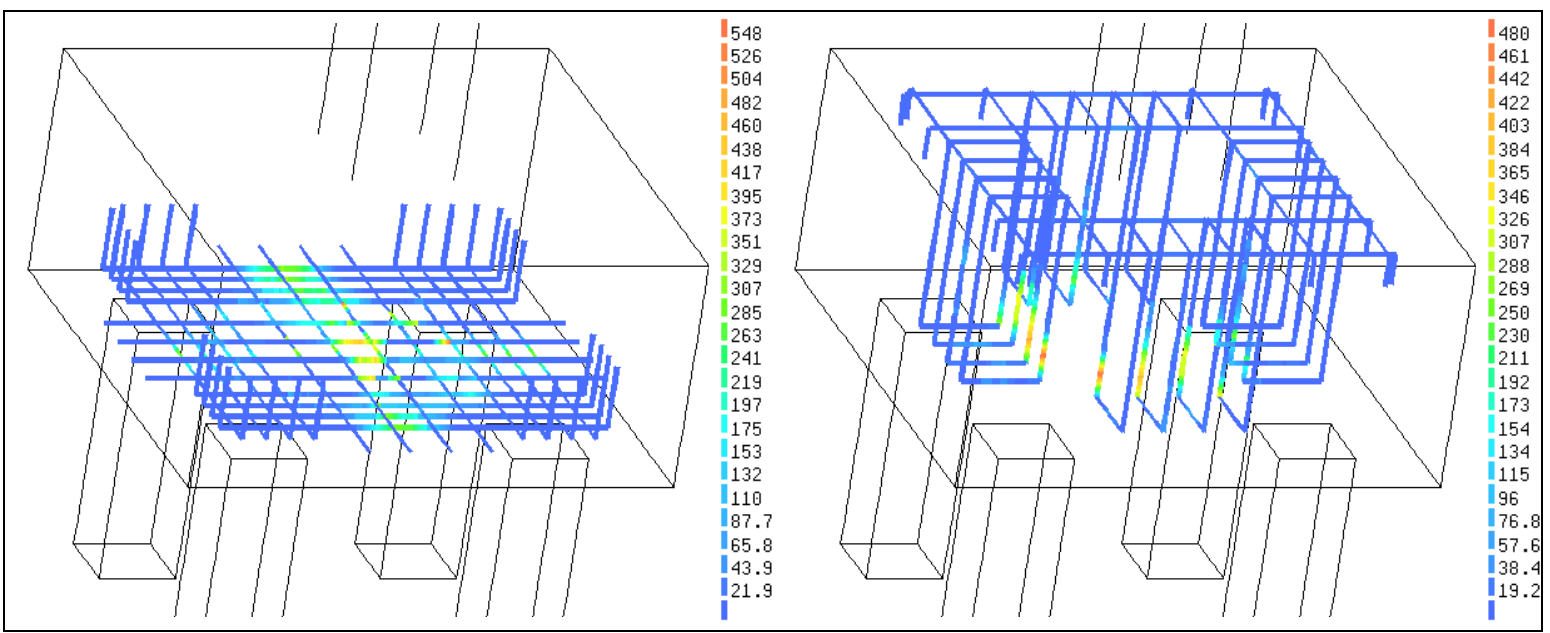

Figura 4.42 - Tensões nas armaduras dos blocos IL-E60-HS30-NMM 


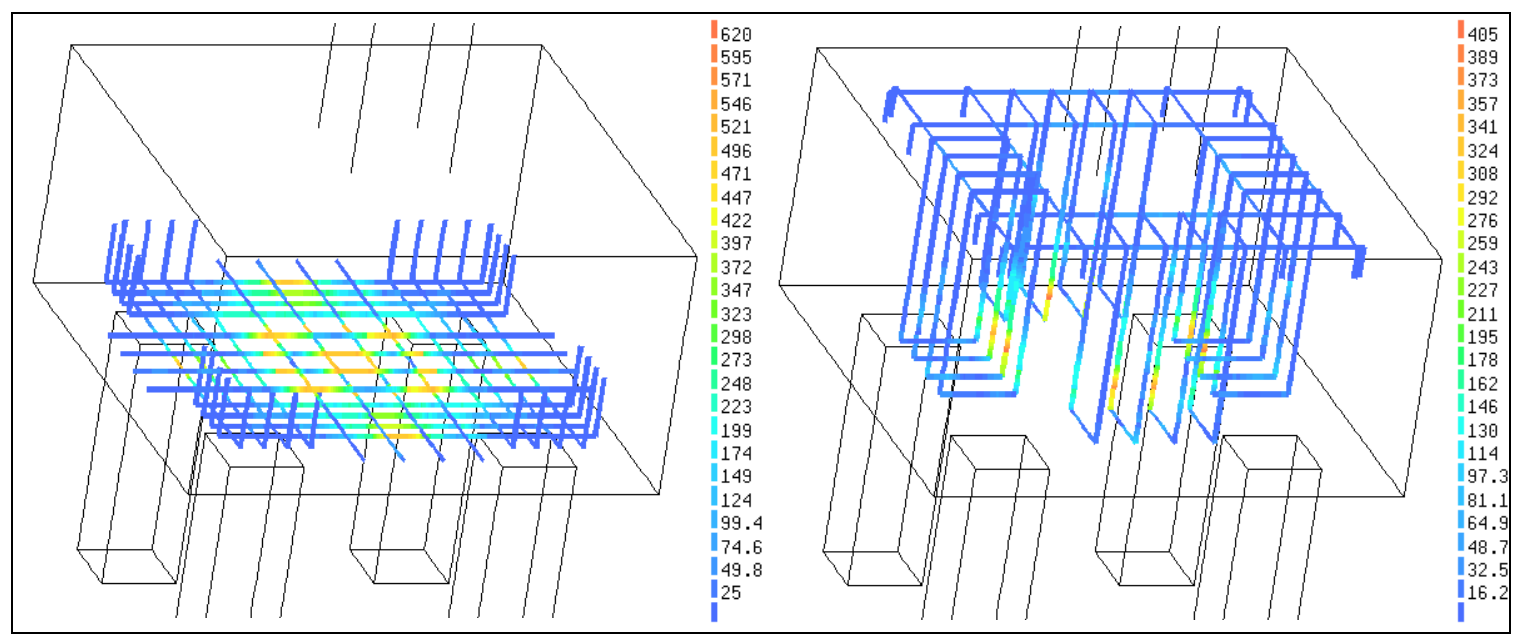

Figura 4.43 - Tensões nas armaduras dos blocos IL-E80-HS20-N

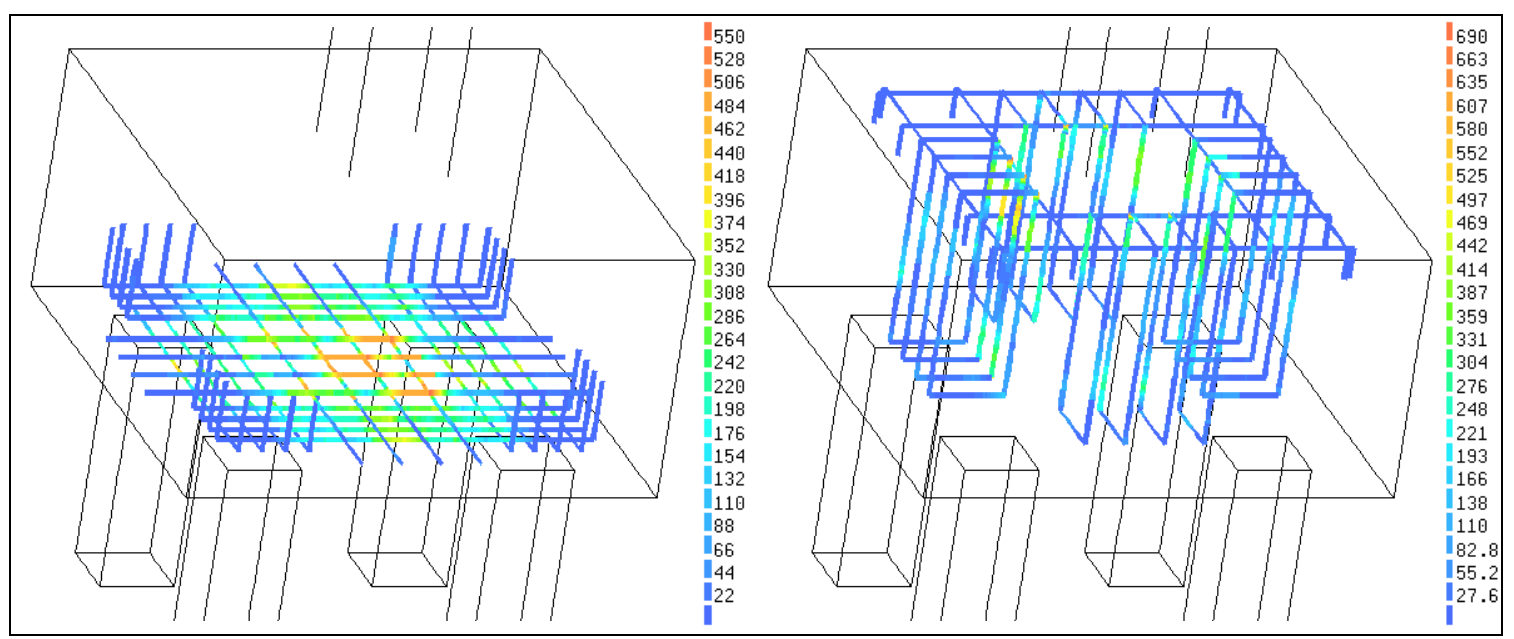

Figura 4.44 - Tensões nas armaduras dos blocos IL-E80-HS20-NM

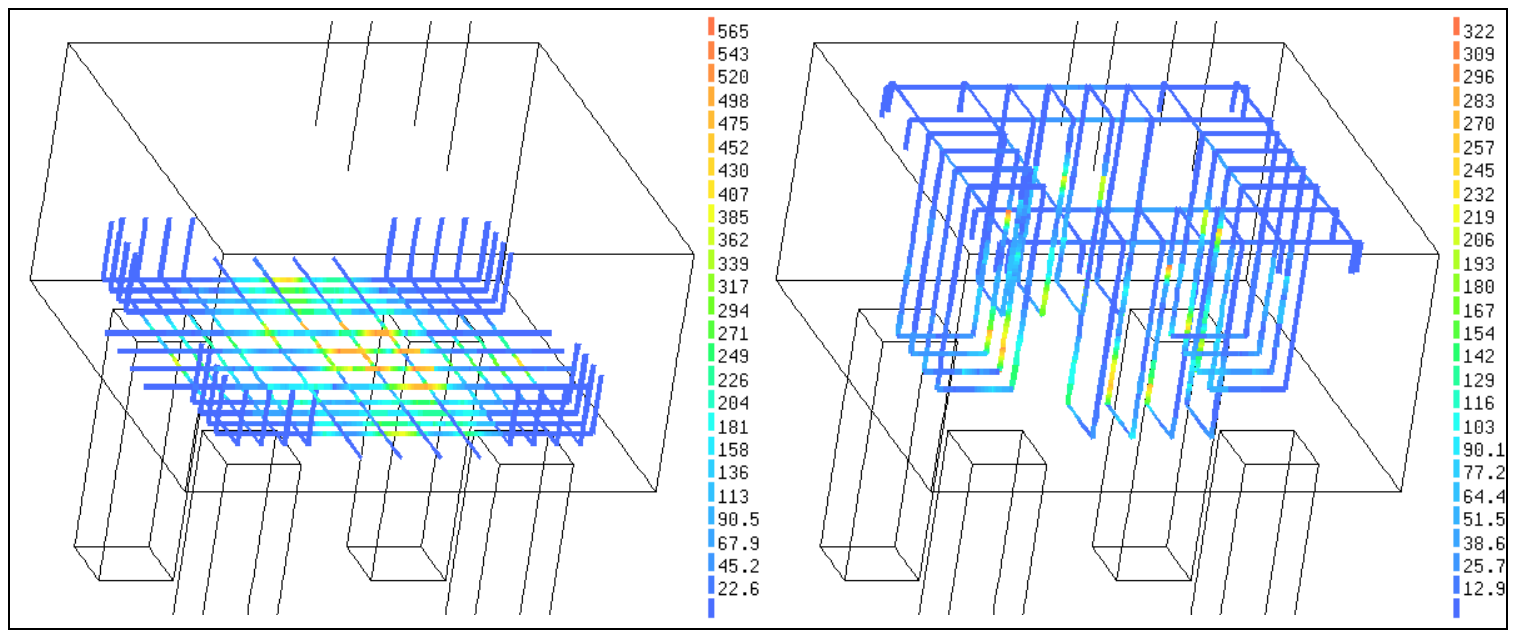

Figura 4.45 - Tensões nas armaduras dos blocos IL-E80-HS20-NMM 


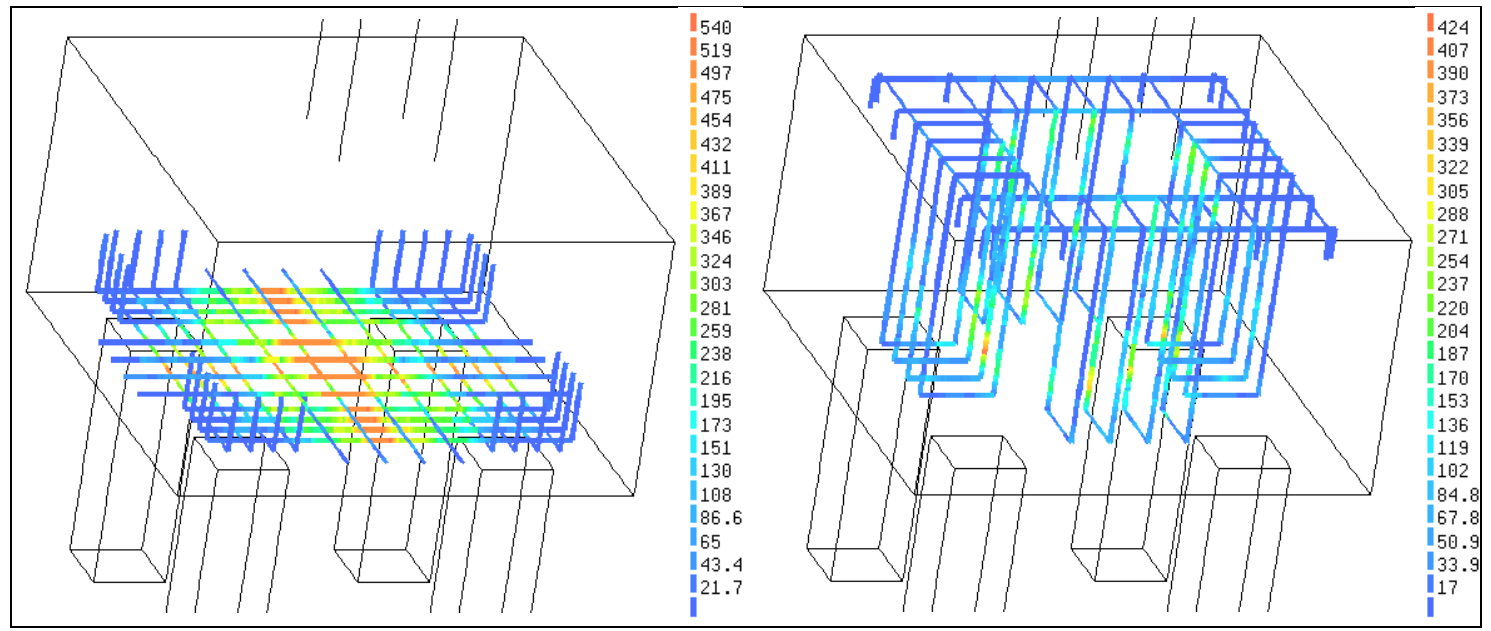

Figura 4.46 - Tensões nas armaduras dos blocos IL-E80-HS30-N

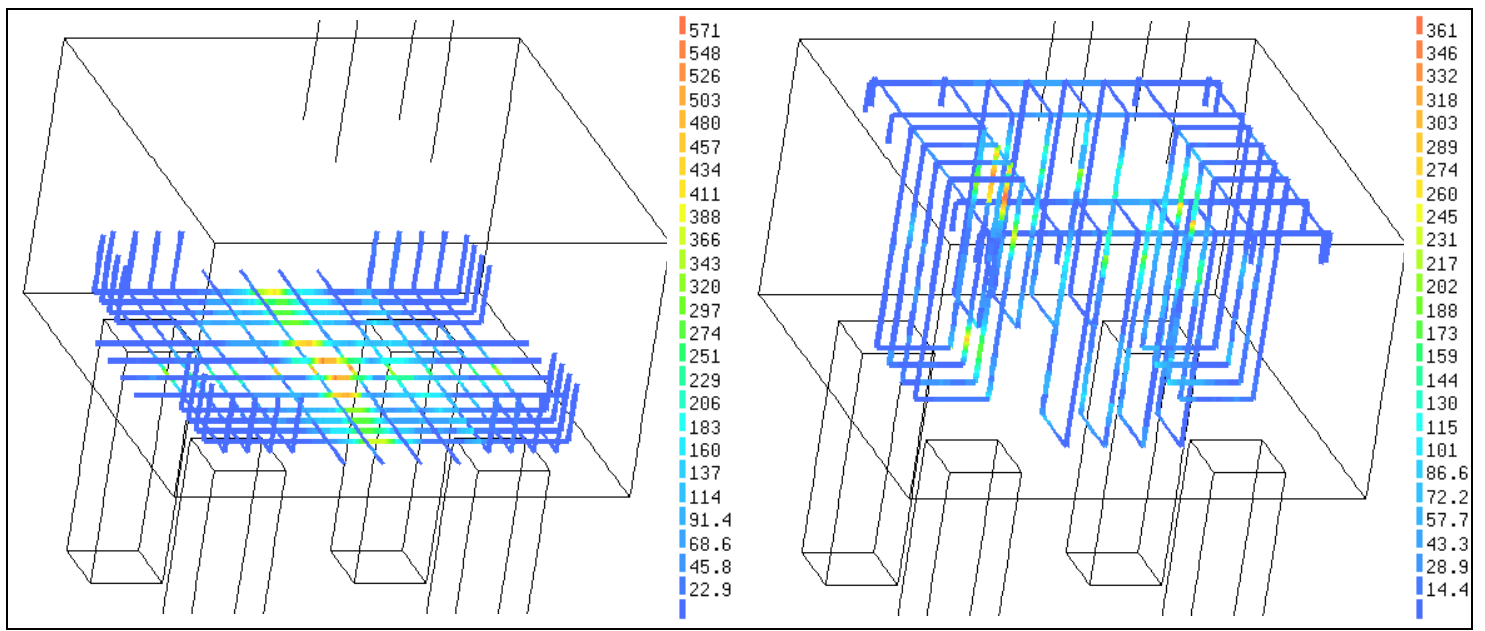

Figura 4.47 - Tensões nas armaduras dos blocos IL-E80-HS30-NM

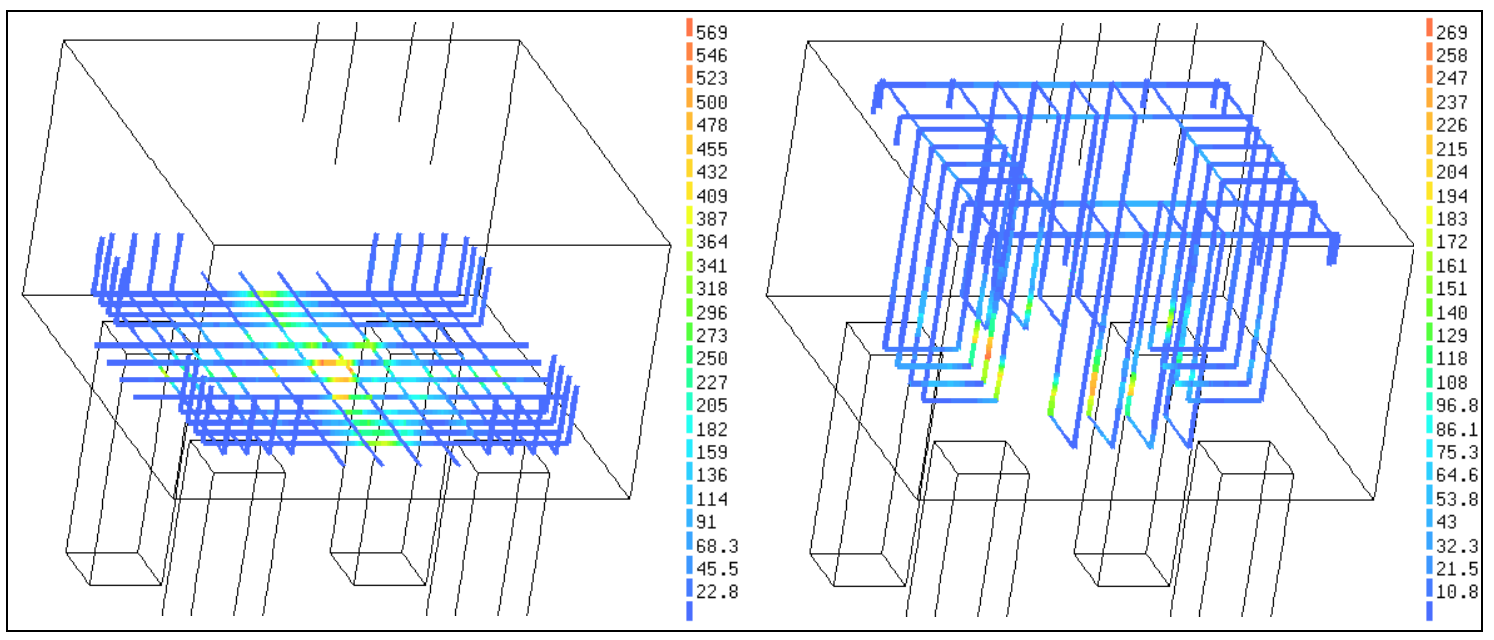

Figura 4.48 - Tensões nas armaduras dos blocos IL-E80-HS30-NMM 
Apesar de o aço ter sido descrito por modelo constitutivo que considera o comportamento elasto-plástico perfeito com critério de plastificação de von Mises e tensão de escoamento de $500 \mathrm{MPa}$, em alguns pontos, as tensões nas barras superaram este valor. A violação do critério de plastificação também foi observada por Barros (2009) e acredita-se que este tipo de resultado tenha se originado em razão da representação das armaduras por elementos do tipo reinforcement, que não são elementos finitos propriamente ditos por não possuírem graus de liberdade próprios, entretanto interferem na rigidez do modelo, pois altera a rigidez dos elementos finitos nas regiões pelas quais atravessa.

Esse comportamento poderia ser admitido caso o modelo constitutivo que representa o aço fosse descrito por uma relação tensão deformação bi-linear sem patamar de escoamento, todavia o modelo constitutivo é bi-linear com patamar de escoamento.

\subsubsection{PANORAMA DE FISSURAÇÃO}

As fissuras, em todos os modelos, começaram a se desenvolver na face inferior do bloco e progrediram em direção às faces laterais do bloco. Em razão da similaridade dos panoramas de fissuração, são apresentadas apenas as fissuras para o bloco IR-E64-HS30-N e IL-E80-HS30-N, Figura 4.49 e Figura 4.50 respectivamente.

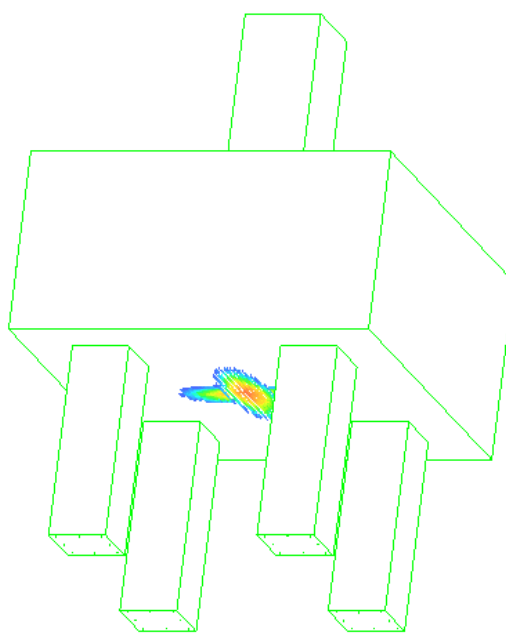

$50 \%$ da força última

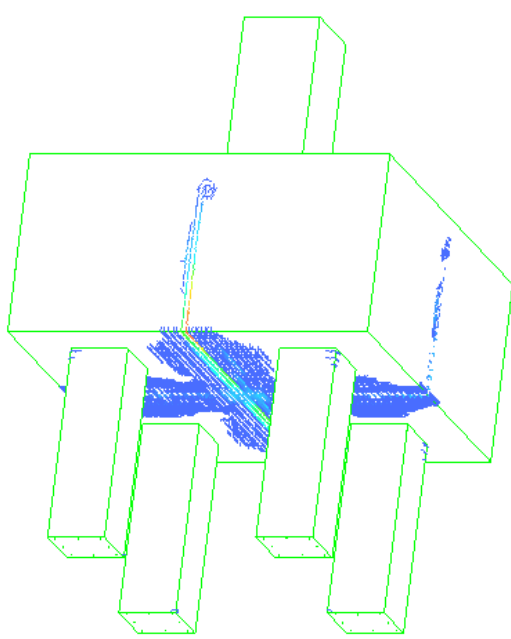

$75 \%$ da força última

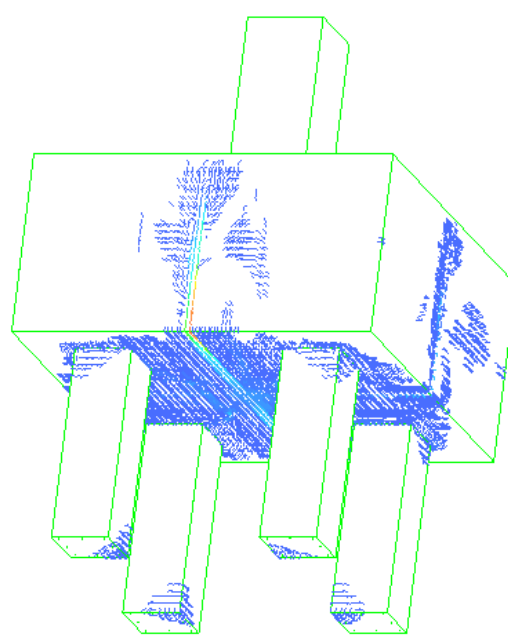

$100 \%$ da força última

Figura 4.49 - Panorama de fissuração no bloco IR-E64-HS30-N 


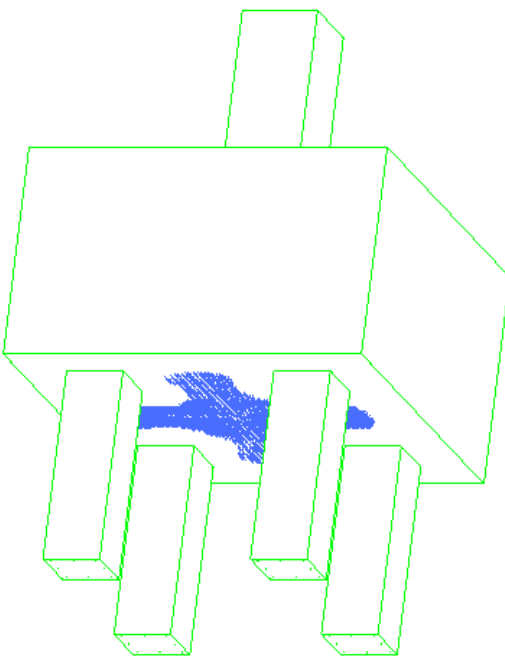

$50 \%$ da força última

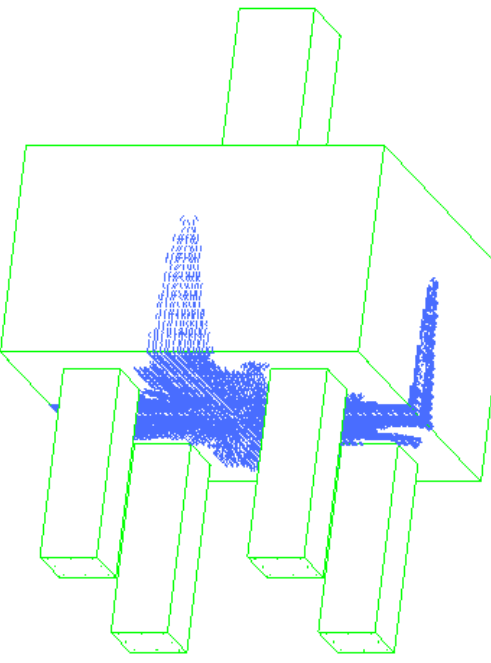

$75 \%$ da força última

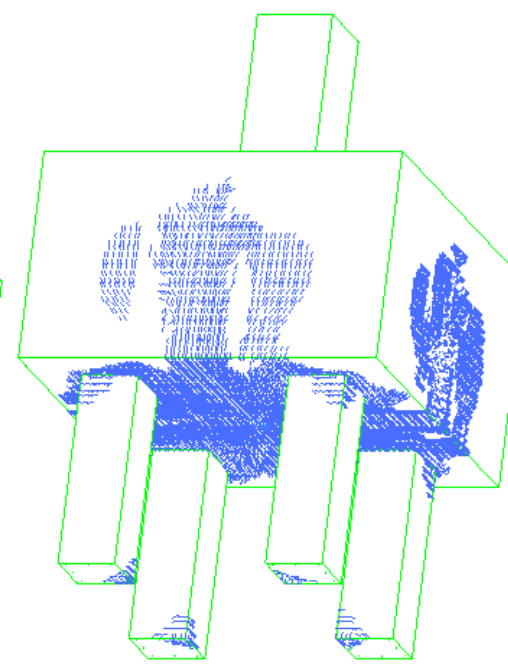

$100 \%$ da força última

Figura 4.50 - Panorama de fissuração no bloco IL-E80-HS30-N

No bloco de interface lisa, percebe-se que as fissuras são mais distribuídas, entretanto ambos os blocos apresentaram fissuras centrais que se estenderam entre os vãos das estacas.

\subsubsection{FORÇAS NAS BIELAS E TIRANTES}

Em razão dos blocos do grupo $\mathrm{B}$, com interface lisa, não terem apresentado a formação de bielas de compressão e em razão das tensões nas barras da armadura dos tirantes terem sido muito pequenas, a força nas bielas e nos tirantes foram apenas determinados para os blocos do grupo A.

A partir das tensões médias na região central das barras das armaduras em faixa, estimou-se a força nos tirantes referentes à atuação da força última dos modelos. A visualização dos valores das tensões ao longo das barras está exemplificada na Figura 4.51. 


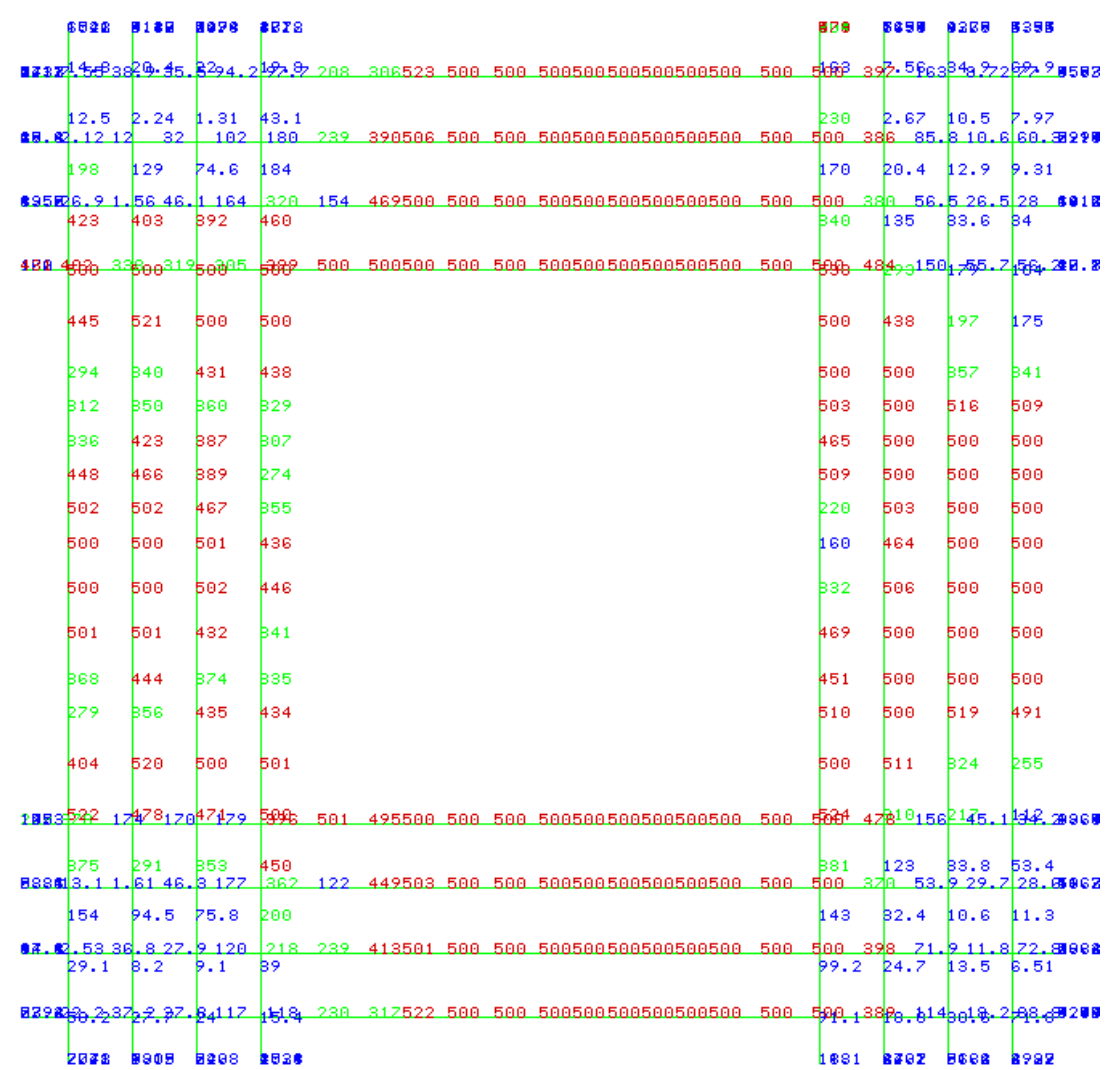

Figura 4.51 - Tensões nas barras da armadura principal do modelo IR-E48-HS30-NMM

Verifica-se que as tensões apresentam uma redução significativa quando as barras atingem o topo das estacas, este comportamento, que se repetiu em todos os modelos, já havia sido verificado em outros trabalhos já referenciados, numéricos e experimentais, sugerindo que a necessidade de ganchos nas extremidades das barras merece um estudo mais aprofundado.

A partir da força nos tirantes e das reações nas estacas foi possível calcular a força nas bielas e o ângulo de inclinação mediante equilíbrio de forças nos nós inferiores, conforme indica a Figura 4.52 . 


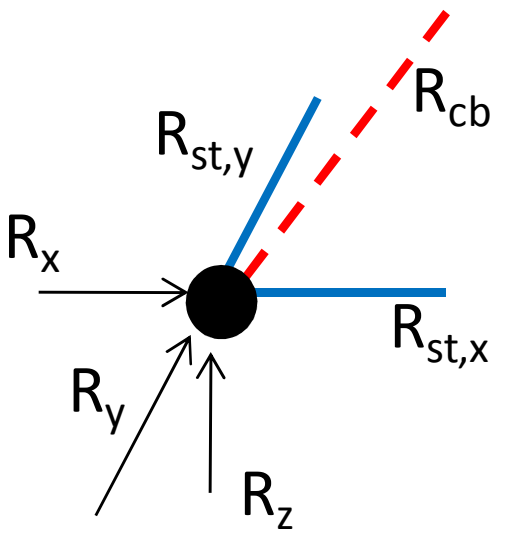

$$
R_{c b}=\sqrt{\left(R_{s t, x}+R_{x}\right)^{2}+\left(R_{s t, y}+R_{y}\right)^{2}+R_{z}^{2}}
$$

Figura 4.52 - Forças atuantes nos nós inferiores dos modelos analisados

A Tabela 4.10 apresenta as forças nos tirantes e as reações verticais nas estacas, entretanto, no equilíbrio de forças nos nós, consideraram-se também as reações horizontais nas estacas.

Tabela 4.10 - Força nos tirantes e reações nas estacas

\begin{tabular}{lcccccccc}
\hline \multirow{2}{*}{ Modelo } & \multicolumn{9}{c}{$\mathbf{R}_{\text {st }}(\mathbf{k N})$} \\
\cline { 2 - 9 } & $\mathbf{T}_{\mathbf{1}}$ & $\mathbf{T}_{\mathbf{2}}$ & $\mathbf{T}_{\mathbf{3}}$ & $\mathbf{T}_{\mathbf{4}}$ & Estaca 1 & Estaca 2 & Estaca 3 & Estaca 4 \\
\hline IR-E48-HS20-N & 398,10 & 389,36 & 358,69 & 369,55 & 1080,03 & 1124,87 & 1097,12 & 1080,23 \\
\hline IR-E48-HS20-NM & 406,45 & 406,15 & 354,87 & 395,49 & 892,14 & 1221,44 & 898,01 & 1219,20 \\
\hline IR-E48-HS20-NMM & 301,09 & 271,34 & 245,20 & 288,63 & 910,24 & 960,19 & 418,11 & 913,36 \\
\hline IR-E48-HS30-N & 388,45 & 386,75 & 387,75 & 395,49 & 1353,05 & 1337,02 & 1337,32 & 1348,56 \\
\hline IR-E48-HS30-NM & 405,04 & 404,74 & 390,97 & 396,49 & 715,59 & 878,93 & 761,82 & 833,79 \\
\hline IR-E48-HS30-NMM & 300,19 & 295,67 & 282,49 & 294,96 & 857,78 & 1095,20 & 521,79 & 859,46 \\
\hline IR-E64-HS20-N & 395,89 & 403,93 & 368,35 & 360,81 & 1276,21 & 1353,54 & 1346,68 & 1273,92 \\
\hline IR-E64-HS20-NM & 403,64 & 404,34 & 396,60 & 402,83 & 994,89 & 1422,44 & 1020,27 & 1390,56 \\
\hline IR-E64-HS20-NMM & 399,51 & 388,25 & 395,60 & 382,33 & 924,66 & 1266,33 & 643,60 & 922,69 \\
\hline IR-E64-HS30-N & 403,64 & 402,23 & 397,81 & 391,67 & 1556,51 & 1554,69 & 1555,97 & 1555,61 \\
\hline IR-E64-HS30-NM & 327,43 & 335,27 & 253,54 & 325,72 & 928,31 & 1323,13 & 940,10 & 1308,15 \\
\hline IR-E64-HS30-NMM & 242,88 & 194,43 & 186,49 & 238,77 & 799,04 & 1055,23 & 508,78 & 798,28 \\
\hline
\end{tabular}

Os valores obtidos foram comparados com os valores analíticos calculados a partir dos modelos de bielas e tirantes. Para os blocos submetidos exclusivamente à força vertical, adotou-se o modelo proposto por Blévot e Frémy (1967). Para os blocos submetidos à força vertical excêntrica em apenas uma direção, foi adotado o modelo presente no Quadro 4.1, semelhante ao apresentado em Nori e Tharval (2007). Já no caso de atuação de força vertical 
com excentricidade em duas direções, foi adotado o modelo do Quadro 4.2, semelhante aos modelos apresentados em Nori e Tharval (2007) e Souza et al. (2007).

Quadro 4.1 - Modelos de bielas para blocos submetidos à força excêntrica em uma direção

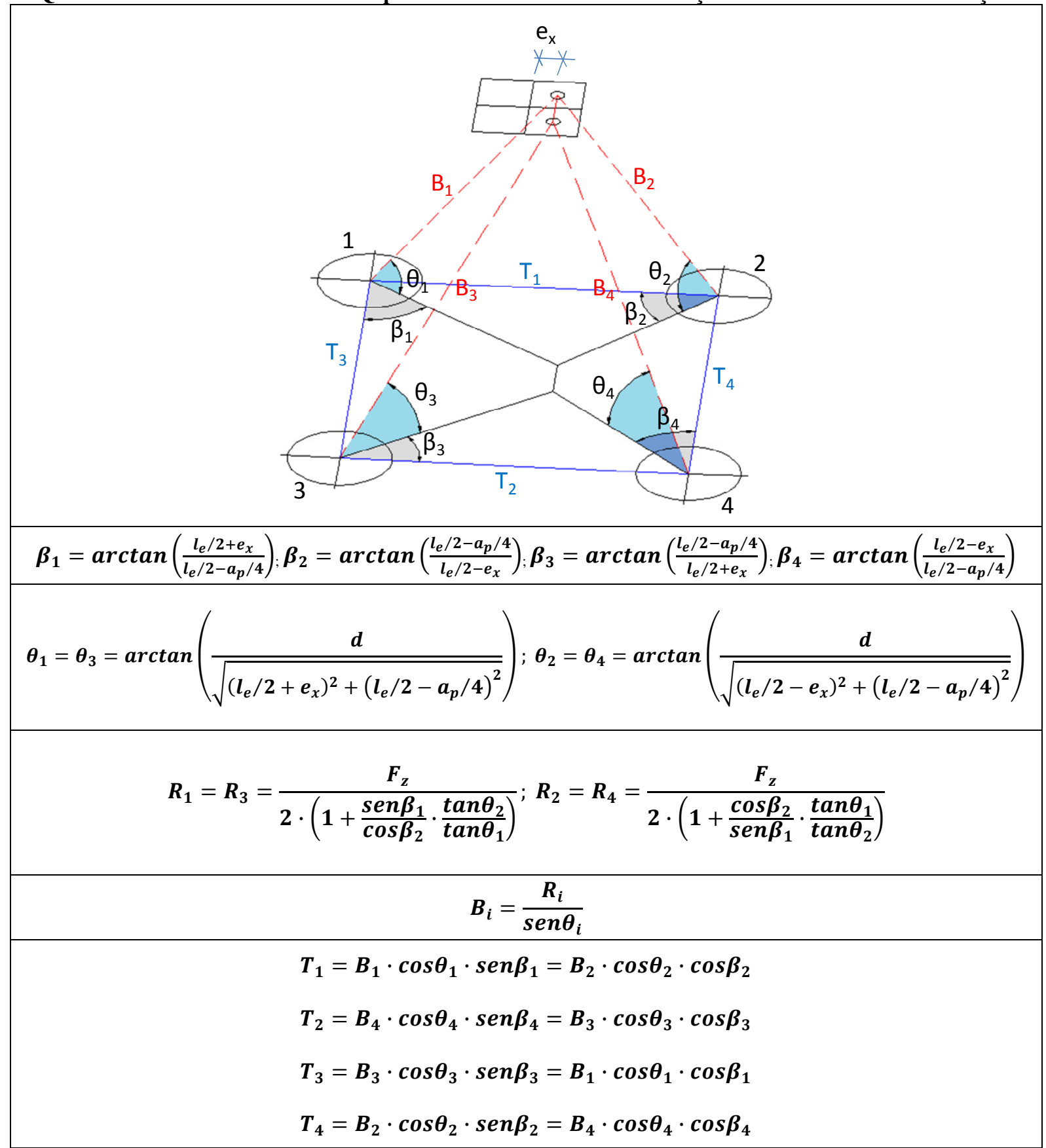


Quadro 4.2 - Modelos de bielas para blocos submetidos à força excêntrica em duas direções

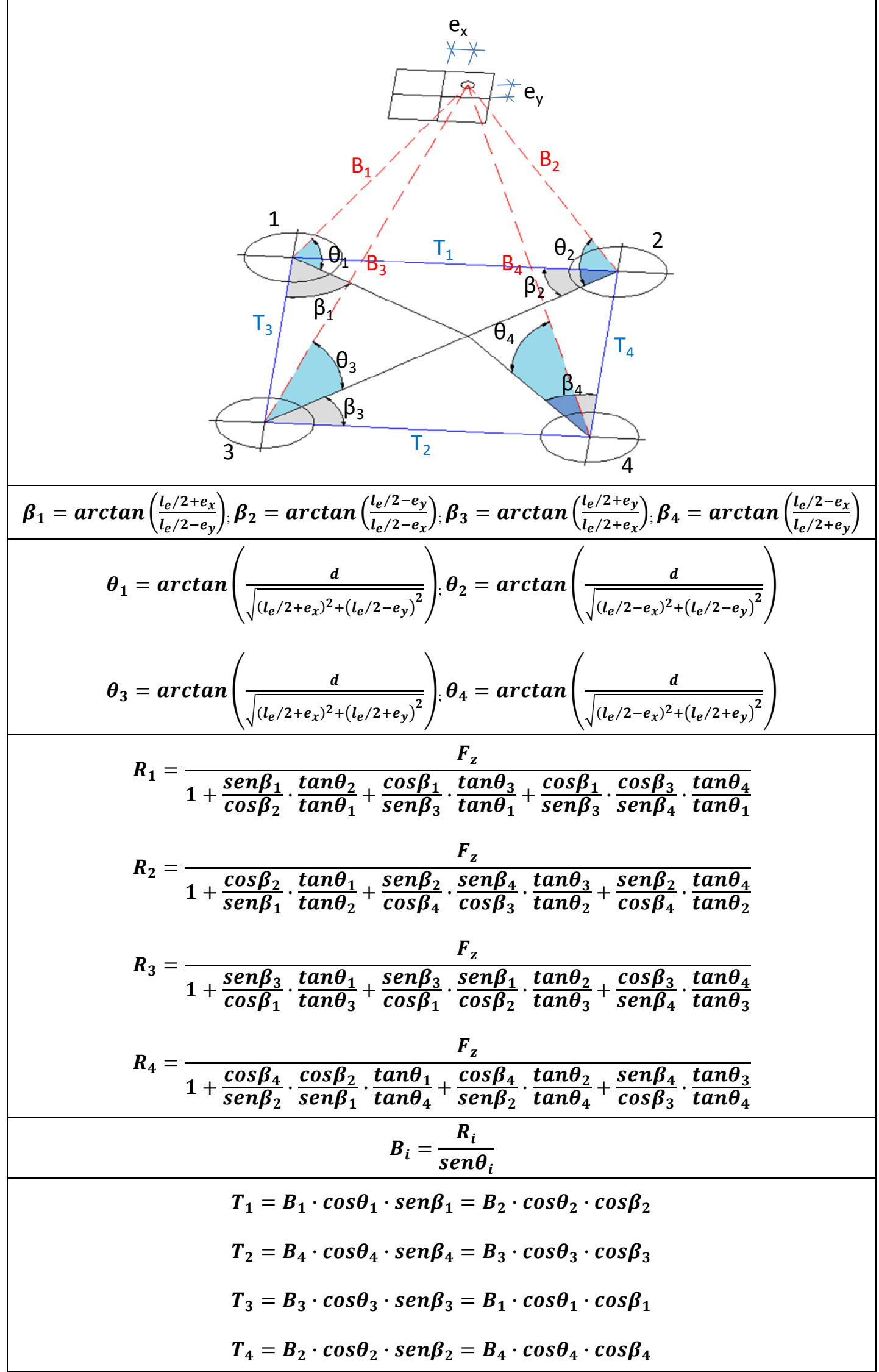


Pela Tabela 4.11 nota-se que os ângulos formados entre as bielas e sua projeção no plano horizontal apresentaram valores superiores àqueles obtidos analiticamente.

Tabela 4.11 - Ângulos entre as bielas e suas projeções no plano horizontal

\begin{tabular}{lcccc|cccc}
\hline \multirow{2}{*}{ Modelo } & \multicolumn{3}{c|}{$\boldsymbol{\theta}_{\text {numérico }}$ (graus) } & \multicolumn{4}{c}{$\boldsymbol{\theta}_{\text {analítico }}$ (graus) } \\
\cline { 2 - 9 } & $\boldsymbol{\theta}_{\mathbf{1}}$ & $\boldsymbol{\theta}_{\mathbf{2}}$ & $\boldsymbol{\theta}_{\mathbf{3}}$ & $\boldsymbol{\theta}_{\mathbf{4}}$ & $\boldsymbol{\theta}_{\mathbf{1}}$ & $\boldsymbol{\theta}_{\mathbf{2}}$ & $\boldsymbol{\theta}_{\mathbf{3}}$ & $\boldsymbol{\theta}_{\mathbf{4}}$ \\
\hline IR-E48-HS20-N & 53,6 & 54,2 & 54,3 & 53,8 & 41,2 & 41,2 & 41,2 & 41,2 \\
\hline IR-E48-HS20-NM & 48,2 & 55,3 & 48,4 & 55,4 & 35,8 & 41,8 & 35,8 & 41,8 \\
\hline IR-E48-HS20-NMM & 58,2 & 56,7 & 38,9 & 58,0 & 35,8 & 41,8 & 31,8 & 35,8 \\
\hline IR-E48-HS30-N & 58,6 & 58,2 & 58,3 & 58,3 & 46,5 & 46,5 & 46,5 & 46,5 \\
\hline IR-E48-HS30-NM & 41,0 & 46,6 & 42,4 & 45,3 & 40,3 & 46,5 & 40,3 & 46,5 \\
\hline IR-E48-HS30-NMM & 56,2 & 60,7 & 42,8 & 56,0 & 40,3 & 46,5 & 36,1 & 40,3 \\
\hline IR-E64-HS20-N & 57,9 & 59,5 & 58,7 & 57,8 & 48,9 & 48,9 & 48,9 & 48,9 \\
\hline IR-E64-HS20-NM & 49,6 & 58,5 & 50,4 & 57,8 & 42,7 & 48,9 & 42,7 & 48,9 \\
\hline IR-E64-HS20-NMM & 50,3 & 57,7 & 39,7 & 51,1 & 42,7 & 48,9 & 38,5 & 42,7 \\
\hline IR-E64-HS30-N & 61,6 & 62,1 & 61,6 & 61,7 & 52,5 & 52,5 & 52,5 & 52,5 \\
\hline IR-E64-HS30-NM & 57,5 & 63,6 & 57,6 & 63,1 & 42,7 & 48,9 & 42,7 & 48,9 \\
\hline IR-E64-HS30-NMM & 62,8 & 63,9 & 52,5 & 62,6 & 46,4 & 52,5 & 42,1 & 46,4 \\
\hline
\end{tabular}

A Tabela 4.12 compara os valores das inclinações nas bielas obtidos numericamente com os valores calculados analiticamente.

Tabela 4.12 - Relação entre os ângulo de inclinação das bielas dos blocos do grupo A

\begin{tabular}{|c|c|c|c|c|c|}
\hline \multirow{2}{*}{ Modelo } & \multicolumn{4}{|c|}{$\theta_{\text {numérico }} / \theta_{\text {analítico }}$} & \multirow{2}{*}{ Valores Médios } \\
\hline & $\theta_{1}$ & $\boldsymbol{\theta}_{2}$ & $\boldsymbol{\theta}_{3}$ & $\boldsymbol{\theta}_{4}$ & \\
\hline IR-E48-HS20-N & 1,30 & 1,32 & 1,32 & 1,31 & 1,31 \\
\hline IR-E48-HS20-NM & 1,35 & 1,32 & 1,35 & 1,33 & 1,34 \\
\hline IR-E48-HS20-NMM & 1,63 & 1,36 & 1,22 & 1,62 & 1,46 \\
\hline IR-E48-HS30-N & 1,26 & 1,25 & 1,25 & 1,25 & 1,25 \\
\hline IR-E48-HS30-NM & 1,02 & 1,00 & 1,05 & 0,97 & 1,01 \\
\hline IR-E48-HS30-NMM & 1,39 & 1,31 & 1,19 & 1,39 & 1,32 \\
\hline IR-E64-HS20-N & 1,18 & 1,22 & 1,20 & 1,18 & 1,20 \\
\hline IR-E64-HS20-NM & 1,16 & 1,20 & 1,18 & 1,18 & 1,18 \\
\hline IR-E64-HS20-NMM & 1,18 & 1,18 & 1,03 & 1,20 & 1,15 \\
\hline IR-E64-HS30-N & 1,17 & 1,18 & 1,17 & 1,18 & 1,18 \\
\hline IR-E64-HS30-NM & 1,35 & 1,30 & 1,35 & 1,29 & 1,32 \\
\hline IR-E64-HS30-NMM & 1,35 & 1,22 & 1,25 & 1,35 & 1,29 \\
\hline \multirow[t]{3}{*}{ Valores Médios } & 1,28 & 1,24 & 1,21 & 1,27 & 1,25 \\
\hline & & & \multicolumn{2}{|c|}{ Desvio padrão } & 0,13 \\
\hline & & & \multicolumn{2}{|c|}{ Coef. de variação } & $\mathbf{0 , 1 0}$ \\
\hline
\end{tabular}


Apesar dos valores obtidos serem superiores, as inclinações das bielas seguem a tendência apresentada nos modelos analíticos propostos em Souza et al. (2007) e Nori e Tharval (2007) indicando que estes modelos, além de serem consistentes, fornecem valores adequados.

Essa diferença pode ser justificada pela imprecisão na medida das forças nos tirantes, pois, além da variação de tensões ao longo da barra, não foram consideradas a contribuição das armaduras secundárias próximas à região dos tirantes para o cálculo destas forças. Além disso, o cálculo destes valores foi para uma situação de carregamento em que as armaduras do tirante já apresentavam escoamento. O mesmo cálculo poderia ter sido feito para o bloco ainda em regime elástico linear, todavia a dificuldade passaria a ser o cálculo da contribuição da resistência à tração do concreto, ainda pouco fissurado, na região dos tirantes.

Tabela 4.13 - Força nas bielas de compressão dos blocos do grupo A

\begin{tabular}{lcccc|cccc}
\hline & \multicolumn{4}{c}{$\mathbf{R}_{\text {cb,numérico }}(\mathbf{k N})$} & \multicolumn{4}{c}{$\mathbf{R}_{\text {cb,analítico }}(\mathbf{k N})$} \\
\cline { 2 - 9 } & $\mathbf{B}_{\mathbf{1}}$ & $\mathbf{B}_{\mathbf{2}}$ & $\mathbf{B}_{\mathbf{3}}$ & $\mathbf{B}_{\mathbf{4}}$ & $\mathbf{B}_{\mathbf{1}}$ & $\mathbf{B}_{\mathbf{2}}$ & $\mathbf{B}_{\mathbf{3}}$ & $\mathbf{B}_{\mathbf{4}}$ \\
\hline IR-E48-HS20-N & 1342,51 & 1386,44 & 1351,40 & 1339,35 & 1663,06 & 1663,06 & 1663,06 & 1663,06 \\
\hline IR-E48-HS20-NM & 1196,04 & 1485,47 & 1201,41 & 1480,95 & 1478,73 & 1872,33 & 1478,73 & 1872,33 \\
\hline IR-E48-HS20-NMM & 1070,54 & 1149,14 & 665,12 & 1077,04 & 1368,33 & 1635,62 & 966,34 & 1368,33 \\
\hline IR-E48-HS30-N & 1584,42 & 1573,11 & 1571,57 & 1585,41 & 1852,15 & 1852,15 & 1852,15 & 1852,15 \\
\hline IR-E48-HS30-NM & 1091,26 & 1208,73 & 1130,02 & 1173,73 & 1030,42 & 1327,20 & 1030,42 & 1327,20 \\
\hline IR-E48-HS30-NMM & 1032,37 & 1255,63 & 768,63 & 1036,36 & 1289,18 & 1567,59 & 900,51 & 1289,18 \\
\hline IR-E64-HS20-N & 1506,08 & 1571,59 & 1575,23 & 1506,29 & 1741,06 & 1741,06 & 1741,06 & 1741,06 \\
\hline IR-E64-HS20-NM & 1305,75 & 1668,67 & 1323,96 & 1642,46 & 1455,09 & 1891,62 & 1455,09 & 1891,62 \\
\hline IR-E64-HS20-NMM & 1201,95 & 1498,70 & 1006,96 & 1186,23 & 1384,50 & 1699,16 & 961,11 & 1384,50 \\
\hline IR-E64-HS30-N & 1769,54 & 1759,44 & 1769,52 & 1766,06 & 1960,35 & 1960,35 & 1960,35 & 1960,35 \\
\hline IR-E64-HS30-NM & 1100,81 & 1477,00 & 1113,03 & 1466,78 & 1356,50 & 1763,45 & 1356,50 & 1763,45 \\
\hline IR-E64-HS30-NMM & 898,05 & 1175,04 & 641,32 & 898,88 & 1091,36 & 1357,92 & 750,40 & 1091,36 \\
\hline
\end{tabular}

A Tabela 4.14 compara os valores das forças de compressão nas bielas obtidos numericamente com os valores calculados analiticamente. Os resultados indicam que existe boa aproximação sendo que os desvios, em sua maioria, foram à favor segurança. 
Tabela 4.14 - Relação entre os valores de força nas bielas de compressão dos blocos do grupo A

\begin{tabular}{|c|c|c|c|c|c|}
\hline \multirow{2}{*}{ Modelo } & \multicolumn{4}{|c|}{$\mathbf{R}_{\mathrm{cb}, \text { numérico }} / \mathbf{R}_{\mathrm{cb}, \text { analítico }}$} & \multirow{2}{*}{ Valores Médios } \\
\hline & $\mathbf{B}_{1}$ & $\mathbf{B}_{2}$ & $\mathbf{B}_{3}$ & $\mathbf{B}_{4}$ & \\
\hline IR-E48-HS20-N & 0,81 & 0,83 & 0,81 & 0,81 & 0,82 \\
\hline IR-E48-HS20-NM & 0,81 & 0,79 & 0,81 & 0,79 & 0,80 \\
\hline IR-E48-HS20-NMM & 0,81 & 0,69 & 0,65 & 0,81 & 0,74 \\
\hline IR-E48-HS30-N & 0,86 & 0,85 & 0,85 & 0,86 & 0,86 \\
\hline IR-E48-HS30-NM & 1,06 & 0,91 & 1,10 & 0,88 & 0,99 \\
\hline IR-E48-HS30-NMM & 0,83 & 0,78 & 0,81 & 0,83 & 0,81 \\
\hline IR-E64-HS20-N & 0,87 & 0,90 & 0,90 & 0,87 & 0,89 \\
\hline IR-E64-HS20-NM & 0,90 & 0,88 & 0,91 & 0,87 & 0,89 \\
\hline IR-E64-HS20-NMM & 0,90 & 0,86 & 1,00 & 0,89 & 0,91 \\
\hline IR-E64-HS30-N & 1,17 & 1,18 & 1,17 & 1,18 & 1,18 \\
\hline IR-E64-HS30-NM & 0,81 & 0,84 & 0,82 & 0,83 & 0,83 \\
\hline IR-E64-HS30-NMM & 0,85 & 0,84 & 0,81 & 0,85 & 0,84 \\
\hline \multirow[t]{3}{*}{ Valores Médios } & 0,89 & 0,86 & 0,89 & 0,87 & $\mathbf{0 , 8 8}$ \\
\hline & & & \multicolumn{2}{|c|}{ Desvio padrão } & 0,11 \\
\hline & & & \multicolumn{2}{|c|}{ Coef. de variação } & 0,12 \\
\hline
\end{tabular}

Pelo fato das bielas de compressão não seguirem o modelo padrão de Blévot e Frémy (1967) nos blocos em que a força vertical atua com excentricidade, as tensões nas bielas não foram calculadas.

A dificuldade para o cálculo das tensões nas bielas, em especial nas seções próximas ao pilar, se justifica pela necessidade de determinação da área da seção transversal das bielas na região abaixo do pilar, uma vez que uma parte da seção do pilar encontra-se mais comprimida, as bielas tendem a convergir para uma região de dimensões reduzidas. 


\section{Capítulo 5 \\ CONCLUSÃO

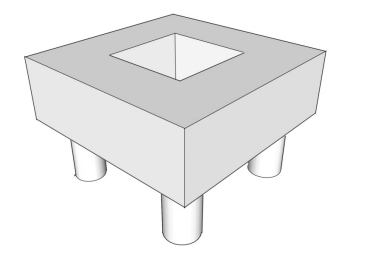

A partir dos resultados dos vinte e quatro blocos analisados concluiu-se que:

- Em todas as situações de carregamento, os blocos do grupo A, de interface rugosa, apresentaram a formação das bielas de compressão a partir do topo do bloco, sendo que naqueles em que a força foi aplicada com excentricidade, a ruína do bloco aconteceu para menores valores de força em razão da maior concentração de tensões em uma ou duas bielas de compressão. Já nos blocos do grupo $\mathrm{B}$, de interface lisa, não se formaram bielas de compressão nos blocos, pois a transferência de tensões tangenciais na ligação foi insuficiente. Desse modo, sugere-se a utilização de outra teoria para o dimensionamento dos blocos que possuem interface de ligação lisa com o pilar tal como a teoria de flexão, considerando o comportamento de placa;

- as inclinações e os valores das forças nas bielas dos blocos com interface de ligação rugosa, considerada monolítica, assemelharam-se àqueles idealizados pelos modelos de Blévot e Frémy (1967), no caso de aplicação de força centrada, e assemelharam-se aos modelos presentes nos trabalhos de Nori e Tharval (2007) e Souza et al. (2007) nos blocos cujo pilar foi submetido à força vertical excêntrica. Conforme se verificou ao comparar os valores dos ângulos de inclinação e das forças nas bielas, os modelos analíticos forneceram previsões favoráveis à segurança em relação aos numéricos;

- tanto nos blocos em que a espessura da "laje de fundo" foi de $20 \mathrm{~cm}$ quanto nos blocos em que ela foi de $30 \mathrm{~cm}$, foram observados elevados valores de tensões nas barras da armadura secundária, além de maior fissuração na região central da face inferior do bloco, indicando que esta região deve ser verificada à punção. Esse comportamento foi verificado para os blocos com ambos os tipos de ligação com o pilar, todavia, para os blocos de interface lisa foi mais acentuado. $\mathrm{O}$ cálculo do valor da tensão resistente à punção no perímetro crítico dado pelo perímetro do pilar, conforme ABNT NBR 6118:2003, mostrou-se favorável à segurança e pode ser usado como um indicativo para o nível de força limite aplicado na região da base do pilar; 
- nos blocos do grupo A, as tensões ao longo das barras da armadura principal não apresentaram valores constantes sendo que, em todos os modelos, houve uma grande redução das tensões nas barras sobre o topo das estacas, causada pelo estado de tensões promovido pela biela de compressão e pelo apoio na região nodal inferior sobre as barras que formam o tirante. Apesar dos ganchos da armadura principal terem sido pouco solicitados, é aconselhado o seu uso em razão da redução de consumo de aço ser insignificante e pela falta de estudos incisivos a respeito do assunto em blocos sobre estacas. Já as armaduras principais dos blocos do grupo B foram pouco solicitadas sendo as armaduras secundárias mais solicitadas em razão da elevada intensidade de força aplicada no fundo do cálice;

- as armaduras de suspensão, da forma como foram detalhadas, não influenciaram os resultados e podem ser dispensadas do detalhamento do bloco, assim como as armaduras superiores que também não foram solicitadas;

- em suma, recomenda-se que as ligações em interfaces de concreto, tais como estas entre pilar e bloco, sejam capazes de transferir solicitações tangenciais, seja por atrito ou mediante o emprego de chaves de cisalhamento. As ligações que dependem unicamente do atrito, tais como as de cálice de interface lisa, devem ser utilizadas com restrição, pois os esforços transferidos dependem fundamentalmente da rugosidade da interface e da pressão normal à ligação que, nem sempre, são conhecidas ou suficientes. A parcela de adesão é muito baixa para os níveis de força que estas ligações estão submetidas;

- nos blocos onde são formadas as bielas de compressão a partir de uma força aplicada com excentricidade, é recomendada a utilização de modelos de bielas e tirantes mais refinados tais como os de Nori e Tharval (2007) e Souza et al. (2007). Estes modelos ainda precisam ser calibrados a partir de ensaios experimentais, todavia se mostraram muito superiores aos modelos elaborados para força vertical centrada e que, freqüentemente, são utilizados para o dimensionamento de blocos submetidos à força vertical e momentos.

- os modelos numéricos de concreto armado utilizados na elaboração dos blocos sobre estacas, por intermédio do programa computacional DIANA, foram capazes de representar o comportamento dos blocos, mas ainda percebe-se que a seqüência da análise torna-se mais difícil após o concreto atingir certo nível de fissuração, em particular nos modelos onde a ruptura do concreto precede ao escoamento da armadura. Esta limitação, em algumas ocasiões, impediu a obtenção do equilíbrio no trecho pós-pico. 
Para a complementação deste e de outros trabalhos e para o desenvolvimento do conhecimento sobre o tema, algumas sugestões de pesquisas de interesse são:

- Realização de ensaios experimentais em blocos sobre quatro estacas com pilares submetidos a forças verticais excêntricas, com a finalidade de avaliar as previsões feitas pelos modelos discutidos;

- estudo da eficiência de outros tipos de armaduras de suspensão na capacidade de transferir parte da força vertical que atua no fundo do cálice dos blocos sobre quatro estacas possuindo cálice de ligação;

- desenvolvimento de modelos de bielas e tirantes para blocos submetidos a forças verticais de grande excentricidade, onde o ponto de atuação da força encontra-se externo ao perímetro da seção transversal do pilar;

- investigação dos efeitos da deformabilidade do solo e das estacas de apoio no comportamento dos blocos sobre estacas;

- realização de ensaios experimentais em blocos com ligação por cálice de fundação a fim de compreender melhor o comportamento destas ligações, em especial as de interface lisa, e para ajuste dos parâmetros necessários para melhorar a representação dessas ligações em modelos numéricos. 



\section{REFERÊNCIAS}

ADEBAR, P.; KUCHMA, D.; COLLINS, M. P. Strut-and-Tie Models for the Design of Pile Caps: An Experimental Study. ACI Structural Journal, v. 87, n. 1, p. 224-273, jan.-fev. 1990.

ADEBAR, P.; ZHOU, Z. Design of Deep Pile Caps by Strut-and-Tie Models. ACI Structural Journal, v. 93, n. 4, p. 1-12, jul.-ago. 1996.

ALONSO, U. R. Exercícios de Fundações. São Paulo: Ed. Edgar Blücher, 1983. 201 p.

AMERICAN CONCRETE INSTITUTE. Committee 318 (ACI 318-08): Building Code Requirements for Structural Concrete and Commentary. Detroit, Michigan, 2008.

ASSOCIAÇÃO BRASILEIRA DE NORMAS TÉCNICAS. NBR 6118: Projeto de Estruturas de Concreto: Procedimento. Rio de Janeiro, 2003.

NBR 6122: Projeto e Execução de Fundações: Procedimento. Rio de Janeiro, 1996.

NBR 9062: Projeto e Execução de Estruturas de Concreto Pré-Moldado. Rio de Janeiro, 2006.

BARROS, R. Análise de Blocos de Concreto Armado sobre Duas Estacas com Cálice Totalmente Embutido Mediante Presença de Viga de Travamento. 2009. 196 p. Dissertação (Mestrado em Engenharia de Estruturas) - Escola de Engenharia de São Carlos, Universidade de São Paulo, São Carlos, 2009.

BLÉVOT, Jean; FRÉMY, Robert. Semelles sur Pieux. Annales de L'Institut Technique du Bâtiment et des Travaux Publics, Paris, v. 20, n. 230, p. 224-273, fev. 1967.

BRUGGELING, A. S. G.; HUYGHE, G. F. Prefabrication with Concrete. Rotterdam: A. A. Balkema, 1991. 405 p.

CALAVERA, José. Cálculo de Estructuras de Cimentación. $4^{\text {a }}$ ed. Madrid: Infoprint, 2000. 529 p. 
CANADIAN STANDARDS ASSOCIATION. CSA A23.3-04: Design of Concrete Structures with Explanatory Notes. Ontario, 2004.

CANHA, R. M. F. Estudo Teórico-Experimental da Ligação Pilar-Fundação por meio de Cálice em Estruturas de Concreto Pré-Moldado. 2004. 155 f. Tese (Doutorado em Engenharia de Estruturas) - Escola de Engenharia de São Carlos, Universidade de São Paulo, São Carlos, 2004.

CARVALHO, I. S. Análise Experimental de Blocos sobre Grupos de Estacas Escavadas de Pequeno Diâmetro. 1995. Dissertação (Mestrado em Engenharia de Estruturas) - Escola de Engenharia de São Carlos, Universidade de São Paulo, São Carlos, 1995.

CHAN, T. K.; POH, C. K. Behavior of Precast Reinforced Concrete Pile Caps. Constructing and Building Materials, v. 14, n. 4, p. 73-78, jan. 2000.

CHEN, W. F. Plasticity in Reinforced Concrete. New York: Ed. McGraw-Hill, 1982. 474 p.

CLARKE, J. L. Behavior and Design of Pile Caps with Four Piles. Technical Report, n.42.489, Cement and Concrete Association, Wexham Springs, 1973.

COMISIÓN PERMANENTE DEL HORMIGÓN. EHE: Instrucción Española de Hormigón Armado. Ministerio de Fomento, Centro de Publicaciones, Madrid, 2008.

COMITÉ EURO-INTERNATIONAL DU BÉTON. CEB-FIP Model Code 1990. London, 1993.

COMITE EUROPÉEN DU BÉTON. Recommandations Particulières au Calcul et à L'Exécution des Semelles de Fondation. Bulletin D'Information. Paris, Fascicule 4, n. 73, p. 27-35, 1970.

DELALIBERA, R. G. Análise Numérica e Experimental de Blocos sobre Duas Estacas com Cálice Embutido Utilizado na Ligação Pilar-Fundação. 2007. 154 f. Relatório de PósDoutorado em Engenharia de Estruturas - Escola de Engenharia de São Carlos, Universidade de São Paulo, São Carlos, 2007.

DIANA. Finite Element Analysis: Users Manual release 9 - Analysis Procedures. Delft, Netherlands: TNO DIANA, 2005a. 636 p. 
DIANA. Finite Element Analysis: Users Manual release 9 - Element Library. Delft, Netherlands: TNO DIANA, 2005b. 662 p.

DIANA. Finite Element Analysis: Users Manual release 9 - Material Library. Delft, Netherlands: TNO DIANA, 2005c. 534 p.

EBELING, E. B. Análise da Base de Pilares Pré-Moldados na Ligação com Cálice de Fundação. 2006. Dissertação (Mestrado em Engenharia de Estruturas) - Escola de Engenharia de São Carlos, Universidade de São Paulo, São Carlos, 2006.

EL DEBS, M. K. Concreto Pré-moldado: Fundamentos e Aplicações. São Carlos: EESCUSP, 2000. $456 \mathrm{p}$.

ELLIOTT, K. S. Multi-Storey Precast Concrete Framed Structures. Oxford, Blackwell Science, 1996.

ELLIOTT, K. S. Precast Concrete Structures. Oxford: Butterworth-Heinemann, 2002.

EUROPEAN COMMITTEE FOR STANDARDIZATION. Eurocode 2 - Design of Concrete Structures - Part 1.1: General Rules and Rules for Buildings. Brussels, 2002.

FUSCO, P. B. Técnica de Armar as Estruturas de Concreto. São Paulo: Ed. Pini, 1995. $382 \mathrm{p}$.

GUERRIN, Andre. Traité de Béton Armé: Les Fondations. Paris: Dunod, 1955. 322 p.

HOBBS, N. B.; STEIN, P. An Investigation into the Stress Distributions in Pile Caps with Some Notes on Design. Proceedings of the Institution of Civil Engineers. v. 7, p. 599-628, jul. 1957.

JAGUARIBE JÚNIOR, K. B. Ligação Pilar-Fundação por meio de Cálice em Estrutuas de Concreto Pré-Moldado com Profundidade de Embutimento Reduzida. 2005. Dissertação (Mestrado em Engenharia de Estruturas) - Escola de Engenharia de São Carlos, Universidade de São Paulo, São Carlos, 2005.

LEONHARDT, F.; MÖNNIG E. Construções de Concreto: v. 3. Rio de Janeiro: Ed. Interciência, 1977. 288 p. 
MAEKAWA, K.; PIMANMAS, A.; OKAMURA, H. Nonlinear Mechanics of Reinforced Concrete. London: Ed. Spon Press, 2003.

MAUTONI, M. Blocos sobre Dois Apoios. São Paulo: Grêmio Politécnico, 1972.

MELO, C. E. E. Manual Munte de Projetos em Pré-fabricados de Concreto. São Paulo: Pini, 2004.

MIGUEL, M. G. Análise Experimental e Numérica de Blocos sobre Três Estacas. 2000. 121 f. Tese (Doutorado em Engenharia de Estruturas) - Escola de Engenharia de São Carlos, Universidade de São Paulo, São Carlos, 2000.

MONTOYA, P. J.; MESEGUER, A. G.; CABRÉ, F. M. Hormigón Armado: v. 1. 14ª ed. Barcelona: Ed. Gustavo Gilli, 2000.

MORAES, M. C. Estruturas de Fundações. São Paulo: Ed. McGraw-Hill do Brasil, 1977.

MUNHOZ, F. S. Análise do Comportamento de Blocos de Concreto Armado sobre Estacas Submetidos à Ação de Força Centrada. 2004. 80 f. Dissertação (Mestrado em Engenharia de Estruturas) - Escola de Engenharia de São Carlos, Universidade de São Paulo, São Carlos, 2004.

NUNES, V. C. P. Estudo do Cálice de Fundação com Ênfase nos Esforços das Paredes Transversais do Colarinho. 2009. Dissertação (Mestrado em Engenharia de Estruturas) Escola de Engenharia de São Carlos, Universidade de São Paulo, São Carlos, 2009.

OLIN, J.; HAKKARAINEN, T.; RÄMÄ, M. Connections and Joints between Precast Concrete Units. Espoo, Julkaisija-Utgivare.

OSANAI, Y.; WATANABE, F.; OKAMOTO, S. Stress Transfer Mechanism of Socket Base Connections with Precast Concrete Columns. ACI Structural Journal, v. 93, n. 3, p.226276, mai.-jun. 1996.

PROENÇA, S. P. B. Análise Não-Linear de Estruturas. Notas de Aula - Escola de Engenharia de São Carlos, Universidade de São Paulo, São Carlos, 2007.

RAMOS, F. A. C. Análise Numérica de Blocos sobre Dez Estacas: Cálculo das Reações de Apoio. 2007. Dissertação (Mestrado em Engenharia de Estruturas) - Escola de Engenharia de São Carlos, Universidade de São Paulo, São Carlos, 2007. 
ROTS, J. G.; BLAAUWENDRAAD, J. Crack Models For Concrete: Discrete or Smeared? Fixed, Multi-Directional or Rotating?. HERON. v. 34, n. 1, 59 p., 1989.

SAM, C.; IYER, P. K. Nonlinear Finite Element Analysis of Reinforced Concrete Four-Pile Caps. Computers \& Structures, v. 57, n. 4, p. 605-622, 1995.

SCHÄFER, K.; SCHLAICH, J. Consistent Design of Structural Concrete Using Strut-and-Tie Models. Colóquio sobre Comportamento de Projeto de Estruturas, 5. Anais, PUC-RJ, Rio de Janeiro, 1988.

SCHIEL, F. Estática das Construções. Publicação N. ${ }^{\circ} 10$ - Escola de Engenharia de São Carlos, Universidade de São Paulo, São Carlos, 1957.

SCHLAICH, J.; SCHÄFER, K. Design and Detailing of Structural Concrete Using Strut-AndTie Models. The Structural Engineer, v. 69, n. 6, p. 113-125, mar. 1991.

SILVA, A. M. S. Ligações entre Elementos Pré-Fabricados de Betão. 2004. Dissertação (Mestrado) - Instituto Superior Técnico, Universidade Técnica de Lisboa, Lisboa, 1998.

SILVA, R. C.; GIONGO, J. S. Modelos de Bielas e Tirantes Aplicados a Estruturas de Concreto Armado. São Carlos: EESC-USP, 2000. 202 p.

SOUZA, R. A. Concreto Estrutural: Análise e Dimensionamento de Elementos com Descontinuidades. 2004. 442 f. Tese (Doutorado em Engenharia de Estruturas) - Escola Politécnica, Universidade de São Paulo, São Paulo, 2004.

SOUZA, R. A.; KUCHMA, D.; PARK, J.; BITTENCOURT, T. Adaptable Strut-and-Tie Model for Design and Verification of Four-Pile Caps. ACI Structural Journal, v. 106, n. 2, p.142-150, mar.-abr. 2009.

SOUZA, R. A.; KUCHMA, D.; PARK, J.; BITTENCOURT, T. Non-Linear Finite Element Analysis of Four-Pile Caps Supporting Columns Subjected to Generic Loading. Computers and Concrete, v. 4, n. 5, p.363-373, 2007.

STRUCTURAL CONNECTIONS FOR PRECAST CONCRETE BUILDINGS - State of Art, FIB, Bulletin 43, Feb. 2008. 
STRUT-AND-TIE RESOURCE WEBSITE. Disponível em: <http://cee.uiuc.edu/kuchma/ strut_and_tie/STM/Models.htm>. Acesso em: 12 de março de 2009.

TAYLOR, H. P. J.; CLARKE, J. L. Some Detailing Problems in Concrete Frame Structures. The Structural Engineer, v. 54, n. 1, p. 19-32, jan. 1976.

WILLERT, O.; KESSER, E. Foundations for Botton-end Fixed Precast Columns. Betonwerk+Fertigteil-Technik, v. 49, n. 3, p. 137-142, 1983. 